\title{
Aerogenic Contamination \\ Control in Operating Theatres
}

- Studies towards effective use of UDF systems -

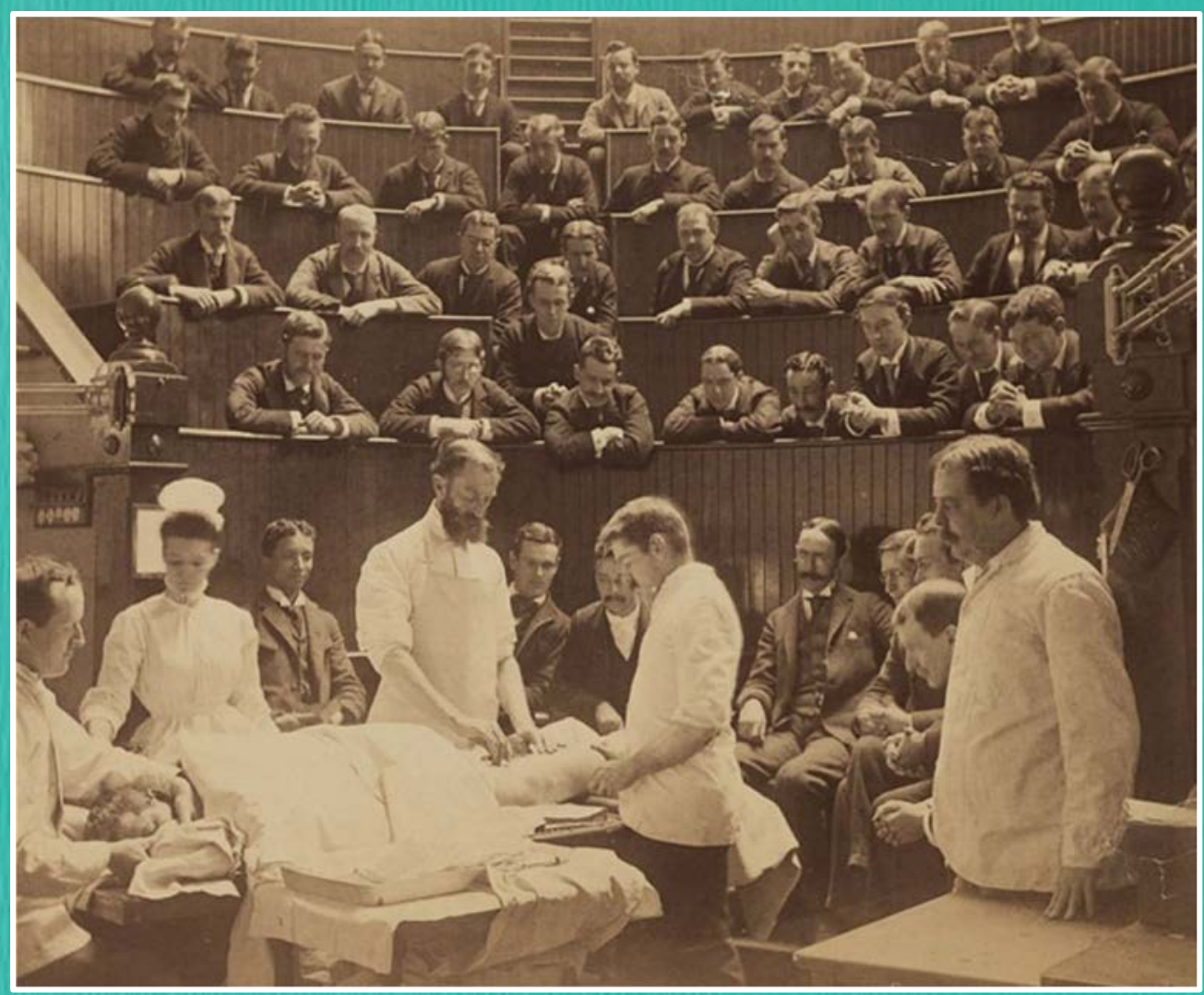

Roberto Traversari 



\section{Aerogenic Contamination Control in Operating Theatres}

- Studies towards effective use of UDF systems -

Albertus Anuello Louis (Roberto) Traversari 


\section{Colofon}

This thesis was completed at CAPHRI Care and Public Health Research Institute,

Department of Orthopedic Surgery of Maastricht University. CAPHRI participates in the Netherlands School of Public Health and Care Research CaRe.

Copyright (C) 2018 by A.A.L. Traversari. All rights reserved

Cover illustration: Operating theater at Boston City Hospital by Augustine H. Folsom, c. 1890. Harvard Medical Library

Cover Layout: Roberto Traversari

Thesis layout: Roberto Traversari

Printed by: Gideprint

ISBN: 978-90-5986-490-0

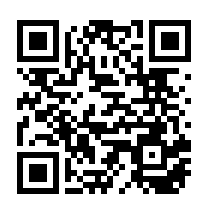

https://umpub.nl/traversari-thesis

DOI: $10.26481 /$ dis.20190207at

Reproduction of this thesis was supported by the sponsors, Appendix $E$. 


\title{
Aerogenic Contamination Control in Operating Theatres
}

- Studies towards effective use of UDF systems -

\author{
Proefschrift \\ ter verkrijging van de graad van doctor \\ aan de Universiteit Maastricht \\ op het gezag van de Rector Magnificus prof.dr. R.M. Letschert, \\ volgens het besluit van het College van Decanen \\ in het openbaar te verdedigen \\ op donderdag 7 februari 2019 om 16:00 uur. \\ door \\ Albertus Anuello Louis (Roberto) Traversari \\ Geboren op 3 april 1967 te Apeldoorn, Nederland
}




\section{Promotor}

Prof.dr. L.W. van Rhijn

\section{Copromotor}

Prof.dr. G.H.I.M. Walenkamp, emeritus-hoogleraar Orthopedie

\section{Beoordelingscommissie}

Prof.dr. P. Savelkoul (voorzitter)

Prof.dr. M. van Kleef

Dr. A. Oude Lashof

Prof.ir. P. Luscuere, Hoogleraar Building Physics and Services, TU Delft

Prof.ir. W. Zeiler, Hoogleraar Building Services, TU Eindhoven 




\section{Table of content}

$\begin{array}{lll}\text { Chapter } 1 & \text { General introduction } & 11\end{array}$

1.1 Air distribution systems in operating theatres: 12

1.2 Turbulent mixing flow 15

$\begin{array}{lll}1.3 & \text { Unidirectional flow (UDF) } & 17\end{array}$

1.4 Historic development of UDF systems for 20

1.5 Deposition of particles and carriage of 24

1.6 The role of air distribution systems in the 29 prevention of aerogenic contamination in the operating room

1.7 Surgical smoke and anaesthetic gasses 36

1.8 Aim of this thesis 39

Chapter 2 Process simulation during the design process makes the 55 difference.

Chapter 3 The effect of operating lamps on the protected area of a $\quad 89$ unidirectional down flow (UDF) system.

Chapter 4 Effect of switching off unidirectional downflow systems of operating theatres during prolonged inactivity on the period before the operating theater can safely be used.

Chapter 5 Laying-up of sterile instruments in the operating theatre:

Equal or superior protection by using a horizontal unidirectional air flow system.

Chapter 6 Mobile ultra-clean unidirectional airflow screen reduces air contamination in a simulated setting for intra-vitreal injection.

$\begin{array}{lll}\text { Chapter } 7 & \text { Laminar flow: the better choice in orthopaedic implants. } & 176\end{array}$

Chapter 8 What if the protected area is smaller than expected? 
Chapter 9 Conclusions, general discussion and future direction of 199 research.

9.1 Answers to the questions 200

9.2 Overall conclusion and discussion 208

9.3 Future direction and concluding remarks 217

$\begin{array}{lll}\text { Chapter } 10 \quad \text { Valorization } & 231\end{array}$

$\begin{array}{lll}\text { Chapter } 11 & \text { Summary } & 241\end{array}$

11.1 Summary 242

$11.2 \quad$ Nederlandse samenvatting 248

Appendix A Equations

A.1 Contamination removal efficiency 259

A.2 Equation for the size distribution of 262

microorganisms carrying particles

$\begin{array}{lll}\text { Appendix B Curriculum Vitae } & 265\end{array}$

$\begin{array}{lll}\text { Appendix C List of publications } & 267\end{array}$

$\begin{array}{lll}\text { Appendix D Dankwoord } & 269\end{array}$

$\begin{array}{lll}\text { Appendix E } & \text { Sponsors } & 273\end{array}$ 
Table of content 


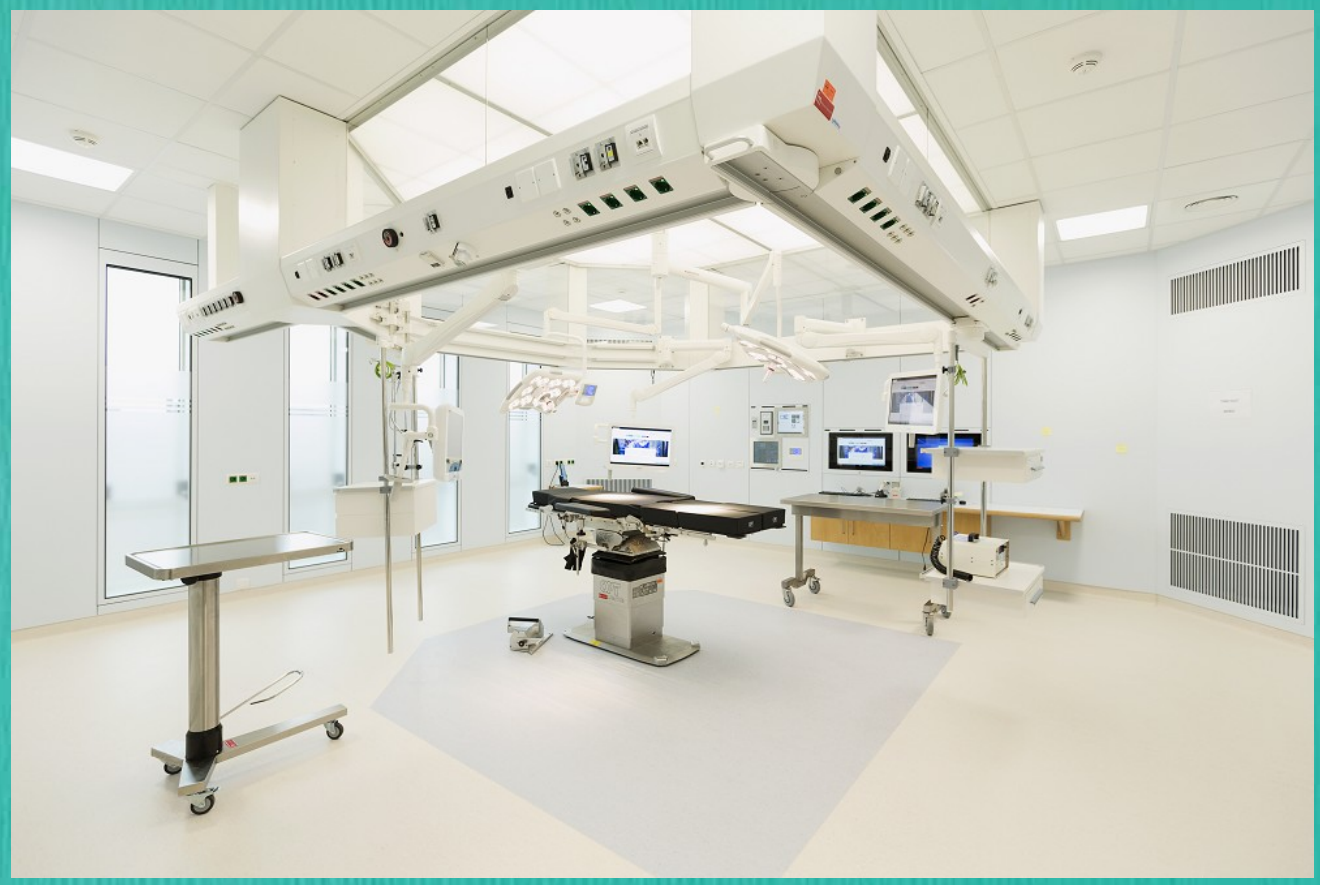




\section{Chapter 1}

General introduction 


\section{General introduction}

\subsection{Air distribution systems in operating theatres: how does it work}

Ventilation is one of the most important engineering techniques for controlling the air quality in enclosed environments like operating rooms. The purpose of a ventilation system is often misunderstood. A ventilation system supplies fresh air to a room, controls comfort parameters like temperature and humidity and removes undesired substances such as dust particles gasses and gas-like substances from the enclosed environment. ${ }^{1-5}$ Figure 1.1 shows aspects influenced by a ventilation system in an operating room. A ventilation system is defined as a combination of appliances designed to supply interior spaces with outdoor air and to extract polluted indoor air. ${ }^{6}$ The supply of fresh conditioned (filtered, heated, cooled, humidified and or dehumidified) outside air into an area is referred to as ventilation.

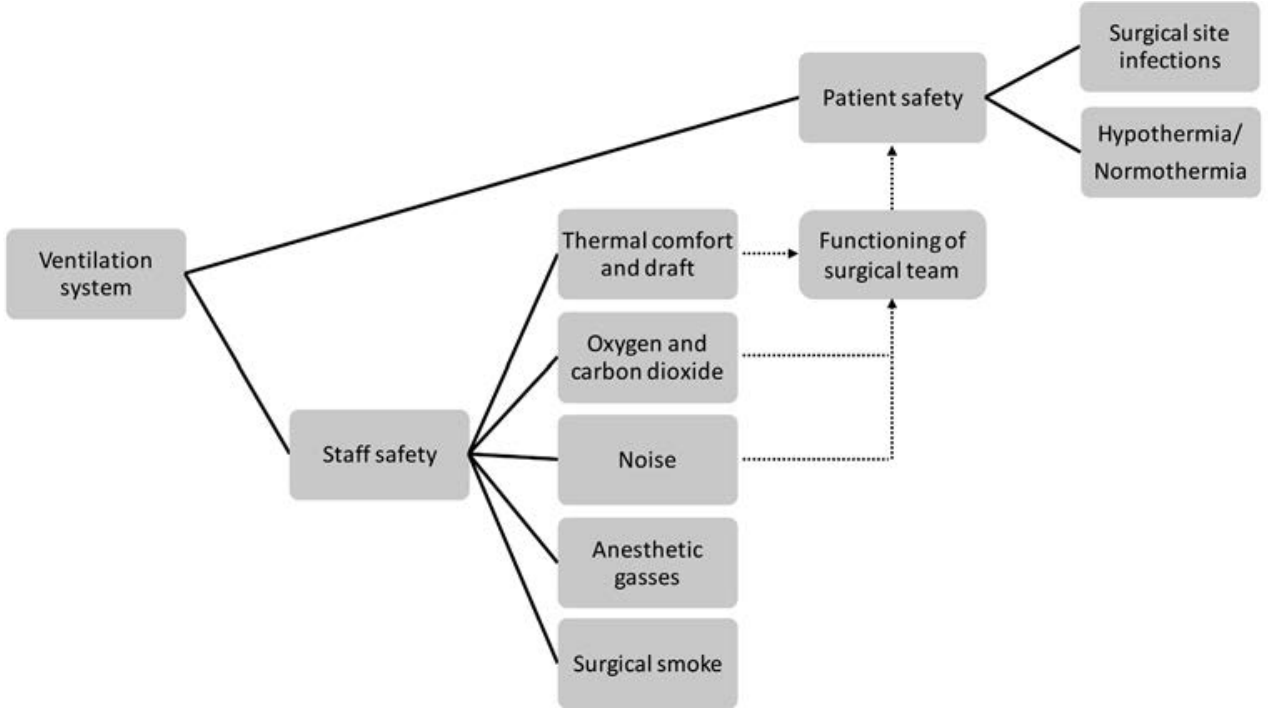

Figure 1.1. Aspects influenced by a ventilation system in an operating room. 
A ventilation system can be divided into several sections: the air inlet section sometimes including pre-filtration of the outdoor air (ODA), the air handling unit including filter stages, the air distribution section with air transport system and room air distribution system and the exhaust section (figure 1.2). In this figure also the most important air flows are defined. ${ }^{6}$ Misunderstanding often occurs because the supply of outside air is confused with secondary or recirculated air. Air supplied to a room (SUP) consists of outdoor air (ODA), secondary air (SEC) and/or recirculated air (REC). Secondary air (SEC) is air taken from a room and supplied to the same room after any kind of treatment (e.g. cooling and/or heating). Recirculated air (RCA) is air extracted from other rooms after which it is returned to the air treatment system and reused as supply air (SUP). In the air handling unit (AHU) outdoor air can be heated, cooled, humidified, dehumidified and filtered. The air handling unit is often positioned close to the air intake and in a hospital mostly situated in a technical area.

To extract the amount of $\mathrm{CO}_{2}$ emitted by the people present in the operating room and to supply fresh $\mathrm{O}_{2}$ a limited amount of outdoor air is needed. According to the Dutch occupational health and safety legislation it is advisable to maintain a minimum ventilation rate (ODA) of $30 \mathrm{~m}^{3} / \mathrm{h}$ per person for lightly physically demanding work and 50 $\mathrm{m}^{3} / \mathrm{h}$ for physically more demanding work. The amount of outdoor air supplied to an operating room in the Netherlands is typically $1,000-2,000 \mathrm{~m}^{3}$ per hour based on the type and amount of anaesthetic gasses used. ${ }^{7}$ The rest of the filtered air supplied to an operating room needed to create a clean environment is mostly secondary air (SEC). All air supplied to an operating room should be filtered. The amount of supply air in an operating room is an important factor with regard to contamination. A high supply air volume reduces the concentration of harmful substances (surgical smoke, anaesthetic gasses and microorganisms carrying particles). However a high supply air volume is also associated with an increase of noise, draft, energy consumption, etc.. The air flow and temperature in the operating room are not only important for staff comfort but can also affect the patient's body temperature. ${ }^{8,9} \mathrm{~A}$ lower core temperature (hypothermia) of the patient is associated with an increase of infections. ${ }^{10-13}$ 
This means that during the design the aspects that are important for both staff and patient must be taken into consideration, a balance between solutions (trade-off) is inevitable.

Air ducts in hospitals are often quite long thus causing air-side resistance. In hospitals this is associated with a high energy consumption. ${ }^{14-16}$ Therefore there is a strong incentive to reduce the energy consumption of systems, which is dictated by economic reasons and European building and energy regulations. ${ }^{17-19}$ During design and operation this aspect cannot be overlooked.

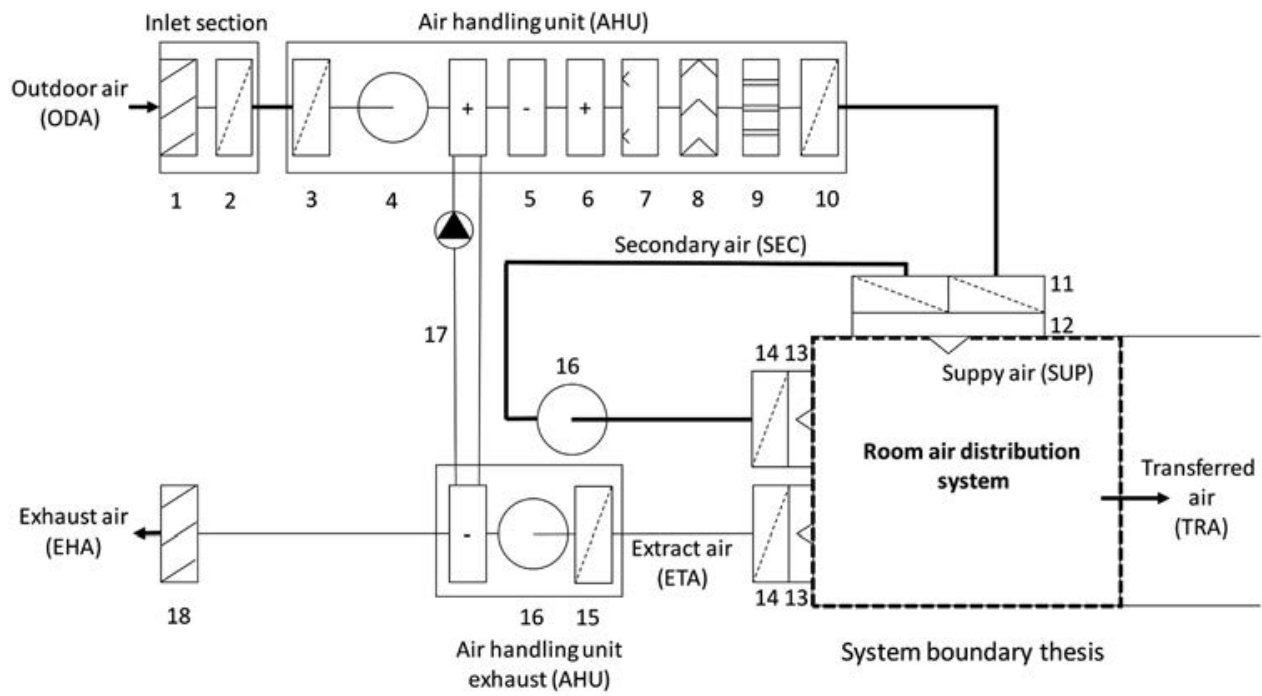
1) Louvre
2) Pre-filter (optional)
3) Filter (first stage)
4) Fan
5) Air cooler
6) Air heater
7) Humidifier
8) Droplet seperator (optional)
9) Attenuator (optional)

10) Filter (second stage)

11) HEPA filter (final filter)

12) Supply air terminal (canopy)

13) Exhaust air terminal

14) (Lint)filte

15) Filter (in case of heat recovery)

16) Fan

17) Heat recovery (optional)

18) Louvre

Figure 1.2. Overview of a ventilation system related to an operating room. ${ }^{20}$ 
This thesis focuses on the air distribution system that creates a clean environment in an operating room of instrument lay-up room. Two profiles can be distinguished in relation to the air flow profile caused by the air supplied: on the one hand turbulent mixing flow and on the other the unidirectional flow (UDF) also referred to as laminar air flow, displacement or plug flow. ${ }^{21,22}$

\subsection{Turbulent mixing flow}

A turbulent mixing flow is a flow regime characterised by chaotic changes in flow velocity, direction and pressure. Turbulent flow occurs when air is supplied to a room at relatively high speed. This supplied air mixes with the contaminated air present in the room, diluting the air in the room and making it cleaner. Depending on the use of the room the supply air can be filtered with different classes of filters. ${ }^{23-25}$ The difference in air speed between the air in the room and the supplied air as well as special supply air terminals create turbulence and will mix supply air with air in the room. For such turbulent flow patterns, the exchange rate (number of times the volume of the room is supplied) is considered to be the most important parameter for removal of aerogenic contaminants. ${ }^{2}$ For operating rooms this kind of air distribution system is known as turbulent, turbulent mixing, diluting mixing or conventional system.

The efficiency of diluting the air in the room is considered as the most important parameter of a diluting mixing system. ${ }^{1,26}$ Mixing of air does not take place in a uniform way and there might be areas within an enclosed environment where room air is hardly affected by the air distribution system. ${ }^{1,27,28}$ The mixing of air depends on many variables related to the characteristics of the room itself and those of the air distribution system. Characteristics of the room are mainly the room layout, dimensions, partitioning and the location and size of heat sources, sinks and other obstacles e.g. furniture. Characteristics of the air distribution system are among others the degree of turbulence, supply and exhaust configuration, diffuser characteristics, supply air velocity and supply air and room temperature. As a consequence, the air flow patterns will be unique to an individual enclosed environment and will vary in response to changes in air distribution system and room characteristics. 
Detailed measurements of air movement in a room, which are difficult and entail complex computer calculations like computational fluid dynamics (CFD), are needed to demonstrate the distribution and movement of a pollutant like gas, particles or microorganisms carrying particles, in a room based on these measurements. ${ }^{27}$ It is more feasible to use tracer gas techniques to determine the ventilation efficiency. In the tracer gas method, a specific well measurable gas is supplied in a known quantity. By measuring the concentration at different positions, the dispersion can be analysed. The tracer gas must have a similar density to air to ensure proper mixing. Beside tracer gas also air borne particles may be used. There are two main parameters to define the systems performance regarding ability to provide clean air in those places within the room where it is required, those are 1) relative contaminant removal effectiveness and 2) absolute contaminant removal effectiveness. ${ }^{1,26,29,30}$

The contaminant removal effectiveness in an enclosed environment is the ratio between the steady state concentration of the contaminant at the exhaust and the concentration of a contaminant at a specific position in the room or the mean concentration in the room. For complete mixing, the pollutant concentration is uniformly distributed in the room and thus the contaminant removal effectiveness is $100 \%$. If mixing is suboptimal e.g. some short-circuit between the supply and exhaust, the room average pollutant concentration will tend to be greater than the concentration at the exhaust of the room, and thus the contaminant removal effectiveness will be lower compared to complete mixing. These parameters are further elaborated in Appendix A.

Both relative and absolute removal effectiveness are parameters at a steady state condition and don't include the aspect of time. However, the time factor in which the reduction takes place is important because this shows the ability of the air distribution system to deal with emission of a pollution during a short period: a "pulse". An amount of air entering any point is a mixture of air already present at that point and air supplied to that point. 
The recovery time in that specific position demonstrates the ability of the air distribution system to reduce the concentration of pollutants in a certain amount of time. ISO 146443: 2005 describes such a test. ${ }^{31}$ This test determines the ability of the air distribution system to dilute airborne pollutions over time. The system test as described by ISO 14644-3: 2005 is recommended and can only be used for air distribution systems with some level of mixing. The recovery time is a function of the ratio between number of air changes (air flow rate in $\mathrm{m}^{3} / \mathrm{h}$ divided by the volume of the room in $\mathrm{m}^{3}$ ) and the geometry of the inlet and outlet terminals, thermal conditions and the air distribution characteristics within the enclosed environment. The time to recover after an event of pollutant emission is a very important parameter of the air distribution system.

\subsection{Unidirectional flow (UDF)}

In a laminar flow regime a medium e.g. air flows in parallel layers without disruption, figure 1.3. ${ }^{21}$ Ideally a "plug" flow or "piston" flow that displaces the air present completely, without any mixing of air, can be created with a laminar flow regime. The supplied air displaces the air in the room and is not mixed with air in the room. This type of flow creates an area that only consists of supplied air.

For plug flow, the contaminant removal effectiveness in the area affected by such flow will be greater than for a complete turbulent mixing flow.

Also the recovery time is very low and in theory only depending on the velocity of the laminar plug flow. For operating rooms this unidirectional plug flow type of air distribution system is also referred to as laminar air flow, plug flow or displacement ventilation. In many older studies a plug air flow is called laminar air flow (LAF) but a pure laminar flow is very hard to create in practice. Small disturbances of the laminar air flow will result in some turbulence. For this reason LAF is called Uni Directional Flow (UDF) in more recent studies. 


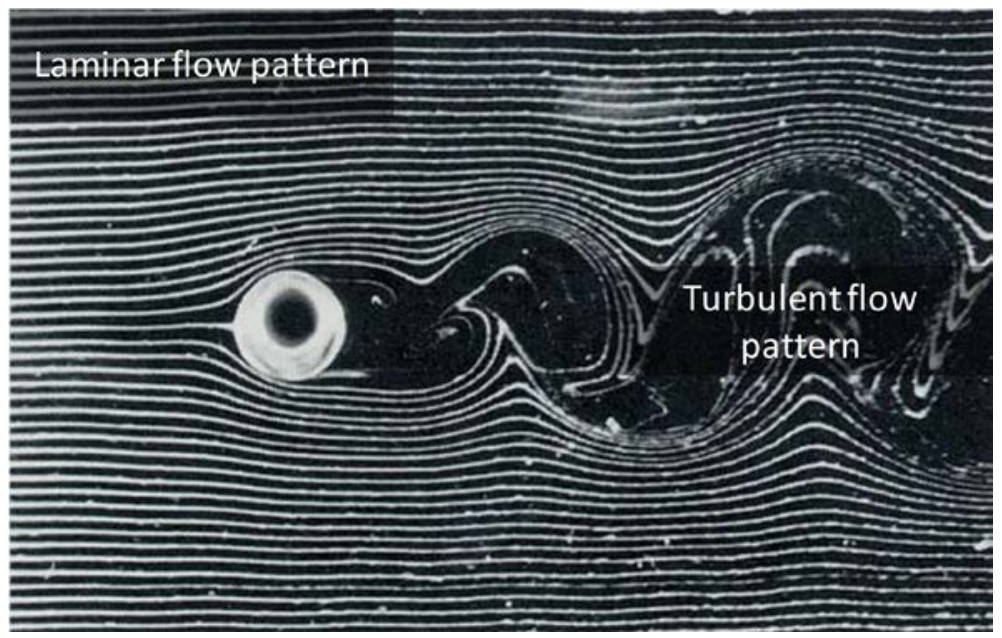

Figure 1.3. Laminar flow pattern disturbed by an object resulting in a turbulent flow pattern. ${ }^{32}$

Between the laminar plug flow and the surrounding environment a shear mixing layer is present (figure 1.4). ${ }^{33,34}$ This shear mixing layer results in a zone where air from the plug flow is mixed with environmental air causing a gradient of the concentration of aerogenic pollutants instead of a very sharp separation between the concentration in the plug flow and the environment. The width of the shear mixing layer depends on many factors. The most important factors are the difference in air speed of the plug flow with the surrounding air and obstacles, the distance to the supply terminal and surrounding conditions e.g. temperature. The airspeed of the plug flow is very important to prevent entrainment further away from the supply system referred to as distance $x_{j}$ in figure 1.4. ${ }^{35}$ However, a high air velocity will also result in high turbulence in the shear mixing layer and turbulence will increase if the airflow encounters an object. 


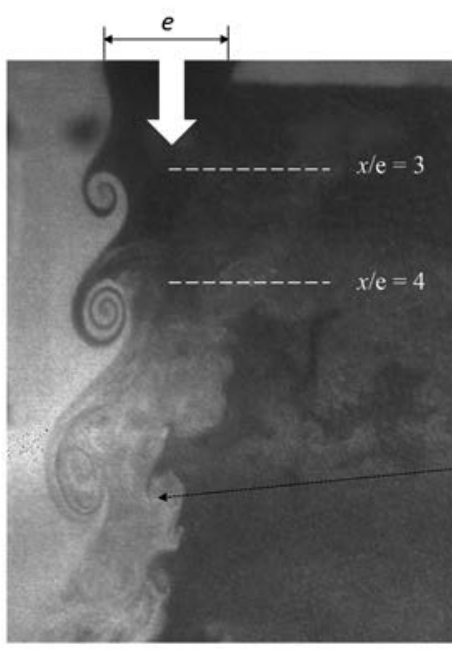

$x=$ Distance to the air suppy terminal $e=$ Width of the air supply terminal

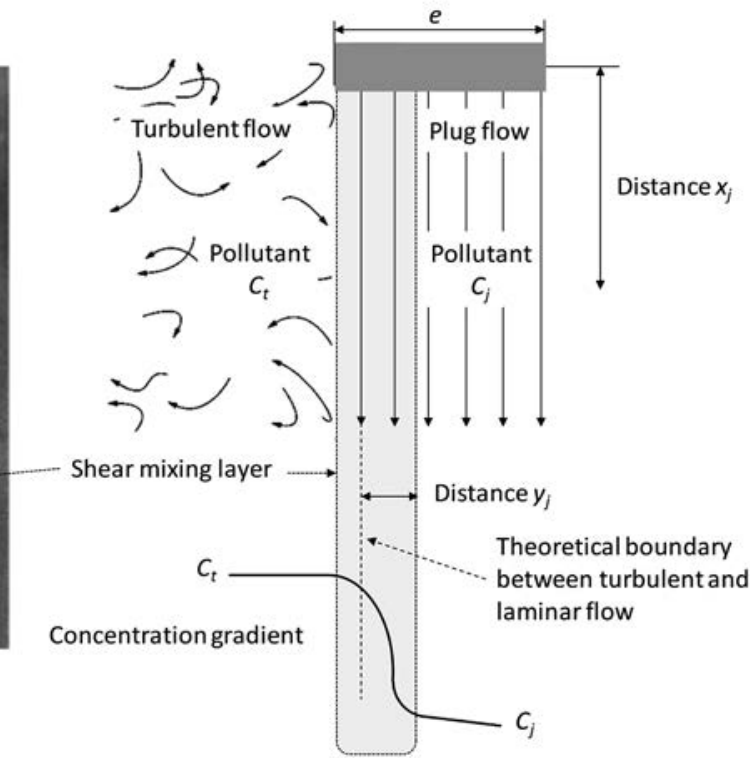

Figure 1.4. Shear mixing layer and principle of the degree of protection. ${ }^{21}$

To measure the protective effect of a unidirectional plug flow the entrainment test or segregation test can be used..$^{36-39}$ The principle of this method is to determine to what extent a pollutant outside the plug flow can enter into the flow. This protective effect is expressed as degree of protection.

The degree of protection is defined as: ${ }^{37-39}$

$$
D P_{j}=-\log \frac{C_{j}}{C_{t}}
$$

\section{Where:}

$D P_{j}$ is the degree of protection at point ${ }_{j}$

$C_{t}$ is the steady state concentration in the air outside the plug flow in number per $\mathrm{m}^{3}$

$C_{j} \quad$ is the steady state concentration at point $j$ in the plug flow in number per $\mathrm{m}^{3}$

A reduction of 100 results in a DP of 2 and a reduction of 1,000 in a DP of 3 . 


\subsection{Historic development of UDF systems for operating rooms}

Around the 1960s the state of the art operating room was equipped with a mechanical exhaust system and natural air supply resulting in a distribution system with some level of turbulence. These systems had no filtration of the supply air and had relative low air exchange rates. The air was supplied from other parts of the hospital mainly from corridors. $^{40}$

In the 1960s Sir John Charnley reduced the number of surgical site infections (SSI) after prosthetic replacements of the hip joint from $7 \%$ to less than $1 \%$ by using several prophylactic measures including a special type of air distribution system. ${ }^{40-42}$ This so called "clean air" distribution system was the bases for the modern Uni Directional Flow (UDF) systems. Together with Harry Graven and Hugh Howorth, Charnley developed between 1961 and 1963 an air distribution system that provided a clean aerogenic environment around the surgical side, sterile surgical instruments and hip implants by means of a special type of air distribution system.

They designed a system to enclose the surgical team and patient and supplied a large amount of well-filtered air (electro static filter) from the top. The air supplied could only flow out of this enclosure at the bottom (figure 1.5). Due to the relative high degree of air changes, the limited number of people (only three) and because no air could enter the area from the periphery, an ultraclean area was realized. Initially this system had 6.8 air changes an hour and was later adapted towards 130 air changes an hour (Table 1.1). This "tent" also referred to as "greenhouse" was approximately 2.3 meter square and 2.3 meters high and was placed inside a normal operating room. The exhaled respiration air from staff and patient was extracted from this enclosure to avoid mixture of this contaminated air with the filtered air in the compartment. 


\begin{tabular}{|c|c|c|c|c|}
\hline Period & 1 & 2 & 3 & 4 \\
\hline Year & $\begin{array}{l}1959 / 01- \\
1961 / 11\end{array}$ & 1961/11-1962/06 & $1962 / 06-1966 / 03$ & $\begin{array}{l}1966 / 06- \\
1967 / 09\end{array}$ \\
\hline $\begin{array}{l}\text { Number of air } \\
\text { changes per hour }\end{array}$ & $\begin{array}{l}\text { Mechanical } \\
\text { exhaust } \\
\text { ventilation, air } \\
\text { supply from } \\
\text { corridors }\end{array}$ & 6.8 & 130 & 300 \\
\hline $\begin{array}{l}\text { Filtered air flow in } \\
\mathrm{m}^{3} / \mathrm{h}\end{array}$ & n.a & $<68$ & 1,360 & $3,400-6,800$ \\
\hline $\begin{array}{l}\text { Downwards air } \\
\text { speed in } \mathrm{cm} / \mathrm{s}\end{array}$ & n.a & 0.4 & 3.7 & $9.2-18.4$ \\
\hline Type of enclosure & n.a & $\begin{array}{l}\text { Tent } 2.3 * 2.3 \\
\text { meter } \\
\text { "Greenhouse" }\end{array}$ & $\begin{array}{c}\text { Fixed } \\
\text { polycarbonate } \\
\text { wall } 3.2 * 3.2 \text { meter }\end{array}$ & $\begin{array}{c}\text { Permanent } \\
\text { installation } \\
3.2 * 3.2\end{array}$ \\
\hline $\begin{array}{l}\text { Expired air sucked } \\
\text { out of the mask of } \\
\text { the OR-team in } \\
\text { enclosure }\end{array}$ & No & yes & \multicolumn{2}{|c|}{ Yes, Improved helmet } \\
\hline Filtration & n.a & \multicolumn{2}{|c|}{$\begin{array}{l}\text { Electrostatic air filter removing parts } \\
\qquad>2 \mu \mathrm{m} \text { from the airstream }\end{array}$} & $\geq 2 \mu \mathrm{m}$ \\
\hline CFU/plate*.hour & 70 & 10 & $0.4-1.8$ & $0-0.2$ \\
\hline $\mathrm{CFU} / \mathrm{m}^{3}$ & $636^{* *}$ & $88^{* *}$ & $7^{* * *}$ & $3.5^{* * *}$ \\
\hline $\begin{array}{ll}{ }^{*} & 31 / 4 \text { " plate }(8.26 \\
{ }^{* *} & \text { Estimated } \\
{ }_{* * *} & \text { Measured with }\end{array}$ & it air sampler & & & \\
\hline
\end{tabular}

Table 1.1. Different phases in the development of the Charnley enclosure system. ${ }^{40-43}$ 


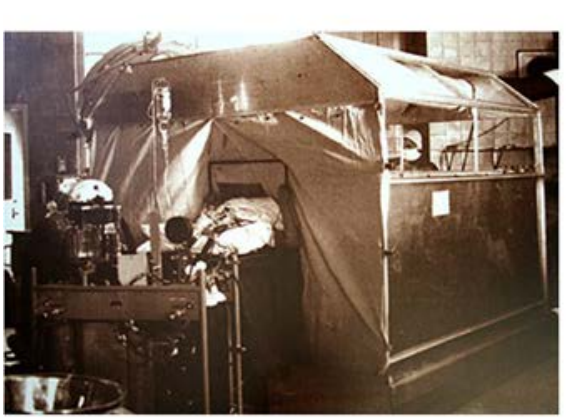

Foto of Charnley's original air distribution system 1961

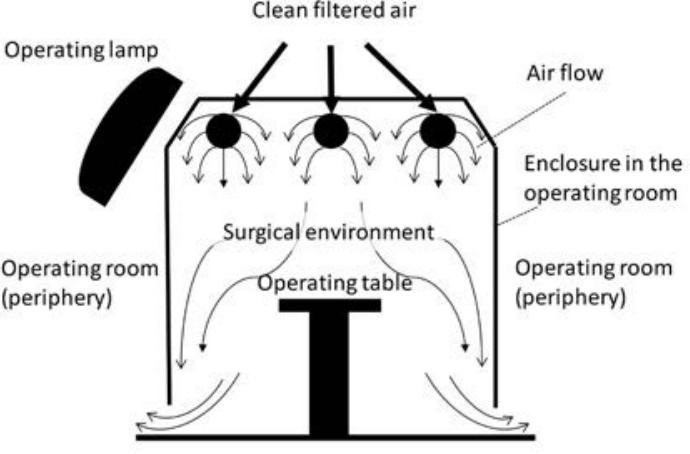

Cross section of Charnley's original air distribution system

Figure 1.5. Charnley's original "Greenhouse" system in 1961-1962.

For each phase of the operation, a set of sterile instruments was handed to the scrub nurse through a small hatch.

Around 1965 a system with a permanent enclosure and an even higher air change rate (300 air changes per hour) was developed by Howorth. Although this system with panels had proved to be effective with respect to the level of microorganisms carrying particles, the panels restricted the surgeons and surgical team movement, the positioning of the instruments and medical equipment inside the enclosure considerably. ${ }^{44,45}$ To avoid these kind of problems systems with partial removable protection panels to approximately 2 meters height from the floor were suggested. ${ }^{35,46,47}$

The Charnley-Howorth system was translated into Meierhans-Weber system in Switzerland. ${ }^{48}$ This Swiss system also involved a cabin with downflow in which the air could flow through openings in the side walls. As Charnley, Weber used a comparable, self-designed "body exhaust suite" with an air exhaust from under the operation clothing of the surgical team. ${ }^{48,49}$ 
Howorth finally improved the Charnley system with enclosure into the Exflow ultraclean ventilating system in 1976. The system was part of the ceiling of the operating room and 3.2 meter square. The walls where dispensed by a polycarbonate partial wall (skirt), at the ceiling around the canopy. Charnley never used this system because he didn't like the absence of a physical barrier between the patient and the rest of the operating room. ${ }^{50}$ His objection was that the air curtain in contrast to the physical barrier could be easily compromised. In 1978 Whyte demonstrated that this system with a skirt around the canopy up to 2.5 meter from floor level will perform optimal at a temperature difference of around $1.5^{\circ} \mathrm{C}$ between the supply air and the room temperature..$^{35}$ When no temperature difference was applied the velocity loss at the operating table is around $30 \%$. If the supply temperature increases, the air speed at operating table level will drop below $0.25 \mathrm{~m} / \mathrm{s}$ and entrainment will take place at floor level. The supply air speed of this system was approximately $0.45 \mathrm{~m} / \mathrm{s}$.

This study shows that the air velocity at operating table height should not be less than $0.25 \mathrm{~m} / \mathrm{s}$ to prevent entrainment at floor level. This was based on the emission of a pollutant at the outside of the skirt. With this system with skirts air speed in the centre of the system was higher (approximately $0.45 \mathrm{~m} / \mathrm{s}$ ) than close to the skirts $(0.31 \mathrm{~m} / \mathrm{s})$. Whyte also mentioned that a skirt around the canopy, from the ceiling up to 2.0 meters from floor level was considered more appropriate for future designs. Nowadays also systems without a skirt around the canopy are installed in operating rooms.

This type of exponential flow is also described by Friberg in a study comparing an exponential flow system with walls from the ceiling up to 2.0 meters from floor level, a vertical down flow system with walls from the ceiling up to 0.2 meters from floor level and a horizontal flow system. ${ }^{45} \mathrm{He}$ concluded that the three systems were comparable regarding the number of microorganisms carrying particles and could be classified as ultraclean operating rooms (less than $10 \mathrm{CFU} / \mathrm{m}^{3}$ ). 


\subsection{Deposition of particles and carriage of microorganisms}

Particles in air that can carry microorganisms may be deposited onto surfaces by five well known mechanisms. ${ }^{51}$ All objects including particles are influenced by the gravitation forces. These forces cause objects (particles) to settle (fall). Gravitational settling is likely to be the most important method of deposition, accounting for the majority of bacteria being deposited in operating rooms. Microrganisms cayrrying particles in operating rooms have an equivalent particle diameter of about $12.3 \mu \mathrm{m}$ with a settling rate of $0.46 \mathrm{~m} / \mathrm{s}^{52} \mathrm{In}$ contrast relatively small particles of $0.5 \mu \mathrm{m}$ or less move by the Brownian motion. This movement occurs when very small particles are randomly hit by molecules in the air. As a result, these small particles spread through a space regardless of the air flow. When a particle in an airflow passes close to a surface it wil be attracted to it by Van der Waal's forces resulting in direct interception. For a $1 \mu \mathrm{m}$ particle the surface force will be equal to the gravitational force when the particle is one diameter away..$^{53}$ Electrostatic forces attract particles at a much greater distance than surface forces like Van der Waal's. These electrostatic forces occur when two surfaces are electrically charged with opposite charges. This principle is also used for filters. Particles with a relative high mass can not follow the airflow during a change of direction of the air flow. This is caused by mass inertia of the particle. ${ }^{54}$ Inertial impaction occurs as a particle leaves the air flow and impacts on a surface. It is suggested that gravitational settling is more important than impaction of particles into containers. ${ }^{55}$

Individual bacteria are generally smaller than $1 \mu \mathrm{m}$ in size and tend to cluster together and attach to other particles. Aerogenic microorganisms carrying particles have a size that vary from $4 \mu \mathrm{m}$ to $20 \mu \mathrm{m} .{ }^{56}$ Charnley demonstrated that the use of a filter through which no particles $>2 \mu \mathrm{m}$ can pass reduces the number of aerogenic microbes in an operating room drastically. ${ }^{42}$ The size distribution of particles in an environment shows that smaller particles are present in a higher concentration than larger particles. 
It was shown in the middle of the last century that most of the microbes in the air of rooms where people are present are attached to skin scales. ${ }^{57}$ Only a few studies have been found demonstrating a relation between the presence of aerogenic bacteria and size of airborne particles in a hospital. ${ }^{42,58-65}$ Only 6 studies gave this relation of the size distribution of microorganisms carrying particles in operating rooms. ${ }^{52,59-62,64}$ The relationship between microbiological sampling and particle counting has rarely been evaluated.

Nobel showed that bacteria carrying particles are in the range from $4 \mu \mathrm{m}$ to $18 \mu \mathrm{m}$ and particles carrying fungi are in the range from aproximately $3 \mu \mathrm{m}$ up to $27 \mu \mathrm{m} .^{52}$ Microorganisms associated with infections were usually present on particles from $4 \mu \mathrm{m}$ to $20 \mu \mathrm{m}$. In contrast to bacteria many fungi are found in the air as single spores. Other studies suggest that the size of aerogenic microbes is bigger than $2 \mu \mathrm{m} .{ }^{41,51}$ Only $1 \%$ of the found microbes are less than $1 \mu \mathrm{m}$ (Table 1.2). During hip-replacement procedures particles with a diameter of $>5 \mu \mathrm{m}$ showed a statistically higher concentration than smaller particles.

\begin{tabular}{lccccc}
\hline Equivalent particle diameter $(\mu \mathrm{m})$ & 1 & 5 & 12 & 20 & 50 \\
\hline Cumulative occurrence & $1 \%$ & $25 \%$ & $50 \%$ & $75 \%$ & $95 \%$
\end{tabular}

Table 1.2. Presence of microorganisms carrying particles equal to, and greater than, given equivalent particle diameters. $51,52,57,66$

Whyte describes the size distribution of bacteria carrying particles with an equation (equation 6, Appendix A.2). ${ }^{67}$ The size distribution of microorganisms carrying particles in the air of occupied rooms calculated with this equation are very similar to the results obtained from different studies and are given in Table 1.2. ${ }^{51,52,57,66}$ As a result of this formula the average equivalent particle diameter is $12 \mu \mathrm{m}$ which is close to the average size of $12.3 \mu \mathrm{m}$ that was found.$^{52}$ Also the presence of microorganisms carrying particles larger than $20 \mu \mathrm{m}$ is $25 \%$. For particles smaller than $4 \mu \mathrm{m}$ this is $75 \%$. 
It can be calculated (appendix A) that the presence of microorganisms carrying particles with a particle diameter above $50 \mu \mathrm{m}$ is less than $5 \%$. The presence of microorganisms carrying particles with an equivalent particle diameter below $1 \mu \mathrm{m}$ is also very low $(1 \%) . .^{22,58}$

There was no statistically significant correlation between the aerogenic microorganisms carrying particles and and particle counts for $>0.5 \mu \mathrm{m}$ and $>5 \mu \mathrm{m}$.

Based on this results Nobel concluded that microbiological monitoring is the most suitable method to evaluate the quality of air in operating rooms. ${ }^{52}$

Birgand conducted a study where air samples were taken during orthopaedic and cardio surgery. This study included 13 different operating rooms distributed over 5 private hospitals and 5 university hospitals. ${ }^{60}$

He concluded that of the 180 samples taken during 60 procedures, the median number of $0.3 \mu \mathrm{m}$ particles was $10^{7}$ per $\mathrm{m}^{3}$, the number of $0.5 \mu \mathrm{m}$ particles was $10^{6.1}$ per $\mathrm{m}^{3}$ and the number of $5.0 \mu \mathrm{m}$ particles was $10^{4,6}$ per $\mathrm{m}^{3}$ (Table 1.3 ). ${ }^{60}$

\begin{tabular}{|c|c|c|c|c|c|c|}
\hline & \multicolumn{3}{|c|}{$\begin{array}{c}\text { Number of particles per } \mathrm{m}^{3} \\
\text { (180 samples during } 60 \text { operations) }\end{array}$} & \multicolumn{3}{|c|}{$\begin{array}{c}\text { Number of CFU/m }{ }^{3} \\
\text { (180 samples during } 60 \\
\text { operations) }\end{array}$} \\
\hline & $\geq 0.3 \mu \mathrm{m}$ & $\geq 0.5 \mu \mathrm{m}$ & $\geq 5.0 \mu \mathrm{m}$ & $<1$ & $1-10$ & $>10$ \\
\hline Incision & $6.31 * 10^{7}$ & $7.94 * 10^{6}$ & $6.31 * 10^{4}$ & 16 & 30 & 14 \\
\hline After bone cut & $7.94 * 10^{6}$ & $1.26 * 10^{6}$ & $2.51 * 10^{4}$ & 17 & 31 & 12 \\
\hline \multirow[t]{3}{*}{ wound closure } & $2.00 * 10^{6}$ & $3.16 * 10^{5}$ & $1.26 * 10^{4}$ & 17 & 29 & 14 \\
\hline & & & & \multicolumn{3}{|c|}{$\begin{array}{l}\text { Number of wound culture } \\
\qquad \mathrm{CFU} / \mathrm{m}^{2}\end{array}$} \\
\hline & & & & $<1$ & $1-10$ & $>10$ \\
\hline Orthopaedic $(n=34)$ & & & & 24 & 10 & 0 \\
\hline Cardiac $(n=26)$ & & & & 9 & 11 & 6 \\
\hline
\end{tabular}

Table 1.3. Results of the 180 air samples and wound cultures. ${ }^{60}$ 
Of 180 air samples taken around the head of the patient, 50 (28\%) did not show any CFU, $90(50 \%)$ had $1-10 \mathrm{CFU} / \mathrm{m}^{3}$ and $40(22 \%)$ had $>10 \mathrm{CFU} / \mathrm{m}^{3}$. Also a sample from the operated wound was taken before closure to determine the level of CFU $/ \mathrm{m}^{3}$.

Birgand suggested that the number of aerogenic microorganisms carrying particles is strongly correlated with particle counts for diluting mixing systems. ${ }^{60}$ However a significant relationship between aerogenic microorganisms carrying particles and wound contamination at closure of the wound was not found.

Darouiche studied the effect of an air barrier system (ABS) positioned in an operating room. ${ }^{59}$ The ABS passes ambient operating room air through a filter that removes $99.997 \%$ of particles of $0.3 \mu \mathrm{m}$ and larger. The filtered air is passed over the surgical wound through a nozzle. This nozzle was attached to the top of the incision drape only a few inches away from the incision. In this study a total of 287 patients, 143 in the intervention group and 144 in the control group, are included. Darouiche concluded that CFU concentration was positively related to the total number of particles $>0,3 \mu \mathrm{m}$ in the control group, however correlation between particle concentration and microorganisms carrying particles in $\mathrm{CFU} / \mathrm{m}^{3}$ could not be demonstrated in the intervention group.

A study in a Korean hospital shows that the detection rate of airborne bacteria was generally highest in the stage covering 1.1-2.1 $\mu \mathrm{m}$ particles and for airborne fungi the stage covering $>7.0 \mu \mathrm{m}$ particles gave the highest numbers. ${ }^{58,68}$ In this study samples were taken at the main lobby, ICU, surgical ward, biomedical laboratory and outside. Even if this study is not performed in operating rooms the results regarding the size of miroorganisms carrying particles are comparable to studies in operating rooms.

Seal corrolated the numbers of bacteria-carrying particles measured in operating rooms with the size distribution of the measured particles. ${ }^{69}$ He concluded that the relationship 
between particle size $5.0-6.99 \mu \mathrm{m}$ and the number of $\mathrm{CFU} / \mathrm{m}^{3}$ gave the highest correlation in an operating room with a UDF system, figure 1.6.

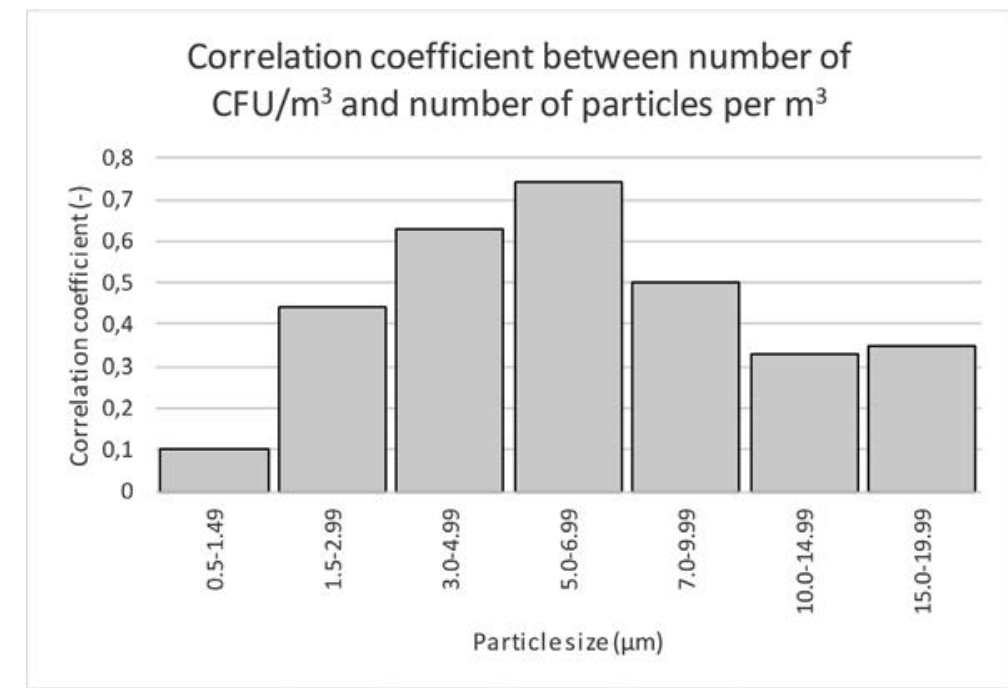

Figure 1.6. Correlation between the number of $\mathrm{CFU} / \mathrm{m}^{3}$ and number of particles per $\mathrm{m}^{3}$ in the periphery of an operation room with a UDF system. ${ }^{69}$

Stocks concluded in his study based on 13 hip and 9 knee arthroplasty surgeries in an operating room with a turbulent mixing flow system that there is no significant correlation between particles $<5 \mu \mathrm{m}$ and the number of $\mathrm{CFU} / \mathrm{m}^{3}$. ${ }^{64}$ For particles $>5 \mu \mathrm{m}$ and $>10 \mu \mathrm{m}$ however he found a significant relation.

It is likely that the correlation of larger particles ( $>5 \mathrm{~mm}$ ) with CFUs observed in this study was caused by the capability of larger particles to carry bacteria.

Landrin concluded in his study that the results obtained from microbiological sampling and particle counting did not correlate. For evaluation of microbiological contamination in operating rooms the measurement of particle concentration doesn't show a reliable relation with the results of microbiological sampling and is therefore not a proper method. ${ }^{62}$ 
Even if there is not a fixed correlation between the number of particles and number of aerogenic microorganisms carrying particles, measurement of particles is a solid predictor of the entrainment of airborne particles into the area of the surgical wound and sterile instruments. ${ }^{36-39}$

\subsection{The role of air distribution systems in the prevention of aerogenic contamination in the operating room}

The main source of microorganisms carrying particles are the people in the operating room..$^{47,52,57,58,70-72}$ Poor cleaning of the operating room may also temorary result in microorganisms carrying particles in the air. Movement of the team in the room creates turbulent air, mobilizing sedimented particles so that they are released into the air.

An important contamination route, but not always recognized as such, is the sedimentation of microorganisms carrying particles via the air to the sterile instruments and so indirect to the wound (figure 1.7). ${ }^{47,70,73,74}$

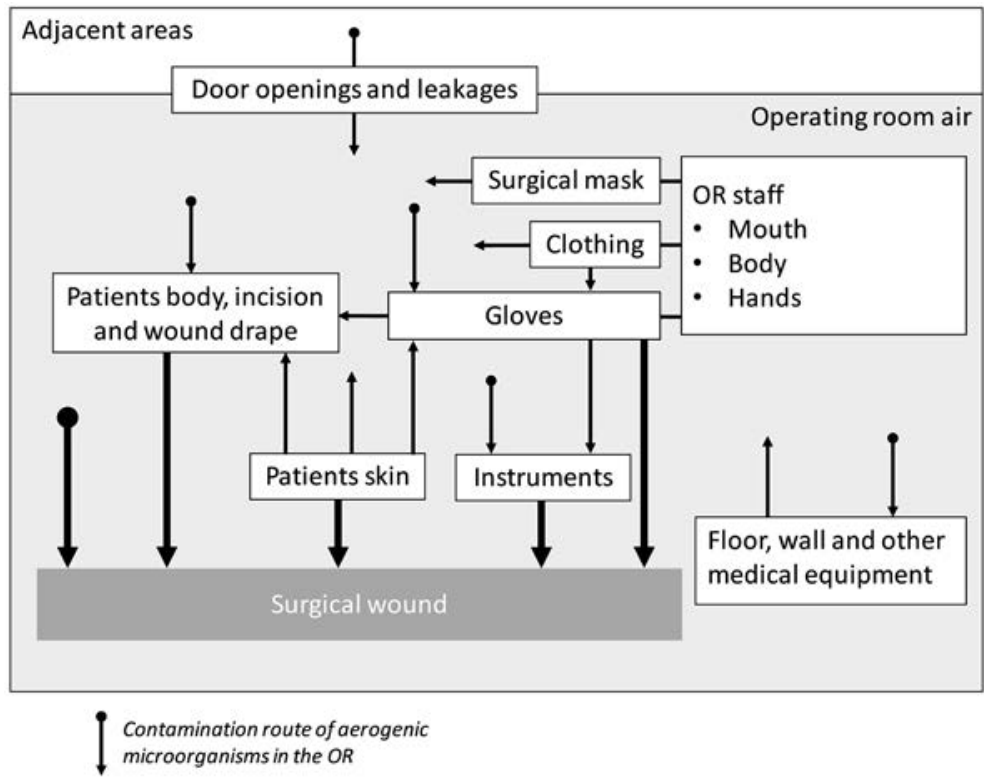

Figure 1.7. Source and routes of wound contamination in the operating room. $47,70,71$ 
Since the air in an operating room is the most important vehicle in the contamination of instruments and wounds, influencing the direction of the airflow by clean air (as in UDF systems) may be used in the prevention of this contamination. Although difficult to proof in patient related studies it is logic to assume that this decrease of contamination is beneficial, and may decrease the postoperative superficial and deep surgical site infections (SSI).

In clarifying the preventive effect of a well-functioning air distribution system it is necessary to distinguish 3 relations in the use of these systems:

A. the relation of the system on the contamination of the air,

B. the relation of the system on the contamination of instruments and wound, C. the relation between the system and surgical site infections.

\section{A: The relation between the system characteristics and air contamination}

The effect of different types of air distribution systems on the aerogenic contamination in clinical practice was studied in the multicentre randomised controlled trial by Lidwell (figure 1.8). ${ }^{75-77}$ This figure is based on 8,055 hip $(6,781)$ and knee $(1,274)$ replacement operations in 19 hospitals in the UK (11), Scotland (4) and Sweden (4), from 1974 up to 1979. The number of air samples on which the $\mathrm{CFU} / \mathrm{m}^{3}$ median is calculated is not given in this article but the samples were taken during all operations at suitable intervals. In this article ultraclean air arbitrarily was defined as air containing fewer than 10 microorganisms carrying particles per $\mathrm{m}^{3}\left(\mathrm{CFU} / \mathrm{m}^{3}\right)$.

In this study however is not described what the amount of supplied air, filter efficiency, number of persons in the operating room, number of door openings and the activity levels were during surgery in the 19 participating hospitals. It is known that, beside the air distribution system, these variables influence the level of aerogenic contamination as. ${ }^{78}$ 


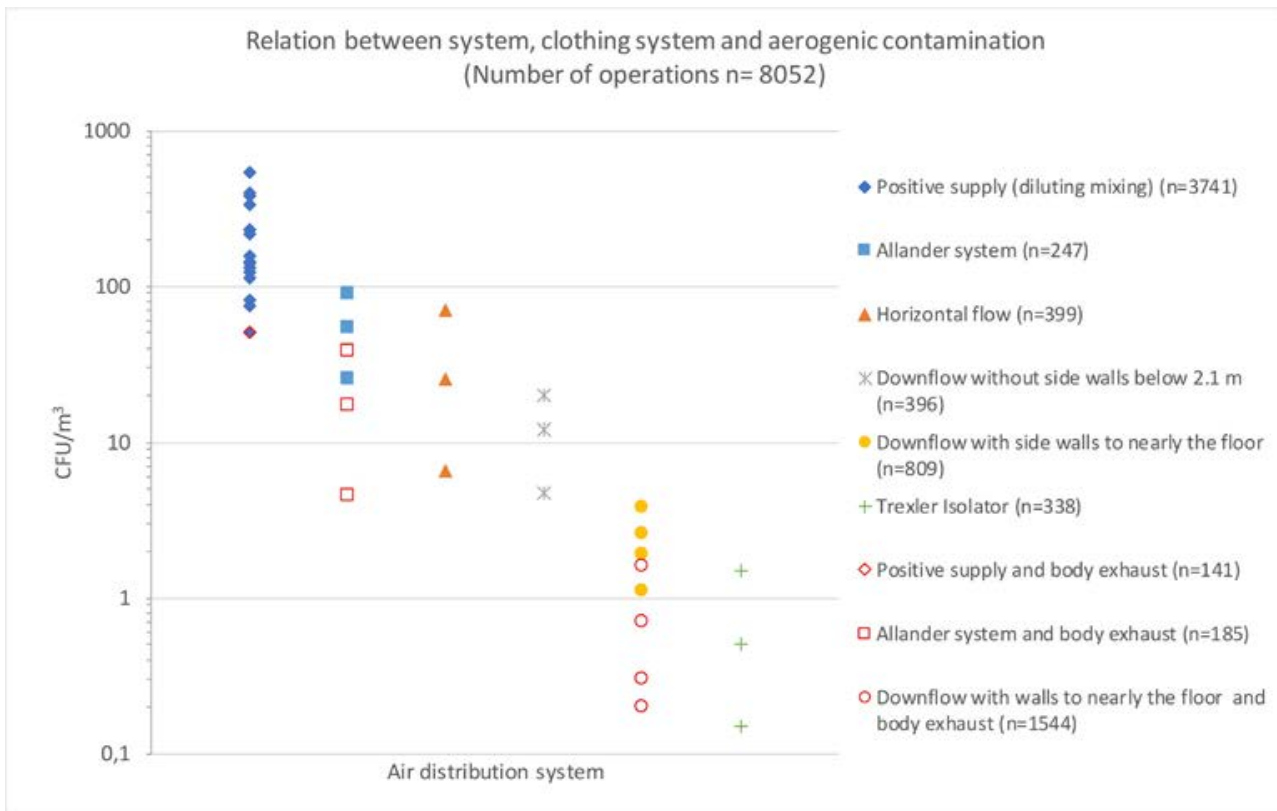

Figure 1.8. Relation between type of system, clothing system and aerogenic contamination, modified from Lidwell. ${ }^{75}$

Agodi shows in his study with 1228 elective prosthesis procedures (60.1\% hip and $39.9 \%$ knee arthroplasty) that a UDF system provides a more robust solution to reduce the number of $\mathrm{CFU} / \mathrm{m}^{3}$ and $\mathrm{CFU} / \mathrm{m}^{2}$.h than diluting mixing systems and small UDF systems referred to as "turbulent airflow ventilation". ${ }^{40,79,80}$ For hip arthroplasty in $49.4 \%$ of cases the CFU level was below the threshold value in operating rooms with UDF systems and for operating rooms equipped with diluting mixing systems and turbulent air flow systems, this percentage was $0 \%$ and $2.3 \%$, respectively.

Although many studies demonstrate the effectiveness of different systems, with respect to the reduction of the number of aerogenic microorganisms close to the wound and sterile instruments, no study was found that investigated the size of the operative area that is needed for different types of surgery. 
$B:$ The relation between system and contamination of wound and instruments Lidwell collected more than 3,000 wound-wash samples during operations in participating hospitals. ${ }^{81}$ Also control samples existing of sterile liquid, with equivalent volumes of fluid were taken for comparison. These samples were processed in the same way. The results of this study demonstrate that the use of ultraclean-air conditions reduces the number of bacteria isolated from wounds during surgery (figure 1.9). The number of isolated bacteria, when in addition to ultraclean air systems, body exhaust suits or a Trexler isolator were used did not differ significantly from those in the control samples. These samples show "clean air" without a detectable level of microorganisms.

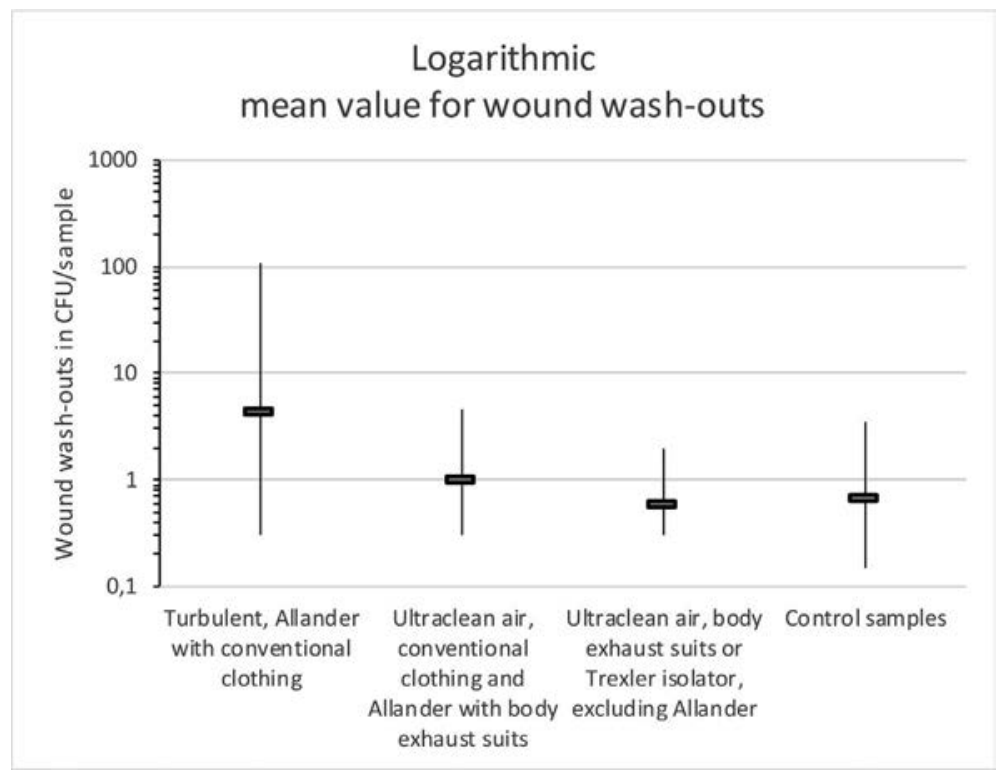

Figure 1.9. Logarithmic mean value wound wash-outs. ${ }^{81}$

Knobben demonstrated by microbiological examination of bone material (acetabulum and femur in case of the hip joint; femur and tibia in case of the knee joint) and swabs from the instruments during 207 operations that optimising only the way of use of a conventional mixing air distribution system did not reduce the Intra-operative 
contamination (number of contaminated samples) significantly (Control group: $32.9 \%$ and group-1:34.3\%). ${ }^{82}$

This first intervention was only a behavioural intervention and consisted of laying-up the sterile instruments under the supply terminal (plenum), unpacking just before surgery and instrumentation never leaving the area under the supply terminal, position of the head of the patient always out of the area under the supply terminal.

A second intervention included further major behavioural changes as well as the replacement of the old conventional airflow system to a UDF system. The air quantity was increased from $2,700 \mathrm{~m}^{3} / \mathrm{h}$ to $8,100 \mathrm{~m}^{3} / \mathrm{h}\left(5,400 \mathrm{~m}^{3} / \mathrm{h}\right.$ recirculation over the HEPA filter) and glass panels were placed around the supply plenum. The air speed was increased from $0.1 \mathrm{~m} / \mathrm{s}$ to $0.2 \mathrm{~m} / \mathrm{s}$. Not only was the amount of air changed but the system was also converted from a system that can be seen as a turbulent mixing flow system to a UDF system. Besides this technical intervention also behavioural interventions were undertaken in the operating room. These behavioural interventions consisted of laying-up sterile instruments in the preparation room and not in the operating room, limiting needless activities and better proper wearing of body coverage. Contamination was studied by culturing at different stages of used and unused instruments as well of removed bone. Postoperative wound discharge was recorded as well as superficial and deep infections.

After the first intervention there was an increase of intra-operative contamination. prolonged wound secretion and superficial wound infection, but a decrease of the incidence of deep periprosthetic infection. These changes however were not significant. After the second intervention there was a significant decrease of contamination (from $34.3 \%$ to $8.6 \%)$, prolonged wound discharge and superficial infections. The decrease of deep prosthesis infection was not significant. 


\section{C: The relation between the system and surgical site infection}

Lidwell published the only clinical randomised controlled trial (RCT) proofing the effect of different type of ventilation systems. ${ }^{81} \mathrm{He}$ found a direct relation between the level of cleanliness of the provided air of a certain system and the risk for a SSI. ${ }^{83} \mathrm{He}$ concluded that using an air distribution system that creates an ultraclean environment (less than 10 $\mathrm{CFU} / \mathrm{m}^{3}$ ) reduces the number of SSI with $50-53 \%$. He analysed also the other preventive measures. The prophylactic use of antibiotics reduces the risk for SSI by $73-76,5 \%$.

The use of body exhaust suits reduces the risk for SSI with $50-56 \%$. The use of a body exhaust suit reduces the emission of skin scales that can carry microorganisms. ${ }^{51,57,66}$ The SSI reduction rates of the different preventive measures may be combined. The relative relation between these three prophylactic measures antibiotics, ultraclean air and body exhaust suits is given in figure 1.10 .

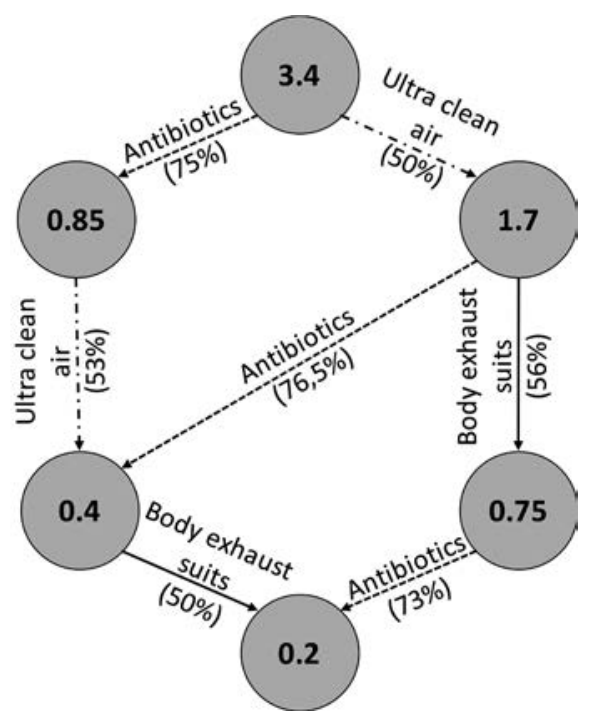

Figure 1.10. Relation between different types of prophylaxis and sepsis of the joint. ${ }^{83}$

This shows clearly that the prevention of SSI is multifactorial, as well that the aerogenic route is important in the reduction of SSI. These findings were confirmed by a comparative analyses of Persson of the Swedish Arthroplasty Register containing data of 148,359 total hip replacements. ${ }^{84}$ 
In their analysis the preventive contribution of antibiotics loaded bone cement (ABC) could also be determined at $50 \%$, as confirmed in a meta-analysis by Parvizi. ${ }^{85}$ Darouiche suggested that an increase in aerogenic microbiological load of $10 \mathrm{CFU} / \mathrm{m}^{3}$ results in an increase of the risk of surgical site infections by $100 \% .{ }^{59}$

Studies from Charnley, Lidwell, Nelson and more recent from Darouiche show a strong relation between the concentration of aerogenic microbes and wound sepsis (figure 1.11). ${ }^{59,60,83,86,87}$ In all studies antibiotic prophylaxis was used except in the study of Charnley. Charnley used antibiotics in the wound for a short period of time (1965-1966) covering 326 of the total amount of 2,085 procedures included in his study. ${ }^{40} \ln 72.4 \%$ $(5,831$ cases $)$ of the operations in Lidwell's study antibiotics were used. ${ }^{75}$

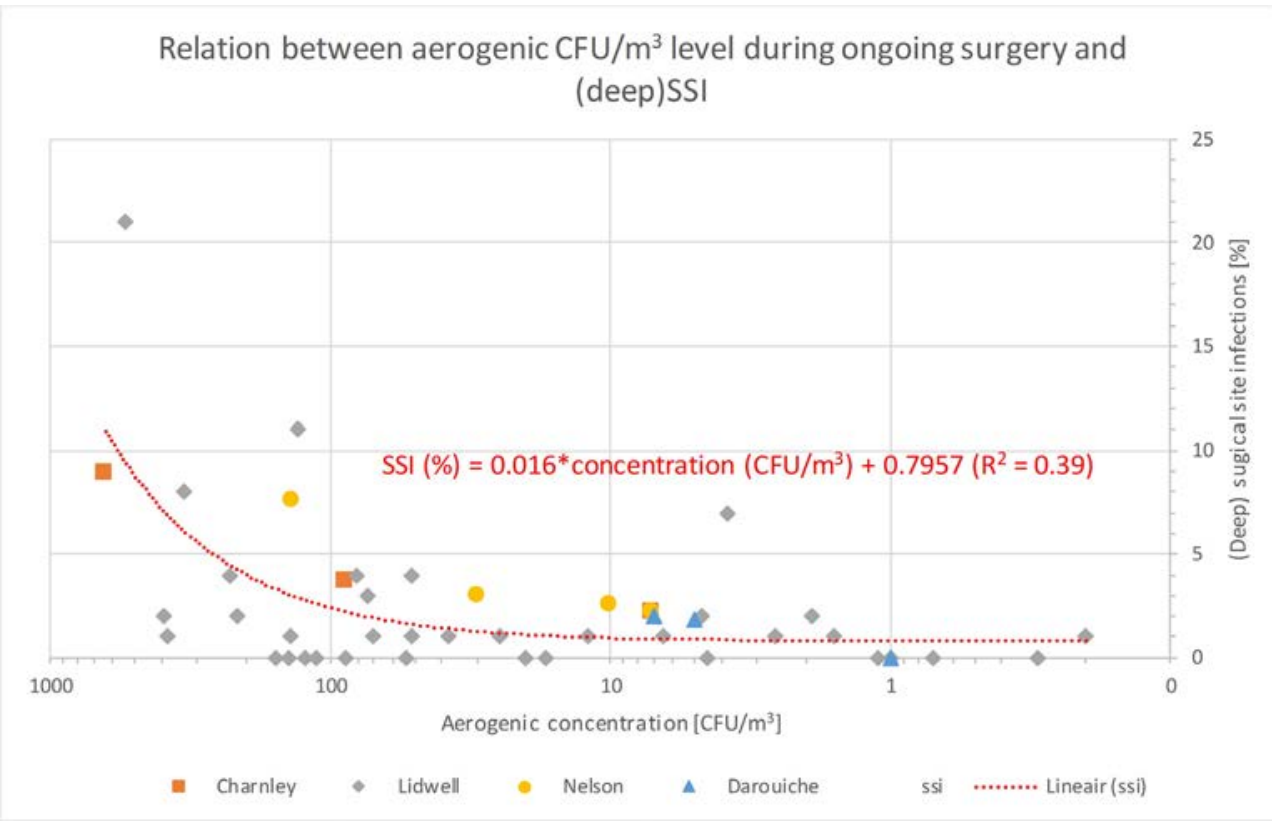

Figure 1.11. Relation between aerogenic contamination and (deep) sepsis. ${ }^{40,59,87,88}$

Some other studies have been published that suggested that UDF systems may increase the level of SSI. ${ }^{89-91}$ The relation between the system characteristics like diluting mixing and UDF and the effect on SSI is subject of debate. ${ }^{89-92}$ 


\subsection{Surgical smoke and anaesthetic gasses}

Electrosurgery is a quite old technique. It was developed in 1926 by W.T. Bovie and initially was not used widely. Nowadays electrosurgery is an indispensable tool to the modern surgeon and is used in most of the surgical procedures. Modern diathermy equipment uses different electrical waveforms resulting in a current passing through tissues. The current flowing through the tissues has an electrical resistance that produces heat causing intracellular water to heat up and the cells to explode. As a result, tissues are separated from each other. By using lower coagulation current less heat will develop, causing cells to dry and thus coagulation to take place. ${ }^{93}$ However all electrosurgery produces surgical smoke that contains particles.

The amount and size of the particles depend on the type of electrosurgery. Surgical smoke is the gaseous by-product of electrosurgery containing particles containing viable and nonviable cellular material. Surgical smoke consists of $95 \%$ water vapour and $5 \%$ cellular debris in the form of particles. The size of the particles in surgical smoke depends on the type of device, Table 1.4.94-97

\begin{tabular}{cl}
\hline Device & $\begin{array}{l}\text { Mean aerodynamic } \\
\text { particle size } \mu \mathrm{m}\end{array}$ \\
\hline Electrosurgical unit & $<0.1$ \\
Abdominoplasty & 0.0747 \\
Nephrectomy & 0.0093 \\
Breast reduction & 0.00774 \\
TURP & 0.0096 \\
Hip replacement & 0.0094 \\
Laser & 0.31 \\
Ultrasonic scalpel & $0.35-6.5$
\end{tabular}

Table 1.4. Particle size of surgical smoke..$^{94-97}$

In literature, the term surgical smoke is also referred to as 'smoke', 'plume' or 'aerosol' ${ }^{98}$ The particles in the plume can be dispersed up to $100 \mathrm{~cm}$ from their point of production. 
The presence of the potentially infectious human papilloma virus (HPV) DNA and HIV in surgical smoke is proven to be a major risk. ${ }^{99-101}$ In one study, intact melanoma cells were found in culture media. For this experiment, pellets of B16-FO mouse melanoma cells were cauterized and thus produced surgical smoke was collected in a culture medium. ${ }^{102}$ Based on this experiment it was concluded that viable cancer cells can be spread in the abdominal cavity and in laparoscopic surgery and can lead to port site metastasis. Not only thermal devices are used but also ultrasonic instruments. Ultrasonic scalpels have tips or blades that vibrate at a frequency of approximately 55,000 times per second. When the vibrating tips touch human tissue heat is produced at that location. This ultrasonic scalpel allow surgeons to coagulate and divide tissue.

The motion of the tip produces a lower tip temperature comparable to electrosurgery resulting in surgical smoke with an even higher risk to carry infectious aerosols. ${ }^{97}$

Surgical smoke is associated with risk factors for the staff in the operating room caused by: $:^{97,103,104}$

- Exposure to human-to-human viral transmission caused by viable particles

- Exposure to particles irritating lungs with approximately the mutagenicity of cigarette smoke

- Exposure to toxic effects of particles in the surgical smoke

- Exposure to mutagens and carcinogens

- Exposure to infectious pathogens

The best way to protect staff against surgical smoke is to use a smoke evacuation system $^{95,103,105}$. These kinds of systems reduce the load of surgical smoke in the operation room but will not completely remove all the surgical smoke. The remaining surgical smoke can be disposed of by the air distribution system in the operating room. ${ }^{96,106}$ Smoke evacuation systems with a capture velocity of $0.5-0.75 \mathrm{~m} / \mathrm{s}(100-150 \mathrm{ft} / \mathrm{min})$ are recommended. 
For proper functioning of a smoke evacuation system the inlet of the suction device should be kept at a maximum distance of $5 \mathrm{~cm}$ from the place where the surgical smoke is generated. ${ }^{105,107-109}$ Despite these precautionary measures it cannot be prevented that surgical smoke enters the environment where surgical staff is present.

Ragde shows in his research in five different ORs in two different hospitals of which 2 operating rooms were equipped with an UDF system that for a short period of time the concentration in the inhalation area can go up to 272,000 ultra-fine particles (0.0056$0.560 \mu \mathrm{m}$ ) per $\mathrm{cm}^{3}$ during breast reduction. ${ }^{95}$ This high value was recorded during bilateral breast reduction when two surgeons were working simultaneously. The smoke evacuator was not used correctly, two electrosurgery pencils were connected to one smoke evacuator which was not dimensioned for this.

Tseng showed in his study that the average level of polycyclic aromatic hydrocarbons concentrations at the surgeon's and anastylosis breathing area were 20 to 30 times higher than those in regular outdoor environment. ${ }^{103}$ No relation between the type of air distribution system and the exposure of the staff is demonstrated. Found studies conclude that the proper use of smoke evacuation systems or the use of high-efficiency masks reduce the potential health hazards to surgical personnel.

The protection offered by the air distribution system in the operating room depends on the position of the staff members (surgical team, anaesthesia team or staff in the periphery of the operating room) and the contaminant removal efficiency of the system at the location of the staff members. However, it can be concluded that the air distribution system plays a role in protecting personnel (reducing the risk) from the harmful substances in surgical smoke that are not removed by the smoke removal systems. However, it is unknown to what extent what type of ventilation system contributes to the protection of personnel (reducing the risk). 
Anaesthetic gasses, especially nitrous oxide $\left(\mathrm{N}_{2} \mathrm{O}\right)$, can cause health effects for surgical staff. ${ }^{110,111}$ Nitrous oxide is still used in general anaesthesia in operating rooms in hospitals. Isoflurane, sevoflurane and other widely used anaesthetic gasses are also associated with health risks for surgical staff. Some studies conclude that isoflurane concentrations in operating rooms can exceed the recommended values of $2 \mathrm{ppm}$ and can be the cause of health disorders of staff. ${ }^{110,112}$ The studies demonstrate that the concentrations depend on the type of air distribution system in the operating room. Operating rooms with standard air distribution systems have a significantly lower concentration of isoflurane than operating rooms without a standard air distribution system. ${ }^{112}$ In a UDF system the position (standing or sitting) of the anaesthesiologist had no significant influence on the inhaled concentration of isoflurane. ${ }^{113}$ The main source of sevoflurane in the operating room is sevoflurane vaporisation in the patient's mouth. Because this kind of exposure is higher for the anaesthesia team than the exposure for the surgical team during craniotomies. However, in both positions the concentration of isoflurane was below the accepted threshold limits of $2 \mathrm{ppm}$.

Even though gasses do not consist of small solid particles, the ventilation system has an important role in diluting and removing anaesthetic gasses and protecting the surgical team against harmful substances in the environment.

\subsection{Aim of this thesis}

UDF systems and prevention of surgical site infections

As shown in this chapter a well-functioning air distribution system in an operating theatre is able to reduce the number of particles in the surgical site (wound area and sterile instruments) thus reducing the number of microorganisms carrying particles. Reducing the number of microorganisms carrying particles will reduce the contamination of the surgical instruments and the surgical wound by the aerogenic route. 
Since the incidence of wound infection is correlated with the number of bacteria that contaminate the wound, it seems logic to conclude that reduction of the number of contaminating bacteria by a proper installed and used air distribution system will reduce this risk. However this beneficial prophylactic effect of e.g. a UDF system on the incidence of SSI is sparsely proven in patient related studies with the highest quality of evidence. The only randomised controlled trial (RCT) as published by Lidwell is often critized and also the many observational studies are often regarded as not sufficient proof of effectivity. ${ }^{81,90,91}$ Studies have been published that even suggested that UDF systems may be harmful. ${ }^{89,91,114}$ These studies however compare the risk for SSI with the type of an air distribution system (UDF versus mixing systems) instead of the performance levels of these systems with the number of SSI, and used non validated questionnaires.

In daily clinical practice there is an important lack of knowledge of the surgical staff, which type of air distribution system is installed, and how such a system should be used in practice optimally.

Sub-optimal use often causes a reduced protective effect of the distribution system and technical possible improvements are often not considered or used. Improper use may cause an increased contamination of the wound instead of protection and may be the reason for contradictory results in publications..$^{89,91}$

Instead of experimental studies in laboratory or operation theatre the effect of modifications of an air distribution system can be studied in computational fluid dynamics (CFD) studies: specific problems and solutions can be simulated.

However the translation to the practice should subsequently still be tested in the practice of operating and instrument lay-up rooms. ${ }^{115-123}$ Most of these CFD studies focus on the differences between system typologies (diluting mixing versus UDF systems), the effect of lamps, the effect of door openings or the effect of buoyant flow on the air flow. 
For the design and daily practice however, it is important have clear and answers on questions about this daily practice, e.g. what the size the protected area must be, where lamps, instruments and the anaesthetic team should best be positioned.

In this thesis studies will be described that focus on a better design and a more optimal use of UDF systems in daily practice, leading towards more effective contamination control.

\section{Research questions}

The five main research questions in this thesis are:

1. Is a clean area of $3 \times 3$ meter, often used in Dutch operating rooms, sufficient to position the patient, sterile instruments and the surgical team?

2. Is the area that is protected by a UDF system influenced by a skirt, different types of operating lamps and the position of the lamp?

3. Is it possible to switch off the ventilation system of operating rooms during prolonged inactivity e.g. during the night and weekend without negative effects on the air quality during normal operational hours?

4. Can a horizontal UDF (UDHF) system in terms of prevention of contamination of the air safely be used during the laying-up process on the instrument table?

5. Does the use of a mobile ultraclean laminar airflow screen reduce the air-borne particle counts in a non-ventilated room to a level safe for the patient?

\section{Research outline and methods}

To answer the question of the size of the protective area, the principle of a real time mock-ups will be used in chapter $2 .{ }^{124}$ During this mock up situation it will be analysed if clean area of $3 \times 3$ meter is adequate and the expected range of users can optimally work in this area during the most decisive surgical procedures, or whether visibility is acceptable and maintainers have good access to the equipment. What subsequently can be done when a distribution system has a too small protected area is described in chapter 8. 
Chapters 3, 4, 5 and 6 deals with research questions 2, 3, 4 and 5. To answer these research questions, a method based on the entrainment principle is used. This method is also used in several classification methods. ${ }^{36-39,125}$ As part of this method, particles are emitted outside the zone protected by the UDF system (the periphery) and the number of particles inside the protected zone are measured.

The location and the quality of the protected area are subsequently determined by calculating the degree of protection (DP) at multiple locations.

Chapter 7 discusses the comparison of the effect on SSI based on the typology of an air distribution system instead of a comparison based on the measured performance levels of these systems with the number of SSI. 


\section{References}

1. Sandberg M. What is ventilation? Energy in Buidings and. 1981;16(2):123-135.

2. Kowalski WJ. Aerobiological engineering handbook - a guide to airborne disease control technologies. 1 edition ed. McGraw-Hill Professional; 2005.

3. Schubert $M$, Musolff $A$, Weiss $H$. Influences of meteorological parameters on indoor radon concentrations ( $222 \mathrm{Rn}$ ) excluding the effects of forced ventilation and radon exhalation from soil and building materials. J Environ Radioact. 2018;192:81-85.

4. Baurès $E$, Blanchard $O$, Mercier $F$, et al. Indoor air quality in two french hospitals: Measurement of chemical and microbiological contaminants. Sci Total Environ. 2018;642:168-179.

5. Lu Y, Liu J, Lu B, Jiang A, Wan C. Study on the removal of indoor VOCs using biotechnology. J Hazard Mater. 2010;182(1-3):204-209.

6. EN 16798-3:2017. Energy performance of buildings - ventilation for buildings - part 3: For non-residential buildings - performance requirements for ventilation and roomconditioning systems (modules M5-1, M5-4). CEN (European Committee for Standardization). 2017.

7. van der Bij M, Kolder Z. Blootstelling aan sevofluraan in operatiekamers, behandelkamers en verkoeverkamers gemeten in zeven universitair medische centra. Tijdschrift voor toegepaste Arbowetenschap. 2010:78-85.

8. ISO 7730: 2. Ergonomics of the thermal environment -- analytical determination and interpretation of thermal comfort using calculation of the PMV and PPD indices and local thermal comfort criteria. CEN (European Committee for Standardization). 2005.

9. Van Gaever R, Jacobs VA, Diltoer M, Peeters L, Vanlanduit S. Thermal comfort of the surgical staff in the operating room. Build Environ. 2014;81:37-41.

10. Simpson JB, Thomas VS, Ismaily SK, Muradov PI, Noble PC, Incavo SJ. Hypothermia in total joint arthroplasty: A wake-up call. J Arthroplasty. 2018;33(4):1012-1018.

11. Katz JD. Control of the environment in the operating room. Anesth Analg. 2017;125(4):1214-1218.

12. Seamon MJ, Wobb J, Gaughan JP, Kulp H, Kamel I, Dempsey DT. The effects of intraoperative hypothermia on surgical site infection: An analysis of 524 trauma laparotomies. Ann Surg. 2012;255(4):789-795. 
13. Kurz A, Sessler DI, Lenhardt R. Perioperative normothermia to reduce the incidence of surgical-wound infection and shorten hospitalization. $N$ Engl J Med.

1996;334(19):1209-1216.

14. Lee $\mathrm{S}$, Liang $\mathrm{C}$. Effect of ventilation rate on air cleanliness and energy consumption in operation rooms at rest. Environmental Monitoring and Assessment. 2018;190(3):178.

15. Alsved M, Civilis A, Ekolind $\mathrm{P}$, et al. Temperature-controlled airflow ventilation in operating rooms compared with laminar airflow and turbulent mixed airflow. J Hosp Infect. 2018;98(2):181-190.

16. Gong N, Zhou J, Liu S, Esparza S, Raju U. Air flow rate control strategies and energy saving for operating rooms. Indoor Air 2014 - 13th International Conference on Indoor Air Quality and Climate. 2014:353-359.

17. Parliament E. Directive 2012/27/EU of the european parliament and of the council of 25 october 2012 on energy efficiency. Official Journal of the European Union Directive. 2012:1-56.

18. EU. Directive 2012/27/EU of the european parliament and of the council of 25 october 2012 on energy efficiency, amending directives 2009/125/EC and 2010/30/EU and repealing directives 2004/8/EC and 2006/32/EC. Official Journal of the European Union. 2012;55:1-97.

19. EU. Directive 2010/31/EU of the european parliament and of the council of 19 may 2010 on the energy performance of buildings (recast). Official Journal of the European Union. 2010:13-35.

20. ISSO P. Model voor de beschrijving van de werking van een klimaatinstallatie. Stichting ISSO. 2002.

21. Batchelor GK, Young AD. An introduction to fluid mechanics. Journal of Applied Mechanics. 1968;35(3):624-624.

22. Batchelor GK. Introduction to fluid mechanics. Cambridge University Press; 1998.

23. EN-ISO 16890-1:2016. Air filters for general ventilation - part 1: Technical specifications, requirements and classification system based upon particulate matter efficiency (ePM). CEN (European Committee for Standardization). 2016. 
24. EN 779. Particulate air filters for general ventilation - determination of the filtration performance. CEN (European Committee for Standardization). 2012.

25. EN 1822-1:2009. High efficiency air filters (EPA, HEPA and ULPA) - part 1: Classification, performance testing, marking. CEN (European Committee for Standardization). 2009.

26. Liddament MW. A guide to energy efficient ventilation. Air Infilteration and Ventilation Center, (AIVC). 1996:252-252.

27. Sandberg M. Ventilation efficiency as a guide to design. Ashrae Transactions. 1983;89(part 2A and B).

28. Skaaret E. Contaminant removal performance in terms of ventilation effectiveness. Environ Int. 1986;12(1-4):419-427.

29. Sutcliffe H. A guide to air change efficiency. 1990;Technical Note AIVC 28.

30. Brouns C, Waters B, in Buildings, I.E.A.Energy Conservation, Programme CS, Infiltration A, Centre V. A guide to contaminant removal effectiveness. Coventry, Eng.] : Air Infiltration and Ventilation Centre; 1991.

31. EN-ISO 14644-3:2006. Cleanrooms and associated controlled environments - part 3: Test methods. CEN-CENELEC. 2006.

32. Hill K. Food coloring, fluid dynamics, and an awesome lab demo | science-based life. https://sciencebasedlife.wordpress.com/2012/10/17/food-coloring-fluid-dynamicsand-an-awesome-lab-demo/. Updated 20122018.

33. Huang RF, Wu YD, Chen HD, et al. Development and evaluation of an air-curtain fume cabinet with considerations of its aerodynamics. Ann Occup Hyg. 2007;51(2):189206.

34. Moureh J, Yataghene M. Large-eddy simulation of an air curtain confining a cavity and subjected to an external lateral flow. Computers and Fluids. 2017;152:134-156.

35. Whyte W, Bailey PV. Effectiveness of a partial-wall laminar-flow system with special regard to air supply temperature. J Soc Environ Eng. 1978;17(4):29-32.

36. Departement of Health. HTM 03-01 part A: Heating and ventilation systems health technical memorandum specialised ventilation for healthcare premises. The Stationery Office (TSO); 2007. 
37. DIN 1946-4:2008. Ventilation and air conditioning - part 4: VAC systems in buildings and rooms used in the health care sector. DIN. 2008.

38. Önorm H 6020. Lüftungstechnische anlagen für medizinisch genutzte räume projektierung, errichtung, betrieb, instandhaltung, technische und hygienische kontrollen. Österreichisches Normungsinstitut. 2015.

39. SWKI VA105. Raumluftechnische anlagen in medizinisch genutzten räumen (planung, realisierung, qualifizierung, betrieb). Schweizerischer Verein von GebäudetechnikIngenieuren. 2015.

40. Charnley J. Postoperative infection after total hip replacement with special reference to air contamination in the operating room. Clin Orthop Relat Res. 1972;87:167-187.

41. Charnley J. A clean-air operating enclosure. Br J Surg. 1964;51(3):202-205.

42. Charnley J, Eftekhar N. Postoperative infection in total prosthetic replacement arthroplasty of the hip-joint with special reference to the bacterial content of the air of the operating room. Br J Surg. 1969;56(9):641-649.

43. Charnley J. Operating-room conditions. The Lancet Infectious Diseases. 1965; October 30:907-908.

44. Friberg BE, Burman LG, Friberg S. Zoned exponential, vertical and horizontal ultraclean laminar airflows. no differences in bacteriological efficiency. Acta Orthop Scand. 1998;69(2):169-172.

45. Friberg B. Ultraclean laminar airflow ORs. AORN J. 1998;67(4):841-2, 845-51.

46. Howorth F. Prevention of airborne infections during surgery. 1993.

47. Lewis JR. Operating room air distribution effectiveness. ASHRAE Transactions. 1993;99(pt 2):1191-1200.

48. Thomas G, Meierhans AT. Das keimstopsystem von meierhans-weber als raumlufttechnische alternative zum laminar-air-flow und seine lufthygienische wirksamkeit. Arch Orthop Traumat Surg. 1981:173-181.

49. Weber BG. Total hip replacement: Problem of infection, i.e. prevention. Arthroplasty of the hip.5th International Symposium 1972 in Nijmegen, Netherlands. 1973:206209. 
50. Anderson J, Neary F, Pickstone JV. Surgeons, manufacturers and patients. Palgrave Macmillan; 2007:212-212. ISBN: 978-1-349-36291-2.

51. Whyte W. Sterility assurance and models for assessing airborne bacterial contamination. Journal of parenteral science and technology : a publication of the Parenteral Drug Association. 1986;40(5):188-197.

52. Noble WC, Lidwell OM, Kingston $D$. The size distribution of airborne particles carrying micro-organisms. J Hyg. 1963;61(4):385-391.

53. Hayakawa I, Fujii S, Kim KY. Design theory for a laminar flow-type clean room and image processing on remotely detected particulates. Aerosol Science and Technology. 1987;7(1):47-56.

54. May KR, Clifford R. The impaction of aerosol particles on cylinders, spheres, ribbons and discs. Ann Occup Hyg. 1967;10(2):83-95.

55. Whyte W. Settling and impaction of particles into containers in manufacturing pharmacies. Journal of Parenteral Science and Technology. 1981;35(5):255-261.

56. Tavitian JD, Ong SM, Taub NA, Taylor GJS. Body-exhaust suit versus occlusive clothing. The Journal of Bone and Joint Surgery. 1991;5:5-7.

57. Davies RR, Noble WC. Dispersal of bacteria on desquamated skin. The Lancet. ;280(7269):1295-1297.

58. Kim KY, Kim YS, Kim D. Distribution characteristics of airborne bacteria and fungi in the general hospitals of korea. Ind Health. 2010;48(2):236-243.

59. Darouiche RO, Green DM, Harrington MA, et al. Association of airborne microorganisms in the operating room with implant infections: A randomized controlled trial. Infection Control and Hospital Epidemiology. 2017;38(1):3-10.

60. Birgand G, Toupet G, Rukly S, et al. Air contamination for predicting wound contamination in clean surgery: A large multicenter study. Am J Infect Control. 2015;43(5):516-521.

61. Cristina ML, Spagnolo AM, Sartini M, et al. Can particulate air sampling predict microbial load in operating theatres for arthroplasty? PLOS ONE. 2012;7(12):1-6.

62. Landrin A, Bissery A, Kac G. Monitoring air sampling in operating theatres: Can particle counting replace microbiological sampling? J Hosp Infect. 2005;61(1):27-29. 
63. Scaltriti S, Cencetti S, Rovesti S, Marchesi I, Bargellini A, Borella P. Risk factors for particulate and microbial contamination of air in operating theatres. $J$ Hosp Infect. 2007;66(4):320-326.

64. Stocks GW, Self SD, Thompson B, Adame XA, O'Connor DP. Predicting bacterial populations based on airborne particulates: A study performed in nonlaminar flow operating rooms during joint arthroplasty surgery. Am J Infect Control. 2010;38(3):199-204.

65. Jalovaara P, Puranen J. Air bacterial and particle counts in total hip replacement operations using non-woven and cotton gowns and drapes. J Hosp Infect. 1989;14(4):333-338.

66. Whyte W, Hejab M. Particle and microbial airborne dispersion from people. European Journal of Parenteral \& Pharmaceutical Sciences. 2007;12:39-46.

67. Whyte W, Green G, Whyte WM. Removal of microbe-carrying particles by high efficiency air filters in cleanrooms. International Journal of Ventilation. 2012;10(4):339-352.

68. Kim KY, Kim CN. Airborne microbiological characteristics in public buildings of Korea. Build Environ. 2007;42(5):2188-2196.

69. Seal DV, Clark RP. Electronic particle counting for evaluating the quality of air in operating theatres: A potential basis for standards? J Appl Bacteriol. 1990;68(3):225230.

70. Memarzadeh F, Manning AP. Comparison of operating room ventilation systems in the protection of the surgical site. ASRAE Trabsitions. 2002;108(2):3-15.

71. Memarzadeh F, Manning A. Reducing risks of surgery. ASHRAE J. 2003;45(2):28-33.

72. Nordenadler J. Något om skyddsventilation i operationsrum. KTH; 2011.

73. Chosky SA, Modha D, Taylor GJ. Optimisation of ultraclean air. the role of instrument preparation. The Journal of bone and joint surgery.British volume. 1996;78(5):835837.

74. Ritter MA, Eitzen HE, French MLV, Hart JB. The effect that time, touch and environment have upon bacterial contamination of instruments during surgery. Ann Surg. 1976;184(5):642-644. 
75. Lidwell OM, Lowbury EJL, Whyte W, Blowers R, Stanley SJ, Lowe D. Airborne contamination of wounds in joint replacement operations: The relationship to sepsis rates. J Hosp Infect. 1983;4(2):111-131.

76. Gruenberg MF Campaner GL Sola CA,Ortolan EG. Ultraclean air for prevention of postoperative infection. Spine. 1987;29(20):2330-2334.

77. Lidwell OM, Elson RA, Lowbury EJL, et al. Ultraclean air and antibiotics for prevention of postoperative infection: A multicenter study of 8,052 joint replacement operations. Acta Orthopaedica. 1987;58(1):4-13.

78. Birgand G, Saliou P, Lucet JC. Influence of staff behavior on infectious risk in operating rooms: What is the evidence? Infection Control and Hospital Epidemiology. 2015;36(1):93-106.

79. Agodi A, Auxilia F, Barchitta M, et al. Operating theatre ventilation systems and microbial air contamination in total joint replacement surgery: Results of the GISIOISCHIA study. J Hosp Infect. 2015;90(3):213-219.

80. Friberg B, Friberg S, Burman LG. Inconsistent correlation between aerobic bacterial surface and air counts in operating rooms with ultra clean laminar air flows: Proposal of a new bacteriological standard for surface contamination. $J$ Hosp Infect. 1999;42(4):287-293.

81. Lidwell OM, Lowbury EJ, Whyte W, Blowers R, Stanley SJ, Lowe D. Effect of ultraclean air in operating rooms on deep sepsis in the joint after total hip or knee replacement: A randomised study. Br Med J (Clin Res Ed). 1982;285(6334):10-4.

82. Knobben BAS, van Horn JR, van dM, Busscher HJ. Evaluation of measures to decrease intra-operative bacterial contamination in orthopaedic implant surgery. J Hosp Infect. 2006;62(2):174-180.

83. Lidwell OM. Clean air at operation and subsequent sepsis in the joint. Clin Orthop. 1986;211(211):91-102.

84. Persson U, Persson M, Malchau $\mathrm{H}$. The economics of preventing revisions in total hip replacement. Acta Orthop Scand. 1999;70(2):163-169.

85. Parvizi J, Saleh KJ, Ragland PS, Pour AE, Mont MA. Efficacy of antibiotic-impregnated cement in total hip replacement: A meta-analysis. Acta Orthopaedica.

2008;79(3):335-341. 
86. Whyte $W$. The effect of mechanical ventilation and clothing on airborne microbes and wound sepsis in hospital operating rooms, part 1. Clean Air and Containment Review. 2015;22:4-11.

87. Nelson JP, Glassburn ARJ, Talbott RD, McElhinney JP. The effect of previous surgery, operating room environment, and preventive antibiotics on postoperative infection following total hip arthroplasty. Clin Orthop. 1980(147):167-169.

88. Lidwell OM, Lowbury EJL, Whyte W, Blowers R, Stanley SJ, Lowe D. Infection and sepsis after operations for total hip or knee-joint replacement: Influence of ultraclean air, prophylactic antibiotics and other factors. J Hyg. 1984;93(3):505-529.

89. Bischoff P, Kubilay NZ, Allegranzi B, Egger M, Gastmeier P. Effect of laminar airflow ventilation on surgical site infections: A systematic review and meta-analysis. The Lancet Infectious Diseases. 2017;17(5):553-561.

90. WIP guideline. Luchtbehandeling in operatiekamer en opdekruimte in operatieafdeling klasse 1. Werkgroep InfectiePreventie. 2014:1-69.

91. Allegranzi B, Zayed B, Bischoff $\mathrm{P}$, et al. New $\mathrm{WHO}$ recommendations on intraoperative and postoperative measures for surgical site infection prevention: An evidence-based global perspective. The Lancet Infectious Diseases. 2016;16(12):e288-e303.

92. Jutte PC, Traversari RAAL, Walenkamp GHIM. Laminar flow: The better choice in orthopaedic implants. The Lancet Infectious Diseases. 2017;17(7):695-696.

93. Sudhindra TV, Joseph A, Haray PN, Hacking BC. Are surgeons aware of the dangers of diathermy? Ann R Coll Surg Engl. 2000;82(6):189-190.

94. Karoo ROS, Whitaker IS, Offer G, Sharpe DT. Surgical smoke without fire: The risks to the plastic surgeon 5]. Plast Reconstr Surg. 2004;114(6):1658-1660.

95. Ragde SF, Jørgensen RB, Føreland S. Characterisation of exposure to ultrafine particles from surgical smoke by use of a fast mobility particle sizer. Ann Occup Hyg. 2016;60(7):860-874.

96. Ulmer BC. The hazards of surgical smoke. AORN J. 2008;87(4):721-734.

97. Barrett WL, Garber SM. Surgical smoke - A review of the literature. is this just a lot of hot air? Surgical Endoscopy and Other Interventional Techniques. 2003;17(6):979987. 
98. Alp E, Bijl D, Bleichrodt RP, Hansson B, Voss A. Surgical smoke and infection control. J Hosp Infect. 2006;62(1):1-5.

99. Champault G, Taffinder N, Ziol M, Riskalla H, Catheline JMC. Cells are present in the smoke created during laparoscopic surgery. Br J Surg. 1997;84(7):993-995.

100. Sawchuk WS, Weber PJ, Lowy DR, Dzubow LM. Infectious papillomavirus in the vapor of warts treated with carbon dioxide laser or electrocoagulation: Detection and protection. J Am Acad Dermatol. 1989;21(1):41-49.

101. Garden JM, O'banion MK, Shelnitz LS, et al. Papillomavirus in the vapor of carbon dioxide laser-treated verrucae. JAMA: The Journal of the American Medical Association. 1988;259(8):1199-1202.

102. Fletcher JN, Mew D, Descôteaux JG. Dissemination of melanoma cells within electrocautery plume. Am J Surg. 1999;178(1):57-59.

103. Tseng HS, Liu SP, Uang SN, et al. Cancer risk of incremental exposure to polycyclic aromatic hydrocarbons in electrocautery smoke for mastectomy personnel. World Journal of Surgical Oncology. 2014;12(1):1-8.

104. ECRI. Should surgical smoke be evacuated? ECRI Technology Management Guide. 1997;26(4):136-139.

105. DHHS (NIOSH) Publication No.96-128. Control of smoke from laser/eletric surgical procedures. National Institute for Occupational Safety and Health (NIOSH). 1996.

106. Romano F, Gustén J, De Antonellis S, Joppolo CM. Electrosurgical smoke: Ultrafine particle measurements and work environment quality in different operating theatres. International Journal of Environmental Research and Public Health. $2017 ; 14(2)$.

107. Bryant C, Gorman R, Stewart J, Whong W. Health-hazard-evaluation report HETA 85126-193 bryn mawr hospital, pennsylvania. National Institute of Occupational Safety and Health (NIOSH). 1988.

108. Moss C,E., Bryant C, Stewart J, Whong W,Z., Fleeger A. Health-hazard-evaluation report HETA 88-101-2008, university of utah health sciences center, salt lake city, utah. 2018.

109. ANSI Z136.1. Safe use of lasers in health. American National Standard Institute. 2014. 
110. Neisi A, Albooghobeish M, Geravandi S, et al. Investigation of health risk assessment sevoflurane on indoor air quality in the operation room in ahvaz city, iran. Toxin Reviews. 2018:1-9.

111. Yilmaz S, Calbayram NC. Exposure to anesthetic gases among operating room personnel and risk of genotoxicity: A systematic review of the human biomonitoring studies. J Clin Anesth. 2016;35:326-331.

112. Neisi A, Albooghobeish M, Geravandi S, Mohammadi MJ, Torabpour M, Hashemzadeh B. Association of anesthetic toxic isoflurane gases of the indoor air of operating room, ahvaz, iran during 2016. Toxin Reviews. 2017;36(2):141-146.

113. Sárkány $P$, Tankó B, Simon É, Gál J, Fülesdi B, Molnár C. Does standing or sitting position of the anesthesiologist in the operating theatre influence sevoflurane exposure during craniotomies? BMC Anesthesiology. 2016;16(1):1-5.

114. Gastmeier P, Breier AC, Brandt C. Influence of laminar airflow on prosthetic joint infections: A systematic review. J Hosp Infect. 2012;81(2):73-78.

115. Wang C, Holmberg S, Sadrizadeh S. Numerical study of temperature-controlled airflow in comparison with turbulent mixing and laminar airflow for operating room ventilation. Build Environ. 2018;144:45-56.

116. Zoon WAC, van dH, Loomans MGLC, Hensen JLM. On the applicability of the laminar flow index when selecting surgical lighting. Build Environ. 2010;45(9):1976-1983.

117. Zoon W, Loomans M, Hensen J. On the numerical accuracy of particle dispersion simulation in operating theatres. 12th International Conference on Indoor Air Quality and Climate 2011. 2011;1:258-262.

118. Kamsah N, Kamar HM, Alhamid MI, Yinn WK. Impacts of temperature on airborne particles in a hospital operating room. Journal of Advanced Research in Fluid Mechanics and Thermal Sciences. 2018;44(1):12-23.

119. Yau YH, Ding LC. A case study on the air distribution in an operating room at sarawak general hospital heart centre (SGHHC) in malaysia. Indoor and Built Environment. 2014;23(8):1129-1141.

120. Yau YH, Ding LC. A comprehensive computational fluid dynamics simulation on the air distribution in an operating room at university of malaya medical centre malaysia. Indoor and Built Environment. 2015;24(3):355-369. 
121. Sadrizadeh S, Tammelin A, Nielsen PV, Holmberg S. Does a mobile laminar airflow screen reduce bacterial contamination in the operating room? A numerical study using computational fluid dynamics technique. Patient Safety in Surgery. 2014;8(1).

122. Stevenson TC. Experimental investigation of hospital operating room air distribution (MSc thesis). Georgia Institute of Technology. 2008:97-97.

123. Chow TT, Lin Z, Bai W. The integrated effect of medical lamp position and diffuser discharge velocity on ultra-clean ventilation performance in an operating theatre. Indoor and Built Environment. 2006;15(4):315-331.

124. Gawron VJ, Dennison TW, Biferno MA. Mock-ups, models, simulations and embedded testing. In: Handbook of human factors testing and evaluation (2nd ed.). 2002.

125. VCCN Richtlijn 7. Methode voor testen en classificeren van operatiekamers en opdekruimten in rust. Vereniging Contamination Control Nederland. 2014. 


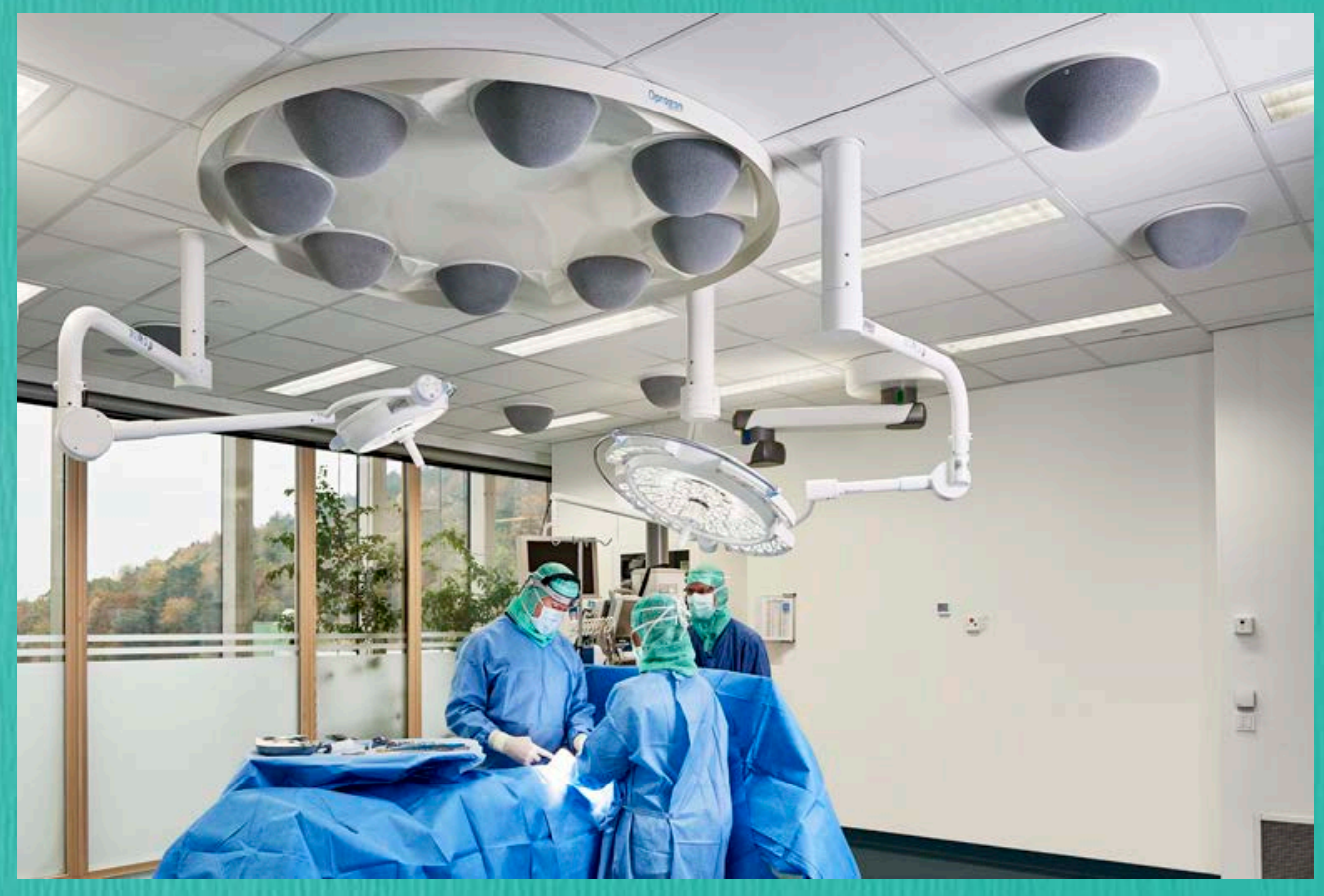




\section{Chapter 2}

\section{Process Simulation During the}

Design Process Makes the

Difference: Process Simulations

Applied to a Traditional Design

Traversari R, Goedhart R, Schraagen JM. Process simulation during the design process makes the difference: Process simulations applied to a traditional design. Health Environments Research and Design Journal. 2013;6(2):58-76. 


\begin{abstract}
Objective: The objective is evaluation of a traditionally designed operating room using simulation of various surgical workflows.
\end{abstract}

Background: A literature search showed that there is no evidence for an optimal operating room layout regarding the position and size of an ultraclean ventilation (UCV) canopy with a separate preparation room for laying out instruments and in which patients are induced in the operating room itself. Neither was literature found reporting on process simulation being used for this application. Many technical guidelines and designs have mainly evolved over time, and there is no evidence on whether the proposed measures are also effective for the optimization of the layout for workflows. Methods: The study was conducted by applying observational techniques to simulated typical surgical procedures. Process simulations which included complete surgical teams and equipment required for the intervention were carried out for four typical interventions. Four observers used a form to record conflicts with the clean area boundaries and the height of the supply bridge. Preferences for particular layouts were discussed with the surgical team after each simulated procedure.

Results: We established that a clean area measuring $3 \times 3 \mathrm{~m}$ and a supply bridge height of $2.05 \mathrm{~m}$ was satisfactory for most situations, provided a movable operation table is used. The only cases in which conflicts with the supply bridge were observed were during the use of a surgical robot (Da Vinci) and a surgical microscope. During multiple trauma interventions, bottlenecks regarding the dimensions of the clean area will probably arise. Conclusions: The process simulation of four typical interventions has led to significantly different operating room layouts than were arrived at through the traditional design process.

Keywords:

Evidence-based design, human factors, work environment, operating room, traditional design, process simulation, surgical workflows 


\section{Acknowledgments:}

The authors thank the participating surgeons, nurses, and staff of the operating department of Erasmus MC and the observers who participated in this project. They also thank the many readers from Erasmus MC and TNO who commented on previous drafts of this article to make it better. In addition they thank Erasmus MC for facilitating the project and the Dutch Ministry of Health, Welfare and Sport for funding the research performed by TNO.

\section{Introduction}

The objective of this study is to evaluate a traditionally designed operating room using simulation of various surgical workflows. The following hypotheses were tested during the evaluation process:

- The $3 \times 3 \mathrm{~m}^{2}$ clean area surface is large enough to carry out all interventions within it.

- Positioning the clean area in the middle of the operating room results in an optimal layout for moving in the patient and equipment in the operating room.

- The classic position of the anesthesia section, near the entrance to the operating room, is optimal for the logistical processes.

- A supply bridge height of $2.05 \mathrm{~m}$ results in the clean area being sufficiently accessible for high medical equipment and reachable for the staff to make connections (electricity, vacuum, etc.).

\section{Background}

A traditional design process is defined as one in which the architect draws a layout based on the descriptions of operating room processes he or she receives (Van Boxel, et al., 2007). The main characteristics of a traditional design process are that it makes use of the experiences and insights of the parties involved, without subjecting the designed situation to functionality testing using simulation prior to the actual construction of the design (Van Boxel et al., 2007). 
Although there is a discernible trend toward an increased use of evidence-based design in healthcare facilities (Bittermann, 2009; Dunston, Arns, \& McGlothlin McGlothlin, 2007; Gawron, Dennison, \& Biferno, 2002; Reiling et al., 2004; Sadler et al., 2011; Sandberg et al., 2005), little evidence is available for the optimal layout of an operating room. We therefore carried out a literature review, starting with the comprehensive literature review by Ulrich et al. (2008).

This review surveyed and evaluated evidencebased healthcare design and extracted its implications for the design of better and safer hospitals. This review was taken as a starting point in order to evaluate whether there were relevant studies on operating room layout-the purpose of this particular study. The literature reviewed regarding operating rooms concerned the following topics: (a) high-efficiency particulate air (HEPA) filters (Sehulster et al., 2004; Wickens, Lee, Liu, \& Gordon Becker, 2004); (b) ventilation systems and airflow control (Gawron et al., 2002; Yavuz et al., 2006); and (c) reducing staff stress by controlling noise (Moorthy, Munz, Undre, \& Darzi, 2004; Sanderson et al., 2005). It can be concluded that no reference to literature that dealt with optimization of operating room layouts as proposed in this study was found in this review (Ulrich et al., 2008).

Next, a literature search was carried out using the following databases: Cochrane Library, PubMed, Scopus, ScienceDirect, and Google Scholar. The search included only literature published between 2004 and 2011, so only studies based on the actual contemporary situation were included. The following search terms or a combination of these terms were used: operation room, operating theatre/theater/room, lay-out/layout, spatial organization, optimization, design/configuration, surgical suite, process simulation. Several studies (17) published after 2008 relating to operating rooms and design can be found that used different research methods. In 2011, Chen et al. studied the clinical practicability of a dual-room 1.5-T intraoperative magnetic resonance imaging (iMRI) suite, and concluded that it easily could be integrated into standard neurosurgical workflow. 
Strauss et al. (2010) compared the ear, nose, and throat (ENT) operating room (OR) with the previous standard, including a surgical workflow analysis, and concluded that a contemporary operation unit can significantly improve safety and efficiency as well as the ergonomics for ENT surgery and related procedures. The concept of operating room zoning has also undergone a dramatic change. Some research suggests that a layout focusing on work efficiency is more desirable than one that follows an excessively rigid zoning pattern (Suzuki, 2010). In order to study the impact of facility change (e.g., from decentralized to centralized ORs) on OR processes, a group of researchers (Baumgart, Denz, Bender, \& Schleppers, 2009) used a mixed method approach (process analysis, process modeling and social network analysis of staff interaction) to analyze contextual factors (e.g., department layout) as well as behavioral patterns (e.g., staff interactions). According to this study, such a mixed method approach, as compared to a single assessment method, enabled a deeper understanding of the OR work context and its influence on outpatient OR processes, concluding that, for example, there is a potential for more errors during handovers in the new centralized design due to a greater interdependency between tasks and staff. This is a "before-after" type of study, where an old situation and a new situation are analyzed and conclusions are made according to the analysis. This study is a good example of the fact that simply analyzing what went wrong after a building is already in use has disadvantages. Various methods can be used to analyze the potential risks of design solutions before they are realized and implemented in a building on a large scale. Process simulation, as described in this paper, could be one of them. Such studies are highly beneficial because the results of these studies can be used to prevent some "obvious" design shortcomings in advance (Sadler et al., 2011).

Another method that can be used for design analysis during the design process is the use of virtual reality mock-ups (Dunston et al., 2007; Peavey, Zoss, \& Watkins, 2012). Virtual models are a good possibility but one needs to carefully consider the costs of building a virtual or physical model based on specific research requirements. Mock-ups enable developers to visualize and evaluate the physical interface while the design is still in progress. 
In order to study whether the expected range of users can optimally use the proposed design solution, or whether visibility is acceptable and maintainers have good access to the equipment, real time mock-ups could be used (Gawron et al., 2002). A group of authors (Sandberg et al., 2005) constructed a three-room suite including an OR, an induction room, and an early recovery area. The authors sought to improve OR throughput and reduce time per case by goal-direct ed design of a demonstration OR (which was constructed) and the perioperative processes occurring within and around it. The authors compared the throughput, cost, and revenue performance of the new OR to traditional ORs. The main conclusions from the study were that intentional OR and perioperative process redesign improved throughput. Better OR throughput entailed additional costs but allowed additional patients to be accommodated in the OR, generating revenue that balanced the additional costs.

In conclusion, the literature review showed that there have been only a few studies employing process simulation in the design of new operating rooms. Our study adds to this limited evidence base by simulating future OR layouts, carrying out process simulations with medical teams in these simulated layouts, and evaluating in advance user response to the proposed designs.

\section{Case Study}

The case study was carried out in a large academic medical teaching hospital in The Netherlands. The schedule of requirements for the new ORs in this hospital described the processes for the future OR in terms of current practices and the perception of the influence of other logistical and technical starting points on this process. The main functional requirements in our case were:

1. The choice to create a separate instrument preparation room connected to the operating room.

2. The choice to make use of standard unidirectional down-flow plenums measuring 3.0 $\times 3.0 \mathrm{~m}^{2}$ as is commonly applied in new buildings in The Netherlands.

3. The choice to make use of a fixed supply bridge with side screens around the plenum. 


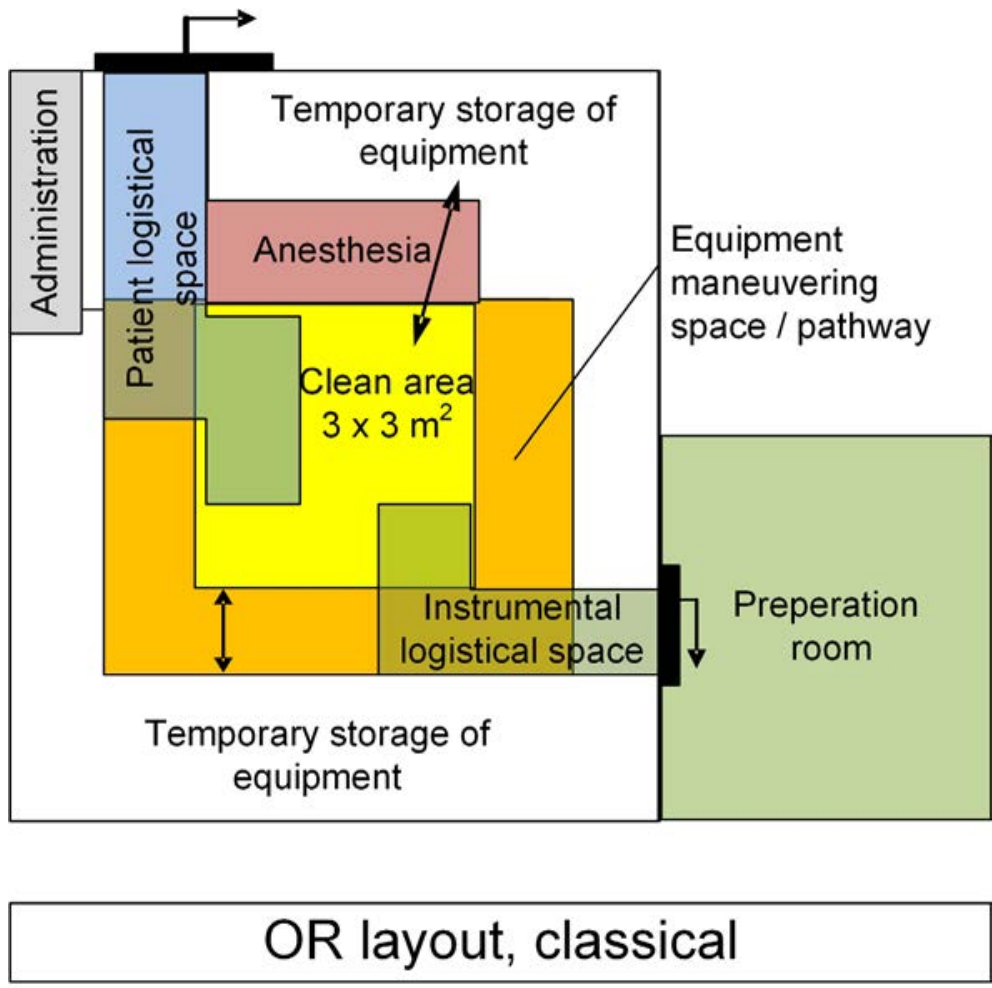

Figure 2.1. OR layout, result of the classic design process.

These starting points were translated to a spatial "classic" layout by the architect (Figure 2.1), resulting in:

1. A spatially centered design of the plenum and, with it, the clean area in the operating room.

2. Positioning of the anesthesia system on the corridor side of the clean area, as is common practice in The Netherlands.

3. An entrance to the preparation room in the wall at right angles to the front. This entrance is situated near the front.

Some doubts on the solutions chosen remained among the future users of the OR because the starting points for the OR layout partly relate to techniques and logistical processes that are new for the hospital. 
The choice of clean area surface, in particular, in combination with the choice for a supply bridge, led to doubts on the feasibility of successfully positioning the surgical teams and equipment within the designated clean zone in the operating room. In particular, the research question was whether the clean area under the unidirectional air flow terminal would be large enough to enable smooth, unhindered task performance, while at the same time not being too far away to reach it with the equipment connections. This research question led to the decision to construct a mock-up supply bridge and to make use of simulations to study whether the dimensions chosen in the design are satisfactory (Gawron et al., 2002; Wickens et al., 2004).

Due to lack of evidence regarding these aspects of the schedule of requirements and the concomitant uncertainty, the decision was made to conduct this study in the form of a process simulation that must answer this question (size of the clean area surface and height of the supply bridge). In order to be able to carry out the process simulations successfully, it was necessary to construct a mock-up of the supply bridge. In addition to the primary question whether the dimensions chosen in the design were satisfactory, the study also offered an opportunity to investigate whether the centered positioning of the clean area in the OR was actually the most practical layout when viewed from the logistical processes in the OR. At the time the simulation was conducted, the design had already entered the final design phase.

A survey of the expectations regarding the design among OR experts such as installation experts, a doctor-microbiologist, and functional designers, as well as the current users and the policy-makers in the hospitals surgery department, was carried out ahead of time. The survey not only looked at the hygiene aspects of the design, but also covered the logistical aspects. The choice for separate preparation rooms connected to the OR resulted in materials and patients entering the clean area through separate routes. This would mean a new logistical process for the hospital that they had not gained any experience with yet. Because of this, the end users adopted a positive, yet critical basic attitude. All of these aspects combined led to the following research questions: 
1. Are the dimensions (surface area and height) of the clean area large enough to carry out most interventions?

2. Is the central position of the clean area in the operating room the most optimal one, when viewed from a logistical processes perspective?

These research questions have been converted into the following hypotheses, which have formed the foundation for the research:

1. The $3 \times 3 \mathrm{~m}^{2}$ clean area surface is large enough to carry out all interventions.

2. Positioning the clean area in the middle of the operating room results in an optimal layout for moving in the patient and equipment in the operating room.

3. The classic position of the anesthesia section, near the entrance to the operating room, is optimal for the logistical processes.

4. A supply bridge height of $2.05 \mathrm{~m}$ results in the clean area being sufficiently accessible for high medical equipment and reachable for the staff to make connections (electricity, vacuum, etc.).

\section{Methods}

\section{Procedure}

The study was conducted through applying observation techniques (Gosbee \& Gosbee, 2012; Israelski, 2011; Rogers, Patterson, \& Render, 2012; Sandberg, 2005). Woods (2003) distinguished three classes of research methods, varying in shaping the conditions for observation: (1) natural history methods, (2) staged world observations using simulated problems, and (3) Spartan lab experiments using experimenter-created artificial tasks. We used staged world observations, in which we "staged" situations of interest through simulations, in this case representative (or typical) surgical procedures. The relative advantage over natural history methods is that there is more control over the conditions shaping the observations: by controlling the environment and manipulating the scenarios, we will be able to answer our research questions with higher validity than when relying on ethnographic observations of work that occurs in situ. 
Compared to Spartan lab experiments, the environment is still sufficiently rich to capture representative expert behavior, thus allowing for higher external validity. In particular, our data collection process involved four observers who sequentially captured in detail both (a) observable activities and verbalizations, and (b) self-report data about how the new physical layout supported performance (Rogers, Patterson, \& Render, 2012). For each of the four typical procedures a specialized surgical team that was accustomed to working together on that specific procedure in practice was used. These four surgical teams carrying out the typical procedures were overtly observed in detail. Ethics approval was unnecessary and therefore not obtained, as no real nor simulated patients were involved.

Because the placement of instruments, equipment and persons will be different than in current practice, we decided to simulate these typical operations in an environment that had the spatial characteristics of the new design (size and height of the ultraclean ventilation (UCV) canopy and support bridge). The typical operations were selected with regard to the positioning of the patient and the number of required instruments (instrument tables), the use of special (large or high) medical equipment and the size of the surgical team given the setting of a university medical center (research, education, etc.). The simulations were directed by a human factors expert with experience in the analysis of workflows using simulation. The expert's main role was to have those present actually carry out the actions rather than limiting themselves describing how they thought they would carry out their actions. This is because our perception of our actions may be quite different from the actual action, especially in the case of routine activities to which we have no conscious access (Anderson, 1987; Nisbett \& Wilson, 1977; Wilson, 2002). 


\begin{tabular}{lcccc}
\hline Surgical team & $\begin{array}{l}\text { Trauma } \\
\text { (hip) }\end{array}$ & $\begin{array}{l}\text { Da Vinci } \\
\text { (surgical } \\
\text { robot) }\end{array}$ & $\begin{array}{l}\text { Intervention } \\
\text { Trepanation } \\
\text { (using } \\
\text { microscope) }\end{array}$ & $\begin{array}{l}\text { Orthopedic } \\
\text { (knee/hip/ } \\
\text { laparoscopy) }\end{array}$ \\
\hline Surgeon & 1 & 1 & 1 & 1 \\
Assistant surgeon & 1 & - & 1 & - \\
Anesthetist & 1 & 1 & 1 & 1 \\
Scrub nurse & 1 & 1 & 1 & 1 \\
Staff in the periphery area & 1 & 1 & 1 & 2 \\
Total size of the medical staff & 6 & 5 & 5 & 6 \\
Observers & 4 & 4 & 4 & 4 \\
Process director & 1 & 1 & 1 & 1 \\
\hline
\end{tabular}

Table 2.1. Composition of Surgical Team for the Simulated Interventions.

In doing this, it is necessary to execute actions that belong together consecutively so that the interface between the actions can also be included. The human factors expert therefore also played an important role in determining the time allocated to simulation and the time allocated to discussion. The four observers (including the human factors expert) who watched the actions carried out by the surgical team during the process simulation received forms prior to the simulation on which they could record their observations. These forms were collected and evaluated after the simulation. After completion of the simulation, the observations were discussed with the surgical teams and either a conclusion was drawn based on consensus, or the positioning was adjusted to see if it would lead to a more workable situation. This is in line with the fundamentally observational and discovery oriented nature of staged world studies (Woods, 2003). The simulations of these operations were also recorded on video for more detailed study later (Mackenzie \& Xiao, 2012). 


\section{Composition of the Surgical Teams Participating in the Simulations}

The research was carried out with four separate complete surgical teams-surgeon(s), anesthetists, and instrument staff-that were accustomed to working together on that specific intervention in practice. This enabled in-depth discussions on the new workflow in the new environment (with a mock-up). It also made it possible to approach the process as realistically as possible in this way, thus enabling sufficient external validity. Table 2.1 presents the composition of each surgical team.

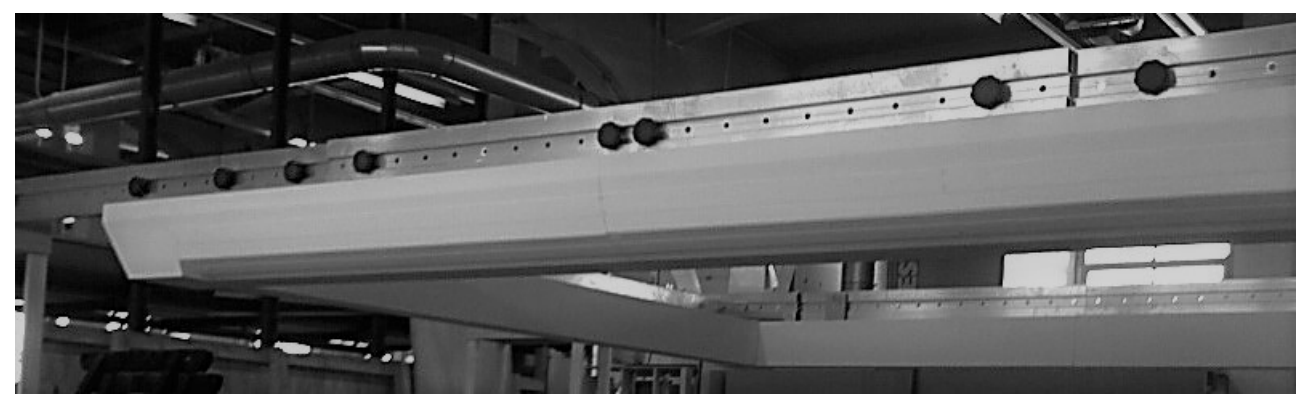

Figure 2.2. Mock-up being built.

\section{Observers}

The observers' task during the process simulation was to watch whether conflicts with the spatial parameters arose during the simulations. Every observer concentrated on one side of the clean area. Prior to the simulation, the observers received a form that showed the initial layout and the boundaries of the clean area. The observers could use these forms to record where conflicts occurred in the phase of the simulation (preparation, operation, completion), for example, where people and equipment that should stay sterile crossed the clean area boundaries, where high equipment touched the supply bridge, whether nonergonomic movements were needed to keep the actions inside the clean area, and other incidents that caught their attention. The forms also provided room for indicating good locations for connecting to compressed air, vacuum, and electricity on the supply bridge. 


\section{Variables}

The variables recorded concern the number and location of conflicts with regard to crossing the clean area boundaries or to touching the supply bridge. The logistical movements of patient and equipment that occurred were also recorded, including the requirements for maneuvering the equipment well. Each surgical team indicated the best locations for the connections of compressed air, vacuum, and electricity on the supply bridge.

\section{Environment}

Because the surface of the clean area and the height of the supply bridge were part of the aspects to be tested, we decided to construct a mock-up of the supply bridge (see Figure 2.2). The height of this supply bridge could be adjusted from 2.0 to $2.15 \mathrm{~m}$, in $5 \mathrm{~cm}$ increments. This mock-up could also be freely moved around in the operating room. It was also possible to use symbols to indicate the desired location for the various connections on the supply bridge. This applied to electrical connections, connections for medical gases, and connections for vacuum (extraction). Furthermore, we decided to carry out the tests in the operating department itself by taking one of the operating rooms out of commission for a week. In this way, we gained access to all the equipment that is typically available in the OR.

All the process steps, from positioning, induction and operation, through to departure from the operating room, were enacted during the simulation, and their spatial consequences were observed.

\section{Scenarios}

Typical interventions for testing the hypotheses were determined in consultation with the clinical teams. While taking into account the variables (size of the clean area and the necessary height), the following typical procedures were chosen:

1. Trauma (hip)

2. Da Vinci surgical robot 
3. Trepanation (brain surgery using microscope)

4. Orthopedic (knee/hip/laparoscopy)

For each of these typical interventions, we determined in advance which staff of the operating theatre, which equipment, and how many instrument tables were involved in the operation. Drawings of probable setups were produced based on this information (see Figures 2.3, 2.4, 2.5, and 2.6).

\section{Trauma (Hip)}

This intervention has typical requirements for the positioning of the patient and the number of required instruments (instrument tables), the use of the mobile imaging equipment (C-arm) and the size of the surgical team. Furthermore, the patient is considered to be part of the dirty zone of the operation room during this type of operation, which means specific positioning within the clean area is needed (Figure 2.3). 


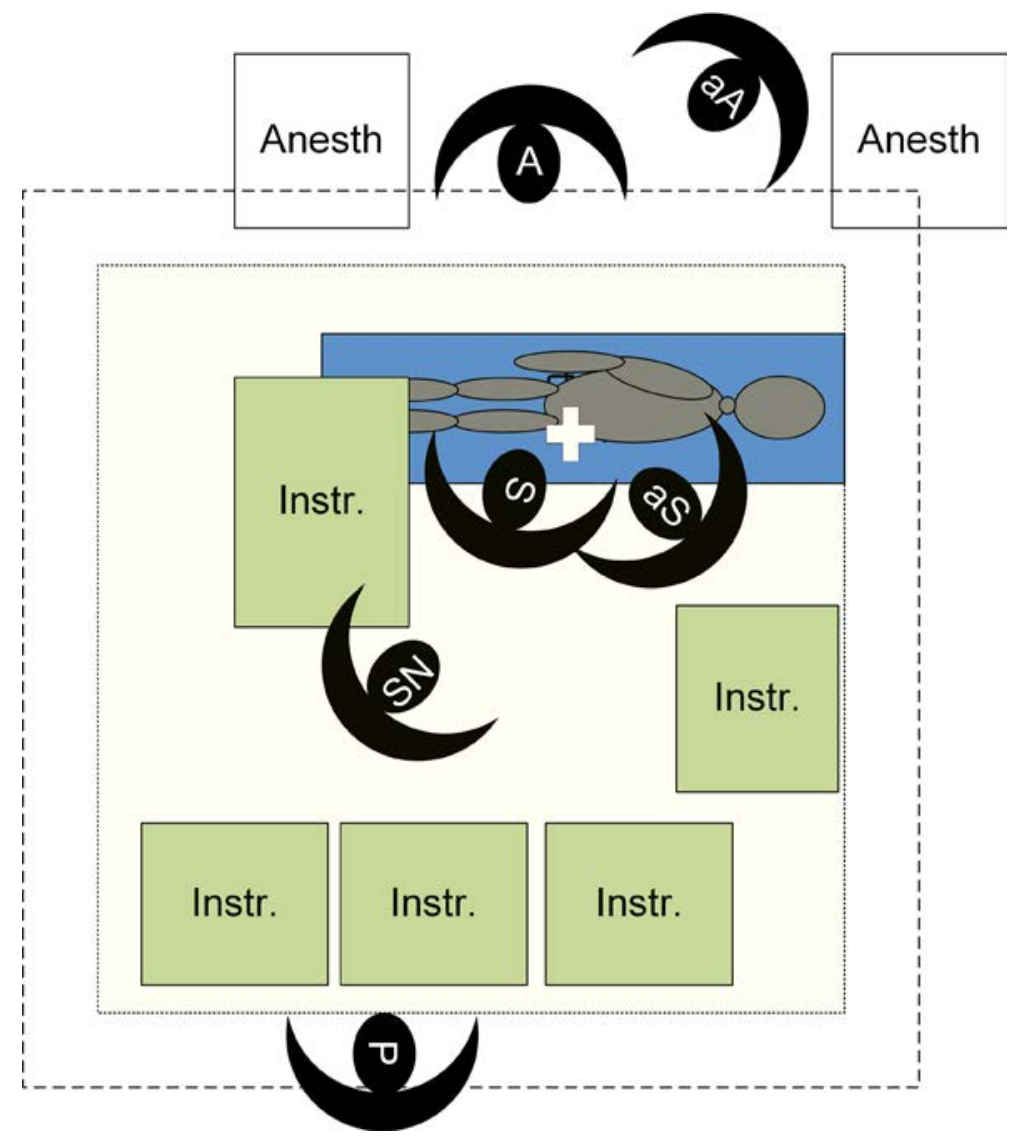

Figure 2.3. Initial position hip trauma.

Da Vinci Surgical Robot

This intervention has typical requirements for the space needed for medical equipment (robot and control console) and the height of the supply bridge while maneuvering the equipment (Figure 2.4). 


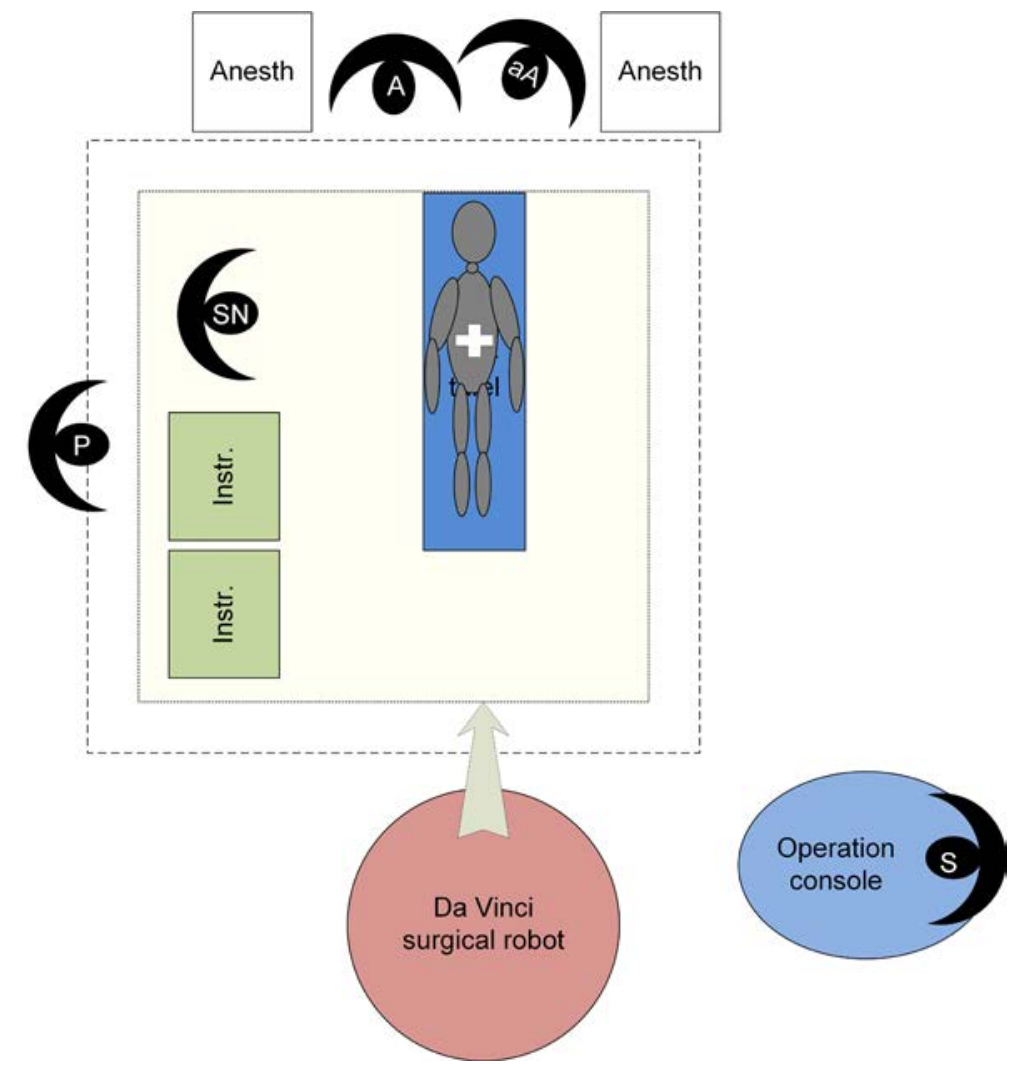

Figure 2.4. Initial position Da Vinci surgical robot.

\section{Trepanation}

This intervention has typical requirements for the space needed for medical equipment (microscope) and the height of the supply bridge (Figure 2.5). 


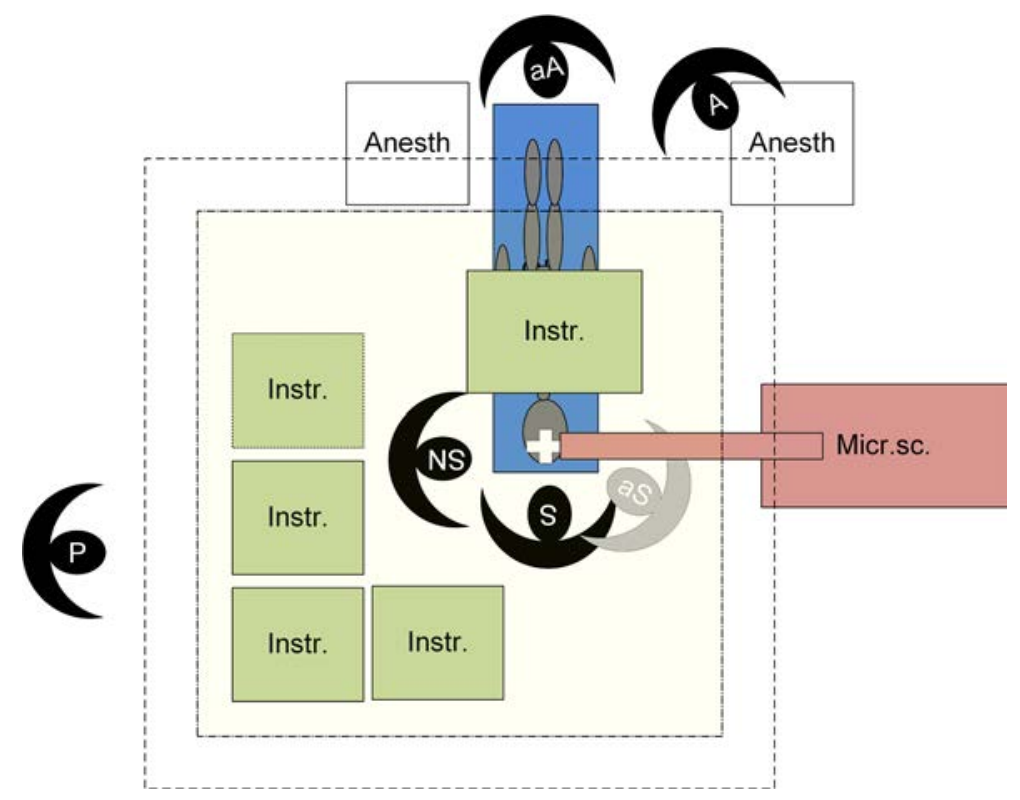

Figure 2.5. Initial position trepanation with surgical microscope.

\section{Orthopedic}

This intervention has typical requirements with regard to the positioning of the patient and the number of required instruments (instrument tables), the use of the $\mathrm{C}$-arm and the size of the surgical team. Furthermore, orthopedic operations are often characterized by a noncentral positioning of the wound area. In addition, the orthopedic surgeons at this hospital make use of helmets, which results in them being larger than other surgeons and more prone to hit the supply bridge with the helmet (Figure 2.6). 


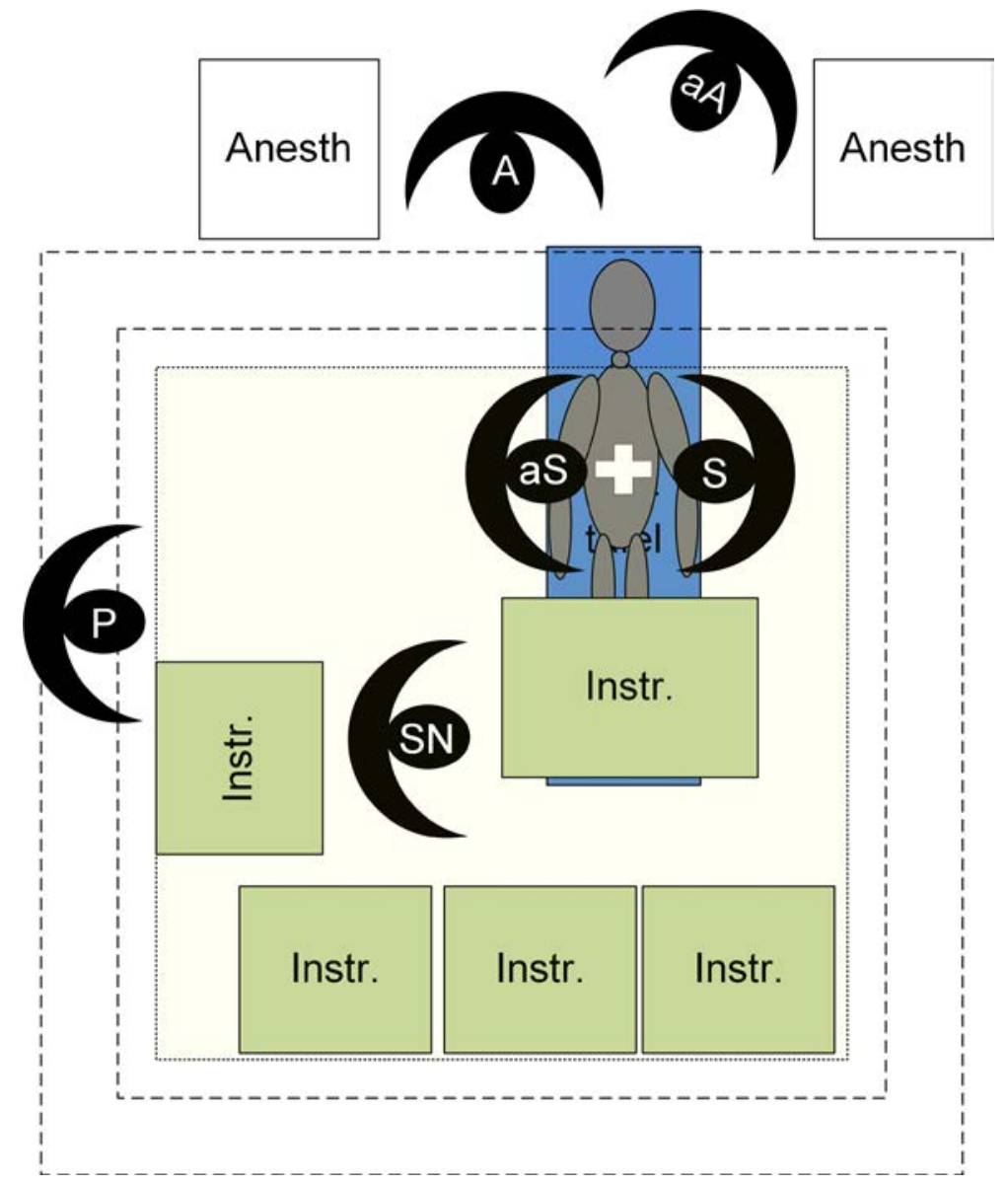

Figure 2.6. Initial position orthopedic intervention.

\section{Results}

Hypothesis 1: The Dimensions of the Clean Area of $3 \times 3 \mathrm{~m}^{2}$ Are Large Enough to Carry Out All Interventions

The lack of conflicts with the boundaries of the clean area and the height of the supply bridge during the simulations shows that a $3.0 \times 3.0 \mathrm{~m}^{2}$ large clean area under the unidirectional down-flow plenum is large enough to satisfactorily position the patient, the surgical team, and the sterile instruments required during the four interventions that were 
simulated. However, an important prerequisite for this to be true is that a movable operation table be used. The space that the instrument staff and instrument tables occupy on one side of the table, is more than half of the clean area (see also Figure 2.1, above). If a fixed operation table is used, the surface of the clean area will need to be larger. The dimensions required in this situation have not been researched as part of this study. The positioning of the instruments relative to the table is also so diverse for the various operations that a fixed noncentral position for the operation table does not offer a solution either.

\section{A $3.0 \times 3.0 \mathrm{~m}^{2}$ large clean area under the unidirectional downflow plenum is large enough to satisfactorily position the patient, the surgical team, and the sterile instruments required during the four interventions that were simulated.}

Discussing these dimensions with the team after the process simulation showed that bottlenecks may arise during operations of the "multiple trauma" type. Although this kind of operation was not simulated, it could be deduced from the various set-ups that if multiple surgical teams were operating on a patient simultaneously, it would become difficult to position the whole wound area, all the instruments, and all the staff in the clean area, straight under the unidirectional air flow terminal together. For this reason, 3 out of 19 operating rooms in the design at hand will be fitted with a larger unidirectional airflow terminal measuring $3.20 \times 3.20 \mathrm{~m}$.

By drawing the set-up it can be determined that these dimensions would offer just enough space for a double team. Even larger dimensions have not been considered for budgetary and technical reasons. Needless to say, these larger dimensions do not form an obstacle 
for the other operations, thus resulting in maximum flexibility (every OR can be used for every type of intervention, excluding the multiple trauma).

Our simulations showed that the hypothesis is true given the use of a movable operation table and excluding multitrauma settings.

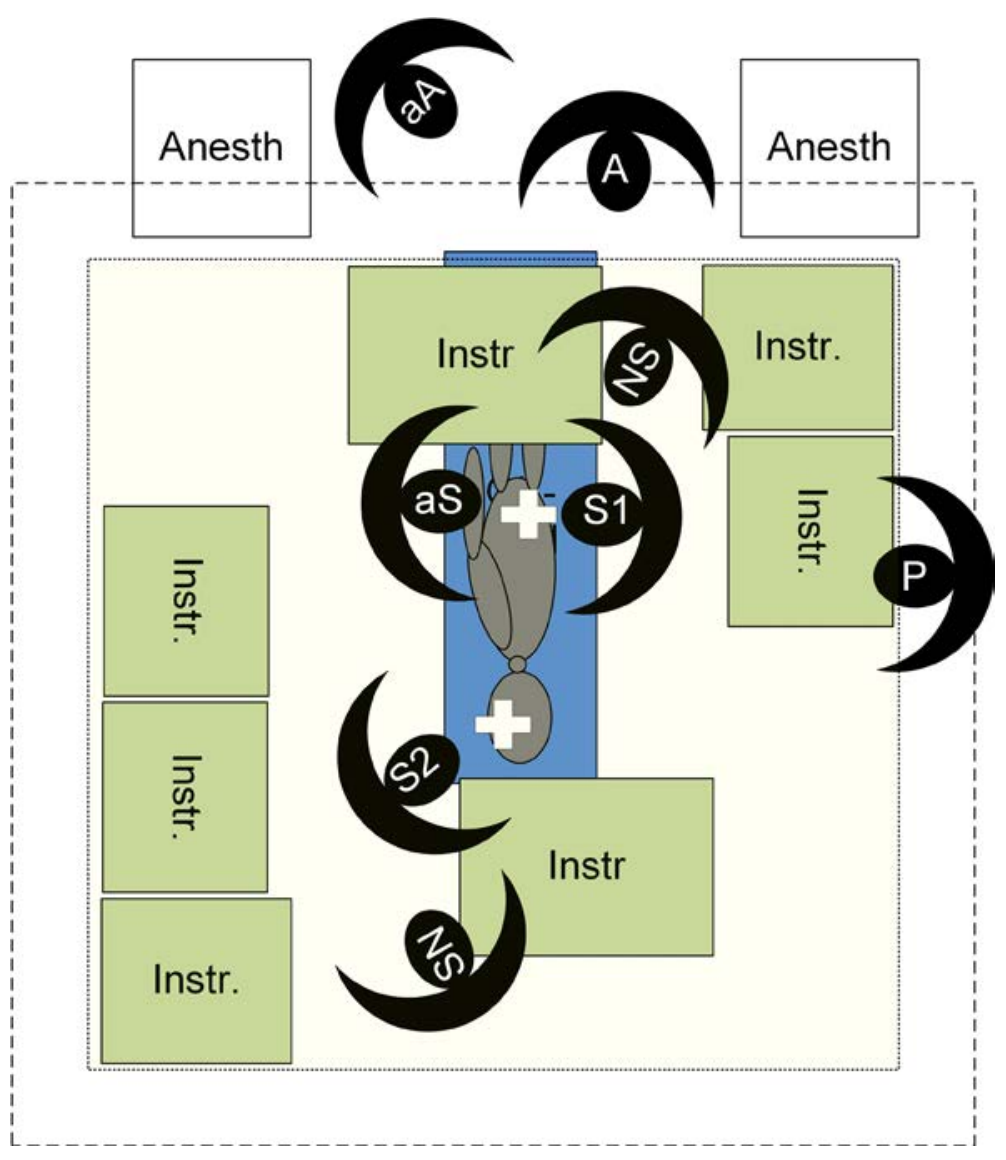

Figure 2.7. Double surgical team set-up under a $3.2 \times 3.2 \mathrm{~m}^{2}$ plenum.

Hypothesis 2: Positioning the Clean Area in the Middle of the Operating Room Results in an Optimal Logistical Layout of the Operating Room

During the process simulations it was shown that, in order to be able to maneuver and position a C-arm well, it is necessary to have at least $1.75 \mathrm{~m}$ of free space between the 
clean area and the walls of the operating room. After taking an X-ray, the C-arm was positioned outside of the clean area again.

A minimum of $2.25 \mathrm{~m}$ was needed for the positioning of the anesthesia staff and the required equipment (crash cart, cart with materials). For this reason, we conclude that there should be a minimum space of $2.25 \mathrm{~m}$ between the clean area and the walls.

Based on the discussion with the staff and medics and the preformed simulations we concluded that the remaining space inside the OR should preferably be situated together on the corridor side, rather than being equally divided around the clean area (see Figure 2.8). In the case of larger dimensions of the operating room the unidirectional downflow terminal (ultraclean ventilation (UCV) canopy) is not positioned centrally in the operating room as is customary in traditional designs. It can also be deduced from this that the minimum size of an operating room that is suitable for all types of operations, with a unidirectional down-flow plenum (UCV canopy) measuring $3.0 \times 3.0 \mathrm{~m}$ and with good logistics is $7.5 \times 7.5=56.25 \mathrm{~m}^{2}$. This size includes the space for the periphery area and the temporary storage of equipment in the operating room. The second hypothesis must thus be rejected: The noncentral set-up of the plenum (in the case of larger ORs) offers a better logistical layout of the operating room.

Hypothesis 3: The Classic Position of the Anesthesia Section in the Operating Room Is Optimal for the logistical Processes

During the process simulations, it became apparent that the classic position of the anesthesia section (with the back facing the corridor) hinders the transport of the patient's bed from the corridor and to position it alongside the operating table without a lot of maneuvering. It was also shown that the risk of bumping into the anesthetic equipment with the bed was high. One outcome of the discussions with the surgical team following the process simulations was that there were no objections to moving the anesthetists' section to the side of the OR. This creates better access to the clean area, both for the patient and for the instruments and equipment (see also Figure 2.8). The third hypothesis must thus be rejected: 
The positioning of the anesthesia section on the side of the clean area offers a better logistical layout of the operating room than the traditional set-up between the clean area and the entrance.

\section{Hypothesis 4: A Supply Bridge Height of $2.05 \mathrm{~m}$ Results in the Clean Area Being}

\section{Sufficiently Accessible to High Medical Equipment}

The scenarios with the surgical microscope and the Da Vinci surgical robot led to conflicts with the supply bridge height. The Da Vinci surgical robot is positioned over the patient with its arms in the highest possible position. Part of the current routine is to put the sterile covers on the arms of the robot outside of the clean area, after which the robot is rolled into the clean area with its arms in the highest position and then placed over the patient. Execution of this common procedure in this manner was shown to be impossible if the supply bridge is $2.05 \mathrm{~m}$ high. However, during the use of the Da Vinci robot, the clean area is so empty (because of the absence of tables, instruments and staff) that there is sufficient space to extend the robot to its highest position after it is under the unidirectional down flow terminal and to subsequently maneuver it over the patient.

During the trepanation, the arm of the current surgical microscope touched the supply bridge when it was positioned next to the patient (see Figure 2.5). It was possible to avoid the conflict by positioning the microscope foot diagonally behind the surgeon and having the microscope arm come over the shoulder of the surgeon. This set-up is workable for the surgeon, albeit less pleasant.

The chance of this type of conflict occurring is largely dependent on the type of microscope arm. An arm in which the highest point of the lower movable part of the arm does not get any higher than $2.0 \mathrm{~m}$ does not conflict with the supply bridge. The current microscope arm reaches up to $2.08 \mathrm{~m}, 3 \mathrm{~cm}$ higher than the bottom edge of the supply bridge. 
During operations involving an operation helmet, such as in orthopedics, there may be a conflict with the height if the surgeons are tall.

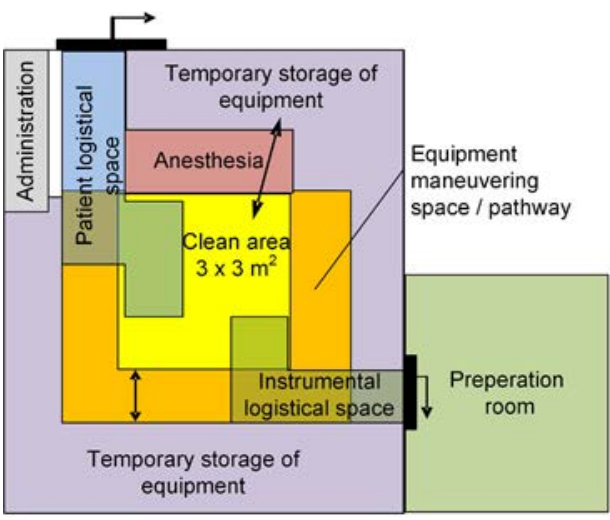

OR layout, classical

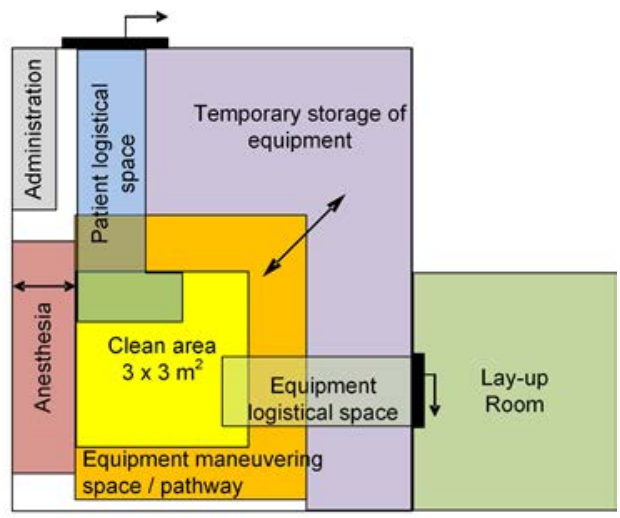

OR layout, after simulations

Figure 2.8. OR layout before and after the simulations.

This actually only occurs when entering and exiting the clean area. During the operation, the members of the surgical team are inside the supply bridge area and thus under the unidirectional down flow terminal.

For many staff in the periphery area, a height of $2.05 \mathrm{~m}$ is workable for making connections in the slanted part of the supply bridge (compressed air, electricity, vacuum, etc.). For shorter people $(<1.65 \mathrm{~m})$ the supply bridge needs to be lower for these activities to be carried out in an ergonomically sound way. A lower height would lead to a marked increase in the number of conflicts. It is therefore suggested that shorter people could make use of a portable step.

In summary, the process simulations showed that because of the height of both the arm of the current microscope and the surgical robot, the supply bridge will need to either be roughly $10 \mathrm{~cm}$ higher, U-shaped, or wider so that the whole microscope fits into the sterile zone. 
However, these solutions have the following drawbacks:

- A higher supply bridge would be more difficult to reach for plugging in equipment and unplugging it.

- When a three-sided U-shaped supply bridge is used, it is more complicated to change the equipment set-up to a mirrored set-up and there is less space for making connections on the supply bridge. A three-sided U-shaped supply bridge is seen to be a lesser solution. In order to keep the release point of the laminar airflow as low as possible, it is desirable to have the supply bridge connect (seamlessly) with the plenum side screen. The fourth side of the

\section{The $2.05 \mathrm{~m}$ height of the supply bridge is a good compromise}

- $\quad$ supply bridge also turns out to be indispensable for some of the many connection points needed. Besides, if the supply bridge were U-shaped, it would only be possible to move equipment hanging on the bridge to the other side of the bridge by way of the anesthesia side of the bridge, which will itself be full of connections and anesthesia equipment already.

- A wider bridge to allow more "arm space" for the microscope means the bridge no longer fits the surface of the unidirectional downflow terminal and that the whole terminal must be made larger. If the bridge does not connect with the plenum, the risks of a poorly directed airflow increase, resulting in possible turbulence along the edges of the downflow. This results in a substantial decrease in the size of the sterile zone. A (standard) larger plenum means more air needs to be blown in, resulting in greater energy usage and a more expensive plenum. 
Taking all these factors into consideration, the $2.05 \mathrm{~m}$ height of the supply bridge is a good compromise. During the discussion with the surgical team after the process simulation, it was therefore stated that a square, closed supply bridge at a height of $2.05 \mathrm{~m}$ from the floor and with internal dimensions of $3.0 \times 3.0 \mathrm{~m}^{2}$ would be the starting point for the future routines and for the purchase of equipment within the hospital. For the robot, this means that the arms will only be moved to the highest position after it has been rolled under the bridge. The simulation showed that there is ample space in the clean area to be able to carry out this maneuver safely. For the microscope, it means that the microscopes to be purchased in the future will be selected partly based on the maximum height of the part of the arm that passes under the bridge.

Taking the aforementioned restrictions into consideration, we can thus state that the fourth hypothesis need not be rejected and that a height of $2.05 \mathrm{~m}$ does not lead to insurmountable conflicts for the accessibility of the clean area with equipment from the pathway.

The layout that has resulted from the process simulations (Figure 2.8, above) differs on essential aspects from the layout that was the result of the traditional design process (see Figure 2.1, above). The main difference is the positioning of the clean area in the operating room (noncentral set-up versus central set-up) and the positioning of the anesthesia section. This has resulted in the modification of the original final design that was arrived at through a traditional design process, to a design based on the results of the process simulation (see Figure 2.8).

\section{Discussion}

The objective of this study was to evaluate a traditionally designed operating room using simulation of various surgical workflows. The primary research question was whether the clean area under the unidirectional airflow terminal would be large enough to enable smooth, unhindered task performance, while at the same time not being too far away to reach it with the equipment connections. 
In addition to the primary question, the study also offered an opportunity to investigate the logistical consequences of the centered positioning of the clean area in the OR. The results clearly showed that a clean area measuring $3 \times 3 \mathrm{~m}$ and a supply bridge height of $2.05 \mathrm{~m}$ was satisfactory for most situations, provided a movable operation table was used. The only cases in which conflicts with the supply bridge were observed were during the use of a surgical robot (Da Vinci) and a surgical microscope. During multiple trauma interventions, bottlenecks regarding the dimensions of the clean area will probably arise.

Due to the choice for a supply bridge with a side screen around the unidirectional downflow terminal, it is assumed that the unidirectional airflow will create a strong division between the clean area and the environment covering the whole surface. After the airflow is no longer directed by the side screen, some mixture of the air with the environment air will take place along the edge of the clean area. This so-called constriction of the air column will in practice reduce the size of the clean area. However, during the process simulations, it was assumed that the plenum surface projected on the floor, determined by the inner dimensions of the side screens, represented the clean area. This position can be defended because the reduction of clean area due to the side screens is presumably very limited at a height of roughly $1.10 \mathrm{~m}$ above the floor, the height at which the intervention is executed. With respect to the height of the supply bridge, one more thing to mention is that the orientation of the surfaces that the connections for the medical gases, earth points, and vacuum are situated in has an influence on the workable free height of the bridge. A person with a given length can still plug in a gas tube at a certain height if it has been turned toward the person in an ergonomic manner. It is easier to plug the tube in at a certain height if it is done diagonally from below, rather than from a position that is parallel to the floor. These matters, however, require additional research to determine what the best orientations and positions of the various connections are.

It is also noted that the simulations made it clear that the accessibility of the operating area with equipment like the $\mathrm{C}$-arm, and the lines of vision in the operating room, have an influence on the ergonomic layout of the supply bridge. 
This is because the equipment wires and tubes hinder the access to the clean area. Both aspects force the connections towards the corners of the bridge.

During process simulations, there is always the issue of whether to study current workflows or future (new) workflow that are better adjusted to the new situation. In this study, the choice was made to base the process simulation on the existing routines in order to prevent the teams from being too self-conscious about how they worked. If there had been more time for preparation, including training on the new future workflow, it would have been possible to have a more compact set-up in some instances. However, the means for such an approach were lacking, for example, for freeing up operating rooms and surgical teams for instruction and training.

In addition to testing the hypotheses, this study also offered the researchers an opportunity to find out whether process simulation is a useable tool in the design process and whether it creates added value. The method is more expensive than a traditional paper design because it requires the construction of a mock-up, the input of staff, and the use of an operating room for one week. Besides, it requires more time due to the necessary preparation.

Process simulations also have made an important contribution to the insights medical personnel have regarding the design and future routines with separate preparation rooms and a unidirectional down-flow system. This has resulted in greater support for the design. The added value of a process simulation, versus the expert opinions that form the basis for the traditional design process, is that issues that reside in peoples' perceptions can be objectivized through observation of the process simulation. People often think that things happen differently than what is shown to happen through the actions they perform. Basic actions can also, unconsciously, be considered to be unimportant while they actually do have an impact on the space. It is difficult to determine how much space an action takes without actually trying it. 
This is an essential question for an operating room that has a relatively limited sterile area. The added value of the process simulation was mainly in the following areas:

- $\quad$ Spatial mapping of dynamic processes

- Determination of required free (logistical) periphery area and lines of sight

- The objectivization of perceptions

- The creation of support for innovative designs

The hospital's project team has found the influence of the process simulations on the design to be considerable, because of their influence on the basic layout and technical installations. Because changes later on in the design process always have concomitant higher costs, it is necessary for the process simulations to take place early on in the design process, as early as the design brief or schematic design phase.

\section{Conclusions}

Process simulation can have significant impact on the final design and is a very suitable method to support the design process. The process simulation of four typical interventions has led to significantly different operating room layouts than were arrived at through the traditional design process. The main difference is the positioning of the clean area in the operating room (noncentral set-up versus central set-up) and the positioning of the anesthesia section.

The results clearly showed that a clean area measuring $3 \times 3 \mathrm{~m}$ and a supply bridge height of $2.05 \mathrm{~m}$ was satisfactory for most situations, provided a movable operation table was used.

Success factors for this type of process simulation have shown to be the following:

- Process simulations should take place early on in the design process, as early as the design brief or schematic design phase. 
- The more realistic a situation is, the more accurate the actions will be. In other words, make as much use of the actual people and instruments and equipment involved in the simulations as possible, and make sure the spatial characteristics of the simulation are the same as those of the design.

- Ensure that the variables being investigated can actually be varied during the simulations. For instance, movable walls to vary the size of the space and the possibility of changing the position of the operating table within the clean area.

- Ensure that all relevant staff members and medics are present during the entire simulation.

- Make sure there is someone in charge who monitors the process and leads the discussions.

- Make use of independent observers that have no other role during the simulations and the

- discussions.

- The clearer the working instructions are, the less discussion there will be about what to do, but make sure people are free to act naturally.

- Go through as many connected actions as possible, but offer space for discussion after a (partial) session.

\section{Implications for Practice}

- This study demonstrates that process simulation can significantly impact the final design

- $\quad$ and is a very suitable method to support the design process.

- Process simulation can play an important role in evidence-based design.

- There are success factors that should be taken into account when using process simulations as a design instrument. 


\section{References}

Anderson, J. R. Skill acquisition: Compilation of weakmethod problem situations. Psychological Review 1987; 94: 192- 210.

Baumgart, A., Denz, C., Bender, H.-J., \& Schleppers, A.. How work context affects operating room processes: Using data mining and computer simulation to analyze facility and process design. Quality Management in Health Care 2009;18(4): 205-314.

Bittermann, M. S. Intelligent Design Objects (IDO): A cognitive approach for performancebased design (Unpublished doctoral dissertation). Delft University of Technology 2009, The Netherlands.

Chen, X., Xu, B. N., Meng, X., Zhang, J., Yu, X., \& Zhou, D..Dual-room 1.5-T intraoperative magnetic resonance imaging suite with a movable magnet: implementation and preliminary experience. Neurosurgical Review 2011; 1-16, article in press.

Dunston, P. S., Arns, L. L., \& McGlothlin, J. D. An immersive virtual reality mock-up for design review of hospital patient rooms. Paper presented at the 7th International Conference on Construction Applications of Virtual Reality 2007(October), University Park, Pennsylvania, U. S.

Gawron, V. J., Dennison, T. W., \& Biferno, M. A. Mock-ups, models, simulations and embedded testing. In S. G. Charlton \& T. G. O'Brien (Eds.), Handbook of human factors testing and evaluation 2002 (2nd ed.). Mahwah, NJ: Lawrence Erlbaum Associates.

Gosbee, J., \& Gosbee, L. L. Usability evaluation in health care. In P. Carayon (Ed.), Handbook of human factors and ergonomics in health care and patient safety 2012 (2nd ed.). Boca Raton, FL: CRC Press.

Israelski, E. W. Testing and evaluation. In M. B. Weinger, M. E. Wiklund, and D. J. GardnerBonneau (Eds.), Handbook of human factors in medical device design 2011. Boca Raton, FL: CRC Press.

Mackenzie, C. F., \& Xiao, Y. Video analysis: An approach for use in health care. In P. Carayon (Ed.), Handbook of human factors and ergonomics in health care and patient safety 2012 ( $2^{\text {nd }}$ ed.). Boca Raton, FL: CRC Press. 
Moorthy, K., Munz, Y., Undre, S., \& Darzi, A. Objective evaluation of the effect of noise on the performance of a complex laparoscopic task. Surgery 2004;136(1): 25-30.

Nisbett, R. E., \& Wilson, T. D. Telling more than we can know: Verbal reports on mental processes. Psychological Review 1977;84(3): 231-259.

Peavey, E., Zoss, J., \& Watkins, N. Simulation and mock-up research methods to enhance design decision-making. Health Environments Research \& Design Journal 2012;5(3):133144.

Reiling, J. G., Knutzen, B. L., Wallen, T. K., McCullough, S., Miller, R., \& Chernos, S. Patient safety: Enhancing the traditional hospital design process: A focus on patient safety. Joint Commission Journal on Quality and Safety 2004;30(3)

Rogers, M. L., Patterson, E. S., \& Render, M. L. Cognitive work analysis in health care. In P. Carayon (Ed.), Handbook of human factors and ergonomics in health care and patient safety 2012 (2nd ed.). Boca Raton, FL: CRC Pr ess.

Sadler, B. L., Berry, L. L., Guenther, R., Hamilton, K., Hessler, F.A., Merritt, C. \& Parker, D. Fable hospital 2.0: The business case for building better healthcare facilities. Hasting Center Report 2011;41(1):13-23.

Sandberg, W. S., Daily, B., Egan, M., Stahl, J.E., Goldman, J. M., Wiklund, R. A., \& Rattner, D. (2005). Deliberate perioperative systems design improves operating room throughput. Anaesthesiology, 103(2), 406-418.

Sanderson, P. M., Tosh, N., Philp, S., Rudie, J., Watson, M. O., \& Russell, W. J. The effects of ambient music on simulated anaesthesia monitoring. Anaesthesia 2005;60(11):10731078.

Sehulster, L. M., Chinn, R. Y. W., Arduino, M. J., Carpenter, J., Donlan, R., Ashford, D., \& Cleveland J. Guidelines for environmental infection control in health-care facilities. Recommendations from CDC and the Healthcare Infection Control Practices Advisory Committee (HICPAC) 2004. Chicago, IL: American Society for Healthcare Engineering/American Hospital Association.

Strauss, G., Aries, F., Abri, O., Dietz, A., Meixensberger, J., \& Lüth, T. Conception, realization and analysis of a modern operating theatre workplace for ENT surgery. HNO 2010;58(11:1074-1084. 
Suzuki, T. Cleanliness in the operating room. Japanese Journal of Anesthesiology 2010;59(5):556-563.

Ulrich, R. S., Zimring, C., Zhu, X., DuBose, J., Seo, H.-B., Choi, Y.-S., Quan, X., \& Joseph, A. A review of the research literature on evidence-based healthcare design, Health Environment Research and Design 2008;1(3):101-165.

Van Boxel, E., Koreman, K., Verweij, M., Rodermond, J., Huijsman R., Hansen, B., \& Schaap, P. M. Bouwen aan de Architectuur van de zorg 2007 (Building health care architecture). Retrieved from www.architectureinhealth.nl

Wickens, C. D., Lee, J. D., Liu, Y., \& Gordon Becker, S. E. An introduction to human factors engineering 2004 (2nd ed.). Upper Saddle River, NJ: Pearson Education.

Wilson, T. D. Strangers to ourselves: Discovering the adaptive unconscious. Cambridge, MA: Belknap Press of Harvard University Press 2002.

Woods, D. D.. Discovering how distributed cognitive systems work. In E. Hollnagel (Ed.), Handbook of cognitive task design. Mahwah, NJ: Lawrence Erlbaum Associates 2003.

Yavuz, S. S., Bicer, Y., Yapici, N., Kalaca, S., Aydin, O. O., Camur, G. et al. Analysis of risk factors for sternal surgical site infection: Emphasizing the appropriate ventilation of operating theaters. Infection Control and Hospital Epidemiology 2006;27(9):958-963. 
Process simulation during the design process makes the difference 


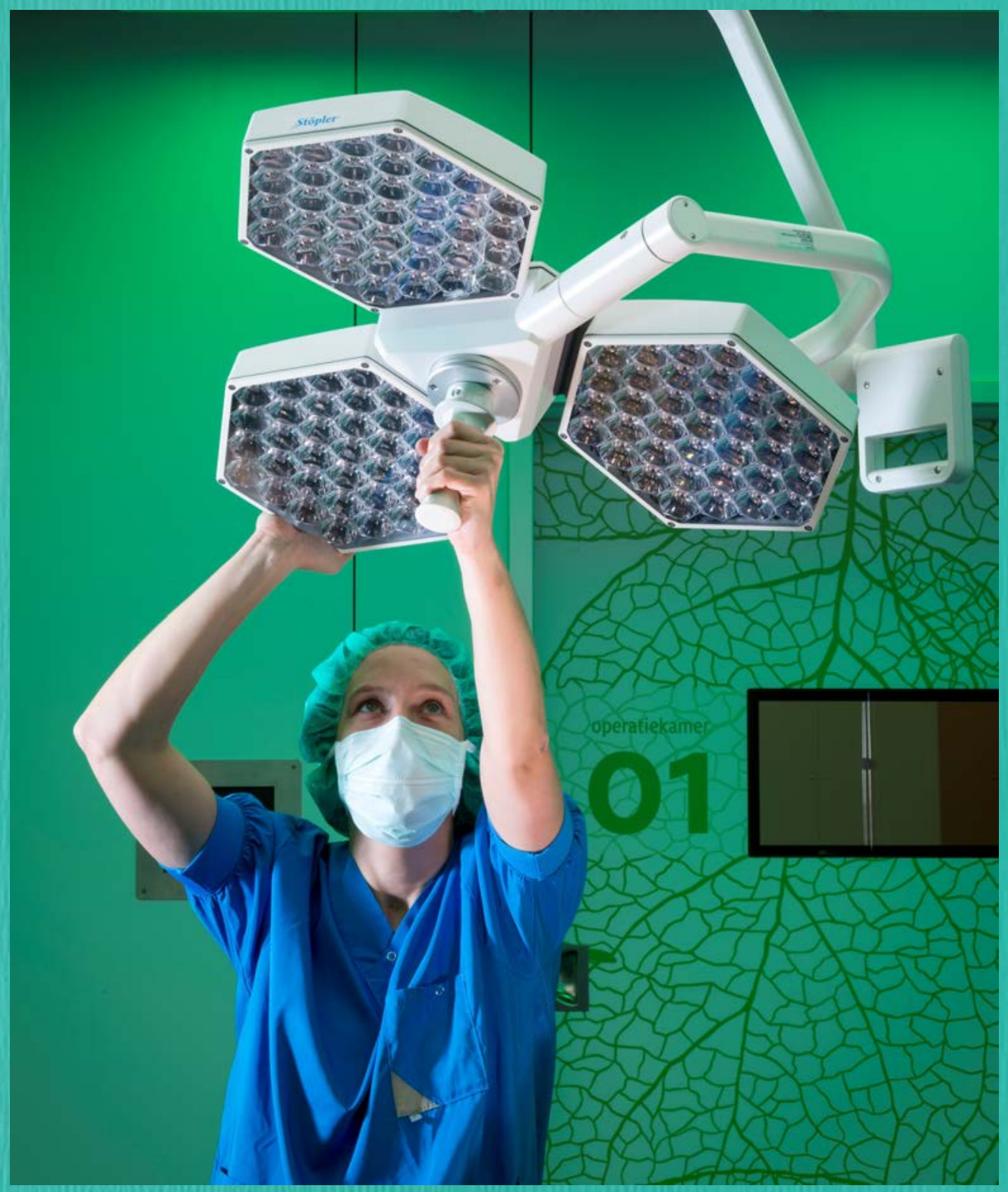




\section{Chapter 3}

\section{The Effect of Operating Lamps on the Protected Area of a Unidirectional Down Flow (UDF) System}

Traversari AAL, Bottenheft C, Louman R, van Heumen SPMPM, Böggemann J. The effect of operating lamps on the protected area of a unidirectional down flow (UDF) system. Health Environments Research and Design Journal. 2017;10(3):40-50. 


\section{Abstract}

Background: Operating lamps are often seen as the most disruptive factors within the protective area in the operating theater (OT). The effect of the operation lamps (with different shapes) should be demonstrated in an OT by trial, since research on the effects of the lamps is still limited.

Objectives: The main aim of this study was to determine the effects of a skirt, different lamps, and the position of the lamp on the protected area. Methods: The concentration of airborne particles was measured under different circumstances, in order to determine the size and quality of the protected area. This entrainment/segregation test is based on the deliberate and controlled emission of particles outside the zone that is protected. Findings and Conclusions: The degree of protection (DP) at the center of the protected area was higher for the case with the skirt. This skirt stimulates more down flow and prevents the early entry of particles into the protected area. It can also be concluded that Lamp Y, due to its open shape, has the most positive effect on the DP at the center. It has also been shown that the position of the lamp has an effect on the protected area.

\section{Keywords}

operating theater, operating lamps, unidirectional down flow (UDF) system, air quality, entrainment/

segregation test

\section{Acknowledgments}

The authors want to thank the staff of the Zuwe Hofpoort hospital for facilitating the project by providing a room (and organizing the operating lamps), for the experiments, and for funding the first measurements. We also want to thank The Dutch Ministry of Health, Welfare and Sports for funding this article. 


\section{Declaration of Conflicting Interests}

The author(s) declared no potential conflicts of interest with respect to the research, authorship, and/or publication of this article.

\section{Funding}

The author(s) disclosed receipt of the following financial support for the research, authorship, and/or publication of this article: The Dutch Ministry of Health, Welfare and Sports.

\section{Introduction}

A ventilation system in an operating theater (OT) is able to provide a clean surgical environment, and it plays an important role in the prevention of contamination through airborne particles. A ventilation system that is often used to provide a clean operating area is a unidirectional down flow (UDF) system. Since the operating lamps are often seen as the most disruptive factors within the protective area in the OT (Schinkel, van den Wildenberg, \& van Vugt, 2008), one of the most important questions is which type (with different shapes) of operating lamp has the least effect on the performance of the total system? The effect of the operation lamps should be demonstrated in an OT by trial, since research on the effects of the lamps in practice is still limited. The OTs of a hospital in the Netherlands are equipped with UDF systems and recently decided to check whether the performance of the total system in their OTs could be improved by placing new operating lamps.

During the same period, a new test method to determine the protected area was developed in the Netherlands by the Association of Contamination Control Netherlands (VCCN-RL-7, 2014). This test method is based on the entrainment/segregation test as described in the Deutsches Institut für Normung (DIN, 1946-4), Health Technical Memorandum (HTM) 03 (Department of Health Estates and Facilities Division, 2007), and Austrian Standards (ÖNORM H 6020, 2007). As part of this method, particles are emitted outside the zone protected by the UDF system (the periphery). 
The periphery accommodates assisting staff, for example, the anesthesiologist, and a circulating nurse as well as the necessary equipment. The protected area is defined as the area in which the concentration of particles with a size of $\geq 0.5 \mu \mathrm{m}$ is at least 100 times less than the concentration in the periphery. In the center of the protected area, the concentration should be at least 1,000 times less than that in the periphery. The protected area often encompasses at least the operating table, surgical team, and the sterile instrument tables. It is assumed that the size and the quality of the protected area can be positively affected by a "skirt," since the skirt stimulates more down flow of the system and prevents the early entry of particles from the periphery into the protected area (Fitzner, 1990).

The goal of this study is twofold. First, the effect of the shape and the position of the surgical operation lamps on the protected area is examined. Based on a pre-evaluation, the hospital selected two different types of operating lamps, Lamp X and Lamp Y, which they would like to have evaluated. Besides the type of lamp, Chow, Lin, and Bai (2006) showed that the position of the lamp also influences the degree of protection (DP) that the ventilation system provides (Chow, Lin, \& Bai, 2006). The position of the lamp can have a serious impact on the movement of infectious particles. Therefore, the effect of the position of the lamp on the protected area also should be considered. Second, this study aims to determine the effect of a skirt around the plenum on the protected area of an OT.

\begin{tabular}{lc}
\hline Size plenum $\left(\mathrm{m}^{2}\right)$ & $9(3 \times 3)$ \\
Size operating theatre $\left(\mathrm{m}^{2}\right)$ & 44 \\
Average air velocity $(\mathrm{m} / \mathrm{s})$ & 0.27 \\
Total amount of air flowing & 8.677 \\
through the plenum $\left(\mathrm{m}^{3} / \mathrm{h}\right)$ & \\
Height of the plenum $(\mathrm{m})$ & 2.891 \\
Date of construction & 2008 \\
\hline Note. OT = operating theater. &
\end{tabular}

Table 3.1. Characteristics of the OT. 


\begin{tabular}{lll}
\hline & Lamp X & Lamp Y \\
\hline Frontal area (A) & $0.35 \mathrm{~m}^{2}$ & $0.05 \mathrm{~m}^{2}$ \\
Shape & Semi-open shape & Open shape \\
\hline
\end{tabular}

Table 3.2. Characteristics of Lamps $X$ and $Y$.

Both aspects are evaluated with the previously mentioned entrainment/ segregation test. The advantage of using this test for this specific research is that it provides an objective manner to compare the different conditions, free from any influence of other parameters such as differing colony-forming units (CFU) levels, operating teams, and operations.

\section{Method}

Two experiments were carried out. In Experiment A, the effect of a skirt around the plenum on the protected area was tested, and in Experiment $B$, the effect of the type and the position of the lamps on the protected area was examined. This study took place from October 2013 till November 2013. During the measurements in both experiments, no surgical activities were performed. In Table 3.1, different characteristics of the OT are shown, and in Table 3.2 and Figure 3.1a and 3.1b, the characteristics of Lamps $X$ and $Y$ are presented. Each type of lamp is tested in pairs of two lamps (one on each side of the operating table).

\section{Principles of the Entrainment Test}

In the Netherlands, a test method was developed based on the entrainment/segregation test as described in the DIN 1946-4, HTM 03, and ÖNORM H 6020. 


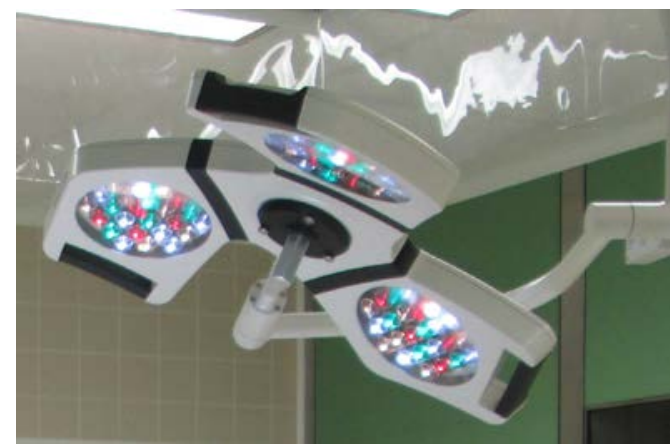

(a)

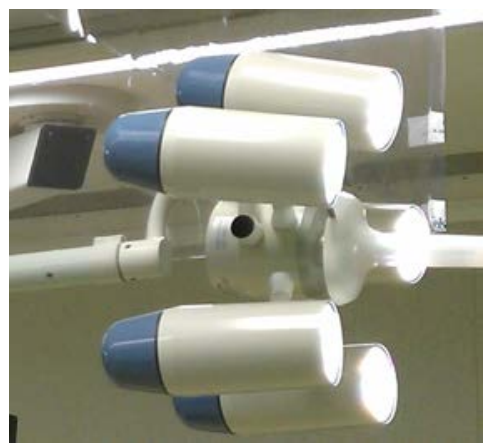

(b)

Figure 3.1. (a) LampX, 9(b) Lamp $Y$.

This method is based on the deliberate and controlled emission of particles in the periphery. The location and the quality of the protected area are subsequently determined by calculating the DP at multiple locations. The DP is defined as the logarithm of the quotient (ratio) of the number of particles with a size of $0.5 \mu \mathrm{m}$ or larger in the protected area compared to the number of particles of this size in the periphery. This corresponds to the following Equation 1 (Traversari et al., 2013).

$D P_{x}=-\log \left(C_{x} / C_{r e f}\right)$

where $D P_{x}$ is the degree of protection in the "clean" area $x, C_{x}$ is the concentration of particles in the clean area $\mathrm{x}$, and $\mathrm{C}_{\text {ref }}$ is the concentration of particles outside the clean area, that is, the background/periphery.

By emitting particles in the periphery and subsequently measuring the concentration of particles at different locations in the OT, it can be determined in what area the requirements of the protected area (DP $\geq 2$ at the sides/corners and $D P \geq 3$ at $1.2 \mathrm{~m}$ above the floor level at the center of the protected zone) are met (Chow et al., 2006). 
The plenum was projected on the floor, and until the requirements were met ( $D P \geq 2$ ), the measuring positions were shifted from the corners of this projection toward its center in steps of $10 \mathrm{~cm}$ (perpendicular to the sides). The more the measuring positions are shifted toward the center, the smaller the protected area is. During these measurements, the DP was capped at DP $=5$ (i.e., a $10^{5}$-fold reduction in counts).

The advantage of using this method for this research is that it eliminates the effect of environmental factors on the performance of the ventilation system. A few examples of possible environmental factors are activities in surrounding rooms, pressure differences, the wind pressure on the facade, and so on. Another advantage of using the DP is that this parameter can also be used to compare measurements that were performed with varying background concentrations. Especially when comparing different systems at different times, it is almost impossible to maintain the background concentration of particles $\left(C_{\text {ref }}\right)$ at exactly the same level for both systems (described in DIN 1946, part 4, annex C.3, and VCCN-RL 7).

\section{Setup}

The experimental setup was determined according to the Dutch guidelines (VCCN-RL-7). The operating table was located in the central position. The height of the "work surface" of the operating table had to be between 0.8 and $1.2 \mathrm{~m}$. Each type of lamp was tested in pairs of two lamps (one on each side of the operating table) and was positioned in standard position according to the DIN 1946-4 and VCCN-RL-7. Both lamps were switched on during the measurements. Additional heat load from monitors and anesthesia equipment was present, which was equal during all measurements. 


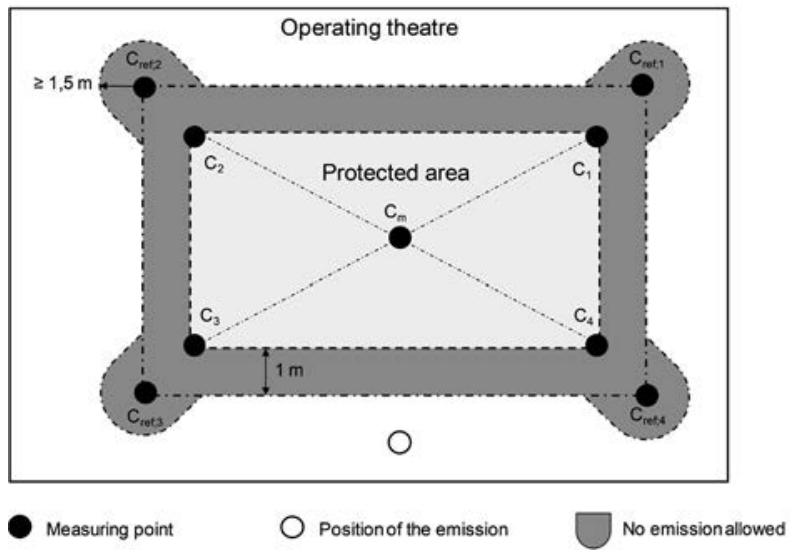

Figure 3.2. Measurement positions.

The measurement positions were defined as follows (see Figure 3.2):

1. All measurement positions $\left(C_{m}, C_{1}, C_{2}, C_{3}, C_{4}, C_{r e f 1}, C_{r e f 2}, C_{r e f 3}\right.$, and $\left.C_{r e f 4}\right)$ were located $1.2 \mathrm{~m}$ above floor level.

2. One measurement point $(\mathrm{Cm})$ was located at the center of the protected area.

3. At least four measurement positions $(\mathrm{C} 1, \mathrm{C} 2, \mathrm{C} 3$, and $\mathrm{C} 4)$ were located at the furthest sides of the protected area.

4. The distance between the point of measurement in the periphery and the point inside the protected area was $1 \mathrm{~m}$.

\section{Materials}

Emitting particles. As explained previously, particles were emitted in the periphery in order to keep the background concentration $\left(C_{\text {ref }}\right)$ in the theater at a relatively high level. The particle concentration in the background was created by the vaporization of boiled tap water with an ultrasonic fogger (Lighthouse Volcano P6). The small water droplets (2$4 \mu \mathrm{m}$ ) emitted by the machine vaporize relatively fast (a few seconds) and the mineral residues of the evaporated tap water remain airborne as solid particles (Hinds, 1999; Porstendo“rfer, Gebhart, \& Röbig, 1977; Rodes, Smith, Crouse, \& Ramachandran, 1990). 
The particles in this study were emitted at a height of $1.5 \mathrm{~m}$ (average neck height; Traversari et al., 2013). It is assumed that most particles are produced by the staff at th at height. Measuring particles. After the particles are emitted, the concentration measurements of particles started. Airborne particles were measured using three particle counters (Lighthouse 3016-IAQ, Fremont, CA) at $1 \mathrm{~m}$ distance of the corner in the periphery, at the corner of the protected zone, and in the middle of the operating table (center). The handheld counter displayed both cumulative and differential particle count data as well as temperature data. The data generated by the particle counters were collected and displayed on the screen with the Lighthouse Monitoring System. The airflow through the instrumentwas $2.8 \mathrm{dm}^{3} / \mathrm{min}$. The countersmeasured the number of particles for every minute, so a total amount of $2.8 \mathrm{dm}^{3}$ of air was sampled per data point. Each measurementwas performed 10 times, thus resulting in a measurement time of at least 10 min. The mean DP was obtained by taking the average of these measurements.

\section{Procedure and Conditions}

Different conditions were created to measure the effect of several variables on the protected area in one OT. The following variables were varied:

1. Skirt: A skirt of $25 \mathrm{~cm}$ was placed around the plenum after the first measurements. The reason for choosing this specific height is that $25 \mathrm{~cm}$ is the maximum height of the skirt at which the movement of the pendants is not prevented. Measurements were performed without a skirt (Measurement A1) and with a skirt (Measurements A2), also referred as Experiment $A$.

2. Operating lamps: Measurements were performed without operating lamps (Measurement A2) and with operating lamps (Measurements B1 and B2). In addition to the effect of the presence of the operating lamps on the total system, the positioning of the lamp may affect the size of the protected area and the quality of the air in the protected area. Two positions of the lamps were compared to each other: the standard position (according to the DIN1946-4; see Figure 3.3) and the total hip position. 
The difference between these positions is that for the total hip position, both lamps are positioned on the same side of the operating table with a distance to the center line of the operating table of $60 \mathrm{~cm}$ and a center-to-center distance of the operating lamps of $110 \mathrm{~cm}$ with a focus on the center of the operating table. These measurements are also referred as Experiment B.

An overview of the conditions during different measurements is shown in Figure 3.4 and is discussed below.
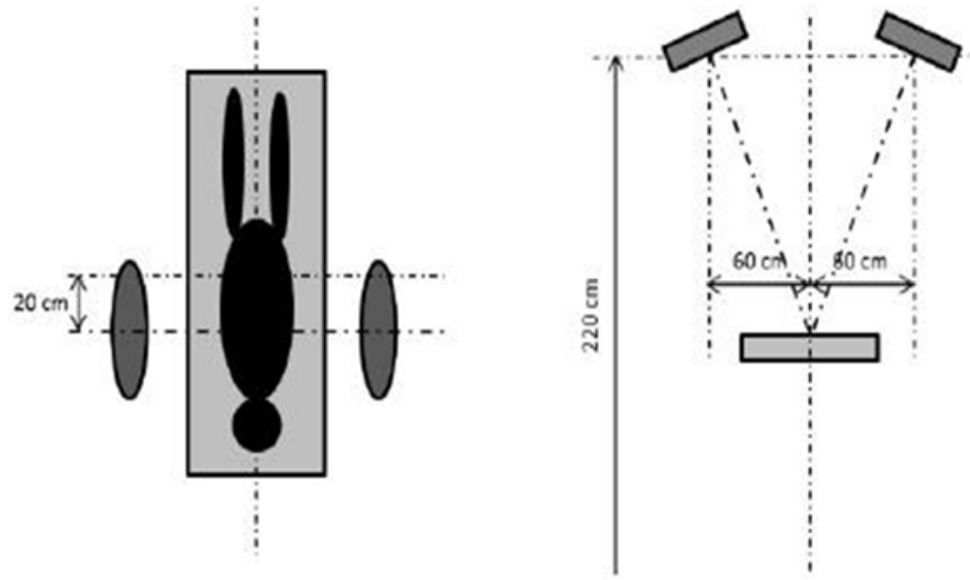

Figure 3.3. The standard position.

\section{Outcome}

The concentration of particles for all conditions and at all three measurement positions has been recorded. All conditions have the following set of outcome variables:

1. The size of the protected area: at each corner, the DP was determined. The outcome variable in this analysis is the smallest reduction (a higher reduction results in a smaller size of the protected area) whereby the mean DP was significantly greater than 2. 
2. The quality of the protected area: at the center of the protected area, the mean DP has been determined. The higher the mean DP, the better the quality of air at that location is.

\section{Design and Statistical Analysis}

Statistical analyses were performed using Statistical Package for the Social Sciences (SPSS 22.0.0) software. For all analyses, the significance level was set to $p<.05$. This study measured the effects of the skirt (Experiment A) and type and positions of the lamps (Experiment B) on the outcome variables size and quality of the protected area. These two outcome variables were analyzed as follows:

1. Size: one-sample t-tests (hypothesis $=95 \%$ of mean DP $\geq 2$ ) have been used to determine the minimally required reduction.

2. Quality: nonparametric statistical analyses and descriptive statistics were used to analyze differences in the mean DP. Because nonparametric analyses are not able to control for interaction effects, analyses of variance (ANOVAs) were used to check for interaction effects.

In general, two peaks in the distribution of the DP can be observed: one peak at 2 (at the corners) and one peak at 5 (at the center). This last value is the highest obtainable DP. 


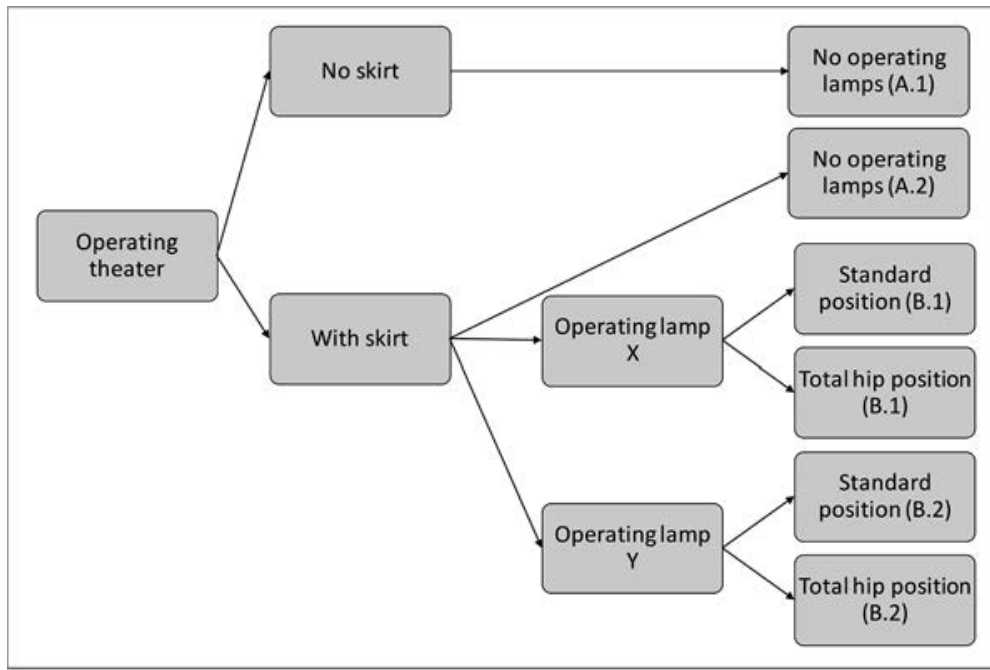

Figure 3.4. Overview of the different conditions.

\begin{tabular}{lcc}
\hline & \multicolumn{2}{c}{ Configuration } \\
\cline { 2 - 3 } & Skirt & Operating lamp \\
\hline Measurement A.1 & No & No \\
Measurement A.2 & Yes & No \\
\hline
\end{tabular}

Table 3.3. Configuration of measurement A.1 and A.2.

\section{Results}

In this section, the results of the statistical analysis are presented. First, the results of Experiment

A are discussed, followed by the results of Experiment B.

\section{Experiment A: Skirt Versus No Skirt}

Size of the protected area. The size of the protected area for both the case with a skirt and the case without a skirt was determined. To select the data for these specific cases, the data were filtered on no lamps (see Table 3.3).

Subsequently, the data were split by corner, by reduction of the protected area, and by the presence of a skirt, after which the DP was analyzed with a one-sample t-test. 


\begin{tabular}{lcc}
\hline & \multicolumn{2}{c}{ Smallest reduction [cm] } \\
\cline { 2 - 3 } & With skirt & No skirt \\
\hline Corner 1 & $40^{* *}$ & $40^{* *}$ \\
Corner 2 & $40^{* *}$ & $40^{* *}$ \\
Corner 3 & $40^{* *}$ & $40^{*}$ \\
Corner 4 & $40 * *$ & $20^{* *}$ \\
\hline$* p<.05 .{ }^{* *} p<.001$. &
\end{tabular}

Table 3.4. Required reduction of the protected area in centimeters per corner.

The smallest reduction whereby the mean DP was significantly greater than 2 has been used as a result and is presented in Table 3.4. The $p$ value, as used in Table 3.4, is the significance level at which the hypothesis can be accepted.

As shown in Table 3.4 and Figure 3.5, the areas of the two cases do not completely overlap. However, there are no major differences between the two conditions, that is, only one step of $10 \mathrm{~cm}$, which implies that the expectation about a positive influence of a skirt on the size of the protected area can be rejected.

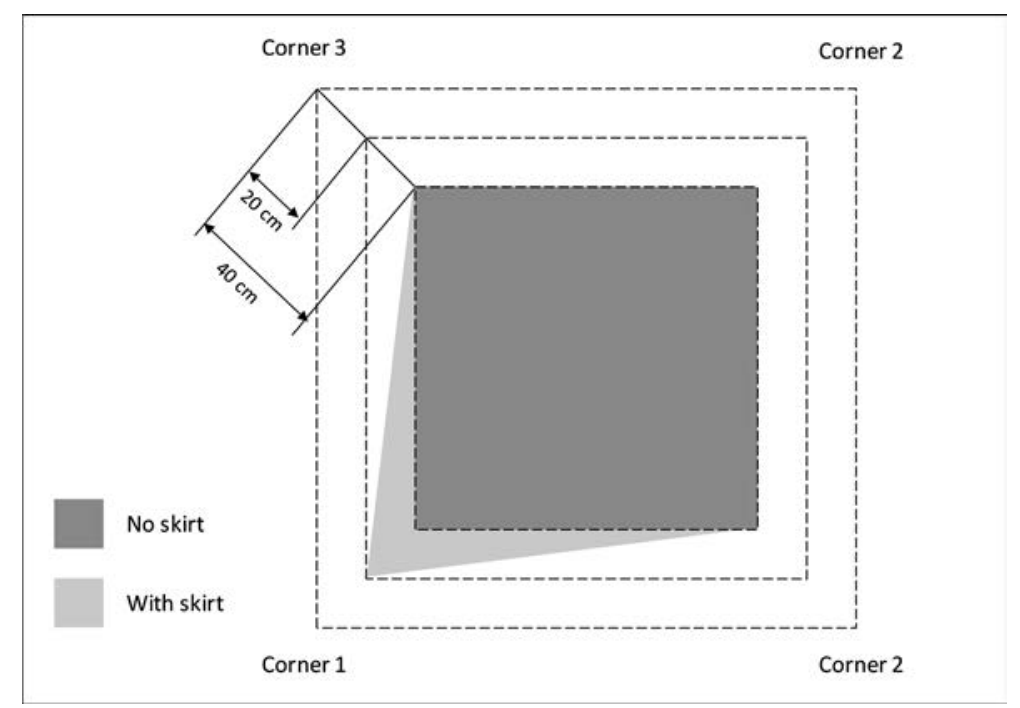

Figure 3.5. Reduction per corner for the case with skirt and for the case without skirt. 


\begin{tabular}{llllllll}
\hline & \multicolumn{3}{c}{ With skirt } & & \multicolumn{3}{c}{ No skirt } \\
\cline { 2 - 4 } \cline { 7 - 8 } & $N$ & $M$ & $S D$ & & & $M$ & $S D$ \\
\hline Centre & 249 & $5.02^{*}$ & .61 & & 78 & 2.91 & .41 \\
\hline
\end{tabular}

Note. $D P=$ degree of protection.

$* p<.001$.

Table 3.5. Mean (M) DP, with standard deviation (SD) and sample size (N), at the center of the protected area, for the case with skirt and for the case without a skirt.

\section{Quality of the protected area.}

Subsequently, the DP at the center of the protected area has been determined in order to investigate the effect of the skirt on the quality of the protected area (see Table 3.5 for descriptive statistics). The assumption of normality was violated, as indicated by significant Kolmogorov-Smirnov statistics.

We present a nonparametric Mann-Whitney $U$ analysis to compare the effects of skirt versus no skirt on the DP in the center of the protected area.

A Mann-Whitney $U$ analysis showed that there was a statistically significant difference in DP at the center of the protected area, DP $(U=810.00, p<.001)$, with mean ranks of 199.75 for the case with a skirt and $\mathbf{4 9 . 8 8}$ for the case without a skirt. This implies that the DP at the center is substantially better when there is a skirt in comparison to when there is no skirt.

\begin{tabular}{lccl}
\hline & \multicolumn{3}{c}{ Configuration } \\
\hline & Skirt & Operating lamp & Characteristics of the operating lamp \\
\hline Measurement A.2 & Yes & No & - \\
Measurement B.1 & Yes & Yes & Type X, standard and total hip position \\
Measurement B.2 & Yes & Yes & Type Y standard and total hip position \\
\hline
\end{tabular}

Table 3.6. Configuration of measurement A.2, B.1 and B.2. 


\section{Experiment B: Type and Position of the Lamp}

Size of the protected area. The effect of the different types of lamps and positions of the lamps on the protected area was also tested with one sample t-tests. To select the data for these specific conditions, the data were first filtered for the case with skirt (see Table 3.6).

Next, the data were split by corner and the reduction in centimeters (steps of $10 \mathrm{~cm}$ ). Per corner and reduction, the mean DP was analyzed for type and position of the lamp with a one sample t-test (hypothesis $=95 \%$ of mean DP $\geq 2$ ). The smallest reduction whereby the mean DP was significantly greater than 2 is used as a result. These results can be found in Table 3.7.

\begin{tabular}{lcccccc}
\hline & \multicolumn{5}{c}{ Smallest reduction [cm] } \\
\hline \multirow{2}{*}{ With skirt } & No lamp & \multicolumn{3}{c}{$\mathrm{X}$} & & \multicolumn{2}{c}{$\mathrm{Y}$} \\
\cline { 3 - 5 } \cline { 6 - 7 } & & $\begin{array}{c}\text { Standard } \\
\text { position }\end{array}$ & $\begin{array}{c}\text { Total hip } \\
\text { Position }\end{array}$ & & $\begin{array}{c}\text { Standard } \\
\text { position }\end{array}$ & $\begin{array}{c}\text { Total hip } \\
\text { position }\end{array}$ \\
\hline Corner 1 & $40^{* *}$ & $40^{* *}$ & $40^{* *}$ & & $40^{* *}$ & - \\
Corner 2 & $40^{* *}$ & $30^{* *}$ & 40 (estimated) & & $40^{*}$ & $40^{*}$ \\
Corner 3 & $40^{* *}$ & $40^{* *}$ & 40 (estimated) & & $30^{* *}$ & $30^{* *}$ \\
Corner 4 & $40^{* *}$ & $30^{* *}$ & $30^{* *}$ & & $40^{* *}$ & 40 (estimated) \\
\hline$* p<.05 .{ }^{* *} p<.001$. & & & &
\end{tabular}

Table 3.7. Required reduction per corner.

If the maximum measured reduction did not lead to significant results, the reduction is estimated for which it is probably significant. In the case of "estimated," the mean DP is higher than 2 but not significant. For example, when Lamp X is placed in total hip position, the mean DP at Corner 3 and a reduction of $40 \mathrm{~cm}$ is 2.38 , but the DP is not significantly higher than 2. There is one exception: for Lamp X in total hip position at Corner 2, the DP is 1.99 at $30 \mathrm{~cm}$. For this reason, the reduction is estimated to be significant at $40 \mathrm{~cm}$. Besides this, data were absent for Lamp $\mathrm{Y}$ in total hip position at Corner 1. 
In Table 3.7, it is shown that for Lamp X, the size of the protected area is larger when the standard position is applied: at Corner 2, the minimal reduction that is needed to reach DP $\geq 2$ is $10 \mathrm{~cm}$ less when compared to the case of the total hip position. From Table 3.7, it can be concluded that if Lamp $\mathrm{Y}$ is used, the positioning of the lamp will not affect the size of the protected area. It is remarkable that the size of the protected area for the condition without a lamp is smaller (the required reduction is $40 \mathrm{~cm}$ at all corners) than for the conditions with a lamp (Both Lamps $\mathrm{X}$ and $\mathrm{Y}$ ).

\section{Quality of the protected area.}

The assumption of normality was violated, as indicated by significant Kolmogorov-Smirnov statistics. We present nonparametric Kruskal-Wallis tests and Mann- Whitney $\mathrm{U}$ analyses to compare the effects of the type of lamp and position of the lamp on the DP at the center of the protected area (descriptive statistics are presented in Table 3.8).

A Kruskal- Wallis test showed that there was a statistically significant difference in mean DP at the center between the different types of lamps, $H(2)=176.12, p<.001$, with a mean rank score of 351.86 for no lamp, 185.81 for Lamp X, and 444.66 for Lamp Y. MannWhitney tests were used to follow up this finding.

\begin{tabular}{ccrcc}
\hline Lamp & Position & $N$ & $M$ & SD \\
\hline No lamp & n/a & 249 & 5.02 & .61 \\
X & Standard & 97 & 4.92 & .29 \\
X & Total hip & 79 & 4.19 & .93 \\
X & All & 176 & 4.59 & .75 \\
Y & Standard & 134 & 5.25 & .30 \\
Y & Total hip & 130 & 5.17 & .16 \\
Y & All & 264 & 5.21 & .24 \\
\hline Note. DP = degree of protection. & & &
\end{tabular}

Table 3.8. The mean (M) DP, with standard deviation (SD) and sample size (N), at the centre of the protected area. 
A Bonferroni correction was applied, and so all effects are reported at a significant level of .0167 (Field, 2009). We did only three comparisons, so that the significance value for the three tests is done $(.05 / 3=.0167)$. These tests found significant differences between no lamp and Lamp $X$ on the mean DP $(U=10,400.50, p<.001)$, between no lamp and Lamp $Y$ $(U=23,063.50, p<.001)$, and between Lamp $X$ and Lamp $Y(U=6,726.00, p<.001)$. Apparently, the DP at the center of the protected area is the highest with Lamp Y.

To analyze the effect of the position of the lamp, a Kruskal-Wallis test is done. A significant difference was found in DP at the center of the protected area between the different positions of the lamps, $\mathrm{H}(2)=25.24, \mathrm{p}<.001$, with a mean rank score of 351.86 for no lamp, 386.04 for standard position, and 291.47 for total hip position. MannWhitney tests were used to follow up this finding. A Bonferroni correction was applied, and so all effects are reported at a significant level of .0167. These tests found significant differences between no lamp and total hip position, for which the combined data of Lamps $\mathrm{X}$ and $\mathrm{Y}$ are used on the mean DP $(\mathrm{U}=21,366.50, \mathrm{p}<.0167)$.

A significant difference was also found between the standard position and total hip position $(U=17,606.50, p<.001)$, for which the combined data of Lamps $X$ and $Y$ are also used.

As explained above, we analyzed interactions effects (Type of Lamp x Position of the Lamp) with a two-way ANOVA. There was a significant interaction effect between the position and type of lamp on the DP at the center of the protected area, $F(1,684)=40.95$, $p<.001$. The position of the lamp affected the DP only in case of Lamp X but not in case of Lamp Y.

\section{Discussion}

The main aim of this study was to determine the effects of a skirt, different lamps, and the position of the lamp on the protected area of an OT. When considering the effect of a skirt on the size of the protected area, it can be observed that the placement of the skirt leads to a slightly smaller area. 
The differences were, however, not substantial when taking into account the step size of the measurements. In contrast to this, the DP at the center of the protected area was significantly higher for the case with the skirt. This indicates that a skirt can lead to a better protection against the intrusion of particles into the protected area. While the second finding was to be expected based on the literature, the first finding is quite surprising.

The small increase in the size of the protected area for the case without the skirt might be due to the diverging region in which the clean air of the UDF mixes with the air in the periphery. It can be envisaged that this diverging mixing region results in a decrease in the DP at the inner boundaries of the projection of the plenum (as was expected), while increasing the DP just outside of the boundaries of the projection of the plenum sufficiently to reach $\mathrm{DP} \geq 2$.

If the DP just outside of the boundaries of the projection of the plenum can indeed be raised to $D P \geq 2$, then minimizing the divergence of the mixing region (by placing a skirt) could indeed lead to a decrease in the size of the protected area.

The main DP at the center of the protected area is the highest when Lamp $\mathrm{Y}$ is used, followed by no lamp. The lowest DP at the center of the protected area is found for Lamp $X$. The result that Lamp Y, with its open shape, performs better than Lamp X, with its semiopen shape, is in agreement with the results of Zoon, van der Heijden, Loomans, and Hensen (2010). A possible explanation for this result is that when the light is directed toward the center of the table, the semi-open shape forces the air outward. This may result in an up draught of the air from the operating table, which can already be contaminated. In contrast to this, the open shape will force the air inward. The latter leads to an increase in the volume of clean air that reaches the center of the protected area, when compared to the case without a lamp or the case with a semi-open lamp. 
However, it should be noted that the standard deviation for the case without a lamp is greater than the difference between the mean DP of the case with lamp $Y$ and the mean DP of the case without a lamp.

This implies that the difference can be statistically contested. The difference in the size of the protected area when comparing the case with the lamp to the case without the lamp was even smaller than the difference between skirt and no skirt. Therefore, these results were deemed negligible and will not be discussed. The same holds for the differences when comparing the results when the position of the lamp was varied.

Considering the position of the lamps (when no distinction between the type of lamp is made), the DP at the center of the protected area was higher for the standard position compared to the total hip position. The result that the position of the lamp affects the flow field was earlier found by Chow et al. (2006). When a distinction between the different types of lamps was made, this effect was only found for Lamp X. The difference between the results for the two positions while testing Lamp $\mathrm{Y}$ is much smaller. This implies an interaction effect of the type and position of the lamp. Since it was already found that the semi-open shape affects the air quality in the protected area more severely than the open shape, the difference in the extent to which the position of the lamps affects the DP at the center of the protected area was to be expected.

However, it cannot yet be explained why the standard position leads to a higher DP in the center of the protected area. It is recommended to design additional experiments that are solely focused on the effect of the position on the protected area.

\section{Strengths and Limitations}

A strength of this study is that it is based on the entrainment/segregation test method (VCCN-RL 7). As a result, the most severe effects of environmental factors were eliminated leading to an objective comparison. It goes without saying that a clinical trial gives a more accurate representation of the real situation in the OT. 
However, due to the large sample sizes that a clinical trial requires and limited resources, a clinical trial did not belong to the possibilities. Furthermore, research on the effects of the type and position of the lamp, as well as the presence of a skirt, is still limited. The results that have been found in this study are in line with the results of the few previous studies that have been found on these subjects (Chow et al., 2006; Zoon, van der Heijden, Loomans, \& Hensen, 2010).

A limitation of this study is that if the demand on the DP of the protected area was not fulfilled at a certain measurement point, the measurement point would be shifted $10 \mathrm{~cm}$ toward the center of the projection of the plenum. This is a relatively large step since it is expected that the DP will show a sudden rise over a short distance in the region just outside of the protected area. For future research, it should be considered to apply smaller steps, in order to obtain the size of the protected area with a higher accuracy.

A second limitation is the absent of some data. For a number of corners, at specific reduction steps, only a limited number of observations was available. This possibly affected the results for the size of the protected area, since small differences in size could not be interpreted in a reliable manner. This study is, despite the absent of some data, very illustrative for the effect of different shapes of surgical lamps on the protection offered by an UDF system. Besides this, notice that a limited number of studies considered and described this effect. This certainly is an area where further research should be conducted.

\section{Conclusions}

In summary, this study showed that a skirt can have a positive effect on the DP at the center and seems to have a minor effect on the size of the protected area. It was concluded that Lamp X has a more negative effect on the DP at the center of the protected area, probably due to its semi-open shape. Finally, it has also been shown that the position of the lamp has an effect on the protected area. 
It was, however, not determined by which mechanisms the position of the lamp affects the protected area. It is recommended to conduct further research in order to better explain this result.

It was concluded that Lamp X has a more negative effect on the DP at the center of the protected area, probably due to its semi-open shape. Finally, it has also been shown that the position of the lamp has an effect on the protected area.

In the end, the entrainment/segmentation test is an appropriate method to carry out this type of study. Furthermore, the process of challenging suppliers, to provide lamps with a minimal detrimental effect on the performance of the ventilation system, has been found useful.

In the end, the entrainment/segmentation test is an appropriate method to carry out this type of study. 


\section{Implications for Practice}

- The main aim of this study was to determine the effects of a skirt, different lamps, and the position of the lamp on the protected area in the OT.

- The DP at the center of the protected area was higher for the case with the skirt. This skirt stimulates more down flow and prevents the early entry of particles into the protected area.

- It can also be concluded that Lamp Y, due to its open shape, has the most positive effect on the DP at the center.

- It has also been shown that the position of the lamp has an effect on the protected area.

- In the end, the entrainment/segmentation test is an appropriate method to carry out this type of study.

- The process of challenging suppliers, to provide lamps with a minimal detrimental effect on the performance of the ventilation system, has been found useful. 


\section{References}

Chow, T. T., Lin, Z., \& Bai, W. (2006). The integrated effect of medical lamp position and diffuser discharge velocity on ultra-clean ventilation performance in an operating theatre. Indoor and Built Environment, 15, 315-331.

Department of Health Estates and Facilities Division. (2007). Health technical memorandum 03-01: Specialised ventilation for healthcare premises- Part A: Design and validation. ISBN 978-0-11- 322805-8. Retrieved from https://www.his.org.uk/ files/4713/7907/0658/HTM_03-

01_Part_A_Specialised_Ventilation_for_Healthcare_Premises.pdf

Deutsche Norm, DIN 1946-4: 2008-12. Ventilation and air conditioning-Part 4: Ventilation in buildings and rooms of health care. Berlin, Germany: Deutsches Institut für Normung; December 2008. ICS 91.040.10; 91.140.30.

Field, A. P. (2009). Discovering statistics using SPSS (4th ed.). London, England: Sage.

Fitzner, K. (1990). Zuluftdecken für operationsräume. Heizung-Lüftung-Haustechn, 41, 319-332.

Hinds, W. C. (1999). Aerosol technology: Properties, behaviour and measurement of airborne particles (2nd ed., pp. 278-303). New York, NY: Wiley.

ÖNORM H 6020. (2007). Lüftungstechnische Anlagen für medizinisch genutzte RäumeProjektierung, Errichtung, Betrieb, Instandhaltung, technische und hygienische Kontrol len. Wien, Austria: ON Östereichisches Normungsinstitut.

Porstendörfer, J., Gebhart, J., \& Röbig, G. (1977). Effect of evaporation on the size distribution of nebulized aerosols. Journal of Aerosol Science, 8, 371-380.

Rodes, C., Smith, T., Crouse, R., \& Ramachandran, G. (1990). Measurements of the size distribution of aerosols produced by ultrasonic humidification. Aerosol Science and Technology, 13, 220-229.

Schinkel, S., van den Wildenberg, P., \& van Vugt, G. (2008). Het kwalificeren van operatiekamers conform nieuwe richtlijnen: Infectiepreventie hoogste prioriteit bij nieuwe internationale richtlijnen. RCC Koude \& Luchtbehandeling, 101, 21-29. 
Traversari, A. A. L., Goedhart, C. A., Dusseldorp, E., Bode, A., Keuning, F., Pelk, M. S., \& Vos, M. C. (2013). Laying-up of sterile instruments in the operating theatre: Equal or superior protection by using a horizontal unidirectional air flow system. Journal of Hospital Infection, 85, 125-133.

VCCN-RL-7. (2013). Methode voor testen en classificeren van operatiekamers en opdekruim- tes in rust. Netherlands: The Association of Contamination Control.

Zoon, W. A. C., van der Heijden, M. G. M., Loomans, M. G. L. C., \& Hensen, J. L. M. (2010). On the applicability of the laminar flow index when selecting surgical lighting. Building and Environment, 45, 1976-1983. 
The effect of operating lamps on the protected area of a UDF system 


\section{Chapter 4}

\section{Effect of switching off}

unidirectional downflow

systems of operating theaters

during prolonged inactivity on

the period before the

operating theater can safely be

\section{used}

Traversari AAL, Bottenheft C, van Heumen SPM, Goedhart CA, Vos MC. Effect of switching off unidirectional downflow systems of operating theaters during prolonged inactivity on the period before the operating theater can safely be used. Am J Infect Control. 2017;45(2):139-144. 


\section{Abstract}

Background: Switching off air handling systems in operating theaters during periods of prolonged inactivity (eg, nights, weekends) can produce a substantial reduction of energy expenditure. However, little evidence is available regarding the effect of switching off the air handling system during periods of prolonged inactivity on the air quality in operating theaters during operational periods. The aim of this study is to determine the amount of time needed after restarting the ventilation system to return to a stable situation, with air quality at least equal to the situation before switching off the system.

Methods: Measurements were performed in 3 operating theaters, all of them equipped with a unidirectional downflow(UDF) system. Measurements (particle counts of emitted particles with a particle size $\geq 0.5 \mu \mathrm{m}$ ) were taken during the start-up of the ventilation system to determine when prespecified degrees of protection were achieved.

Temperature readings were taken to determine when a stable temperature difference between the periphery and the protected area was reached, signifying achievement of a stable condition.

Results: After starting up the system, the protected area achieved the required degrees of protection within 20 minutes (95\% upper confidence limit). A stable temperature difference was achieved within 23 minutes (95\% upper confidence limit). Both findings lie well within the period of 25 minutes normally required for preparations before the start of surgical procedures.

Conclusions: Switching off the ventilation system during prolonged inactivity (during the night and weekend) has no negative effect on the air quality in UDF operating theaters during normal operational hours.

KeyWords:

UDF system, Recovery time, Degree of protection, Energy saving, Air quality, Operating theater, Airborne particles. 


\section{Acknowledgments}

We thank Erasmus MC, University Medical Center Rotterdam, Bergman Clinics Naarden, and Equipe Zorgbedrijven Enschede for facilitating the project by providing operation departments and facilitating staff. We also thank Lighthouse Worldwide Solutions Benelux BV for unconditionally providing measuring instruments.

\section{Introduction}

To reduce the risk of surgical site infections, treated and high efficiency particulate air (HEPA) filtered air is supplied to operating theaters. Most operating theaters in The Netherlands use unidirectional downflow(UDF) systems. In these systems, directed, treated, and HEPA-filtered air is used to create a protected area. The criteria for such an area are specified in applicable national performance requirements. ${ }^{1-4}$ The air quality in protected areas is heavily affected by the performance of the heating, ventilation, and air conditioning system. It is often assumed that switching off air ventilation systems during prolonged periods of inactivity will have a detrimental effect on air quality during operational hours (when the system is switched on). Concerns underlying this assumption are as follows: first, the entrainment of contaminants from the corridor into the operating theaters during periods of switch off of ventilation systems; and second, the possible attraction of particles and germs to potential electrostatically charged HEPA filter and synthetic air distributor surfaces during periods of switch off of ventilation systems. Therefore, responsible professionals are often reluctant to switch off ventilation systems outside of operational hours for fear of compromising patient safety. However, if these systems are switched off during prolonged periods of inactivity, calculations suggest that up to a $70 \%$ reduction in energy consumption can be achieved relative to systems operating at full capacity continuously. Dettenkofer et al ${ }^{5}$ published their research into the infection control and environmental aspects of switching off operating theater ventilation when the theater is not in use. They note that in the hospitals included in their study, ventilation in operating theaters was often reduced to between $20 \%$ and $50 \%$ of its full capacity. 
Apart from this study, little research has been done on the effect on the air quality of the ventilation system during start-up of the system after a period of shutdown. For safe use of an operating theater, it is vital that the system is fully restarted and air has regained quality before any surgical activity takes place. This means that stable conditions meeting applicable national requirements must be achieved. The BritishWorking Party of the Healthcare Infection Society ${ }^{6}$ recommends a minimum of a 15-minute interval for UDF systems that are started up after night setback. Dettenkofer et al ${ }^{5}$ mention a start-up time of 30 minutes for UDF systems after switching off the ventilation system. We evaluated these recommendations against our experimental findings and compared our findings with the time generally considered necessary to get prepared for an operation, as described by for example Collantes et al. ${ }^{7}$ This study aims to investigate whether it is safe, in terms of air quality, to shutdown the ventilation system of the operating theater during prolonged inactivity (eg, during the night and weekend).

\section{Methods}

\section{Principles}

The basis for our study is the entrainment test, described in the Deutsches Institut fur Normung 1946-4, Health Technical Memorandum 03, and Onorm. ${ }^{1-3}$ Particles are emitted outside the protected area of the operating theater (periphery). Through detection of the number of particles at designated measuring points within and outside the supposed protected area, the precise spatial area actually fulfilling the demands for adequate protection can be determined, and the exact degree of protection (DP) within this zone. In this test, the particle concentrations created in the periphery (approximately 106 particles $/ \mathrm{m}^{3}$ ) exceed by far the particle concentrations found in operating theaters during normal operational conditions. This method can therefore be considered independent from environmental factors that can have an influence on the performance of the ventilation system, such as activities in surrounding rooms, pressure differences, wind pressure on the facade, and so forth. The results of the entrainment test are the values of the DP and the size of the protected zone. 
A protected area should encompass the operating table, surgical team, and sterile instrument tables to allow for safe execution of normal operational procedures. For an area to be considered functionally protected, it must meet the following threshold values: $\mathrm{DP} \geq 2$ at the sides or corners and DP $\geq 3$ at $1.2 \mathrm{~m}$ above the floor level in the middle of the protected zone. ${ }^{8}$ The temperature in the protected area is a reliable proxy indicator for the stability of the system. A system is considered stable if a stable temperature difference is measured between the protected area and the periphery. In this study, the temperature difference to be measured is defined as $T 2-T 1$, where $T 1$ is the temperature at the corners of the protected area (Figure 4.1 ) and $T 2$ is the temperature in the periphery. The periphery is defined as the area of the operating theater outside the area covered by the protected area. The DP is the negative of the logarithm of the quotient (ratio) of the number of particles with a size $\geq 0.5 \mu \mathrm{m}$ in the protected area and in the periphery. This logarithmic value expresses the DP offered by the ventilation system against the entry of particles from the periphery. A DP of 2, for instance, means that the concentration of particles of that size in the protected area is 100 times lower than the concentration in the periphery. A DP of 0 means that the concentration of particles in the protected area is equal to the concentration in the periphery. The DP is derived according to the following formula ${ }^{1,8,9}$ :

$$
D P_{x}=\log \left(\frac{C_{x}}{C_{r e f, x}}\right) \text {, }
$$

where $\mathrm{DP}_{x}$ is the degree of protection in the clean area at position $x$ (where 1, 2, 3 and 4 stand for corner 1-4 and stands for the middle of the operating table); $C_{x}$ is the concentration of particles in the clean area at position $x$; and $C_{r e f, x}$ is the concentration of particles outside the clean area related to position $x$ (ie, background-periphery). $\mathrm{DP}_{m, x}$ is the DP in the middle of the operating table related to $C_{r e f, x} . N$ designates the number of measurements taken; and NE designates the number of experiments conducted. For measurements in which no particles were found at a given measuring point in the protected area, no DP could be determined. In these cases, a theoretical DP of 5 was assigned, representing a 105-fold reduction in particle counts. 


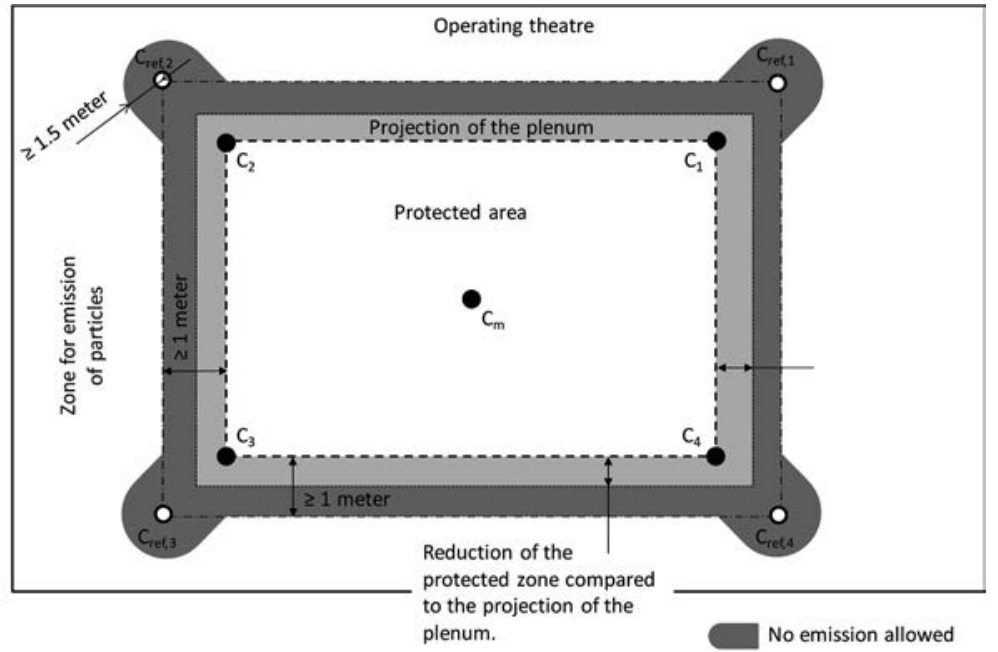

Figure 4.1. Layout of the measuring points, position of the emission, and protected area. $C_{1}=$ particle concentration in the clean area of corner $1 ; C_{2}=$ particle concentration in the clean area of corner 2; $C_{3}=$ particle concentration in the clean area of corner $3 ; C_{4}=$ particle concentration in the clean area of corner $4 ; C_{m}=$ particle concentration in the clean area in the middle of the operating table; $C_{\text {ref, } 1}$ particle concentration outside the clean area of corner $1 ; C_{\text {ref,2 }}$ particle concentration outside the clean area of corner 2; $C_{\text {ref, } 3}$ particle concentration outside the clean area of corner 3; $C_{\text {ref, } 4}$ particle concentration outside the clean area of corner 4.

\begin{tabular}{lccc}
\hline & Theater A & Theater B & Theater C \\
\hline Size plenum $(\mathrm{m})$ & $2.85 \times 2.85$ & $2.88 \times 2.88$ & $1.47 \times 2.40$ \\
Size plenum $\left(\mathrm{m}^{2}\right)$ & 8.12 & 8.29 & 3.51 \\
Size operating theater $\left(\mathrm{m}^{2}\right)$ & 45.6 & 39.9 & 37.4 \\
Average air velocity $(\mathrm{m} / \mathrm{s})^{*}$ & 0.25 & 0.28 & 0.25 \\
Height of the plenum $(\mathrm{m}){ }^{* *}$ & 3.00 & 3.00 & 2.96 \\
Date of construction & 2010 & 2012 & 1993 \\
Use of skirt or canopy around the plenum & No & No & No \\
Recovery time periphery, 95\% upper confidence & $7.65 / 12$ & $9.89 / 12$ & $12.43 / 6$ \\
limit (min)/no. of experiments & & & $9.30 / 6$ \\
Recovery time in the middle of the operating table, & $7.43 / 12$ & $6.81 / 12$ & \\
95\% upper confidence limit (min)/no. of & & & \\
experiments & & & \\
\hline${ }^{*}$ Outlet velocity plenum \\
${ }^{* *}$ Height from floor to the air outlet of the plenum
\end{tabular}

Table 4.1. Characteristics of the three operating theatres. 
The recovery time of an operating theater is defined as the time needed to lower by a factor of 100 the detected number of particles with a size $\geq 0.5 \mu \mathrm{m}$. It is a reliable proxy indicator for the performance of the system (ventilation efficiency and amount of clean supplied air). The recovery time is determined for an operating theater in a rest state: fully equipped and with systems switched on, but with no human presence.

\section{Systems}

This study was conducted from April-August 2014 in 3 different operating theaters in The Netherlands, designated theaters A, B, and C. Table 4.1 lists relevant characteristics of the 3 operating theaters. The measurements were carried out in time slots when no surgical activity was planned.

\section{Experiments}

Airborne particles were measured using 9 particle counters: 4 in the periphery area and 5 in the protected area. Of the latter, 4 were placed in the corners of the protected area and 1 in the middle of the table. The counters measured the number of particles continuously, and data were generated every minute. The experiment consisted of 4 phases. Phases 2-4 were repeated at least 8 times for each operating theater to collect data.

For operating theater $A$ these phases were repeated 14 times, for operating theater $B$ they were repeated 10 times, and for operating theater $C$ they were repeated a total of 8 times. For each operating theater, these experiments were conducted over a period of several days. The experiment was divided into 4 distinct phases. Phase 1 was the baseline measurement (system and emission on), phase 2 was the off period (system and emission off), phase 3 was the start-up period (system and emission on), and phase 4 was the measure of DPx and temperature differences (system and emission on). After phase 4 of each iteration of the experiment, particle emission was switched off and the ventilation systems were switched back on to allow the operating theater to return to normal operational conditions as previously described under recovery time, relative to the number of particles detected at the end of phase 4 . 
The recovery process was monitored, and recovery times were established for both the protected area and the periphery, using the measurement setup in place. The recovery times established for the 3 operating theaters as a proxy for general system performance are listed in Table 4.1.

\section{Setup}

The experimental setup was determined according to the entrainment test methodology. For all experiments in all 3 theaters, the operating table was located in the central position. The height of the work surface of the operating table varied between 0.8 and 1.2 $\mathrm{m}$. No instrument tables were present during the experiments. The operating lamps, 2 in all cases, were positioned in standard position according to the entrainment test methodology, as described in Deutsches Institut fur Normung 1946-4. ${ }^{1}$ Heat loadgenerating equipment normally used during surgery was present and in the normal position.

To determine the maximum theoretical size of the protected area, the size of the plenum was projected onto the floor of the operating theater. To determine the actual area satisfying the protection requirement ( $D P \geq 2.0$ at every corner of the protected area), the measuring points were moved inward from starting positions on the edge of the plenum projection toward the center in discrete steps perpendicular to the sides of the plenum projection.

Ten-centimeter steps were used for measurements in operating theaters $A$ and $C$. For measurements in operating theater B, 5-cm steps were used. The position of the measurement points for the determination of the protective area was defined as follows (Fig 1): 1. All measurement (counters 1-9) points were located $1.2 \mathrm{~m}$ above floor level. 2. One measurement point $\left(C_{m}\right)$ was located in the middle of the protected area. 3. Four measurement positions $\left(C_{1}, C_{2}, C_{3}\right.$, and $\left.C_{4}\right)$ were located at the furthest sides of the protected area. 4 . The measurement points in the periphery $\left(\mathrm{C}_{\mathrm{ref}, 1,}, \mathrm{C}_{\mathrm{ref}, 2,} \mathrm{C}_{\mathrm{ref}, 3}\right.$ and $\left.\mathrm{C}_{\mathrm{ref}, 4}\right)$ were located at least $1 \mathrm{~m}$ away from their nearest measurement point inside the protected area. This was done to avoid the risk of positioning the particle counters in a possible transitional zone between periphery and protected area rather than in the 
periphery proper. A high background particle concentration in the theater was created by emitting particles in the theater through vaporization of tap water with an ultrasonic fogger (Lighthouse Volcano V622; Lighthouse Worldwide Solutions, Fremont, CA). ${ }^{8-11}$ The particles in this study were emitted at a height of $1.5 \mathrm{~m}$ (average neck height for staff). ${ }^{8}$ Two types of particle counters (Lighthouse 3013 and Lighthouse 3016-IAQ; Lighthouse Worldwide Solutions) were used in the experiments. Measurements were continuous; data readouts were generated every minute. These data readouts comprised both cumulative and differential particle count data and temperature data. The data generated by the particle counters were collected and displayed on-screen with the Lighthouse Monitoring System (Lighthouse Worldwide Solutions).

\section{Measurements phase 1: Baseline measurement (system and emission on)}

As the first step in this phase, the actual size of the protected area was determined. Once the size of the actual protected area was determined, the position of the measuring points was fixed for measurements in the other phases.

The average $D P_{x ; 95}$ for the pair of measurement counters in each corner $\left(C_{1}-C_{r e f, 1}, C_{2}-C_{r e f, 2}\right.$, $\mathrm{C}_{3}-\mathrm{C}_{\text {ref,3, }}$, and $\mathrm{C}_{4}-\mathrm{C}_{\text {ref, } 4}$ ) was calculated using the following formula:

$$
\left(D P_{x ; 95} \text { or } D P_{m ; x ; 95}=D P_{x}-\left[t_{95} \cdot \frac{S D}{\sqrt{n}}\right]\right),
$$

Where $\mathrm{DP}_{\mathrm{x}}$ is the average DP at measuring location $x, t_{95}$ is the $t$ distribution for the $95 \%$ lower confidence limit, SD is the standard deviation, and $n$ is the number of measurements.

\section{Measurements phase 2: Off period (system and emission off)}

After phase 1 was finalized, the ventilation system was turned off and the emission of particles was simultaneously stopped. 
The concentration of particles across the operating theater became more or less homogeneous and decreased slowly toward a stable situation, defined as a constant concentration of particles measured over a period of at least 30 minutes. This decrease of airborne particle concentration is caused by sedimentation of larger particles ( $\geq 4.5 \mu \mathrm{m}$ ). Previous research has shown that smaller particles $(<4.5 \mu \mathrm{m})$ remain completely airborne. ${ }^{12}$ Once the concentration of particles in the operating theater was determined to be stable, the next phase was initiated. The average off period of the ventilation system was approximately 4 hours (range, 1-16 hours). The duration of this off period during the experiments could be reduced and be shorter than a night or weekend because we emitted a large number of particles during the start-up period of the system (phase 3). This way the contamination of the operating room during the off period was simulated and much higher than in practice.

\section{Measurements phase 3: Start-up period (system and emission on)}

In this phase, particles were emitted into the operating theater. Once the particle concentration measured at the corners and at the middle of the table reached the threshold value, $\mathrm{C} 0$ and $\mathrm{Cmiddle} 0 \geq 106$ particles $/ \mathrm{m}^{3}$ of $0.5 \mu \mathrm{m}$, the air treatment system was started up.

\section{Measurements phase 4: Measure DP and temperature difference (system and emission on)}

In this phase, particle count measurements were conducted at every corner of the protected area $\left(\mathrm{C}_{1}-\mathrm{C}_{4}\right)$, in the background $\left(\mathrm{C}_{\mathrm{ref}, 1-}-\mathrm{C}_{\mathrm{ref}, 4}\right)$, and at the middle of the table $\left(\mathrm{C}_{\mathrm{m}}\right)$.

The objective of these measurements was to determine the temporal interval between start-up of the system and the conditions $D P_{x} \geq 2$ and $D P_{m, x} \geq 3$ prevailing for $\geq 10$ minutes. Also, the time required to achieve a stable temperature difference $(T 2-T 1) \geq 0.5^{\circ} \mathrm{C}$ was determined. 
To calculate whether the criteria were met, the following formula was used:

IF(average $\left.\left[X_{1}-X_{10}\right]-t_{95} \times \mathrm{SD}\left[X_{1}-X_{10}\right] / S Q R T[10]\right) \geq$ criteria; $1 ; 0[\mathrm{SD}=$ standard deviation; SQRT = square root, $\mathrm{X}_{1}-\mathrm{X}_{10}=$ values for $D P_{\mathrm{x}}$ and $\left(\mathrm{T}_{2}-\mathrm{T}_{1}\right)$ over a period of 10 minutes]), where $t_{95}=1.833(t$ distribution $) .{ }^{13}$

In some of the experiments the threshold value of $D P \geq 2$ was not reached even when the measurement area was reduced to the lower size limit set for the dimensions of the protected area, namely the dimensions of the operating table itself. When this occurred, the DP value established at the edge of the minimum protected area was used as the starting point for establishing stability.

\section{Operating theater recovery after the experiment}

After phase 4 of each experiment, the operating theater was allowed to recover to normal operational conditions. Ventilation systems were kept on, and the emission of particles was stopped. Recovery (defined as a 100-fold reduction in particle concentration) was monitored in the periphery and in the protected area to determine recovery times for both areas. Determination of the recovery time ${ }^{14}$ was done using a semilog graph, with the concentration of particles on the $y$ axis (with a logarithmic scale) and time in minutes on the $x$ axis. The recovery time was determined within the time period in which the decrease in the particle concentration was described by an exponential line.

The recovery time was determined with the following formula:

$t_{0,01}=\left(t_{n}-t_{100 n}\right)$ (minutes)

where $t_{n}$ and $t_{100 n}$ are the times where the concentration at $t_{100 n}$ is 100 times bigger than at $t_{n}$. The mean recovery time plus the maximum $95 \%$ confidence interval of the 4 counters was calculated. 


\section{Results}

\section{Baseline measurement: Reduction of the protected area and DP}

We found that the distance between the theoretical (plenum projection) protected area and its empirically determined size was $40 \mathrm{~cm}$ in all corners for theater A, 30-40 cm for theater $B$, and $40-60 \mathrm{~cm}$ for theater $C$. The final positions of the counters were based on satisfaction of either of 2 criteria: (1) DP $\geq 2.0$ established during the baseline measurements; or (2) minimum conceivable protected area reached, defined as the dimensions of the operating table. The counter position was determined on the basis of the criterion satisfied first. In all 3 operating theaters, at 1 of the 4 corners, the minimum conceivable protected area criterion was achieved first, hence without DP $\geq 2.0$ being achieved.

\section{Outcome 1: Measure DP}

Table 4.2 shows the average start-up time in minutes needed for the protected area to reach the criteria of the baseline measurement. The empty fields demonstrate that some of the measurements did not find a continuous period of 10 minutes in which the DP equaled or exceeded the criteria. On average it took between 11 and 17 minutes to meet the criteria of the baseline measurement. For corners 3 and 4 in theater $B$, the measurements did not reach the DP criteria for the DP within the time frame allotted for the experiment. The number of experiments for corner 4 in theater A was 4. 


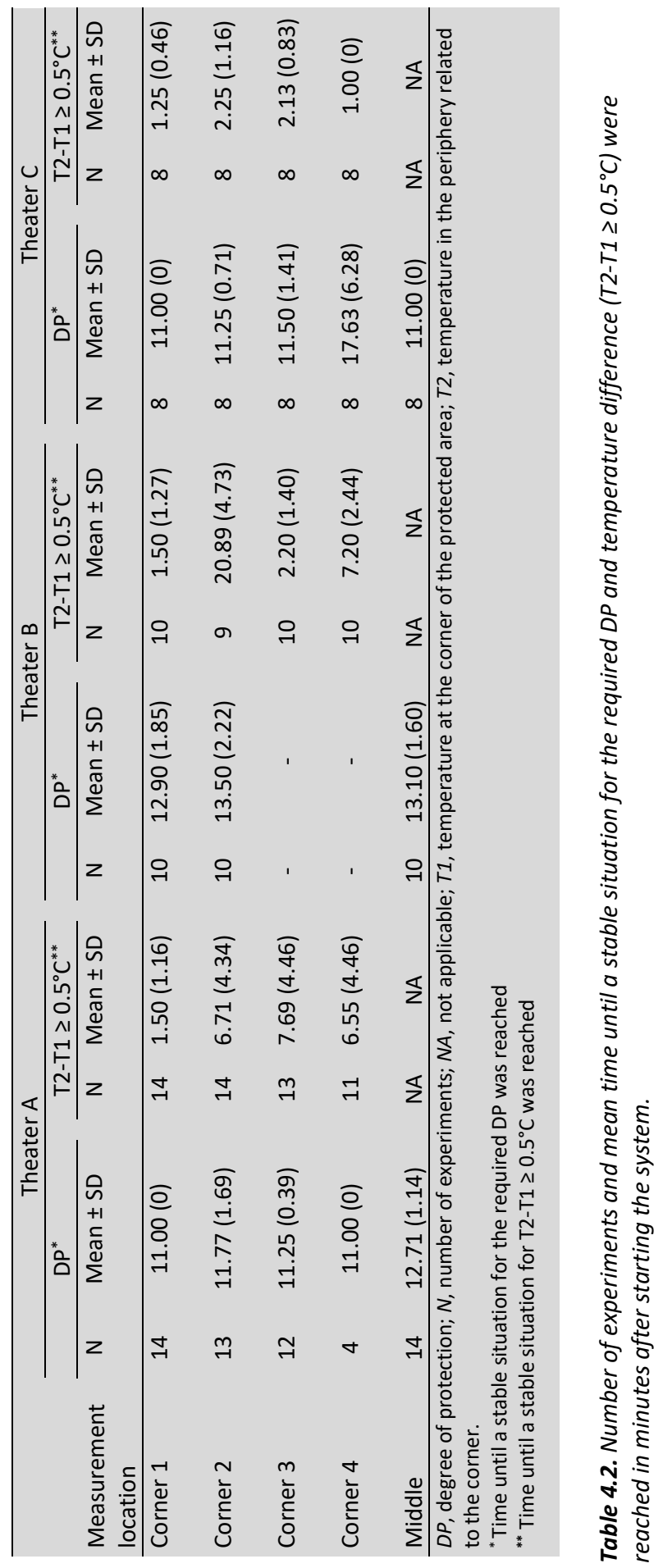




\section{Outcome 2: Temperature difference}

Table 4.2 shows measurement outcomes generated in phase 4 for the time required for a stable temperature gradient $\geq 0.5^{\circ} \mathrm{C}$ to be achieved. The difference in the number of experiments $(N E)$ indicates that during some experiments the defined minimum criteria for the temperature difference were not reached. As shown in Table 4.2, in successful experiments, the time required to reach the target conditions varied between 1 and 21 minutes. Based on the SD, the number of experiments, and the $t$ distribution, the $95 \%$ upper confidence limit was determined. For operating theater $A$, the $95 \%$ upper confidence limit was 13 minutes, for operating theater B it was 23 minutes, and for operating theater $\mathrm{C}$ it was 20 minutes.

\section{Discussion}

This study has shown that, in all cases where the ventilation system of the operating theater was shut down during the night and weekend, a safe situation regarding the air quality was reached well within 30 minutes after starting up the system, the recommended safety margin before surgical activity commences. ${ }^{3}$ When combining the 2 outcomes of this study (stable situation for the DP and temperature difference), we see that stable conditions equal or superior to the baseline conditions are reached within 23 minutes (95\% upper confidence limit) in all 3 operating theaters. The study design used also covers the possibility of the operating theater not being completely airtight, and the possible absence of a (sufficient) pressure difference (air flow from the operation room to the adjacent room or corridor).

Both adverse conditions were simulated through the release of a very much larger number of particles in the operating theater than under normal conditions. Experimental results showed that even under those circumstances, modern UDF ventilation systems will provide a clean and stable environment within 23 minutes (95\% upper confidence limit) after starting the system. Experience in trauma theaters shows that it took a mean of 25 minutes $^{7}$ (transit time, including time between arrival in the room and induction) to organize all of the preparations for an operation. 
Therefore, starting the ventilation system when a patient is announced will give ample time to start the system and reach stable operating conditions equal to the baseline conditions, as long as the doors of the operating theater remain closed during this start-up period and the preparation can take place outside the operating theater. Preparation for a surgery include the setup of the instrument table, which should be done under sterile conditions $\mathrm{s}^{15}$ and therefore under a stable UDF system. If a separate room for setting up the instrument table is provided, with a UDF system that can be used immediately (eg, UDF system running $24 \mathrm{~h} / \mathrm{d}, 7 \mathrm{~d} / \mathrm{wk}$ ), the setup of the instrument table can take place concurrently with the ventilation system start-up in the operating theater. If instrument table setup takes place in the operating theater, the time required for this should be added to the 25- minute lead time.

\section{Limitations}

We recognize a number of limitations of this study. One limitation is the determination of the baseline measurement: in some of the experiments the minimum criteria for the baseline measurement ( $D P \geq 2.0$ ) were not achieved. Another limitation concerns the difficulty to determine the exact spatial position where the requirements ( $D P \geq 2.0$ ) were met from the graphs produced on the screen of the laptop computer used for the measurements. Future studies in this field may wish to opt for online calculation of performance against performance criteria, or to measure the DP for every possible step of protected area reduction $(10,20,30,40,50$, and $60 \mathrm{~cm})$ to standardize measurements taken across the different measuring points. We did not study the effect of switching off the ventilation system on the air tightness and functional life span of the seals of the HEPA end filter and system.

Because the study limited itself to 3 operating theaters, all equipped with the same type of air treatment system, the results cannot be reliably extrapolated to other operating theaters using a different type of air treatment system. Furthermore, because the operating theaters were quite similar in size and layout, it cannot be assumed that the results can be generalized to other operating theaters using UDF systems if these operating theaters are of substantially different size or design. 
The method outlined in this article does lend itself to performance measurement in other operating theaters because it is independent of the background particle concentration and measures DP and system stability, rather than the absolute, system-specific performance level. Finally, the study did not look into contamination of the surfaces in the operating theater.

\section{Implications for hospital management}

When the air tightness of the operating theater is poor and because of the absence of a pressure difference (air between the operating theater and the adjacent room or corridor), air from the surrounding area can enter the theater during the shut-off period. On the basis of the outcomes of our study, this does not seem to have an influence on the length of start-up period. However, this and should be prevented. Therefore, the doors of the theater should be kept closed (if possible automatically) during the period the system is off; therefore, entrance of air to the room is minimized and backflow through the system is prevented. The finding is that it is safe to shut down the ventilation system during prolonged inactivity. In this study the off period had an average of approximately 4 hours (range, 1-16 hours). These results are also valid for a longer period of a switched off system because we emitted a large number of particles during the start-up period of the system; therefore, the potential contamination of the operating room during the off period is less relevant. Switching off the system during the night and weekend can result in energy saving, up to $70 \%$ of energy consumption (ventilation, cooling, heating, and humidification) compared with systems that function on full capacity continuously, and therefore costs saving. This estimate is based on calculations made using the assumption that the normal operational hours are $10 \mathrm{~h} / \mathrm{d}, 5 \mathrm{~d} / \mathrm{wk}(2,607 \mathrm{~h} / \mathrm{y})$ and the relation between reduction of the amount of ventilation air and the reduction in total energy consumption is linear. Compared with systems with night set back (reduction to $20 \%$ of the normal ventilation flow rate) it is estimated that a reduction of $14 \%$ of the energy consumption is feasible by switching off the system completely. One should consider the change on emerging situations in which an operation theater is rapidly needed. 
In this situation, switching off part of the ventilation systems during the night period and over the weekend would be safe and still lead to substantial energy savings. With the ventilation system switched off, the internal load of the medical equipment in the operating theater can drive up air temperature in the operating theater. To prevent this, all medical requirements should be switched off when the ventilation system is not running. This will also result in additional energy savings. Our study methodologic differs at some points from the earlier study from Dettenkofer et al. ${ }^{5}$ In our study we used 9 particle counters; therefore, the total area, including the position of the instrument tables, was covered instead of one particle counter in the middle of the protected area and one in the periphery. We also assessed the air quality in the protected area relative to the air quality in the rest of the operating theater, instead of on the basis of an absolute particle count. This was done with emission of particles (contamination source) instead of a situation without a source of particles. This results in a better understanding of the performance of the ventilation system. In our study we did not use microbiologic measurements. Despite these differences, there is a good similarity in the results. Dettenkofer stated that after 20 minutes, the 95\% prediction interval was below the limit. He concluded that normal ventilation can be reestablished by restarting the system with a safety margin of at least 30 minutes before surgical activity commences. With this study, we demonstrated that it safe to shut down the ventilation system of the operation theater during periods of prolonged inactivity (eg, nights, weekends) as long as the system is switched on 30 minutes before starting the program again. Further studies are needed to establish the generalizability of our findings to different systems and situations and the effect of switching off ventilation systems on the sedimentation of particles, including microorganisms on surfaces. 


\section{References}

1. Deutsche Norm. DIN 1946-4: 2008-12. Ventilation and air conditioning-part 4: ventilation in buildings and rooms of health care. Berlin, Germany: Deutsches Institut fur Normung; 2008. ICS 91. 040.10; 91.140.30.

2. Department of Health Estates and Facilities Division. Health Technical Memorandum 03-01: specialised ventilation for healthcare premises-part A: design and validation. 2007.

3. Onorm H. 6020: Ventilation systems formedically used rooms- Project planning, construction, operation, maintenance, technical and hygienic Controls. Vienna, Austria: Austrian Standards; 2007.

4. Guideline SWKI 99-3: Heating, ventilation and air conditioning systems in hospital buildings (planning, construction, operation). Schonbuhl, Switzerland: Swiss Society of Building Technology Engineers; 2003.

5. Dettenkofer M, Scherrer M, Hock V, Glaser H, Schwarzer G, Zentner J, et al. Shutting down operating theatre ventilation when the theatre is not in use: infection control and environmental aspects. Infect Control Hosp Epidemiol 2003;24:596-600.

6. Hoffman PN, Williams J, Stacey A, Bennett AM, Ridgway GL, Dobson C, et al. Microbiological commissioning and monitoring of operating theatre suites. J Hosp Infect 2002;52:1-28.

7. Collantes E, Mauffrey C, Lewis C, Brewster M. A review of 1241 trauma cases: a study of efficiency in trauma theatres. Injury 2008;39:742-7 8.

8. Traversari AAL, Goedhart CA, Dusseldorp E, Bode A, Keuning F, Pelk MSJ, et al..Layingup of sterile instruments in the operating theatre: equal or superior protection by using a horizontal unidirectional air flow system. J Hosp Infect 2013;85:125-33.

9. Porstendorfer J, Gebhart J, Robig G. Effect of evaporation on the size distribution of nebulized aerosols. J Aerosol Sci 1977;8:371-80.

10. Rodes C, Smith T, Crouse R, Ramachandran G. Measurements of the size distribution of aerosols produced by ultrasonic humidification. Aerosol Sci Technol 1990;13:220-9. 
11. HindsWC. Aerosol technology: properties, behavior and measurement of airborne particles. 2nd ed. New York (NY): Wiley; 1999:278-303.

12. Murakami S, Kato S, Nagano S, Tanaka Y. Diffusion characteristics of airborne particles with gravitational settling in a convection dominant indoor flow field. Ashrae, Transactions, Vol 98, Part 1, 1992.

13. Field AP. Discovering statistics using SPSS. London, England: SAGE; 2009. 14. International Organization for Standardization. ISO 14644-3: Cleanrooms and associated controlled environments -Part 3: test methods. Geneve: International Organization for Standardization; 2005.

14. Chosky SA, Modha D, Taylor GJ. Optimisation of ultraclean air: the role of instrument preparation. J Bone Joint Surg Br 1996;78:835-7. 


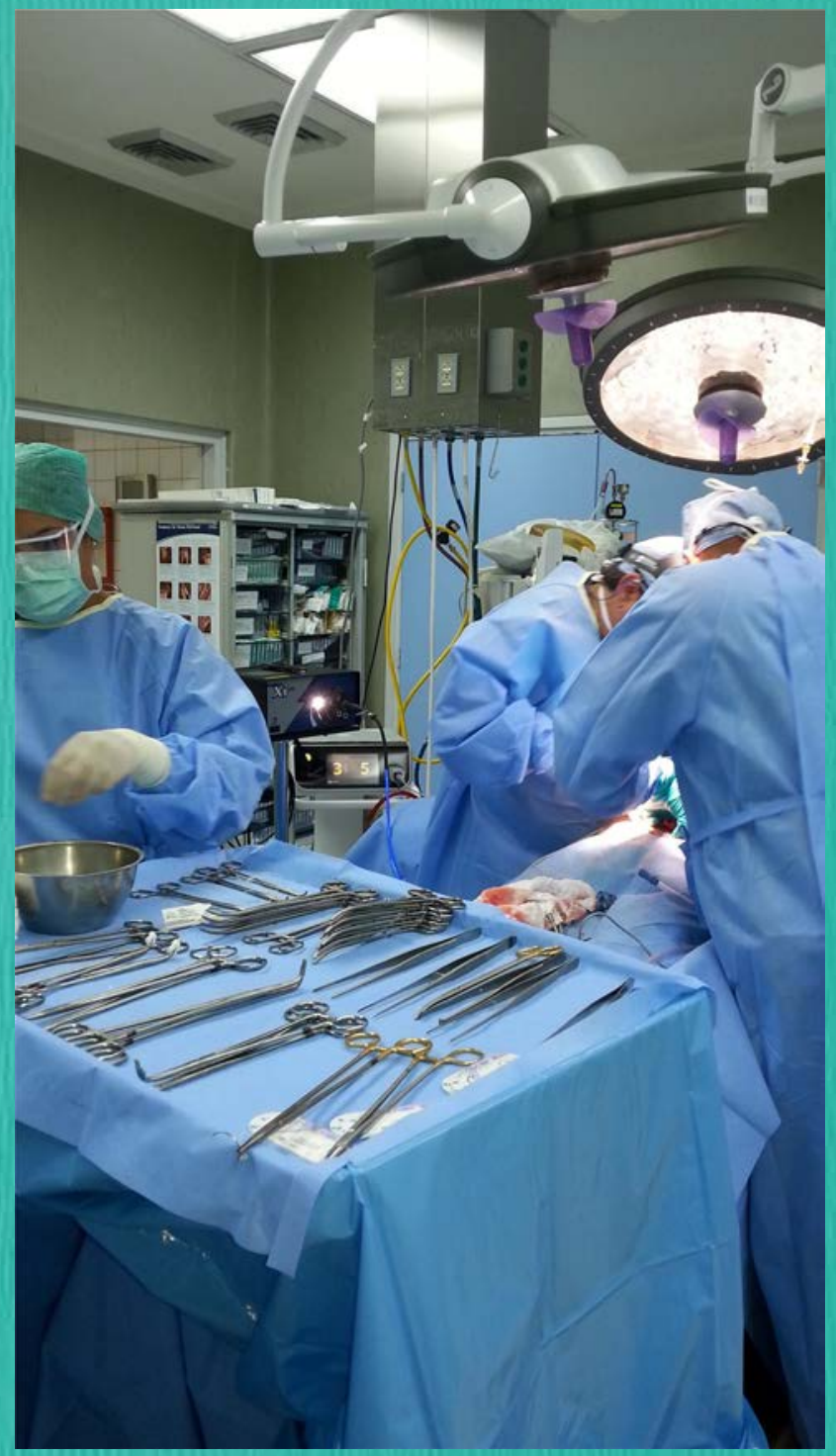




\section{Chapter 5}

\section{Laying-up of sterile}

instruments in the operating

theatre: equal or superior

protection by using a

\section{horizontal unidirectional air}

\section{flow system}

Traversari AAL, Goedhart CA, Dusseldorp E, et al. Laying-up of sterile instruments in the operating theatre: Equal or superior protection by using a horizontal unidirectional air flow system. J Hosp Infect. 2013;85(2):125-133. 


\section{Summary}

Background: A system for the preparation of sterilized instruments with unidirectional horizontal air flow (UDHF) has several advantages over a unidirectional down flow system (UDDF). The advantages are based on the installation of the system being more flexible and easier to use, no cooling of the air flow being necessary and less air being needed for circulation, resulting in reduced energy use.

Objectives: The objective of this study was to determine whether a system with UDHF performs equal or superior to a system with UDDF in terms of prevention of contamination of the air (the presence of particles and micro-organisms) during the laying-up process.

Methods: The degree of protection (DP) offered by two UDHF system variants and two UDDF system variants was determined for several static set-ups and a dynamic simulation of the process. In addition to determining the level of protection for several categories of particle size, colony-forming units (CFU) were also measured during process simulations. Findings: When maximum protection (no particles present) is considered, the UDHF systems performed significantly better than the UDDF systems for particles $\geq 2.5 \mu \mathrm{m}$. When particles were present, there was no significant difference between systems for particles $\geq 0.3$ and $\geq 0.5 \mathrm{~mm}$. However, the performance of the UDHF system was superior to that of the UDDF system (DP) for particles $\geq 1.0 \mathrm{~mm}$ representing the bacteria-carrying particles. During the process measurements, no CFU were found with the UDDF system in $64 \%$ of the measurements, compared with $90 \%$ for the UDHF system $(P=0.012)$. Conclusions: The UDHF system offers equal or superior protection to the UDDF system against contamination of the clean area within which the laying up takes place. Despite our finding that the differences did not always reach statistical significance (due to low background concentrations), there is a clear trend, from the small-sized particles ( $\geq 1.0$ $\mu \mathrm{m})$ up to the largest sizes considered, including bacteria-carrying particles, that demonstrates the superiority of the horizontal flow system. The UDHF system offers a more robust solution than the UDDF system, provided that good work instructions are given and the height of the table and height of the plenum are properly adjusted. 


\section{Keywords:}

Air quality, Contamination, Laying-up process, Operation theatre, Unidirectional flow system.

\section{Acknowledgements:}

We thank the scrub nurses and staff of the operating department of Erasmus Medical Center who participated in this project. In addition, we thank the Erasmus MC, University Medical Center Rotterdam for facilitating the project by providing a room for the experiments, and Telstar Medical Components for providing the systems.

Conflict of interest statement None declared.

\section{Funding source:}

The Dutch Ministry of Health, Welfare and Sport for funding the research performed by TNO Dutch Centre for Health Assets (TNO DUCHA).

\section{Introduction}

Laying-up of sterile instruments in the operating theatre is an important quality process and should keep instruments sterile to be used for the procedure. There is an unresolved and ongoing debate as to which air treatment systems create the best conditions for this process. In The Netherlands, laying-up of sterile instruments is increasingly done in a separate and dedicated preparation room with a special ventilation system to provide an ultraclean environment for the lay-up process in order to reduce the number of surgical side infections as much as possible. These rooms are attached to an operation room or more centrally located in the operating department. Newly built lay-up systems in The Netherlands almost exclusively use unidirectional down flow systems (UDDF systems), similar to the systems used in operating rooms. However, a system with horizontal flow [unidirectional horizontal flow system (UDHF system)] would seem to offer advantages from a hygiene point of view. 
In the case of a down flow system, the person doing the lay-up is (partially) located within the down flow. In the case of emission of particles by this person (the so-called spraying from the neck opening of the clothing), these particles e possibly contaminated with micro-organisms e are carried to the laying-up table by the down flow, creating a risk of contamination of the instruments. By contrast, in a system with a UDHF the falling particles are carried away from the instrument table, as long as the particles are not too heavy and the air flow is strong enough.

From an installation point of view, a UDHF system also has advantages for both new build and renovation of operating rooms. The advantages of a UDHF system compared with a UDDF system are three-fold. First, the system is simpler because it requires no cooling (energy conservation and cost reduction). Because of this, it is easier to install and may even be mobile. Second, less air is needed to protect the same number of instrument tables (energy conservation). Third, the system set-up results in a less ambiguous process because of the location of sterile material between the air coming from the UDHF and the scrub nurse. Hoffman et al. pointed out that the air change rate in preparation rooms used for laying up sterile instruments should be around 37 air changes per hour e a greater air change rate than in theatres. ${ }^{1,2}$

Until now, it has not been clear whether the performance in terms of air quality achieved in the laying-up zone of a UDHF system equals or exceeds that of a UDDF system during the laying-up of instruments in a separate preparation room.

The objective of this experimental comparative study is to answer the following research question: What is the difference in contamination (presence of particles and microorganisms) of the clean area within which laying up takes place when a UDHF system is used versus when a UDDF system is used? 


\section{Methods}

\section{Principles}

By emitting particles in the lay-up area and evaluating whether these particles land on the instrument table, it may be determined whether there is a risk of contamination and whether the system offers protection from these environmental conditions. If the number of particles found is the same or less with a UDHF system as with a UDDF system, we conclude that it gives at least the same level of protection against airborne contamination as the UDDF system.

Because it is impossible to maintain the background concentration of particles ( $C_{\text {ref, }}$ see below) at exactly the same level for both systems, we chose to make use of the degree of protection (DP) concept described in DIN 1946, part 4, annex C. ${ }^{3}$ The DP is derived according to the following formula?:

$$
D P_{x}=-\log \left(\frac{C_{x}}{C_{r e f}}\right)
$$

$\mathrm{DP}_{\mathrm{x}}=$ degree of protection in the 'clean' area $\mathrm{x}$

$C_{x}=$ concentration of particles in the 'clean' area $x$

$C_{\text {ref }}=$ concentration of particles outside the 'clean' area, i.e. the background

The DP in our analysis was limited to a factor of 7 (i.e. a 107- fold reduction in counts) for the situation in which no particles were found at a given measuring point $(x)$.

A range of particle sizes was used including the range of particles containing bacteria. ${ }^{4}$ The sizes were divided into six categories $(\mathrm{mm}): \geq 0.30, \geq 0.50, \geq 1.0, \geq 2.5, \geq 5.0$ and $\geq 10.0$. 


\section{Systems}

The two systems (UDHF and UDDF) were subjected to the same experimental procedures. The experiments with the UDHF system were carried out with a nominal air velocity of $0.45 \mathrm{~m} / \mathrm{s}$ (UDHF) and a lowered air velocity: 'low flow' (UDHF_LF: $0.3 \mathrm{~m} / \mathrm{s}$ ).

The experiments with the UDDF system were carried out at an air velocity of $0.3 \mathrm{~m} / \mathrm{s}$ with air cooling (UDDF) and without air cooling: 'no cooling' (UDDF_NC). The temperature of the cooled air was roughly $2 \mathrm{e} 3 \mathrm{~K}$ lower than the ambient temperature. The systems were installed and tested in the same room, one after the other, so that the environmental factors during the experiments (air flow, temperature, number of people present, etc.) were as similar as possible.

\section{Experiments}

Particles were emitted into the room so that the background concentration $\left(\mathrm{C}_{\mathrm{ref}}\right)$ in the room was kept at a relatively high level. The particle concentration in the background was created by the vaporization of tap water with an ultrasonic fogger (Lighthouse Volcano P6). The small (2-4 $\mu \mathrm{m})$ water droplets emitted by the machine vaporize very fast (a few seconds) and the mineral residues from the evaporated tap water remain as solid particles airborne in the air flow in the room..$^{5-7}$ Two emission positions $A$ and $B$ were used one at a time (Figure 5.1).

The particles in this study were emitted at a height of $1.5 \mathrm{~m}$ (average neck height). Airborne particles were measured using three particle counters (Lighthouse 3016-IAQ, Fremont, CA, USA).

\section{Set-up}

The experimental set-up used was placed in a general purpose room with no special air ventilation in the hospital.

The UDHF and UDDF systems were supplied with air by two ventilator boxes connected to the plenum with tubes. The plenum was supplied with air using two filter boxes fitted with high efficiency particulate air (HEPA) grade 14 (H 14) filters. ${ }^{8}$ 
A homogeneous air velocity over the outlet surface of the plenum was created by fitting the plenum chambers with an air distributor consisting of two layers of air distribution cloth that were $\sim 1 \mathrm{~cm}$ apart.

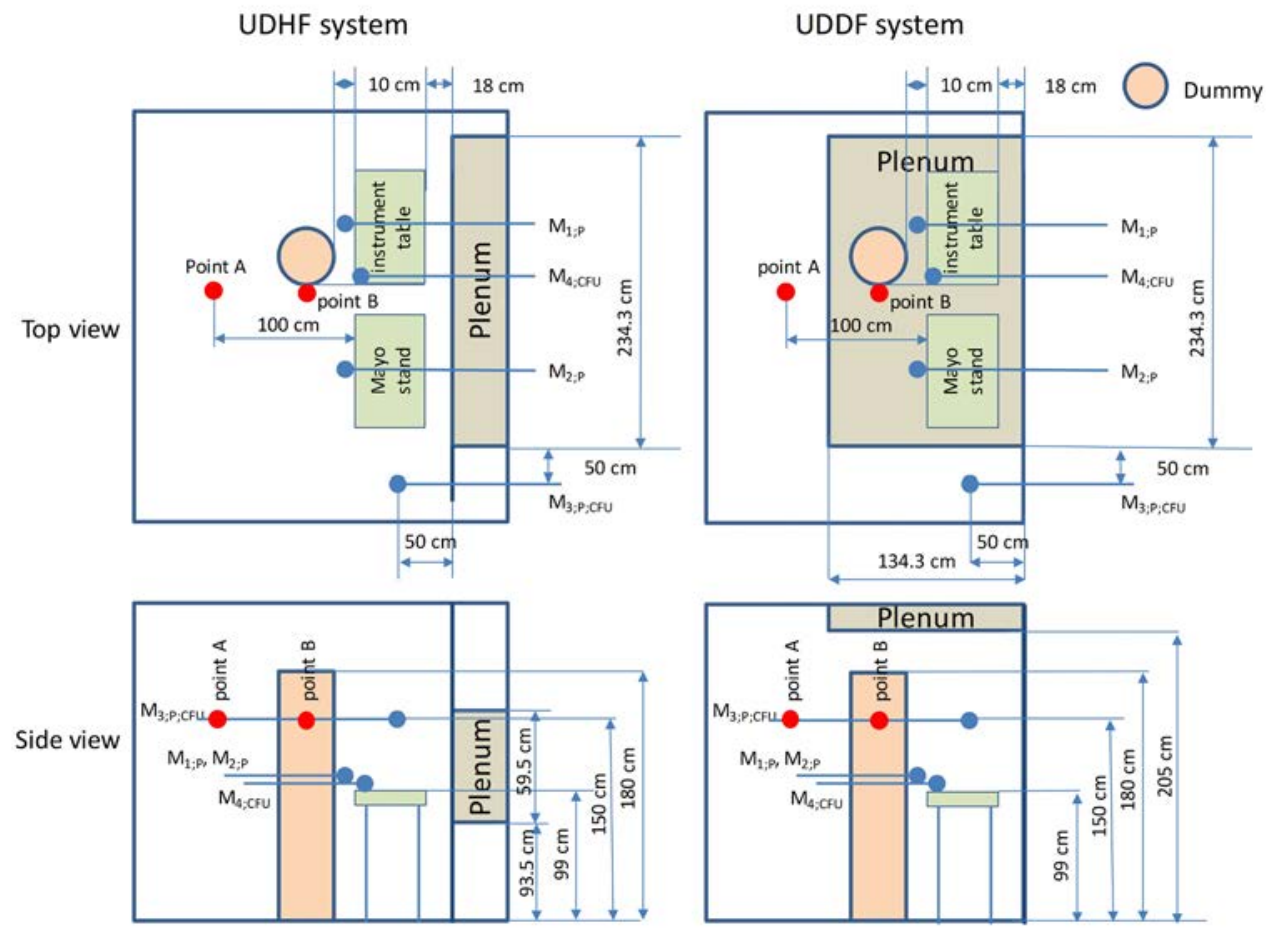

Figure 5.1. Layout of the set-up, unidirectional horizontal air flow (UDHF) and unidirectional down flow (UDDF) system. Point $A$, emission particle position $A ;$ point $B$, emission particles position $B ; M_{1 ; P}$, measuring point 1, particles; $M_{2 ; p}$, measuring point 2; particles; $M_{3 ; ; ; C F U}$, measuring point 3, particles and CFU; M4;FU, measuring point 4, CFU; Dummy, $120 \mathrm{~W}$.

\section{Particle measurement}

Airborne particles were measured on the instrument table $\left(M_{2, P}\right)$, the Mayo stand $(M 1, P)$,

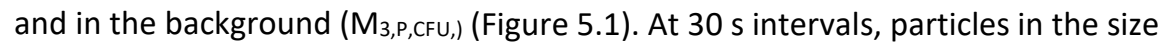
categories $(\mathrm{mg})$ of $\geq 0.3, \geq 0.5, \geq 1.0, \geq 2.5, \geq 5.0$, and $\geq 10.0$ were read online via a computer. The airflow through the instrument was $2.8 \mathrm{dm}^{3} / \mathrm{min}$. Each measurement had a duration of $\geq 10 \mathrm{~min}$, so a total amount of $\geq 28 \mathrm{dm}^{3}$ of air was sampled. 
Outcome parameter was the DP at the instrument table and the Mayo stand, determined on the basis of the reduction in particle counts at these measuring points compared with the background measurement.

\section{Colony-forming units measurement}

The number of micro-organisms was determined using an active air sampler, sampling at a volume flow of $200 \mathrm{dm}^{3} / \mathrm{min}$. Two Biotest Diagnostics' RCS Plus Centrifugal Air Samplers (Denville, NJ, USA) were used for this purpose.

One of these air samplers measured the background concentration ( $\left.\mathrm{M}_{3, \mathrm{P}, \mathrm{CFU}}\right)$, just as with the particle measurement (Figure 5.1), and the other air sampler was placed between the instrument table and the Mayo stand at a height level with the top of the tables ( $\mathrm{M}_{4, \mathrm{CFu}}$ ). At least $200 \mathrm{dm}^{3}$ of air was passed over the strips per sample. The strips contained Tryptone Soya Agar, and were incubated for $48 \mathrm{~h}$ at $30^{\circ} \mathrm{C}$. All CFU were counted but identification was not performed.

\section{Measurement 1 (experiments carried out without instruments or Mayo stand)} The size and quality of the clean area for the given configuration of the systems was determined by using a grid. No instrument table or Mayo stand was present in the clean area when these measurements were conducted; particles were only emitted from position A (Figure 5.1).

\section{Measurement 2 (experiments carried out with instruments and Mayo stand)}

This was carried out with the instrument table and Mayo stand in place and covered with a sheet. By carrying out measurements with and without a heated dummy, the effect of the presence of a 'person' on the protective function of the system during emission from positions $A$ and $B$ was determined. The convective air stream that is created by the heat effect of this person will cause particles to move upwards into the unidirectional air stream. The dummy was a $1.80 \mathrm{~m}$ high cylindrical body with a uniform heat emission of $120 \mathrm{~W}$. It was fitted with clothing customary for scrub nurses and placed in the working position of the scrub nurse (Figure 5.1). 


\section{Measurement 3 (experiments carried out with a simulated process)}

This was carried out during a simulated laying-up process. In addition to measuring the number of particles the number of CFU was also determined, both in the background and between the instrument table and the Mayo stand. The simulated process was executed by two scrub nurses (one sterile scrub nurse and one pathway scrub nurse). Both scrub nurses wore scrub suits, the sterile scrub nurse was additionally equipped with a sterile gown and gloves, surgical mask and cap, protective equipment usually worn during these activities. The simulated process involved laying up one instrument table and one Mayo stand with a basic surgical kit, and involved the following process steps: (i) preparing materials; (ii) placing sterile cloth over instrument table plus opening packet by the nonsterile staff; (iii) putting on sterile overcoat and gloves by sterile scrub nurse (handing the coat and closing it on the back by nonsterile scrub nurse); (iv) placing cover on the Mayo stand by sterile scrub nurse; (v) laying up by sterile scrub nurse; (vi) cleaning up by sterile scrub nurse. The simulated process followed an actual laying-up protocol. The measurements started at step 2 and ended after step 5.

\section{Statistical analysis}

For most particle sizes, the distribution of DP was negatively skewed, with a high peak at the value of 7 (indicating maximum protection; values $>7$ were not possible). Therefore, we split per particle size the variable DP into two outcome variables. The first outcome variable was maximum protection (yes or no), where 'yes' equalled a DP value of 7 , and 'no' equalled a value $<7$. The second outcome variable was DP (value $<7$ ) and was only applicable for the situations without maximum protection (i.e. value of 7 removed). The latter outcome was approximately normally distributed. Consequently, for each particle size, we analysed the data to answer the following research questions: first, do the systems differ in their percentages of maximum protection? (i.e. 'no particles present'); second, in the situations without maximum protection: do the systems differ in their mean DP? The difference between the systems in percentages of maximum protection was analysed by chi-square tests. 
Whether the difference in percentages depended on the type of table ('instrument table' or 'Mayo stand') or the dummy variable ('present' or 'not present') was analysed using logistic regression analysis. The outcome variable in this analysis was maximum protection (yes or no); the predictor variables were type of system (categorical variable with four categories: UDDF, UDHF, UDDF_NC, UDHF_LF), type of table and the interaction effect between type of system and type of table (i.e. cross-product).

The same type of analysis was repeated with, instead of type of table, either the dummy variable (with dummy or no dummy) or the emission variable (position A or B).

The difference between the systems in mean DP (for the situations without maximum protection) was tested with analysis of variance. The outcome variable in this analysis was DP, and the independent factor was type of system. Whether the differences between the systems in mean DP depended on type of table or dummy or emission, was also investigated with analysis of variance. Type of table (or dummy or emission) was included as an extra factor, and a full-factorial design was used (including the interaction effect). Again, a significant interaction effect indicated that the difference between the systems in mean DP depended on, for example, type of table. For all analyses, two-sided a $=0.05$ was considered significant. The analyses were performed using SPSS, version 20 (SPSS, Inc., Chicago, IL, USA).

\section{Results}

Measurement 1 (experiments carried out without instruments or Mayo stand) The DP offered by the UDDF system without cooling at $1.0 \mathrm{~m}$ was $\geq 2$ at $70 \mathrm{~cm}$ from the back wall and $\geq 1$ at $105 \mathrm{~cm}$. Both sides of the system showed a similar rapid decrease in DP (constriction). At $69 \mathrm{~cm}$ from the sides and $70 \mathrm{~cm}$ from the back wall, a DP of 2 was reached. The DP of this area was not symmetrical relative to the central line. This is because the air on the left side cannot flow out freely.

Cooling the air emitted by the UDDF system to 2 - $3 \mathrm{~K}$ lower than the ambient temperature was found to increase the size of the clean area at $1 \mathrm{~m}$ above the ground. 
At $105 \mathrm{~cm}$ from the back wall, the DP was still maximum (no particles found). At $117 \mathrm{~cm}$ from the back wall, the DP had decreased to $<1$.

Substantial improvement was also measured along the sides of the system. At $70 \mathrm{~cm}$ from the back wall and $56 \mathrm{~cm}$ from the side, the DP was still maximum. At $43 \mathrm{~cm}$ from the side a DP of 1.0 was measured. In conclusion, the area with a DP of $\geq 2$ with a UDDF system with cooling was found to be substantially larger (1.281 vs $0.672 \mathrm{~m}^{2}$ of usable clean area, DP $\geq$ 2) than with a UDDF system without cooling.

The experiments with a UDHF system resulted in an area with a DP > 2 reaching to $110 \mathrm{~cm}$ from the plenum. Measured at a height of $30 \mathrm{~cm}$ above the bottom of the plenum (at half height) and at a distance of $80 \mathrm{~cm}$ from the plenum and $30 \mathrm{~cm}$ to the side, the DP was still maximum. Thus the breadth and depth of this area $\left(1.914 \mathrm{~m}^{2}\right)$ exceeded that of the UDDF system with cooling. At a lower air velocity (reduced from 0.45 to $0.30 \mathrm{~m} / \mathrm{s}$ ), the size of the equivalent area measured at $30 \mathrm{~cm}$ above the bottom of the plenum hardly changes in comparison with the UDHF system. A higher air velocity was found to have positive effects (less constriction) for the outer area. Compared with the UDHF system the size of the usable clean area (DP $\geq 2$ ) of the UDDF system was $49 \%$ smaller (1.281 vs $1.914 \mathrm{~m}^{2}$ ).

Before starting measurements 2 and 3, experiments were conducted to determine the optimum positioning of air supply and tables. Initially, the bottom of the air supply surface was positioned at a level that was nearly the same as the top of the tables. This set-up offered no protection because contaminated air was entrained from the environment. The horizontal flow attracted air containing particles from under the table, 'sucking' the particles into the 'clean area' (Figure 5.2, left). By lowering the air supply surface, the air flow split into a flow over the table with covering material and a flow under the table (Figure 5.2, right), creating a clean area above the table. All experiments were carried out with tables that were $99 \mathrm{~cm}$ high and with the bottom of the air supply surface located 79 $\mathrm{cm}$ above the floor, that is, $20 \mathrm{~cm}$ below the surface of the table. The distance between the air supply surface and the tables became an important parameter. 
Positioning the air supply surface so that there was a $20 \mathrm{~cm}$ distance to the tables led to an increase of entrained air from under the table.

At a distance of $\sim 5 \mathrm{~cm}$ between the air supply surface and the tables, the UDHF system functioned properly. This is the distance that was used during all experiments with the tables.

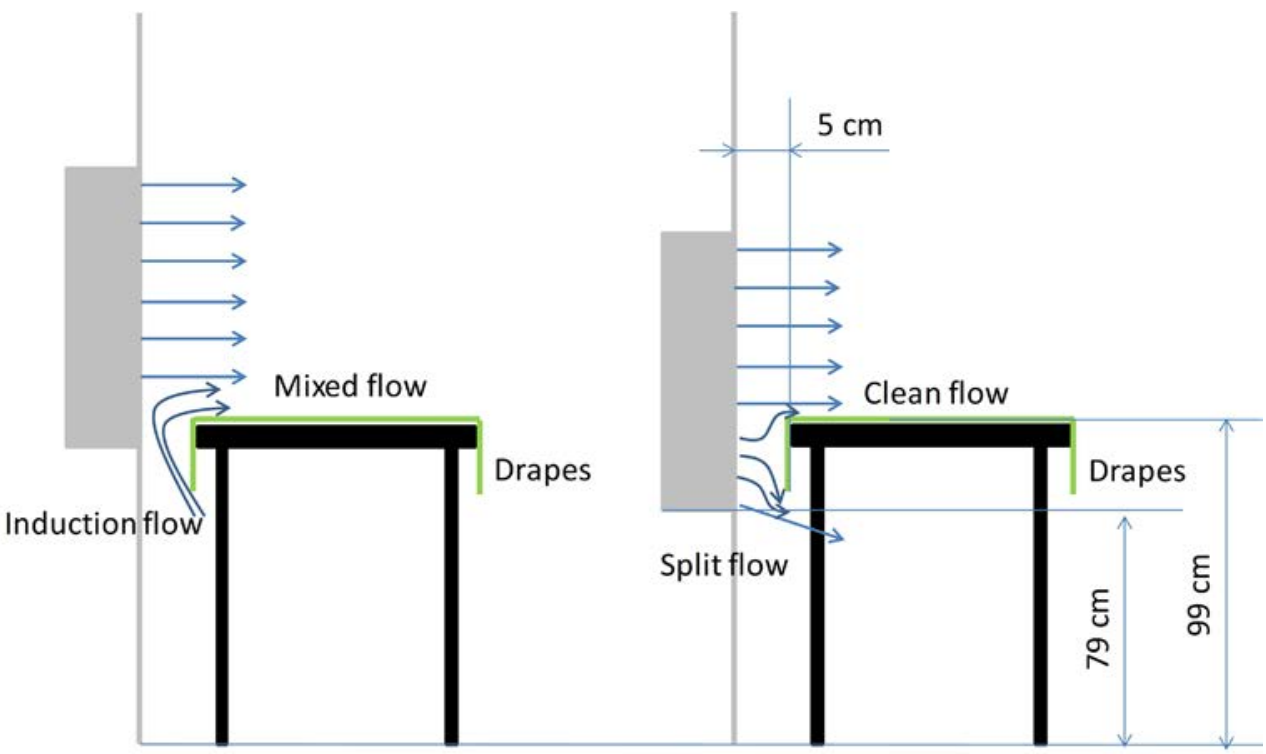

Figure 5.2. Air flow for too high positioning and proper positioning of the air supply surface for a unidirectional horizontal air flow system.

Measurement 2 (experiments carried out with instruments and Mayo stand)

Table 5. 1 gives an overview per system showing that the percentage of observations in which no particles were found on the tables (maximum protection) increases with the size of the particles. The percentage is especially low for the two lowest particle categories ( $\geq$ 0.3 and $\geq 0.5 \mu \mathrm{m}$ ). There is a significant difference between the systems for all particle categories except for the $\geq 0.3 \mu \mathrm{m}$ category. 
If only the UDDF and UDHF systems are compared, the UDHF systems performs significantly better than the UDDF systems for the particle categories $\geq 2.5, \geq 5.0$ and $\geq$ $10.0 \mu \mathrm{m}(P<0.01)$, whereas for particle size $\geq 0.5 \mu \mathrm{m}$ the UDDF system performs better. For the $\geq 5.0$ and $\geq 10.0 \mu \mathrm{m}$ particle categories almost no particles were found ( $\geq 99 \%$ of the observations) using the UDHF system. The UDDF system shows that in $68 \%$ of the observations no particles are encountered.

The difference in the percentage of observations in which no particles were found between the four systems does not depend on the type of table (instrument table or Mayo stand) except for the case of the $\geq 5.0 \mu \mathrm{m}$ particle category.

The difference between the two most important system types (UDDF, UDHF) does not depend on the type of table either. In addition, the difference between UDDF and UDHF depends on the presence of a dummy only in the case of the $\geq 1.0 \mu \mathrm{m}$ particle category. The difference between UDDF and UDHF does not depend on the emission position (position A or B).

Table 5.2 shows the mean DP per system for the observations in which particles were found (DP < 7) for the UDDF and UDHF system. Only the particle categories $\geq 0.3, \geq 0.5, \geq$ 1.0 and $\geq 2.5 \mu \mathrm{m}$ are displayed. The number of observations in which particles are found for the UDHF system particle categories $\geq 5.0$ and $\geq 10.0 \mu \mathrm{m}(\mathrm{N} \leq 1)$ was too low for statistical analyses. 


\begin{tabular}{lcccccc}
\hline & $\geq 0.3 \mu \mathrm{m}$ & $\geq 0.5 \mu \mathrm{m}$ & $\geq 1.0 \mu \mathrm{m}$ & $\geq 2.5 \mu \mathrm{m}$ & $\geq 5.0 \mu \mathrm{m}$ & $\geq 10.0 \mu \mathrm{m}$ \\
\hline UDDF $(N=84)$ & $1 \%$ & $24 \%$ & $52 \%$ & $57 \%$ & $68 \%$ & $68 \%$ \\
UDHF $(N=86)$ & $0 \%$ & $0 \%$ & $58 \%$ & $91 \%$ & $99 \%$ & $100 \%$ \\
UDDF_NC $(N=80)$ & $1 \%$ & $19 \%$ & $36 \%$ & $48 \%$ & $54 \%$ & $63 \%$ \\
UDHF_LF $(N=40)$ & $0 \%$ & $0 \%$ & $18 \%$ & $30 \%$ & $65 \%$ & $85 \%$ \\
P-value & 0.66 & $<0.01$ & $<0.01$ & $<0.01$ & $<0.01$ & $<0.01$ \\
P-value $^{a, b}$ & 0.49 & $<0.01$ & 0.45 & $<0.01$ & $<0.01$ & $<0.01$ \\
\hline
\end{tabular}

$U D D F$, Unidirectional down flow; UDHF, Unidirectional horizontal flow; UDDF_NC, Unidirectional down flow without cooling the supply air; UDHF_LF, Unidirectional horizontal flow with a lower air velocity

a Results from chi-square tests are given for differences between the systems in maximal protection (yes or no) for particle sizes $\geq 1.0 \mu \mathrm{m}$, and $\geq 2.5 \mu \mathrm{m}$. Results from Fisher Exact tests are reported for particle sizes $\geq 0.3 \mu \mathrm{m}, \geq 0.5 \mu \mathrm{m}, \geq 5.0 \mu \mathrm{m}$, and $\geq 10.0 \mu \mathrm{m}$ due to frequencies smaller than 5 .

$b$ Comparison between the UDDF and UDHF only.

Table 5. 1. Percentage of observations with maximal protection $(D P=7)$ per type of system.

Results of analysis of variance indicated that there was no significant difference between the performance of the two systems for the $\geq 0.3$ and $\geq 0.5 \mu \mathrm{m}$ particle categories. In the case of the $\geq 1.0$ and $\geq 2.5 \mu \mathrm{m}$ particle categories, the UDHF system performs significantly better than the UDDF system $(P<0.01)$. The difference in performance of the two systems was slightly influenced by 'type of table' (instrument table or Mayo stand). Only for the $\geq$ $0.5 \mu \mathrm{m}$ particle category was a significant interaction effect between 'table' and 'type of system' found $(P<0.01)$. In this situation the DP of UDHF system on the Mayo stand was higher.

The presence or absence of a heated dummy has an effect on all particle categories. There was a significant interaction effect for the $\geq 0.3$ and $\geq 0.5 \mu \mathrm{m}$ particle categories. For these particle sizes, the UDDF system performed better than the UDHF system when the dummy was present.

The mean values in Table 5. 2 show that there is a remarkable difference between the performance of the UDDF system with and without a dummy, whereas there was hardly any difference between the performance of the UDHF system with and without a dummy. 
If the position from which the particles are emitted (position $A$ or $B$ ) is taken into consideration, the emission position only had an effect on the difference in performance of the systems for the $\geq 0.5$ and $\geq 1.0 \mu \mathrm{m}$ particle categories.

\begin{tabular}{|c|c|c|c|c|c|c|c|c|c|c|c|c|c|}
\hline \multirow{2}{*}{$\begin{array}{l}\text { Design } \\
\text { factor }\end{array}$} & \multirow[t]{2}{*}{ Levels } & \multicolumn{3}{|c|}{$\geq 0.3 \mu \mathrm{m}$} & \multicolumn{3}{|c|}{$\geq 0.5 \mu \mathrm{m}$} & \multicolumn{3}{|c|}{$\geq 1.0 \mu \mathrm{m}$} & \multicolumn{3}{|c|}{$\geq 2.5 \mu \mathrm{m}$} \\
\hline & & $\begin{array}{l}\text { UDDF } \\
(N=83)\end{array}$ & $\begin{array}{l}\begin{array}{l}\text { UDHF } \\
(N=86)\end{array}\end{array}$ & $P$ & $\begin{array}{l}\text { UDDF } \\
(N=64)\end{array}$ & $\begin{array}{l}\text { UDHF } \\
(N=86)\end{array}$ & $P$ & $\begin{array}{l}\text { UDDF } \\
(N=40)\end{array}$ & $\begin{array}{l}\begin{array}{l}\text { UDHF } \\
(N=36)\end{array}\end{array}$ & $P$ & $\begin{array}{l}\text { UDDF } \\
(N=36)\end{array}$ & $\begin{array}{l}\text { UDHF } \\
(N=8)\end{array}$ & $P$ \\
\hline Total & - & 4.10 & 3.99 & .58 & 3.81 & 4.11 & .14 & 2.59 & 3.92 & $<.01$ & 2.32 & 4.13 & $<.01$ \\
\hline \multirow[t]{2}{*}{ Table } & $\begin{array}{l}\text { Instrument } \\
\text { table }\end{array}$ & 4.17 & 4.01 & & 4.49 & 4.18 & & 2.82 & 3.93 & & 1.94 & 3.99 & \\
\hline & $\begin{array}{l}\text { Mayo } \\
\text { stand }\end{array}$ & 4.03 & 3.98 & $.78^{\mathrm{a}}$ & 2.89 & 4.03 & $<.01^{a}$ & 2.44 & 3.91 & $.49^{\mathrm{a}}$ & 2.51 & 4.26 & $.79^{\circ}$ \\
\hline \multirow[t]{2}{*}{ Dummy } & $\begin{array}{l}\text { Without } \\
\text { dummy }\end{array}$ & 3.75 & 3.97 & & 3.63 & 4.09 & & 2.49 & 3.76 & & 2.15 & 4.06 & \\
\hline & $\begin{array}{l}\text { With } \\
\text { dummy }\end{array}$ & 5.19 & 4.02 & $<.01^{\mathrm{a}}$ & 4.70 & 4.13 & $.03^{a}$ & 3.29 & 4.05 & $.45^{\mathrm{a}}$ & 3.35 & 4.17 & $.36^{\circ}$ \\
\hline \multirow[t]{2}{*}{ Location } & A & 4.37 & 3.97 & & 4.20 & 4.05 & & 3.19 & 3.88 & & 2.93 & 3.85 & \\
\hline & B & 3.83 & 4.01 & $.13^{\mathrm{a}}$ & 3.43 & 4.17 & $.02^{\mathrm{a}}$ & 2.00 & 3.96 & $.01^{\mathrm{a}}$ & 1.77 & 4.29 & $.13^{\circ}$ \\
\hline
\end{tabular}

UDDF, Unidirectional down flow; UDHF, Unidirectional horizontal flow.

Observations with maximum protection were disregarded, Results from univariate analyses of variance are reported. a P-value of interaction effect: System (UDDF, UDHF) * Design factor.

Table 5. 2. Differences between the two main systems in mean degree of protection (DP) for different particle sizes and different design factors. Observations with maximal protection were disregarded. Results from univariate analyses-of-variance are reported.

\section{Measurement 3 (experiments carried out with a simulated process)}

Table 5.3 shows that during the process measurements, no CFU were found with the UDDF system in $64 \%$ of the measurements, compared with $90 \%$ for the UDHF system ( $P=$ 0.012).

When CFU were found, the mean number of CFU for the UDDF system was $19.2 \mathrm{CFU} / \mathrm{m}^{3}$ compared with $5.0 \mathrm{CFU} / \mathrm{m}^{3}$ for the UDHF system $(P=0.05)$. The difference in background concentrations was not significant $(P=0.96)$ for the different experiments at $91.4 \mathrm{CFU} / \mathrm{m}^{3}$ for the UDDF system, and at $90.7 \mathrm{CFU} / \mathrm{m}^{3}$ for the UDHF system. 
Based on the analysis of variance of the mean DP for the laying-up process (process steps 2-5) the difference in performance (DP) between the two main systems was not significant for any of the particle categories. If 'type of table' (instrument table or Mayo stand) was taken into consideration, there was a limited and non-significant influence $(P>0.05)$ on performance of the different systems.

\section{Discussion}

This study has partially answered the research question of whether the UDHF system equals or performs better than a UDDF system in controlling contamination (presence of particles and micro-organisms) of the clean area within which laying up takes place. On the one hand, there is a significant difference in the percentage of observations where no particles were found for the larger particle categories ( $\geq 2.5, \geq 5.0$ and $\geq 10.0 \mu \mathrm{m})$, clearly favouring the UDHF system.

\begin{tabular}{lcccc}
\hline & \multicolumn{2}{c}{ CFUs between the tables } & & CFUs back ground \\
\cline { 2 - 3 } & $\begin{array}{c}\text { Percentage of } \\
\text { observations } \\
\text { without CFU }\end{array}$ & $\begin{array}{c}\text { Mean CFU } / \mathrm{m}^{3} \text { if } \\
\text { CFUs were } \\
\text { observed }\end{array}$ & & Mean $\left[\mathrm{CFU} / \mathrm{m}^{3}\right]$ \\
\hline UDDF & $64 \%(N=21)$ & $19.2(N=12)$ & $91.4(N=17)$ \\
UDHF & $90 \%(N=28)$ & $5.0(N=3)$ & $90.7(\mathrm{~N}=19)$ \\
P-value & 0.01 & 0.05 & 0.96
\end{tabular}

Table 5. 3. Percentage of observations for which no colony-forming units (CFU) were observed at the table and mean CFU counts if CFUs were detected.

On the other hand, for the $\geq 0.5 \mathrm{~mm}$ category, there is a significant difference favouring the UDDF system. For the $\geq 5.0$ and $\geq 10.0 \mu \mathrm{m}$ particle categories, almost no particles were found ( $\geq 99 \%$ of the observations) using the UDHF system. The UDDF system yielded a no-particles result in only $68 \%$ of the observations. 
If particles were detected, there was no significant difference in the performance of the UDDF system and the UDHF system for the small particles ( $\geq 0.3$ and $\geq 0.5 \mu \mathrm{m}$ ), although the results point in the direction of better performance with the UDHF system. The performance of the UDHF system is better than the performance of the UDDF system for the larger particles ( $\geq 1.0$ and $\geq 2.5 \mu \mathrm{m}$ ).

However, the reliability of observations for the $\geq 5.0$ and $\geq 10.0 \mu \mathrm{m}$ particle categories is low due to the relatively low background concentration (Figure 5.3).

ISO 14644-1 Annex B.4.2 indicates that, for a statistically reliable measurement, it should be possible to detect a minimum of 20 particles at the class limit. ${ }^{9}$

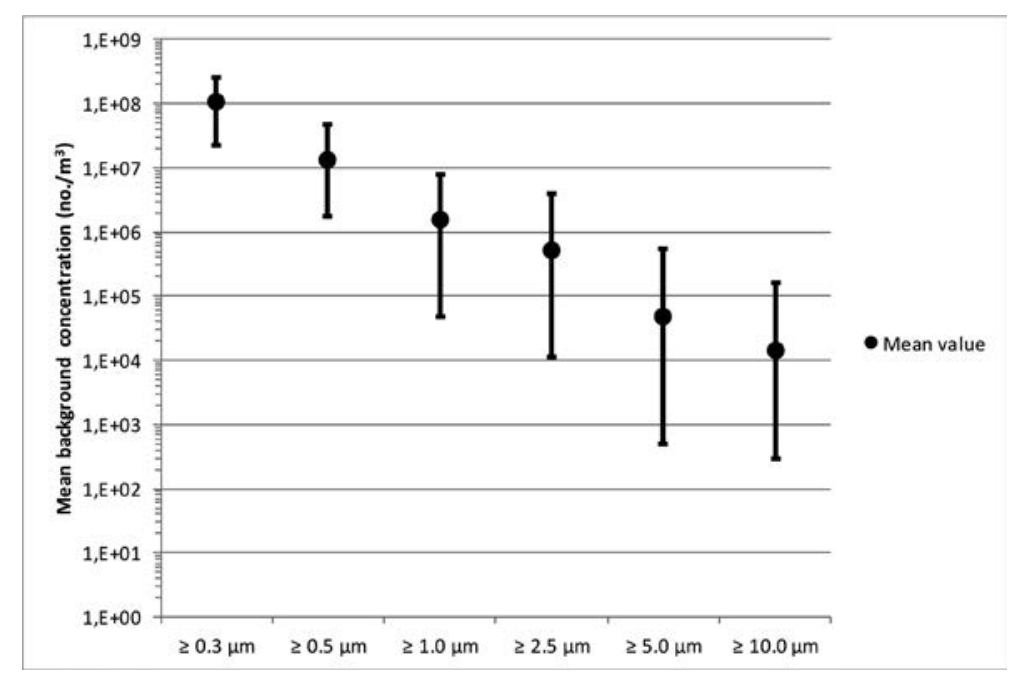

Figure 5.3. Mean background concentration $(\bullet)$ during the measurements.

This research took a similar approach and used this minimum number of particles that would be acceptable to find, given the background concentration and DP, to check whether the measurements were reliable. At the sample volume used $(28.8 \mathrm{~L}$ per measurement), a DP of 5.0, 4.0, 3.0 and 2.5 were determined to be statistically reliable for the particle categories $\geq 0.3, \geq 0.5, \geq 1.0$ and $\geq 2.5 \mu \mathrm{m}$, respectively. 
No statistically reliable degrees of protection were determined for the $\geq 5.0$ and $\geq 10.0 \mu \mathrm{m}$ particles due to the low background concentration for these particle sizes.

The presence or absence of a dummy has an influence on the performance of the systems for the 0.3 and $0.5 \mu \mathrm{m}$ particle categories. The UDDF system performs better with a dummy than without a heated dummy. For the UDHF system there is hardly any difference in performance with or without a heated dummy. This is probably because the static dummy guides the UDDF air stream over the instrument table. This effect is not likely to occur if a moving person is present.

The difference in performance with and without a dummy is much larger for the UDDF system than for the UDHF system, leading to the conclusion that the UDDF system is less robust than the UDHF system.

The position from which the particles were emitted is of importance because of the unusual behaviour of these particles in the air stream. ${ }^{10}$ In order for these experiments to reflect the actual situation in the operating room as closely as possible, particles needed to be emitted from the position they would come from in practice. We chose to emit the particles at a height of $1.5 \mathrm{~m}$ (average neck height), on the assumption that when dressed in operation clothing with cuffs and a sterile overcoat and gloves, particles (flakes of skin) are mainly released from the neck area. This release of particles is caused by the presence of a gap between the clothing and the body at the neck, and the convection effect (upward flow of air around the body).

The percentage of observations for which no CFU were found was significantly higher for the UDHF system. When CFU were found, their number was higher for the UDDF system than for the UDHF system $(P=0.05)$. The DP during the process did not vary significantly between a UDDF and UDHF system. Taking both systems into consideration, based on the bigger difference in performance of the UDDF system for the design factors table, dummy and location (Table 5. 2), we conclude that the UDHF system offers a more robust solution than the UDDF system, provided that good work instructions are given and the height of the table and height of the plenum are correctly adjusted. 
A UDHF system could easily be made mobile because cooling is not necessary. However, whether a mobile system would also offer a more robust solution needs to be carefully considered.

The DP offered by the different systems is influenced by environmental factors and human behaviour. For instance, the differences in measurements with the UDHF system on the left and right side shows that the distance of the plenum to the side wall or other obstructions is of influence. It is clear from our experiments that the height of the instrument tables relative to the height of the UDHF system is also critical. If the tables are too low in relation to the UDHF system, the non-filtered air below the table is sucked along by the air flow from the UDHF system, possibly leading to contamination of the instruments. To function properly, the UDHF system needs to be set up in such a way that the air flow from it is divided into a flow above and below the table.

We based our research method on the fact that the presence of particles has been shown to be a good proxy of the risk of the instruments being contaminated with microorganisms. ${ }^{11}$ Particle composition includes bacteria with a mean equivalent diameter of $12.3 \mu \mathrm{m}$, with a distribution of between 4 and $18 \mu \mathrm{m}$. Research in a Korean hospital has shown that most airborne bacteria occur in the range between 1.1 and $2.1 \mu \mathrm{m} .{ }^{12}$ There was also a good correlation between particles sized 5-7 $\mu \mathrm{m}$ and the number of microorganisms found in air samples in ultra-clean operating theatres. ${ }^{12}$ Hambraeus et al. showed that $7.9 \%$ of the measured bacteria-carrying particles in an operating room have a diameter from 1.1 to $2.1 \mu \mathrm{m}, 12.7 \%$ from 2.1 to $3.3 \mu \mathrm{m}, 17.9 \%$ from 3.3 to $4.7 \mu \mathrm{m}, 23.7 \%$ from 4.7 to $7.0 \mu \mathrm{m}$, and $35.7 \%>7.0 \mu \mathrm{m} .{ }^{4}$ Based on these studies it can be stated that smaller particles (1.1-5.0 $\mu \mathrm{m})$ may carry bacteria as well as larger ones. Very small-sized particles $(<1.0 \mu \mathrm{m})$ are seen as 'indicator' particles for larger particles which potentially carry bacteria. Counting of these particles is considered a good approximation of the relative presence of larger particles. Since they are more frequently present in higher numbers they can be measured more reliably than the larger bacteria-carrying particles. Particles with sizes $<4.5 \mu \mathrm{m}$ are also considered to be completely airborne. ${ }^{13}$ They behave much like a gas ('Brownian motion'), and will follow the air stream they are in. ${ }^{14}$ 
Skin particles released by staff are a potentially greater source of contamination because they may carry more micro-organisms than other particles, and these micro-organisms come directly from humans. ${ }^{15}$ These skin particles, measuring 10-25 $\mu \mathrm{m}$ and $\sim 1 \mu \mathrm{m}$ thick, bear many staphylococci. ${ }^{16-19}$ This group of micro-organisms is responsible for postoperative wound infections especially in implantation surgery. ${ }^{15}$ We have found no other research literature related to contamination of sterile instruments during the layingup process with respect to different air systems or to the air quality provided by different systems during this process.

Apart from the choice of UDDF or UDHD, other procedures are also important to protect instruments from contamination. It was shown that the contamination rate of surgical instruments exposed to the air in an operating theatre was 1.18 times higher than that of instruments which had been covered with sterile guard..$^{20,21}$ The exposure time also had a positive correlation with the bacterial contamination rate. Chosky et al. concluded that setting up instruments in the ultra-clean air theatre and covering them until the patient was transferred on to the operating table produced an overall 28 -fold reduction in instrument contamination compared with instruments set up in the conventional plenum-ventilated preparation room. ${ }^{22}$ By contrast, covering the instruments after setting them up in the preparation room produced only an overall fourfold reduction compared with not covering them.

In conclusion, The UDHF system offers the same or better protection against contamination (the presence of particles and micro-organisms) of the clean area within which the layingup takes place compared with the UDDF system. For large particles, the UDHF system offers superior protection. However, for the $\geq 5.0$ and $\geq 10.0 \mu \mathrm{m}$ particles the difference is not statistically reliable due to the low background concentration for these particle sizes. The results based on the measurements of particles (DP) and the measured number of CFU both show that the UDHF system offers the same or better protection against contamination. 
Although the differences between the two systems did not always reach statistical significance, there is a clear trend, from small-sized particles up to the largest sizes considered, including bacteria-carrying particles $(\geq 1.1 \mu \mathrm{m})$, that demonstrates the superiority of the horizontal flow system. The UDHF system offers a more robust solution than the UDDF system, provided that good work instructions are given and the height of the table and height of the plenum are properly adjusted. 


\section{References}

1. Hoffman PN, Williams J, Stacey A, et al. Microbiological commissioning and monitoring of operating theatre suites. A report of a working party of the Hospital Infection Society. J Hosp Infect 2002;52:1-28.

2. Whyte $\mathrm{W}$, Hodgson $\mathrm{R}$, Tinkler J. The importance of airborne bacterial contamination of wounds. J Hosp Infect 1982;3:123-135.

3. Deutsche Norm, DIN 1946e4: 2008-12. Ventilation and air conditioning - part 4: ventilation in buildings and rooms of health care. Berlin: Deutsches Institut für Normung; December 2008. ICS 91.040.10; 91.140.30.

4. Hambraeus A, Benediktsdóttir E. Airborne non-sporeforming anaerobic bacteria. J Hyg (Camb) 1980;84:181-189.

5. Rodes C, Smith T, Crouse R, Ramachandran G. Measurements of the size distribution of aerosols produced by ultrasonic humidification. Aerosol Sci Technol 1990;13:220229.

6. Porstendörfer J, Gebhart J, Röbig G. Effect of evaporation on the size distribution of nebulized aerosols. J Aerosol Sci 1977;8:371-380.

7. Hinds WC. Aerosol technology: properties, behaviour and measurement of airborne particles. 2nd ed. New York: Wiley; 1999. p. 278-303.

8. European Standard, EN 1822-1: 2009 (E). High efficiency air filters (EPA, HEPA and ULPA) e part 1: classification, performance testing, marking. 1st ed. 2009-11.

9. International ISO Standard, ISO 14644-3:2005(E). Clean rooms and associated controlled environments e part 3: test methods. $1^{\text {st }}$ ed. 2005.

10. Kowalski WJ. Aerobiological engineering handbook. 1st ed. New York: McGraw-Hill; 2005. p. 119-141.

11. Seal DV, Clark RP. Electronic particle counting for evaluating the quality of air in operating theatres: a potential basis for standards? J Appl Bacteriol 1990;68:225-300. 
12. Kim KY, Kim YS, Kim D. Distribution characteristics of airborne bacteria and fungi in the general hospitals of Korea. Ind Health 2010;48:236-243.

13. Murakami S, Kato S, Nagano S, Tanaka Y. Diffusion characteristics of airborne particles with gravitational settling in a convectiondominant indoor flow field. ASHRAE Winter Meeting; Anaheim, California, USA, 25e29 January 1992. p. 82-97.

14. Noble WC, Lidwell OM, Kingston D. The size distribution of airborne particles carrying micro-organisms. J Hyg (Lond) 1963;61:385-391.

15. Henderson RJ. Staphylococcal infection of surgical wounds: the source of infection. $\mathrm{Br}$ J Surg 1967;54:756-760.

16. Clark RP. Skin scales among airborne particles. J Hyg (Lond) 1974;72:47-51.

17. Toshkova K, Annemüller C, Akineden Ö, Lämmler C. The significance of nasal carriage of Staphylococcus aureus as risk factor for human skin infections. FEMS Microbiol Lett 2001;202:17-24.

18. Whyte W, Hodgson R, Tinkler J, Graham J. The isolation of bacteria of low pathogenicity from faulty orthopaedic implants. J Hosp Infect 1981;2:219-230.

19. Yavuz SS, Bicer Y, Yapici N, et al. Analysis of risk factors for sternal surgical site infection: emphasizing the appropriate ventilation of the operating theaters. Infect Control Hosp Epidemiol 2006;27:958-963.

20. Maini L. Clean operating rooms for optimizing surgical outcome. J Clin Orthop Trauma 2011;2:1-2.

21. Yin SH, Xu SH, Bo YC. Study of surgical instruments contamination by bacteria from air during the operation. Zonghua Hu Li Za Zhi 1996;31:690-691.

22. Chosky SA, Modha D, Taylor GJS. Optimisation of ultraclean air: the role of instrument preparation. J Bone Joint Surg Br 1996;78:835-837. 


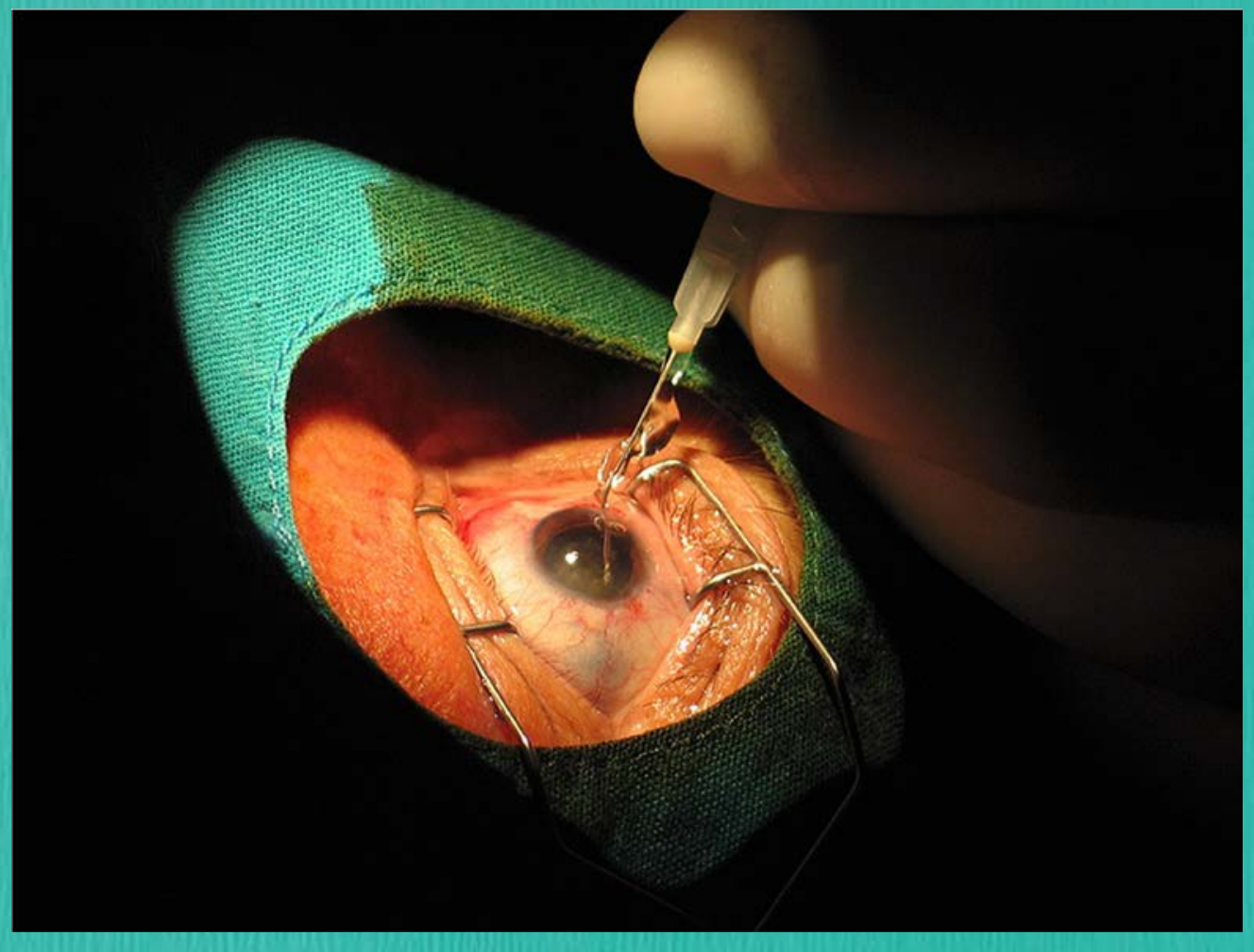




\section{Chapter 6}

\section{Mobile ultra-clean}

\section{unidirectional airflow screen}

reduces air contamination in a simulated setting for intravitreal injection

Lapid-Gortzak R, Traversari R, van der Linden JW, Lesnik Oberstein SY, Lapid O, Schlingemann RO. Mobile ultra-clean unidirectional airflow screen reduces air contamination in a simulated setting for intra-vitreal injection. Int Ophthalmol. 2016;37(1):131-137. 


\section{Abstract}

The aim of this study is to determine whether the use of a mobile ultra-clean laminar airflow screen reduces the air-borne particle counts in the setting of a simulated procedure of an intra-vitreal injection. A mobile ultra-clean unidirectional airflow (UDF) screen was tested in a simulated procedure for intra-vitreal injections in a treatment room without mechanical ventilation. One UDF was passed over the instrument tray and the surgical area. The concentration of particles was measured in the background, over the instrument table, and next to the ocular area. The degree of protection was calculated at the instrument table and at the surgical site. Use of the UDF mobile screen reduced the mean particle concentration (particles $>0.3$ microns) on the instrument table by a factor of at least $100.000(p<0.05)$, and over the patient's eye by at least a factor of $436(p<$ $0.05)$, which in clinical practice translates into significantly reduced air contamination. Mobile UDF screen reduces the mean particle concentration substantially. The mobile UDF screen may therefore allow for a safer procedural environment for ambulatory care procedures such as intra-vitreal injections in treatment rooms.

\section{Keywords}

Unidirectional, ultra-clean, laminar airflow, Intra-vitreal injections, Endophthalmitis prevention, HEPA filters, Contamination.

\section{Funding}

Ruth Lapid-Gortzak has received speaker fees from Alcon, Hanita lenses, and Santen, and is a clinical investigator for Alcon. Roberto Traversari has received fees from LUWA.

\section{Conflict of interest}

None of the authors has a financial or proprietary interest in any material or method mentioned. 


\section{Introduction}

Intra-vitreal injections are commonly performed ambulatory treatments. The risk of infection, according to the literature, is between 0.2 and $0.03 \%{ }^{1-3}$ However, the risk is repetitive and cumulative due to the need for repeated injections in this patient population. Notwithstanding the low incidence of infection, this complication is devastating to the patient, and difficult and expensive to treat. Most infections are caused by the patients' or health workers skin flora. ${ }^{4,5}$ Topical prophylaxis with antibiotic drops has been shown to be ineffective secondary to bacterial resistance. ${ }^{6,7}$

It has been suggested that when performing injections, aseptic techniques need to be adhered to in addition to povidone iodine rinsing and antibiotic eye drops. ${ }^{1}$ Nevertheless, international guidelines include variable instructions for the surroundings in which intravitreal injections need to be done. The British Royal College of Ophthalmology guidelines mandate that the procedure needs to be done in an operating room, or a dedicated treatment room. ${ }^{1}$ The policy statement of the American Academy of Ophthalmology does not set guidelines for the immediate environment in which the intra-vitreal injection should take place. ${ }^{2}$ Outside ophthalmology, the importance of air-borne particles in causing infection has been proven in orthopedic implant surgery, where the infection rates have been significantly reduced using measures to decrease air-borne particle concentration. $^{4}$

Measures aimed at reducing air contamination include surgical garb for the team, ${ }^{5-7}$ and proper operating theater ventilation. ${ }^{5}$ The purpose of air treatment is to prevent stagnation of air and its contaminants, removal of air-borne contaminants, and to provide a comfortable environment for the patient and surgical team. ${ }^{5}$ Over the years, the concept of operating boxes has been developed in which a smaller area of ultra-clean laminar airflow was utilized to reduce infection rates. ${ }^{8}$ 
The use of mobile ultra-clean unidirectional airflow screens (UDF) has added value in settings where the existing ventilation does not suffice and in situations where the mobile screen may be an independent means of achieving clean air in the surgical area, when the procedure is not deemed to necessitate a full operating theater setting. ${ }^{4,-10}$ This is the situation of intra-vitreal injections.

Air is contaminated by not only particles, mostly skin scales, but also bacteria. In simulation studies of contaminated air as well as in air samples in ultraclean operating theaters, it has been shown that there is a good correlation between particles of 5-7 microns and the amount of microorganisms present in the air. ${ }^{11}$ These particle sizes have the same behavioral characteristics in flowing air as the larger but much rarer bacteriacarrying particles. ${ }^{12}$ Counting these 5-7 micron particles, which are present in higher numbers and can be measured more reliably, is therefore considered to provide a good estimate of the presence of larger particles. ${ }^{11}$ In addition, in simulated circumstances, it is very difficult to produce enough large particles, and as a result, standardized measurements in simulated conditions are being done on the smaller particles.

The purpose of our study was to evaluate whether the use of a commercially available mobile screen UDF with a unidirectional HEPA 14 filtered laminar air flow will decrease levels of air contamination on the instrument table as well as the surgical area, in a simulated model for intra-vitreal injections.

\section{Methods}

A simulation of an intra-vitreal injection was performed in an operating room (OR). The OR was used as an environment for simulation. The door closed, and all s-control systems turned off. As a result, the head position of the patient is not consequential, as the particles, like gas particles, are diffusely and evenly spread in the room. ${ }^{13,14} \mathrm{~A}$ setup was arranged in which particles were emitted on one side of the $\mathrm{OR}$, and particles were measured at 3 sites: (1) at the instrument table, (2) at the operative site, and (3) at the other side of the patient, representing the background measurement (Figure 6.1). In this 
approach, the particles are spread throughout the space, and the measured concentration at the reference point is lower than that which the system is exposed to, ${ }^{15}$ as such the effect of emitting at different positions is very limited. The UDF unit was placed in such a manner, that the air flow was directed in sequence from the unit, over the instrument table and draping onto the operative site with no mechanical barriers on its path. The mechanical ventilation system of the operating room was switched off so the only air circulation and filtration was established by the UDF unit. Air-borne particles were measured on the instrument table, at the operative site, and in the background, both at rest with a volunteer and surgeon in place without movement, and with a sham procedure in place, with the surgeon simulating the actual movements, but without actual instruments. The air was sampled at 30-s intervals and simultaneously measured with 3 particle counters (Lighthouse3016-IAQ, Fremont, Ca, USA) for particles in the size categories of $\geq 0.3 \mu \mathrm{m}, \geq 0.5 \mu \mathrm{m}, \geq 1.0 \mu \mathrm{m}, \geq 2.5 \mu \mathrm{m}, \geq 5.0 \mu \mathrm{m}$, and $\geq 10.0 \mu \mathrm{m}$. A steady high background flow of particles was obtained by the vaporization of tap water with an ultrasonic fogger (Lighthouse Volcano P6). After vaporization of the water droplets emitted by the machine, the solid particles remain air borne in the air flow in the room. The background concentration (particles/scan) was measured at this site. Outcome parameters are the reduction in the number of particles at the instrument table and at the ocular surface, and the reduction in these as compared to the background concentration.

The area at the instrument table and at the surgical site were covered by flow from the unidirectional flow unit, which has an air discharge opening of $37949.5 \mathrm{~cm}$, airflow of 400 $\mathrm{m}_{3} / \mathrm{h}$, and producing an airspeed of $0.5-0.7 \mathrm{~m} / \mathrm{s}$ (Figure 6.2). The HEPA H14 filter was used, with $99.995 \%$ efficiency for filtering the most penetrating particles from the air [ISO 29463, High-efficiency filters and filter media for removing particles in air]. 
The protective factor of this system was derived according to the following formula: ${ }^{16}$

$D P_{x}=-\log \left(C_{x} / C_{\text {ref }}\right)$

where $\mathrm{DP}_{\mathrm{x}}$ is the degree of protection at position $\mathrm{x}, \mathrm{C}_{\mathrm{x}}$ is the concentration of particles in the "clean" area at position $x$, and Cref is the concentration of particles outside the "clean" area, i.e., the background.

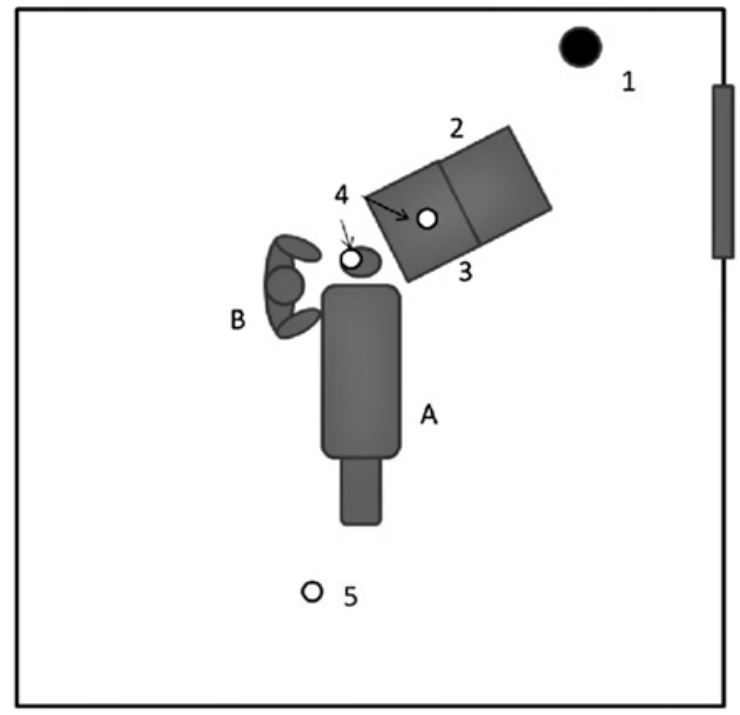

1. Emission of particles, 2. Toul 400 unit, 3. Instrument table,

4. Particle scans at instrument table and at surgical site,

5. Particle scan background. A. Patient, B. Surgeon.

Figure 6.1. This figure schematically renders the setup of the measurements in the operating theater.

The large black dot is the site of particle emission and measurement of the background particles, while the smaller white dots are the site where the measurements were done on the instrument table and near the operative site, i.e., the intra-vitreal injection site.

A degree of protection at location of 0 means that the particle concentration in the operative field is the same as in the background. 
A protective factor of 4 means that there is a reduction of a factor 10.000 of particles in the clean area compared to the background area. A negative factor means that the operative area carries more particles than the background area.

The degree of protection in our analysis was limited (truncated) to a factor 5 for the situation in which no particles were found in the location $x$, the clean area. This means a reduction factor of at least 100.000 .

The ISO14644-1 standard shows the correlation between air sampling size, number of background particles measured, and number of particles counted in order to be able to calculate a degree of protection for a minimal sample volume. ${ }^{17}$. Under the circumstances measured, in which the sample volume was $28.3 \mathrm{dm}^{3}$ for the amount of particles measured for the size of 0.3 micron particle, a degree of protection of 5 is statistically significant. For particle sizes of 0.5 microns, a degree of protection of 3.5 is statistically significant. For particles of 1 micron, a degree of protection of 2.5 is statistically significant. As stated in the ISO 14644-1, a sufficient volume of air should be sampled in order to be able to detect a minimum of 20 particles, which is defined as the limit for the designated ISO class. Using this method, a back calculation was performed in order to be able to establish the reliability of the degree of protection that was found. During each of the measurements at least $28.8 \mathrm{dm}^{3}$ [cubic foot] of air was sampled.

\section{Results}

The simulation included 10 measurements of the background particle concentration. The measurement of the particle count over the instrument table and surgical site at rest was repeated 4 times, while the same setup with the simulated intervention was measured 10 times.

A significant degree of protection could be demonstrated for the simulated procedure both at the operating table and at the instrument table. At the instrument table, the degree of protection was constant and maximal at a value of 5.00 (Table 6.1). 
At the operative area, the degree of protection measured was between 2.64 (Cl $95 \%$ 2.31-2.96) for 0.3 micron particles, to a constant value of 5.00 for 10 micron

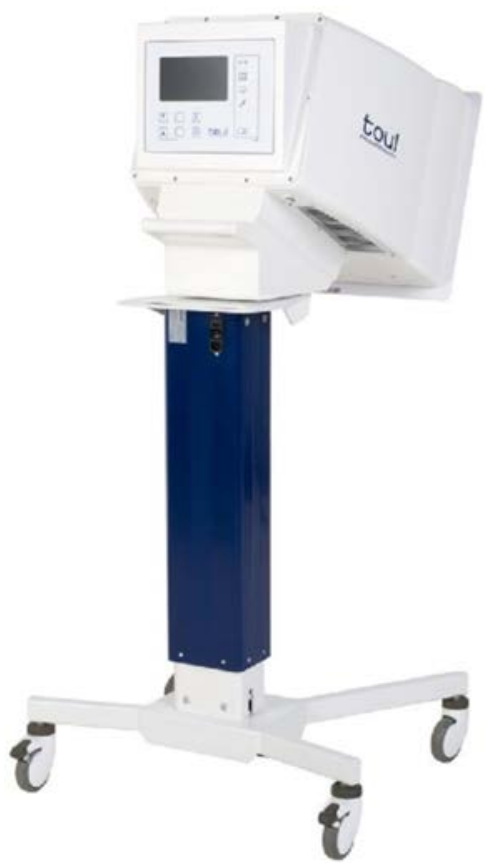

Figure 6.2. The Toul 400 mobile ultra-clean laminar air flow unit. On top of the standard equipped with 4 wheels is the flow unit with the HEPA filter. Positioning of the flow is done by placing the unidirectional laminar device adjacent to the area that needs to be treated.

particles. In Figure 6.3, the degrees of protection are rendered graphically. Table 6.1 shows that the degree of protection at rest (when measurements were done without movement of the surgeon over the instrument tray or the surgical site) was lower than that in the simulated injection procedure. 
However, the influence of the simulated procedure was small and the difference in the degree of protection was only significant $(p<0.05)$ for the $\geq 0.3$ micrometer particles on the instrument table and the $\geq 5.0$ micrometer particles at the ocular area. For the $\geq 5.0$ micrometer particles, the background concentration between the different situations differed significantly $(p<0.05)$ too, but because of the low incidence of the larger particles in the background, it is more difficult to get a significant reduction in their already low numbers. In order to ascertain that the observed reduction in particles is statistically significant, back calculation of the relation between air sampling size, number, and size of particles measured was done, according to the ISO 14644-1, and a degree of protection of 5.0 for the $\geq 0.3 \mu \mathrm{m}$ particles could be demonstrated as being statistically reliable. For the $\geq 0.5 \mu \mathrm{m}$ particles, the statistically reliable degree of protection is 3.5 and for the $1.0 \mu \mathrm{m}$ particles, this value is 2.5 (Figure 6.4).

The degree of protection is shown in Figure 6.3. It is evident that the large particles, acting as a marker for the larger particles carrying bacteria, are most significantly reduced by use of the UDF setup.

\section{Discussion}

Reduction of endophthalmitis rates for office-based procedures is highly pertinent at this time where frequent and repeated intra-vitreal injections are performed outside an operating room setting.

We observed that the commercially available UDF mobile unit employed in this study enables the reduction of air-borne particles over the instrument table and surgical area during a simulation of an intravitreal injection procedure. The degree of protection is at least $5(p<0.05)$ over the instrument table and at least $2.64(p<0.05)$ in the ocular area for the smallest particles. The background measurements were unaffected. Our results confirm previous findings of other authors. ${ }^{9,} 10,17$ 
Based on the notion that the particles measured are a surrogate marker for the behavior of particles carrying bacteria (the guiding particles), we conclude that at the instrument table, the degree of protection is significant $(p<0.05)$. However, at the operative site, the degree of protection conveyed also depends on the background particle count. The degree of protection was sufficient, but much more dependent on how many people are in the room and the ventilation of the room itself, a factor which influences the background counts.

There are no universal guidelines for the air quality in treatment rooms where intra-vitreal injections take place. In the literature, there is no evidence that airborne particles play a role in post-intra-vitreal injection endophthalmitis. A 100 -fold decrease of air-borne particles may allow for much safer environment for intra-vitreal injections. Our results show that a degree of protection between 2.39 and 2.55, a reduction of at least 200-fold, can be achieved for the surgical area. We believe that this reduction in particulate matter will convey a good degree of protection for intravitreal injections. 


\begin{tabular}{|c|c|c|c|c|c|c|}
\hline Particle size & $\geq 0.3 \mu \mathrm{m}$ & $\geq 0.5 \mu \mathrm{m}$ & $\geq 1.0 \mu \mathrm{m}$ & $\geq 2.5 \mu \mathrm{m}$ & $\geq 5.0 \mu \mathrm{m}$ & $\geq 10.0 \mu \mathrm{m}$ \\
\hline \multicolumn{7}{|c|}{ Instrument table (operational, $n=10$ ) } \\
\hline Mean value & $5.00^{\mathrm{a}, \mathrm{b}}$ & $5.00^{\mathrm{b}}$ & $5.00^{b}$ & $5.00^{b}$ & $5.00^{b}$ & $5.00^{b}$ \\
\hline \multicolumn{7}{|l|}{ Standard deviation } \\
\hline \multicolumn{7}{|l|}{$95 \% \mathrm{Cl}$ upper boundary } \\
\hline \multicolumn{7}{|l|}{$95 \% \mathrm{Cl}$ lower boundary } \\
\hline \multicolumn{7}{|c|}{ Instrument table (at rest, $n=4$ ) } \\
\hline Mean value & $5.25^{a}$ & $5.00^{b}$ & $5.00^{b}$ & $5.00^{b}$ & $5.00^{b}$ & $5.00^{b}$ \\
\hline Standard deviation & 0.69 & & & & & \\
\hline $95 \% \mathrm{Cl}$ upper boundary & 6.34 & & & & & \\
\hline $95 \% \mathrm{Cl}$ lower boundary & 4.15 & & & & & \\
\hline \multicolumn{7}{|c|}{ Ocular area (operational, $n=10$ ) } \\
\hline Mean value & 2.64 & 2.70 & 3.39 & 4.31 & 4.57 & $5.00^{b}$ \\
\hline Standard deviation & 0.45 & 0.50 & 1.39 & 1.46 & 1.37 & \\
\hline $95 \% \mathrm{Cl}$ upper boundary & 2.96 & 3.05 & 4.38 & 5.35 & 5.55 & \\
\hline $95 \% \mathrm{Cl}$ lower boundary & 2.32 & 2.34 & 2.39 & 3.27 & 3.58 & \\
\hline \multicolumn{7}{|l|}{ Ocular area (at rest, $n=4$ ) } \\
\hline Mean value & 2.63 & 2.63 & 2.70 & 3.19 & 2.78 & 3.43 \\
\hline Standard deviation & 0.83 & 0.84 & 0.82 & 1.34 & 1.49 & 1.83 \\
\hline $95 \% \mathrm{Cl}$ upper boundary & 3.95 & 3.97 & 4.00 & 5.32 & 5.15 & 6.33 \\
\hline $95 \% \mathrm{Cl}$ lower boundary & 1.31 & 1.28 & 1.39 & 1.06 & 0.41 & .52 \\
\hline
\end{tabular}

Table 6.1. The measured degree of protection with the UDF mobile and the $95 \%$ confidence interval during the at rest and operational condition is shown here. 


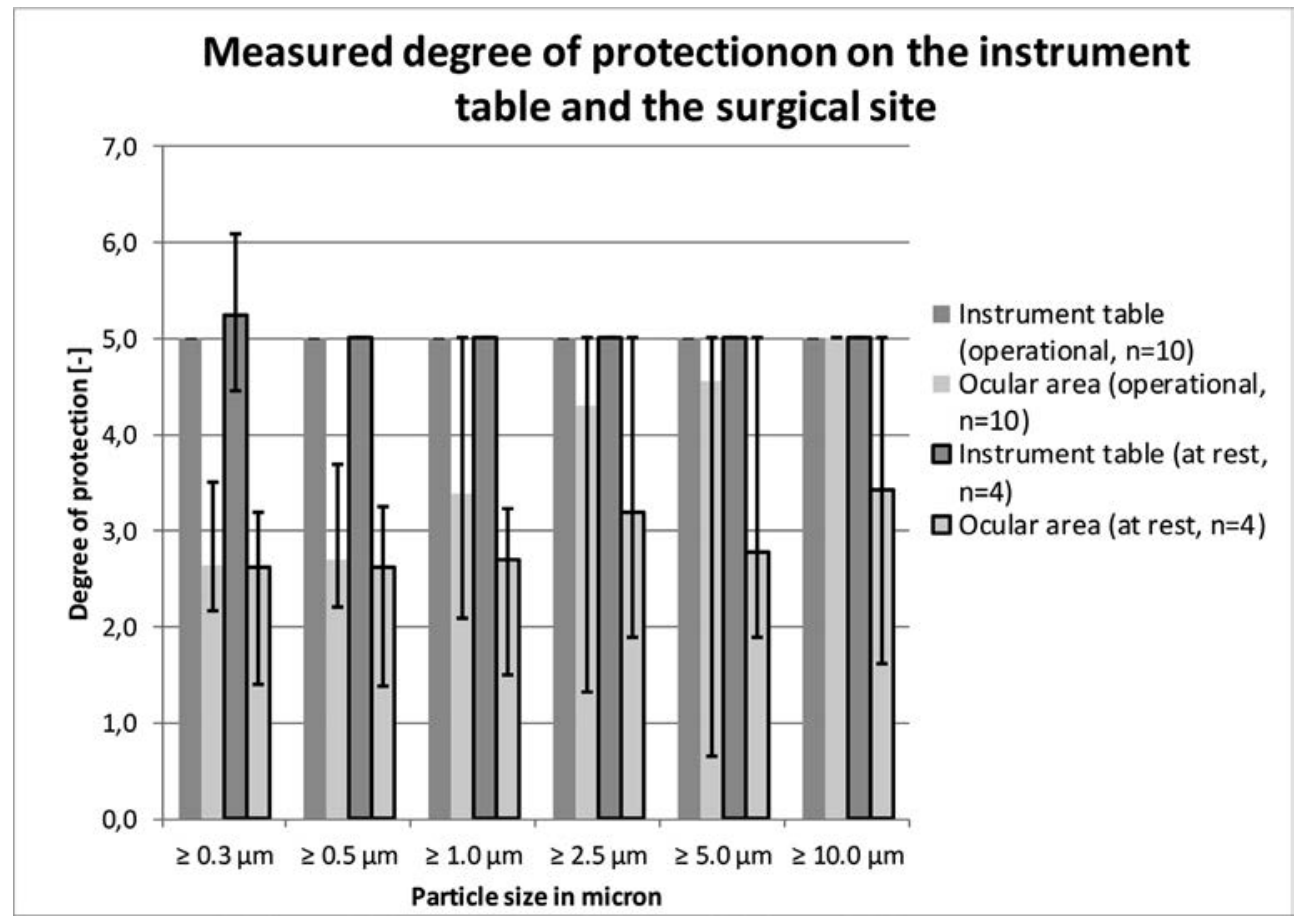

Figure 6.3. This figure shows the degree of protection at the ocular area and on the instrument table, comparing the working state at the resting state.

It is difficult to extrapolate our findings to the situation in different settings and treatments rooms. For example, in orthopedic surgery, the surface of the implants and the operative areas are many times larger than that of an intra-vitreal injection site, and the procedures leave the patient exposed and vulnerable for much longer times. However, we can make a theoretical calculation of the conditions needed for the UDF to be effective in reducing particle counts to levels acceptable in the most stringent conditions, such as orthopedic surgery. 


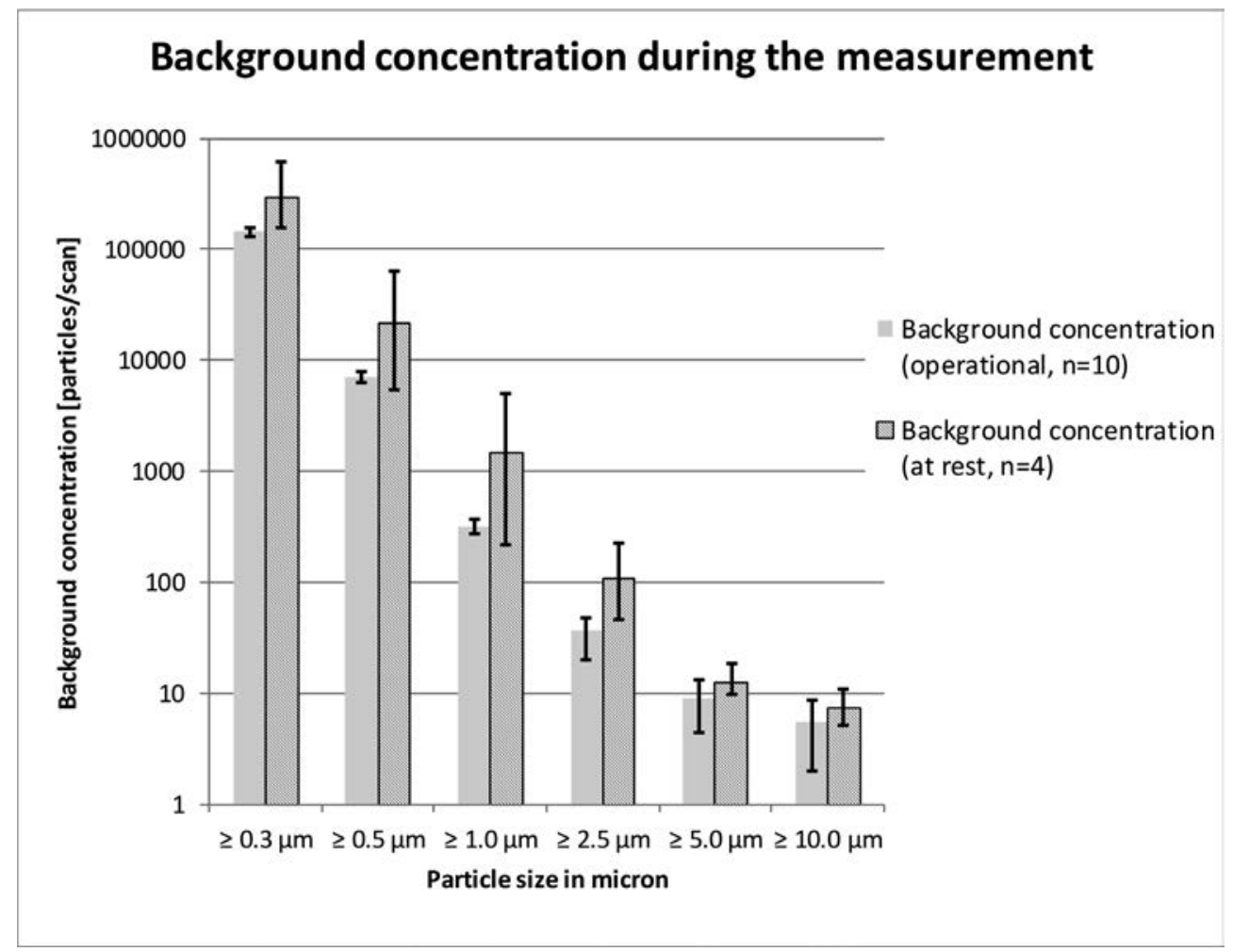

Figure 6.4. This figure shows the background concentration of particles during the sham procedure and at rest. The smallest particles present in large amount, compared to the larger particles.

People present in the operating room emit 10 colony-forming units (CFU)/s/person. ${ }^{18}$ Previous studies have shown that the outside air carries between 1400 and 2500 $\mathrm{CFU} / \mathrm{m}^{3} .{ }^{19}$ Based on a ventilation rate of $100 \mathrm{~m}^{3} / \mathrm{h}$ without filtration, 2 staff members wearing cuffed mixed-material washed scrubs (emitting $4.2 \mathrm{CFU} / \mathrm{s} /$ person) and the patient emitting the same amount of CFU, present in the room with a background concentration between 1854 and $2954 \mathrm{CFU} / \mathrm{m}^{3}$, respectively, can be expected. ${ }^{20}$ This means that a reduction of 185-295-fold (degree of protection 2.27-2.47) is necessary to realize a concentration of less than $10 \mathrm{CFU} / \mathrm{m}^{3}$. Achieving a degree of protection of 2.64 will not require extra measures for air quality (e.g., filtration of the supplied fresh air) in addition to use of the UDF. So, with a degree of protection of at least 2.55 , no additional measures are needed at the above stated concentration in open air. 
In order to prevent a bias, we performed a calculation based on the air sample volume, the number of particles found, and the degree of protection that ensued. This was based on the standards provided by the ISO $14644-1 .{ }^{16}$ The results of our calculations show that for particles of 0.3 microns and larger a degree of protection of 5 is statistically reliable, while for the 0.5 particles this is 3.5 , and for particles over 1 micron in diameter a degree of protection of 2.5 suffices. We conclude therefore that in intra-vitreal injections, the instrument table is more than adequately protected with the UDF, and that the adequacy of degree of protection conveyed at the operative site by the UDF is dependent on the background levels of air contamination caused by the ventilation rate of the room, the number of CFU's in the outdoor/supply air, number of staff, and the used surgical garb.

Our results suggest that the UDF mobile unit may provide an environment for intra-vitreal injections in which the risk of air-borne infection can be markedly reduced. It is clear that the settings would have to be precisely adjusted for each particular site, in order to calculate the actually present degree of protection. In the ambulatory setting of intravitreal injections that carry a low, but repetitive risk of a serious complication like endophthalmitis, the use of a UDF unit provides extra safety to the patient, while keeping costs lower than when using a full-fledged operating room.

\section{Conclusion}

In an environment simulating intra-vitreal injection procedures, the unidirectional flow mobile unit has shown a protection factor of up to 5 for the instrument table and a protection factor of $2.64(p<0.05)$ to $5(p<0.05)$ for the ocular surface. The UDF mobile unit may therefore sufficiently prevent air-borne infections in the setting of intra-vitreal injections. 


\section{References}

1. Jager RD, Aiello LP, Patel SC, Cunningham ET Jr (2004) Risks of intravitreous injection: a comprehensive review. Retina 24:676-698

2. Pilli S, Kotsolis A, Spaide RF et al (2008) Endophthalmitis associated with intravitreal anti-vascular endothelial growth factor therapy injections in an office setting. Am J Ophthalmol 145:879-882

3. Ta CN (2004) Minimizing the risk of endophthalmitis following intravitreous injections. Retina 24:699-705

4. Dharan S, Pittet D (2002) Environmental controls in operating theatres. J Hosp Infect 51:79-84

5. Honnart-Thomas M (2004) Hygiene in ophthalmological care quality: in the operating room. J Fr Ophtalmol 27:424-428

6. Yin VT, Weisbrod DJ, Eng KT, Schwartz C, Kohly R, Mandelcorn E, Lam WC, Daneman N, Simor A, Kertes PJ (2013) Antibiotic resistance of ocular surface flora with repeated use of a topical antibiotic after intravitreal injection. JAMA Ophthalmol 131(4):456461. doi:10.1001/jamaophthalmol.2013.2379

7. Milder E, Vander J, Shah C, Garg S (2012) Changes in antibiotic resistance patterns of conjunctival flora due to repeated use of topical antibiotics after intravitreal injection. Ophthalmology 119(7):1420-1424. doi:10.1016/j.ophtha. 2012.01.016

8. Friberg BE, Friberg S, Burman LG (1996) Zoned vertical ultraclean operating room ventilation. A novel concept making long side walls unnecessary. Acta Orthop Scand 67:578-582

9. Friberg S, Ardnor B, Lundholm R, Friberg B (2003) The addition of a mobile ultra-clean exponential laminar airflow screen to conventional operating room ventilation reduces bacterial contamination to operating box levels. J Hosp Infect 55:92-97

10. Nilsson KG, Lundholm R, Friberg S (2010) Assessment of horizontal laminar air flow instrument table for additional ultraclean space during surgery. J Hosp Infect 76:243246 
11. Seal DV, Clark RP (1990) Electronic particle counting for evaluating the quality of air in operating theatres: a potential basis for standards? J Appl Bacteriol 68:225-230

12. Murakami SKS, Nagano S, Tanaka Y (1992) Diffusion characteristics of airborne particles with gravitational settling in a convention-dominant indoor flow field. ASHRAE Trans 98:82-97

13. Brown R (1828) A brief account of microscopical observations made on the particles contained in the pollen of plants. Phil Mag 4:161-173

14. Traversari ALL, Goedhart CA, Dusseldorp E, Bode A, Keuning F, Pelk MSJ, Vos MC (2013) Laying-up of sterile instruments in the operating theatre: equal or superior protection by using a horizontal unidirectional air flow system. J Hosp Infect 85:125133

15. DIN 1946-4 Ventilation and air conditioning, part 4: VAC systems in buildings and rooms used in the health care sector; annex $\mathrm{C}$

16. International Organisation for Standardization, ISO 14644-1 (2013) Cleanrooms and associated controlled environments-Part 1: Classification of air cleanliness

17. Friberg B (1998) Ultraclean laminar airflow ORs. AORN J 67(841-842):5-51

18. Brohus H, Balling KD, Jeppesen D (2006) Influence of movements on contaminant transport in an operating room. Indoor Air 16:356-372

19. Bugajny AKM, Piotraszewska-Pajak A, Sekulska-Stryjakowska M, Stach A, Filipiak M (2005) On the microbiological quality of the outdoor air in Poznan, Poland. Polish J Environ Stud 14:287-293

20. Tammelin A, Ljungqvist B, Reinmuller B (2012) Comparison of three distinct surgical clothing systems for protection of air-borne bacteria: a prospective observation study. Patient Saf Surg 6(1):23. doi:10.1186/1754-9493-6-23 
Mobile ultra-clean unidirectional airflow screen reduces air contamination 


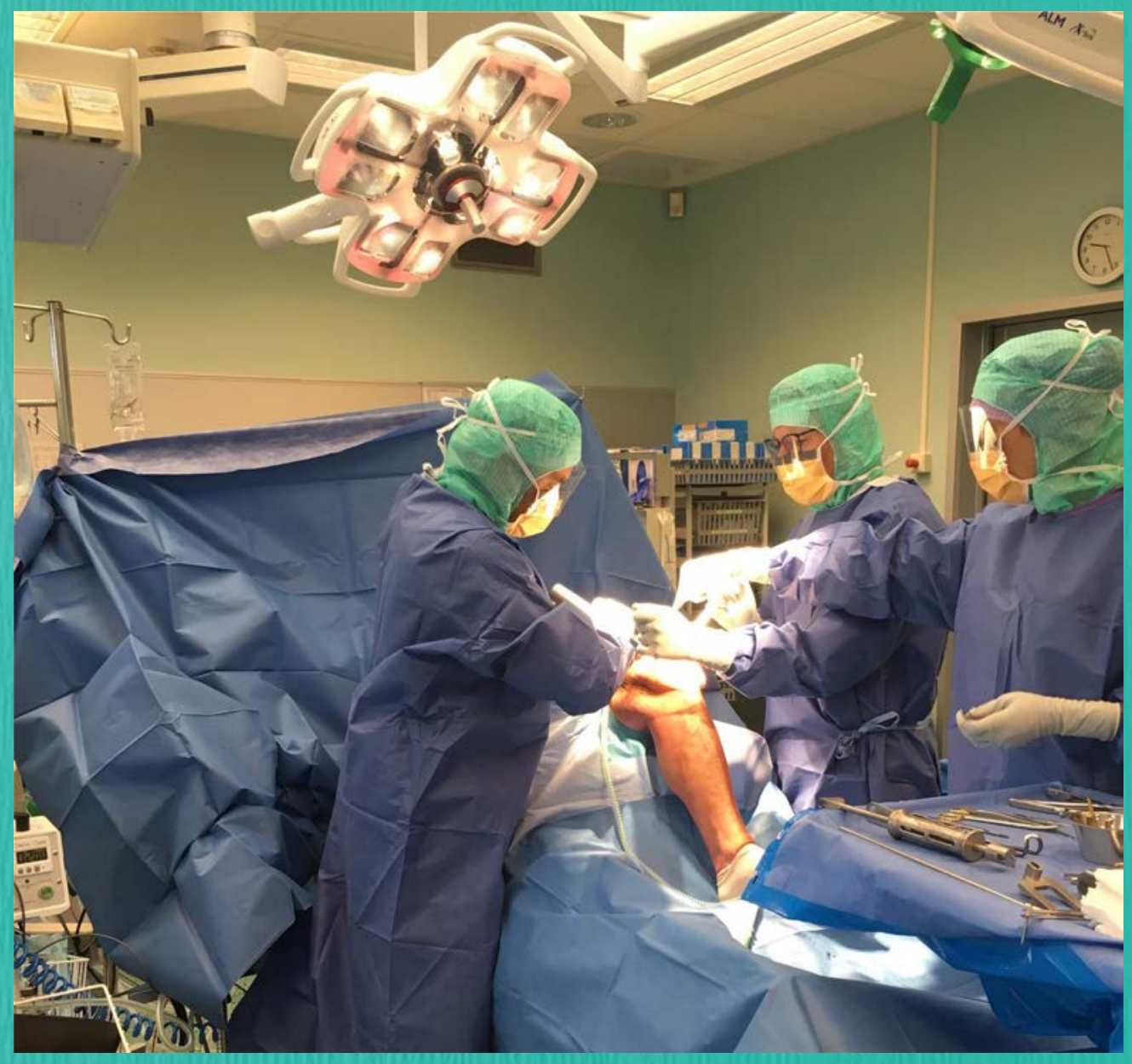




\section{Chapter 7}

\section{Laminar flow: the better choice in orthopaedic implants - Correspondence}

Jutte PC, Traversari RA, Walenkamp GH. Laminar flow: The better choice in orthopaedic implants. The Lancet Infectious Diseases. 2017;17(7):695-696. 
Peter Bisschof and colleagues published a systematic review and meta-analysis in The Lancet Infectious Diseases regarding the effect of laminar airflow ventilation on surgical site infection (SSI). ${ }^{1}$ This study was done in the context of guidelines on $\mathrm{SSI}$ by $\mathrm{WHO}^{2,3}$ and was also in line with publications of the same institution. ${ }^{4}$ We disagree with the conclusion that laminar airflow ventilation should not be used, especially in case of biomaterial implantation, for various reasons.

The studies of the Charite-group and some other studies included in the meta-analysis ${ }^{4-6}$ were based on large surveillance or registry databases combined with a questionnaire about the used airflow system. These questionnaires were not validated, so the reliability of the answers is questionable. Surgeons and medical professionals in general are unaware of the type of airflow system present in an operating theatre. Furthermore, data derived from arthroplasty registry studies underestimate the percentage of periprosthetic joint infection by up to $40 \%{ }^{7}$

Another important fundamental weakness of these studies is that the mere presence of laminar airflow ventilation does not guarantee its proper function-for example, during commissioning and classification measurements it often appears that systems do not permit air to flow as intended, thus not protecting patient and sterile instruments sufficiently.

The authors use high cost as decisive argument not to use laminar airflow ventilation. However, they do not cite the complete literature and select only the articles that support their case. Cacciari and colleagues ${ }^{8}$ found that the building of facilities with suitable airflow increased costs by $24 \%$ compared with nonspecialized facilities, including a much better air filtration system to provide an ultra-clean system (increasing the total surgical facility cost by $5.5 \%)$. Another publication ${ }^{9}$ showed no additional costs per patient for laminar airflow ventilation (2.8-6.7 D-Mark in an operating theatre with a laminar airflow system vs 4.5-6.7 D-Mark if conventional air is present), and we have found the costs to be similarly low at present in the Netherlands. The investment and operational cost of a 
ventilation or air handling system are mostly defined by the amount of air to be conditioned (cooled, heated, humidified, or dehumidified).

The use and combination of big data that are not designed to assess the effectiveness of laminar airflow ventilation is not justifiable and not the solution for the scarcity of randomised trials. The next level of evidence must then be used: observational and experimental studies. In the Netherlands, an evidence based guideline for air handling systems in operating theatres has been established by a multidisciplinary group that includes microbiologists.10 We have found clear evidence that laminar airflow reduces the number of bacteria in the air at the level of the incision and instrument table at rest as well as during surgery. Therefore, Dutch orthopaedic surgeons persist on the use of a well functioning and properly used laminar airflow ventilation system.

We declare no competing interests.

*Paul C Jutte, Roberto AAL Traversari, Geert HIM Walenkamp

\section{p.c.jutte@umcg.nl}

Department of Orthopedic Surgery, University Medical Center Groningen, University of Groningen, Groningen, PO-Box 30.001, 9700RB, Netherlands (PCJ); Dutch Organization for Applied Scientific Research, Innovation Centre Building, Delft, Netherlands (RAALT); and Department of Orthopedic Surgery, Maastricht University Medical Centre, Maastricht, Netherlands (GHIMW) 


\section{References}

1. Bischoff P, Zeynep Kubilay N, Allegranzi B, Egger M, Gastmeier P. Effect of laminar airflow ventilation on surgical site infections: a systematic review and meta-analysis. Lancet Infect Dis 2017; 17: 553-61.

2. WHO. WHO guidelines for the prevention of surgical site infection. Geneva: World Health Organization, 2016.

3. Allegranzi B, Zayed B, Bischoff $P$, et al. New WHO recommendations on intraoperative and postoperative measures for surgical site infection prevention: an evidence-based global perspective. Lancet Infect Dis 2016; 16: e288-303.

4. Gastmeier P, Breier AC, Brandt C. Influence of laminar airflow on prosthetic joint infections: a systematic review. J Hosp Infect 2012; 81: 73-78.

5. Brandt C, Hott U, Sohr D, Daschner F, Gastmeier P, Ruden H. Operating room ventilation with laminar airflow shows no protective effect on the surgical site infection rate in orthopedic and abdominal surgery. Ann Surg 2008; 248: 695-700. 
Laminar flow: the better choice in orthopaedic implants 


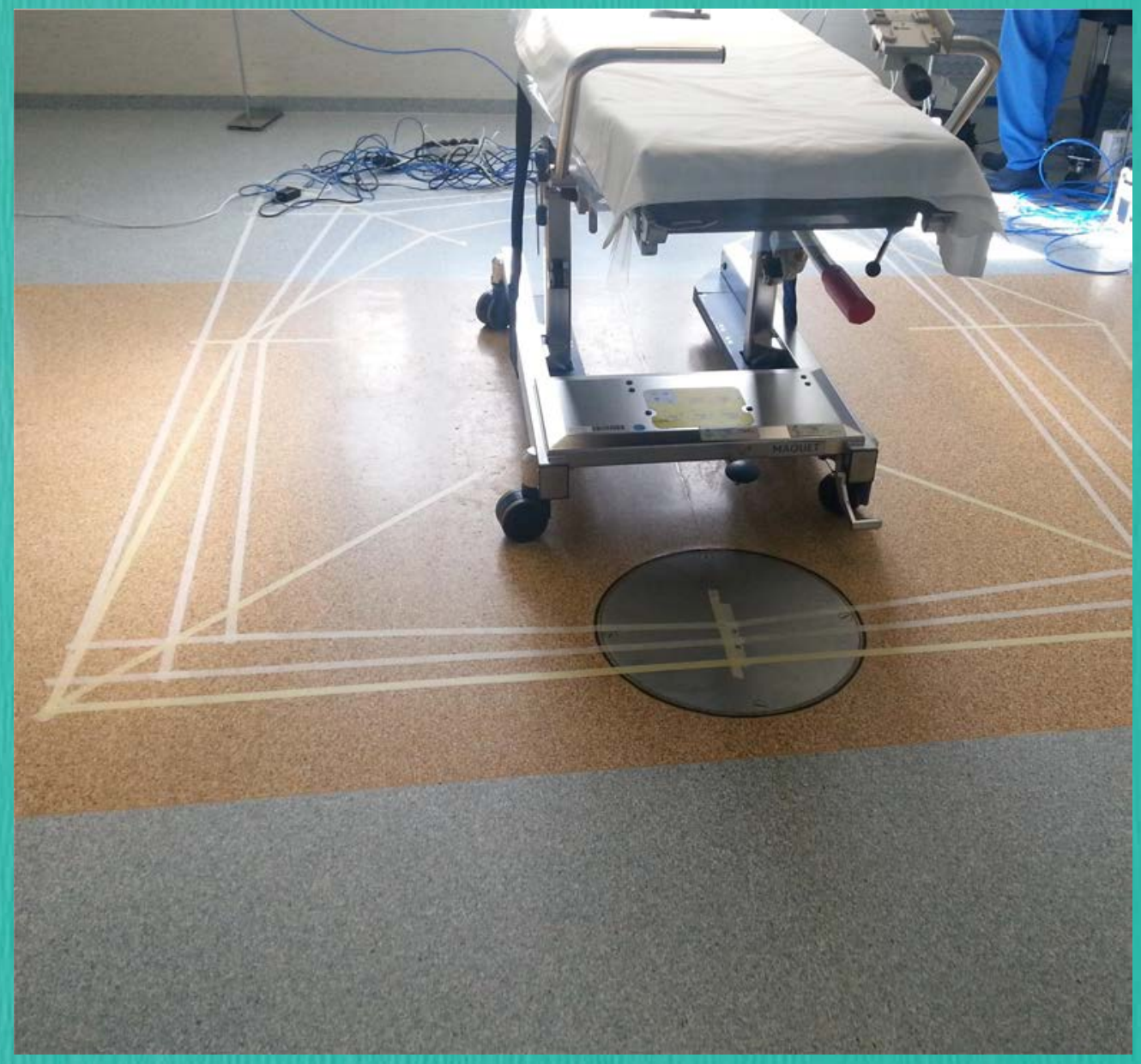




\section{Chapter 8}

\section{What if the protected area is smaller than expected?}

Translated from:

Traversari R, Van Den Broek P, Saurwalt F. Wat nu als het beschermd gebied kleiner is dan verwacht? Ned Tijdschr Med Microbiol. 2017;25(1):14-18. 


\section{Summary}

The Dutch Healthcare-associated Infections Prevention Working Group (WIP) published its guidelines on "Air treatment in operating rooms and in instrument preparation areas of Class 1 surgery departments" in 2014. Measurements performed according to guideline 7 of the Association of Contamination Control Netherlands (VCCN) have found that some protected areas are substantially smaller than expected based on the size and supposed functionality of the plenum ( $>40 \mathrm{~cm}$ indent on all sides relative to the projected size of the plenum).

The authors of this article argue that in cases where a smaller than expected protected area is found, it is not always necessary to impose restrictions on the range of procedures that can be performed and/or shut the operating room down completely. The authors distinguish three feasible approaches in the case of a smaller than expected protected area. One of these does not tackle the air handling system directly, but demonstrates equivalency of protection, using adjustments to primary and support processes where necessary. The authors argue that if process adjustments demonstrably result in a colonyforming unit (CFU) level continuously below $10 \mathrm{CFU} / \mathrm{m}^{3}$, the degree of protection in the operating zone will be equivalent to the Class 1 protection level described in the WIP guidelines.

\section{Introduction}

The Dutch Healthcare-associated Infections Prevention Working Group (WIP) published its guidelines on "Air treatment in operating rooms and in instrument preparation areas of Class 1 surgery departments" in 2014. Since then, these guidelines apply as field standard for this subject. In these guidelines the performance of an operating room concerning the air handling system, is divided into two protection levels, Class 1 and Class 2 . The method how to measure these performance levels is described in guideline 7 of the Association of Contamination Control Netherlands (VCCN), "method for testing and classification of operating rooms and instrument preparation areas in rest". 
Now many measurements according to guideline 7 of the VCCN have been carried out, it seems that some protected areas are substantially smaller than expected based on the size and supposed functionality of the plenum. What does this mean in practice and what should happen following these findings? In this article the authors state their opinion about this matter.

\section{Background of the WIP guidelines}

The basic thought of the WIP guidelines on "Air treatment in operating rooms and in instrument preparation areas of Class 1 surgery departments" is that bacteria (or microorganisms), the main causers of surgical site infections, do not appear freely in the air, but stick to particles like skin scales, hair and dust. ${ }^{1,2,3,4}$ People in an operating room or instrument preparation area are the main source of those airborne particles and microorganisms. The purpose of an air handling system is to reduce the number of particles and micro-organisms in the air and to keep this amount within acceptable limits.

In the guidelines the expert group of the WIP concludes that there is clear backing in literature for the fact that unidirectional downflow (UDF) systems lead to less contaminated air over the operating area and less contamination of instruments during surgical operations than dilution (turbulent-flow) ventilation systems. However, there is no clear evidence for the decrease of the amount of surgical site infections using a UDF system instead of a dilution ventilation system. ${ }^{1}$ On the ground that a decrease of the amount of wound infections has not been found in the analysis of registration files that describe daily practice $e^{5,16,17}$, the expert group concludes that the use of a UDF system does not necessarily result in a decreasing amount of wound infections. This is probably caused by the importance of a correct use of the air handling system and the actually measured performance (quality) of het system itself. The microbiological load of the system caused by 1) people present, 2) strength of the source and 3) cleaning practice, are also important variables. ${ }^{15}$ The higher the microbiological load, the harder it gets for the air handling system to remove this load. 
These three factors (way of use, strength of the source and cleaning practice) can form an explanation for the results of research by Hooper, Brand and Breier. ${ }^{5,16,17}$

This means that there are also a lot of non-technical factors influencing the air quality and thereby having an effect on the amount of surgical site infections. Contamination of a wound by air-borne micro-organisms can take place via two routes: directly from the air into the surgical wound or indirectly via surgical instruments. Out of a qualitative risk analysis (precautionary principle) we might say that the decrease of the number of airborne micro-organisms is lowering the chance of contamination of the surgical wound and thus lowering the chance of creating surgical site infections.

There is no correlation between the amount of particles and the amount of microorganisms in the air during surgical operations. ${ }^{6,7}$ The performance as required in the WIPguidelines are nevertheless based on air-borne particles, because they act in the same way as air-borne micro-organisms. ${ }^{8,9,10}$ By consciously emitting particles, in order to determine the performance of the system, the behaviour (like the movement through the air) of released micro-organisms (amongst others by the surgical team) in an operating room can be simulated. ${ }^{11,12}$ The measurement of particles doesn't say anything about the actually expected concentration of micro-organisms, but must be seen as a way to simulate the spread of released micro-organisms through the air. 


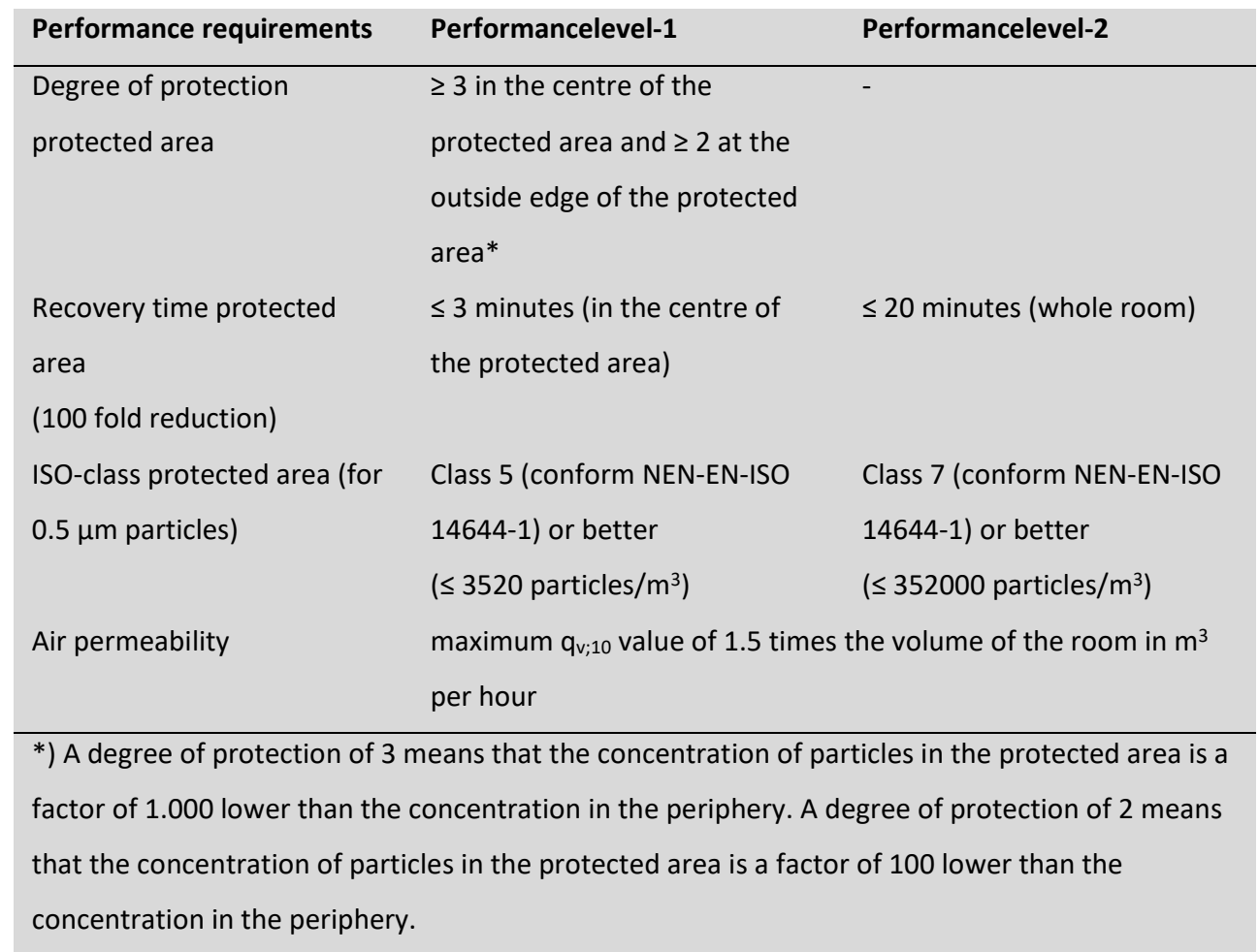

Table 8.1. Performance requirements of an operating room and instrument preparation area in rest' for a surgery department.

On the basis of the general level of process quality, clothing system, discipline and cleaning the WIP-guidelines state that joint replacement surgeries should with strong preference be carried out in an operation room equipped with an air handling system that complies with performancelevel-1. Besides the air quality in the protected area, expressed in the ISO-class, the degree of protection and recovery time (table 8.1), also the size of the protected area is of importance. The dimensions of the protected area should at least be big enough to enclose the operation area, surgical team and sterile instrument tables.

It is precisely the size of the protected area that, after measuring, seems to be disappointing, smaller than expected and sometimes reduced to the size of the operation table. As a result, the area can be too small for certain types of surgeries. 
The question is, how to deal with these findings. Should the system be adapted directly? Will some surgeries no longer take place in the operation room?

\section{Equivalency}

In the authors view, a smaller area than expected not necessarily has to lead to the decision that certain kind of surgeries no longer may be performed in the operation room or even worse, the closure of the operation room. If the size of the protected area is smaller than expected, three routes are possible. In the first route the system is technically adapted in order to increase the protected area until the desired size is reached. The second route does not directly lead to the adaption of the system and uses a method that proves whether an equal performance is reached with modifications in the surgical process. These equal performances can be proved by constantly determining the amount of colony forming units (CFU) per $\mathrm{m}^{3}$ during the surgical operations and taking care that this amount stays below a maximum level. This will be worked out further on in this article. The third route is a combination of the two routes described above, (simple) technical modifications that result in an improvement but are not sufficient enough and the proving of an environment with a maximum level of $\mathrm{CFU} / \mathrm{m}^{3}$.

As described, there is no correlation between the number of particles and the number of micro-organisms in the air during surgeries. ${ }^{6,7}$ The measurement of particles as described in the WIP-guidelines has to be considered as a method to simulate the diffusion of released micro-organisms through the air. The number of airborne micro-organisms is a direct indicator for the risk of contamination of the wound through the air, where the method of simulating by emitting and measuring particles only gives a global insight in the spread of released micro-organisms.

While measuring the number of airborne micro-organisms during the surgery, also the effects of the process (like movements, clothing system and cleaning) become clear, which is not the case using the performance-requirements as described in the WIP-guidelines. 
Studies carried out in the eighties, which still seem to be valid, suggest that a concentration of $10 \mathrm{CFU} / \mathrm{m}^{3}$ or less during surgeries is desirable for joint replacement surgeries to keep the infection percentage lower than 1.5\%. Research by Lidwell proves that there is a correlation between the type of air handling system and the amount of found $\mathrm{CFU} / \mathrm{m}^{3}$ and between the amount of found $\mathrm{CFU} / \mathrm{m}^{3}$ and the amount of surgical site infections (SSI). ${ }^{18}$ The relation between the amount of found $\mathrm{CFU} / \mathrm{m}^{3}$ and the amount of SSI is described by the following equation: $\operatorname{SSI}(\%)=0.84+0.18 \sqrt{\frac{C F U}{m^{3}}}$ (correlation coefficient $0.90 ; P<0.02$ with a standard deviation of the gradient of \pm 0.044 ) that is defined on the basis of a population of 8046 surgeries. ${ }^{12}$ Another study by Whyte, based on the studies by Lidwell, indicates that a "clean air system" (nowadays a UDF system) may be called effective, only if a level of $10 \mathrm{CFU} / \mathrm{m}^{3}$ is not exceeded during the surgery.$^{13,}$ ${ }^{19}$ In Sweden a mean value of $10 \mathrm{CFU} / \mathrm{m}^{3}$ or less over 5 to 10 surgeries is used, with surgeries of vulnerability to infection, whereas the maximum mean value of 3-4 measurements during one surgical operation may count no more than $30 \mathrm{CFU} / \mathrm{m}^{3}$ during the surgery (SIS-TS39, 2015). ${ }^{20}$

Therefore it seems justified that if it is continuously proved that the requirement of no more than $10 \mathrm{CFU} / \mathrm{m}^{3}$ during surgery (average of 3-4 measurements) on both the instrument tables and the wound area are met, an equal solution is realized as meant by the performance-requirements in the WIP-guidelines for performance level 1 . If it is not the case with the regular process, additional process adjustments will mostly help to reduce the amount of $\mathrm{CFU} / \mathrm{m}^{3}$. These (additional) adjustments can be for example: a higher level of quality of clothing, extra cleaning or a more stringent dealing with procedures, like the "door discipline".

This means that with surgeries that are vulnerable to infection, the amount of CFU's will have to be monitored constantly during the surgery on both the instrument tables and the wound area, using an adopted procedure. A good method for this could be the Swedish guidelines (SIS TS 39,2012). ${ }^{20}$ 
This means extra work, but can also prevent technical investments or the delay of surgical operation. We, of course, realize that this always has to be certified afterwards (postoperative), but if the frequency of this type of surgery is relatively high, it provides a very good indication of the combination of technology, process and cleaning. If the microbiological level stays low $\left(<10 \mathrm{CFU} / \mathrm{m}^{3}\right)$, the risk on a surgical site infection for the patient is equal to a performance level 1 operation room, judging from the general level of process quality, clothing system, discipline and cleaning.

The performance-requirements as described in the WIP-guidelines "Air treatment in operating rooms and in instrument preparation areas of Class 1 surgery departments" are, as indicated earlier, based on studies where the general level of process quality, clothing system, discipline and cleaning is used. If there were no emission from the surgical team and the cleaning would be in order, the level of the performance-requirements could be significantly lower, because the number of particles and micro-organisms that has to be eliminated is strongly reduced to nearly zero. In that case, the air treatment is only necessary for the elimination of surgical smoke, (inhalation) anaesthetics and possible swirling particles with micro-organisms during the cleaning of the operation room or instrument preparation area. It therefore is preferable that practical requirements will be defined for the emission of micro-organisms from surgical clothing and the result of the cleaning of an operation room.

Several studies have been carried out on het effect of different clothing systems on the emission of particles and CFU's. ${ }^{21,22,23,24,25,26}$ These studies point out that the emission of different clothing systems can be strongly reduced. Furthermore, by adding additional clean air to the periphery, there is more dilution in that area and the concentration of particles and CFU's could be reduced. 
This approach as described above, is completely in line with the essence of the new WIPguidelines, namely: an organization should be provable 'in control' regarding the three footholds of preventing the contamination of the surgical wound: technology in form of air treatment, limiting the spread of micro-organisms by human sources (processes) and the cleaning. A good outcome for this is the amount of CFU's during surgery at the wound area and the sterile instrument tables. VCCN-project group 4 is working on a method to monitor the air quality during surgery as clearly as possible. With this approach it is also possible to give form to the observation of the representatives of the Dutch Medical Microbiology association (NVMM) that, besides the mentioned preference for an air handling system complying with performancelevel-1 (UDF), there is also tolerance in using a dilution ventilation system with HEPA-filtration is. ${ }^{1}$

\section{Discussion}

However, some critical notes on this approach could be made. This in particular applies to the maximum level of $\mathrm{CFU} / \mathrm{m}^{3}$. Limited research has been done on the relationship between the number of micro-organisms near the wound and at the instrument tables, and the amount of surgical site infections. The numerical value of $10 \mathrm{CFU} / \mathrm{m}^{3}$ is derived from earlier research by Lidwell. ${ }^{6}$ This value is internationally seen as a safe maximum value with surgeries of vulnerability to infection, but there is limited evidence for this.

The results are also depending on the used measuringmethod. ${ }^{27,28,}{ }^{29}$ Measurements in studies upon which the maximum amount of $\mathrm{CFU} / \mathrm{m}^{3}$ is defined, have been carried out in the different involved hospitals with Slit-to-Agar (STA) air samplers, cascade impactors and gelatine filters. ${ }^{18,30}$ These samplers generally have a $d_{50}$ (50\% efficiency) for particles of 2 $\mu \mathrm{m}$ or smaller. ${ }^{31}$ The measuring equipment by which the amount of colony forming units (CFU) during surgery has to be measured, should therefore have a $d_{50}$ for particles $\leq 2 \mu \mathrm{m}$ considering the expected low concentration of CFU, as also described in the Swedish guidelines (SIS-TS39, 2015). ${ }^{20,31}$ 
With this equipment it should also be possible to take samples with a sterile tube on a good ventilated location without disturbing the airflow in the room. Using a "centrifugal sampler" therefore seems to be less suitable for this purpose.

The authors state that when using the method that does not lead to the complete adaption of the system in order to increase the protected area sufficiently, it constantly has to be proved whether an equal performance is reached regarding the amount of $\mathrm{CFU} / \mathrm{m}^{3}$. Of course, it is not realistic to take measurements during every surgery vulnerable to infection, but it has to be proved that maximum values are not structurally exceeded. This means that at the beginning of the route, the frequency shall be relatively high and depending on the results (e.g. absolute values and distribution), this frequency (statistically) can be lowered safely.

In order to keep the risks under control, it is important that, within the described approach, the system complies with all performance-requirements (Table 1), with the exception of the requirement that the size of the protected area should be big enough to cover the operation area, surgical team and sterile instrument tables.

\section{Conclusions}

We believe that an operation room with performance level 1 and a protected area smaller than expected or too small to cover the operation area, surgical team and sterile instrument tables, not necessarily has to lead to the direct adaptation of the system or to stop performing "clean" surgery. By keeping the amount of CFU $/ \mathrm{m}^{3}$ for clean surgery demonstrably on a level beneath $10 \mathrm{CFU} / \mathrm{m}^{3}$ (whether or not with additional adjustments) an environment is being created equal to the quality as intended with performance level 1. This also gives an interpretation to the notice that, besides the mentioned preference for an air handling system complying with performancelevel-1 (UDF), there is also tolerance in using a dilution ventilation system with HEPA-filtration is. ${ }^{1}$ 
To gain more insight in, and to be able to reduce the knowledge gaps, we suggest besides this a more process orientated approach in order to: 1) gather all Dutch measuring data so we can evaluate the guidelines, 2) do more research on the amount of micro-organisms above the wound and the instrument table during the use of the operation room, and (3) learn from the measuring results so that design and users requirements really match with each other and lead to a low and acceptable risk on surgical site infections. 


\section{References}

1. Werkgroep Infectie Preventie (WIP). Luchtbehandeling in operatiekamers en opdekruimte in operatieafdeling klasse 1. Leiden, november 2014.

2. Ahl T, Dalen $\mathrm{N}$, Jorbeck $\mathrm{H}$, Hoborn J. Air contamination during hip and knee arthroplasties. Horizontal laminar flow randomized vs. conventional ventilation. Acta Orthop Scand 1995; 66(1):17-20.

3. Birgand G, Saliou P, Lucet LC. Influence of staff behavior on infectious risk in operating rooms: what is the evidence?, Infect Control Hosp Epidemiol 2015; 36(1):93-106.

4. Mackintosh CA, Lidwell OM, Towers AG, Marples RR. The dimensions of skin fragments dispersed into the air during activity. Journal of Hygiene 1978; 81(3): 471480

5. Hooper GJ, Rothwell AG, Frampton C, Wyatt MC. Does the use of laminar flow and space suits reduce early deep infection after total hip and knee replacement?: the ten-year results of the New Zealand Joint Registry. J Bone Joint Surg Br 2011; 93(1):85-90.

6. Cristina ML, Spagnolo AM, Sartini MS, Panatto D, Gasparini R, Orlando P, Ottria G, Perdelli F. Can Particulate Air Sampling Predict Microbial Load in Operating Rooms for Arthroplasty. PLoS One v.7(12); 2012: PMC3528722

7. Landrin A, Bissery A, Kac G. Monitoring air sampling in operating rooms: can particle counting replace microbiological sampling? J Hosp Infect. 2005; 61(1):27-9.

8. Seal DV, Clark RP. Electronic particle counting for evaluating the quality of air in operating rooms: a potential basis for standards? J Appl Bacteriol 1990; 68:225-300.

9. Kim KY, Kim YS, Kim D. Distribution characteristics of airborne bacteria and fungi in the general hospitals of Korea. Ind Health 2010; 48:236-243.

10. Murakami S, Kato S, Nagano T, Tanaka Y. Diffusion characteristics of airborne particles with gravitational settling in a convectiondominant indoor flow field. ASHRAE Winter Meeting; Anaheim, California, USA, 25-29 January 1992: 82-97. 
11. Noble WC, Lidwell OM, Kingston D. The size distribution of airborne particles carrying micro-organisms. J Hyg (Lond) 1963; 61:385-391.

12. Henderson RJ. Staphylococcal infection of surgical wounds: the source of infection. Br J Surg 1967; 54:756-760.

13. Lidwell OM, Lowbury EJL, Whyte W, Blowers R, Stanley SJ, Lowell D. Airborne contamination of wounds in joint replacement operations: the relationship to sepsis rates. Journal of Hospital Infection 1983; 4:111-131.

14. Vereniging Contamination Control Nederland (VCCN). Guidelines: Method voor testen en classificeren van OK's en opdekruimten in rust. Woerden, november 2014.

15. Ljungqvist B, Nordenadler J, Reinmüller B. Results from a Swedish survey investigations in operating rooms. European Journal of Parenteral and Pharmaceutical Sciences 2013; 18(4):125-127.

16. Brand C, Hott U, Daschener F, Gastmeier P, Ruden H. Operating room ventilation with laminar airflow shows no protective effect on the surgical site infection rate in orthopedic and abdominal surgery. Ann Surg 2008; 248(5):695-700.

17. Breier AC, Brand C, Sohr D, Geffers P. Laminar airflow ceiling size: no impact on infection rates following hip and knee prosthesis. Infect Control Hosp Epidemiol 2011; 32(11):97-102.

18. Lidwell OM. Air, antibiotics and sepsis in replacement joints. Journal of Hospital Infection 1988; 11:18-40.

19. Whyte W, Lidwell OM, Lowbury EJL, Blowers R. Suggested bacteriological standards for air in ultraclean operating rooms. Journal of Hospital Infection 1983; 4:133-139.

20. Swedish Standards Institute (SIS), Technical Specification 39. Microbiological cleanliness in the operating room - Preventing airborne contamination - Guidance and fundamental requirements. 2015.

21. Reinmüller B, Ljungqvist $B$. Modern cleanroom clothing systems: People as a contamination source, PDA Journal of Pharmaceutical Science and Technology 2003; 57(2):114-125. 
22. Whyte W, Hamblen DL, Kelly IG, Hambraeusj A, Laurellt G. An investigation of occlusive polyester surgical clothing. Journal of Hospital Infection 1990; 15(4):363374.

23. Scheibel HJ, Jensen I, Pedersen S. Bacterial contamination of air and surgical wounds during joint replacement operations. Comparison of two different types of staff clothing. Journal of Hospital Infection. Journal of Hospital Infection 1991; 19:167-174.

24. Tammelin A, Ljungqvist B, Reinmüller B. Comparison of three distinct surgical clothing systems for protection from airborne bacteria, a prospective observational study. Patient safety in Surgery 2012; 6:23.

25. Tammelin A, Ljungqvist B, Reinmüller B. Single-use surgical clothing system for reduction of airborne bacteria in the operating room. Journal of Hospital Infection 2013; 84:245-247.

26. Ljungqvist $B$, Reinmüller B. Clothing systems evaluated in a dispersal chamber. European Journal of Parenteral and Pharmaceutical Sciences 2014: 67-69.

27. Würst G, Freidl H, Haas D, Köck MPSF, Schlacher R, Marth E. A comparison between Andersen (ACFM) and Reuter Centrifugal Sampler (RCS-plus) for indoor sampling of airborne molds. Aerobiologia 2003; 19:125-128.

28. Lewandowski R, Kozlowska K, Szpakowska M, Trafny E. Evaluation of applicability of the Sartorius Airport MD8 sampler for detection of Bacillus endospores in indoor air. Eviron Monit Assess 2013; 185:3517-3526.

29. Ljungqvist B, Reinmüller B, Tammelin A. Comparison between two measuring methods with active air sampling of airborne viable particles. European Journal of Parenteral \& Pharmacutical Science 2012; 17(2):56-59.

30. Lidwell OM, Lowbury EL, Whyte W, Blowers R, Stanley S, Lowe D. Effect of ultraclean air in operating rooms on deep sepsis in the joint after total hip or knee replacement: a randomised study. British Medical Journal 1982; 285:10-14.

31. EN-ISO 14698-1. Cleanrooms and associated controlled environments Biocontamination control - Part 1:General principles and methods. 2003. 
What if the protected area is smaller than expected? 


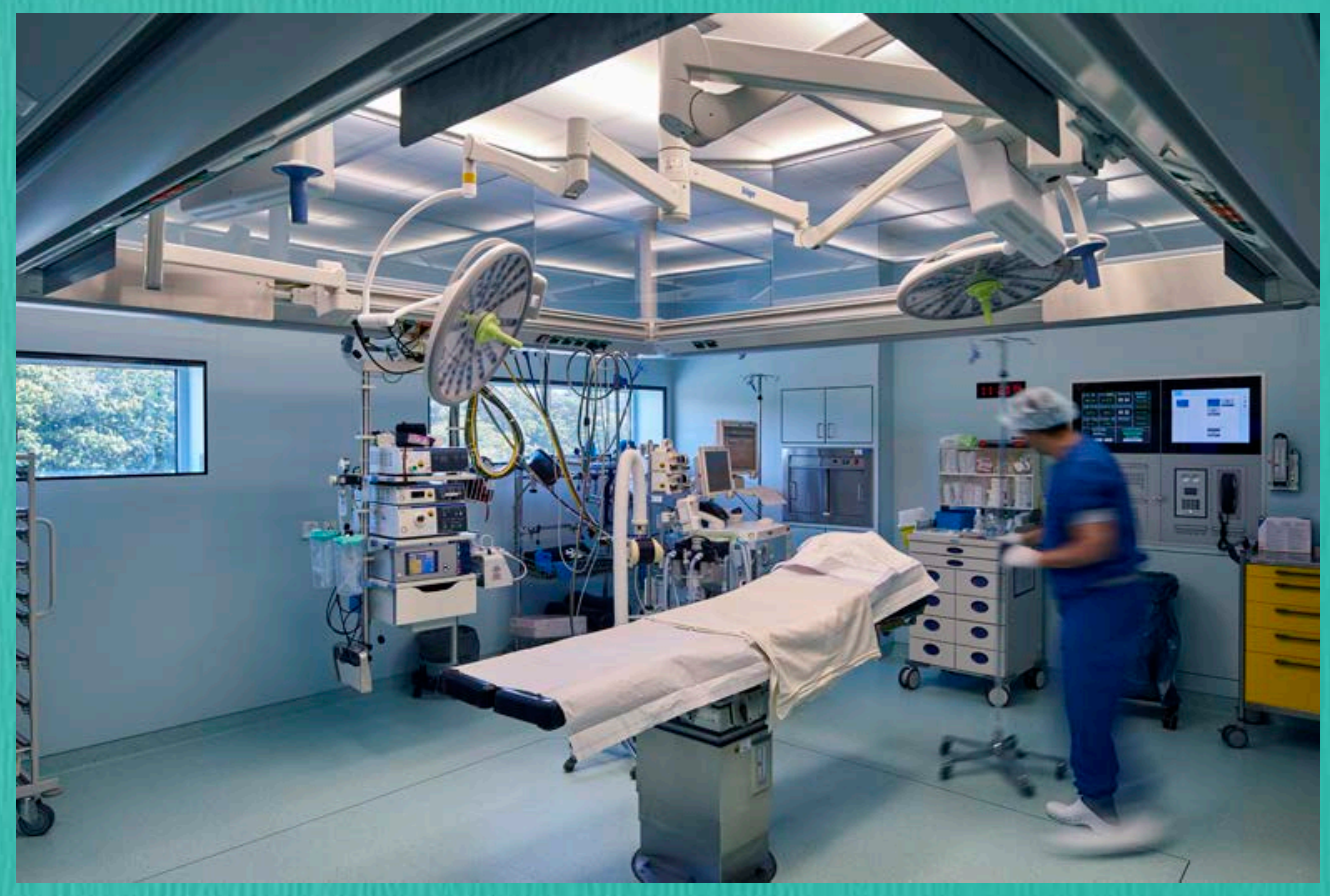


Chapter 9

Conclusions, general discussion and future directions of research 


\section{Conclusions, general discussion and future direction of research}

This chapter presents the conclusions of the different studies as conducted to provide answers to the research questions formulated in chapter $1 .^{1-5}$ Based on this studies general conclusions will then be presented as well as directions of future research.

\subsection{Answers to the research questions}

1) Is a clean area of $3 \times 3$ meter, often used in Dutch operating rooms, sufficient to position the patient, sterile instruments and the surgical team?

Chapter 2 describes a study in which a traditional design has been evaluated by process simulations of various surgical workflows with different types of surgery. This study was conducted in one of the academic hospitals in the Netherlands and followed the surgical workflow processes in this particular hospital. Four hypotheses were tested during the process simulations:

a) The $3 \times 3 \mathrm{~m}^{2}$ sized clean area surface is large enough to carry out all interventions.

b) Positioning the clean area in the middle of the operating room results in an optimal layout for moving of both the patient and equipment in the operating room.

c) The classic positioning of the anaesthesia section, near the entrance of the operating room, is the optimal position for the logistical processes in the operating room.

d) A supply bridge height of $2.05 \mathrm{~m}$ results in the clean area being sufficiently accessible for high medical equipment and reachable for the staff to make connections (electricity, vacuum, etc.). 
Conclusions:

a) It is concluded that a clean area measuring $3 \times 3$ meter was satisfying for most defined situations, provided a movable operation table is used. ${ }^{1}$ The operations taken into account were 1) trauma hip, 2) surgical robot (Da Vinci), 3) trepanation including movable microscope and 4) orthopaedic (knee arthroscopy and hip arthroscopy including the use of a C-arm). During polytrauma interventions however, bottlenecks regarding the dimensions of the clean area occurred. For this type of surgery, a size of $3.20 \times 3.20$ meter is proposed.

b) In case of larger dimensions of the operating room the unidirectional downflow terminal should not be positioned centrally in the operating room for an optimal logistic layout as is customary in traditional designs. For the temporary storage of equipment during the procedure it is more effective to position the plenum eccentrically so additional space is created at the main entrance to the operating room rather than being equally divided around the clean area.

c) The positioning of the anaesthesia section on the side of the clean area offers a better logistical layout of the operating room than the traditional set-up between the clean area and the entrance. During the process simulations it became apparent that the classic positioning of the anaesthesia section (with the back facing the corridor) hinders the transport of the patient's bed from the corridor into position alongside the operating table without a lot of manoeuvring. The simulations also showed the increased risk of bumping into the anaesthetic equipment with the bed.

A disadvantage was the longer route of the anaesthesiologist from entering the operating room to the anaesthesia section. This may cause more disturbance of the UDF air flow.

d) To improve the UDF air flow a skirt and supply bridge around the canopy was considered in this design. ${ }^{6}$ The supply bridge was positioned 2.05 meter above floor level. 
For most staff, a height of $2.05 \mathrm{~m}$ is workable for making connections in the slanted part of the supply bridge. A lower height of the supply bridge would lead to an increase in the number of collisions with equipment like the Da Vinci operating robot and the surgical microscope. If tall surgeons use an operation helmet, like in orthopaedics, there may also be a conflict with the height.

It is concluded that process simulations have great value during the design of an operating room lay-out. Even though there is always the issue whether to study the current or future (new) workflow that is adjusted to the new situation.

Knowing the required size of the protected zone in an operating room is very important during the design phase of the air distribution system in the operating room, especially if UDF systems are used that generate a cleaner zone. Outside this zone the number of microorganism carrying particles will be higher than inside this zone. ${ }^{6}$ If sterile instruments are positioned outside this zone the risk of contamination by microorganisms will increase. For the surgical team it is essential to know where to best position the sterile instruments and implants during surgery. ${ }^{7,8}$ If a movable operation table is used it is easier for the staff to position sterile instruments and implants within the zone protected by a UDF system. ${ }^{1}$

However, the protected area realized with a UDF system is determined in the "at rest" condition according to test methods based on the entrainment test. ${ }^{9-12}$ In this type of measurements all equipment is present and in operation but without the process or the presence of people. ${ }^{13}$ As a result, the size of the protected area may deviate from the test during operational process. Operational means including the complete process and realistic positioning of medical equipment and instrument tables. The effect of operational conditions on the size of the protected area according to different test methods has not been investigated. ${ }^{9-12,14}$ 
2) Is the area that is protected by a UDF system influenced by a skirt, different types of operating lamps and the position of the lamp?

The size and shape of the operating lamp influences the size and quality of the protected zone of a UDF system as shown in chapter $3 .^{2}$ This experimental study shows that the type and position of the operating lamps may have a significant effect on the area protected by the system. The study also shows that a skirt around the supply terminal does not influence the size of the area protected by the system as such, but has a significant effect on the quality of the protected area. The degree of protection in the centre of the protected zone e.g. position of the operating table increased from 2.91 to 5.02 (no skirt versus with skirt). In practice this means that for this UDF system a skirt around the canopy results in an even 100 times cleaner centre of the protected area than without a skirt. It was also demonstrated that an operating lamp with an open structure has less effect on the size of the protected area than an operating lamp with a closed structure. Figure 9.1 shows the difference in size of the protected zone created by a UDF system in the operating room for different operating lamps. In this situation the operating lamps were in the standard position. ${ }^{10}$ These findings are in agreement with other studies. ${ }^{15}$ So when adjusting existing systems to improve performance, the optimal design would be a skirt around the canopy of the UDF system and operating lamps with an open structure that allows air to pass through. This combination may also be used in new designs to maximize the effectiveness of the air distribution system. 


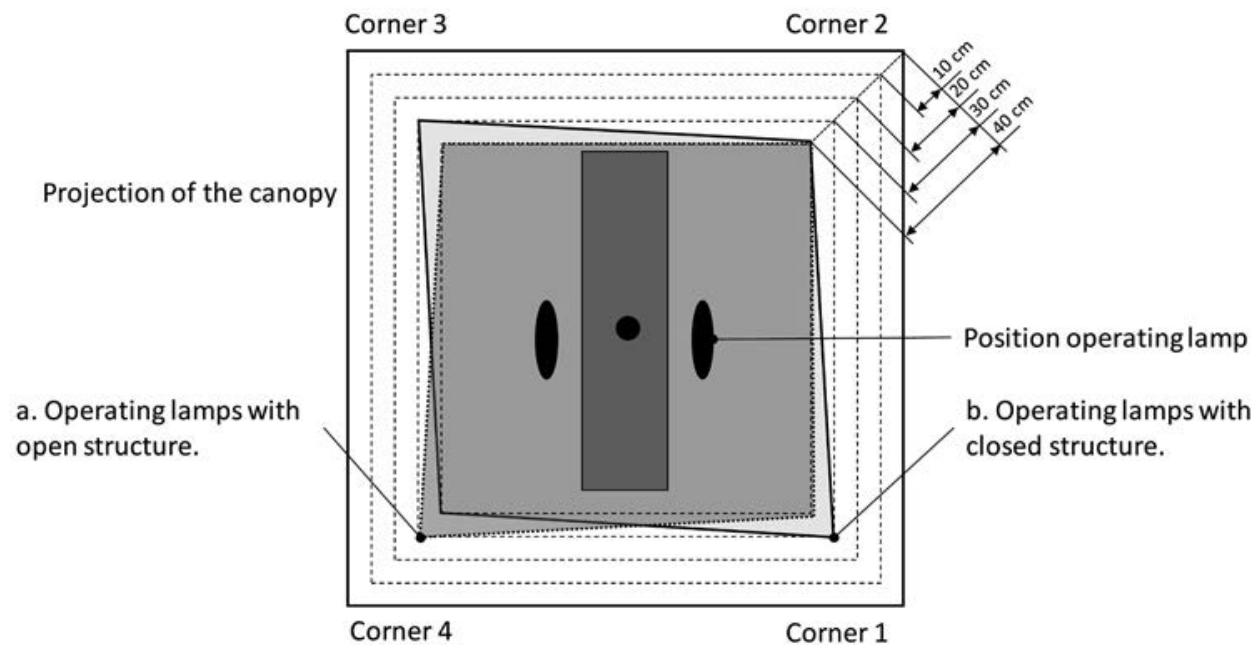

Figure 9.1. Size and quality of the protected zone for operating lamps with an open structure (a) and closed structure (b), both in the standard position. ${ }^{2}$ Area: a. degree of protection in the centre of the protected zone is $5.24, b$. degree of protection in the centre of the protected zone is 4.92

3) Is it possible to switch off the ventilation system of operating rooms during prolonged inactivity e.g. during the night and weekend without negative effects on the air quality during normal operational hours?

In chapter 1 it is mentioned that distribution of air through hospitals is associated with high energy consumption. ${ }^{16-18}$ Switching off ventilation systems during prolonged inactivity can help save energy. Chapter 4 concludes that switching off the ventilation system during prolonged inactivity (e.g. during nights and weekends) has no negative effect on the air quality in UDF operating theatres during regular operational hours. ${ }^{3}$ In three different operating rooms at three different sites measurements are performed indicating that after starting up the system, the protected area achieved the required degree of protection within 20 minutes. The findings are in agreement with other studies. ${ }^{19}$ 
The results also show a stable temperature difference, between the supply air temperature and the temperature in the periphery, within 23 minutes after starting up the system.

In practice this time seems long enough to start up the system and start with the preparations for surgery. Based on 1241 trauma cases the time needed for preparing patients before the start of surgical procedures is estimated at 25 minutes. ${ }^{20}$ If lying-up instruments is performed in the operating room this start-up time must also be taken into account. It is only safe to start this process if the required degree of protection is achieved. If a separate lay-up room is used with a continuously running system the laying up process and patient preparation can be performed in parallel.

To control the temperature in the operating room during prolonged inactivity, a small amount of air is required to reduce the heat load caused by e.g. medical equipment, lighting, solar radiation through windows and heat transfer through walls of the operating room. Medical equipment in the operating room is often not switched off during prolonged inactivity. Without the minimal airflow, the temperature in the operating room will increase because of the heat load, regardless of the type of air distribution system. A small amount of fresh air also is necessary to remove unpleasant odours and the emission of substances from e.g. cleaning agents and building/construction materials. ${ }^{21-23}$

\section{4) Can a horizontal UDF (UDHF) system in terms of prevention of contamination of the air safely be used during the laying-up process on the instrument table?}

The instruments used during surgery are also an important source of contamination of the surgical wound, figure 1.6. ${ }^{24,25}$ The reusable instruments are handled with great care. To prevent contamination during laying-up of the sterile surgical instruments this should be performed in a clean environment without disturbance by other activities in the same room. Reusable instruments are cleaned, checked, packed sterilized by steam and stored with great care but may already preoperatively be contaminated by a sub-optimal layingup process. ${ }^{26}$ 
Chapter 5 demonstrates in an experimental setting with a simulated process the effect of different systems with respect to the protection of sterile instruments during the laying-up process against aerogenic contaminations. ${ }^{4}$ In this study it is concluded that a horizontal UDF system offers at least the same protection against aerogenic contamination during the laying-up process as UDF downflow systems.

Although the differences between the two systems did not always show statistical significance, there is a clear trend, from small-sized particles up to the largest sizes considered, including bacteria-carrying particles that demonstrate the superiority of the horizontal flow system to a UDF downflow system during a laying-up process. The horizontal system offers a more robust solution than the downflow system, provided that good work processes are used and the height of the instrument table is adapted to the height of the supply plenum. In this study the number of particles as well as the number of microorganism carrying particles was measured.

\section{5) Does the use of a mobile ultraclean laminar airflow screen reduce the air-borne} particle counts in a non-ventilated room to a level safe for the patient? For surgery with a small surgical wound and a limited number of surgical instruments systems with a small protected area in the operating room may be used. Chapter 6 shows that even mobile UDF systems can be used for small ambulatory procedures like intravitreal injection in a clean environment. ${ }^{19}$ Mobile unidirectional flow units show a degree of protection up to 5 for the instrument table and a degree of protection of 2.64 for the area near the ocular surface. If used in a poorly ventilated room with the proper positioning of the unit and surgical drapes placed correctly a mobile UDF mobile unit may sufficiently prevent aerogenic contamination in the setting of intra-vitreal injections. To do so it is important to precisely adjust the setting for each particular site, in order to determine the actual present degree of protection. In this study only one type of system was used.

Other systems are available like the air barrier system (ABS) and complete modules covering the patient and surgeon. ${ }^{27}$ 
The latter is specially designed for eye surgery in treatment rooms. However, for these mobile modules no scientific papers regarding the protection against entrainment of particles or resulting levels of CFU or SSIs are available.

\section{Limitations of the studies}

The limitation of the used method for research question 1 is that the results are only valid for the surgical procedures as analysed, the medical equipment as used, and the workflow as used. During process simulations, there is always the issue of whether to study current workflows or future (new) workflows that are better adjusted to a new situation. In this study, the process simulation was performed based on the existing routines. ${ }^{1}$

Measurements based on the entrainment principle as used in the studies to research questions 2-5 in chapters 3-6, also have limitations. The limitations of these type of measurements are that mainly airborne particles are considered and not the deposition of the larger particle sizes. The emitted particles are however a good proxy for the behaviour of the air flow and it is assumed that these emitted particles behave approximately the same way as microorganism carrying particles. These measurements are performed during an at rest situation in a limited number of situations. This means that during the measurements no staff or patients were present in the operating rooms or instrument layup rooms. Presence of moving people in these rooms will influence the results. 


\subsection{Overall conclusion and discussion}

\section{1) Comparison of systems}

Based on the studies presented in chapters 2-6 it is concluded that UDF systems have the ability to protect an area against aerogenic contaminants in an effective way at different places of the operating theatre: lay-up room, large and small operating rooms. The effectiveness of a system against entrainment of microorganisms carrying particles from outside the protected area is affected by many variables. Various studies confirm that technical variables like size of the supply canopy, air speed, temperature difference between the supply air and the temperature in the periphery, position of the exhaust points, type of operating lamps and presence of a partial wall around the canopy are all important variables that need to be considered..$^{2-6,15-18,28-35}$ Also more process-oriented variables are considered important like activity level in the operating room including number of door openings, positioning of instrument tables, number of persons in the operating room, clothing system and speed of movement of the staff. ${ }^{8,36-43}$ These processoriented parameters also effect the performance of diluting mixing systems in at least the same way. Based on this research the classification of a system only by terms like UDF or diluting mixing system is not enough to define a system. If a differentiation between UDF and diluting mixing systems is to be made other parameters like amount of supply air, size of the supply canopy (UDF), level of filtration, should be mentioned.

Several studies based on retrospective analyses of surveillance SSI registers investigating the influence of air distribution systems on the risk for SSI don't define the different air distribution systems as used unambiguously. ${ }^{44-48}$ These studies mostly obtained information about the type of the air distribution system as used in the operating room by questionnaires. But if a diffuser, canopy or plenum is used the system will be classified as UDF system in most cases without knowing whether this system indeed performs as a UDF system based on performance tests. Moreover, in these publications the answers on the questionnaires by the hospital or surgeons were not validated. 
A system equipped with a diffuser, canopy or plenum in the ceiling does not automatically mean that these systems will function as a UDF system. ${ }^{28-32,49,50}$ The size of the area protected by a UDF system depends on many factors like the presence of a skirt, the positions of the exhaust terminals, air speed and profile of the supply air, etc.. ${ }^{6,28,30,33}$ Chapter 3 shows the typical shear mixing layer of the UDF plug flow in an operating room is about $40 \mathrm{~cm}$ in the corners of a rectangular or square supply diffuser, canopy or plenum for a system working properly, figure 9.1. For a not optimal performing UDF system the size of the protected zone is given in figure 9.2 as an example. Even if the systems are tested according to national guidelines this often only gives a performance on the operating table and does not include the performance at the level of the instrument tables. ${ }^{10,12,14}$

Also in studies regarding the cost of ventilation systems the different air distribution systems are not defined unambiguously. ${ }^{51}$ In the study of Cacciari an operation department with a low supply volume of the air supply system and without proper filtration was changed into a modern operation department with HEPA filtration and high supply volumes. Most of the cost reported refer to the filter system and not the air distribution system in the operating theatre itself. 


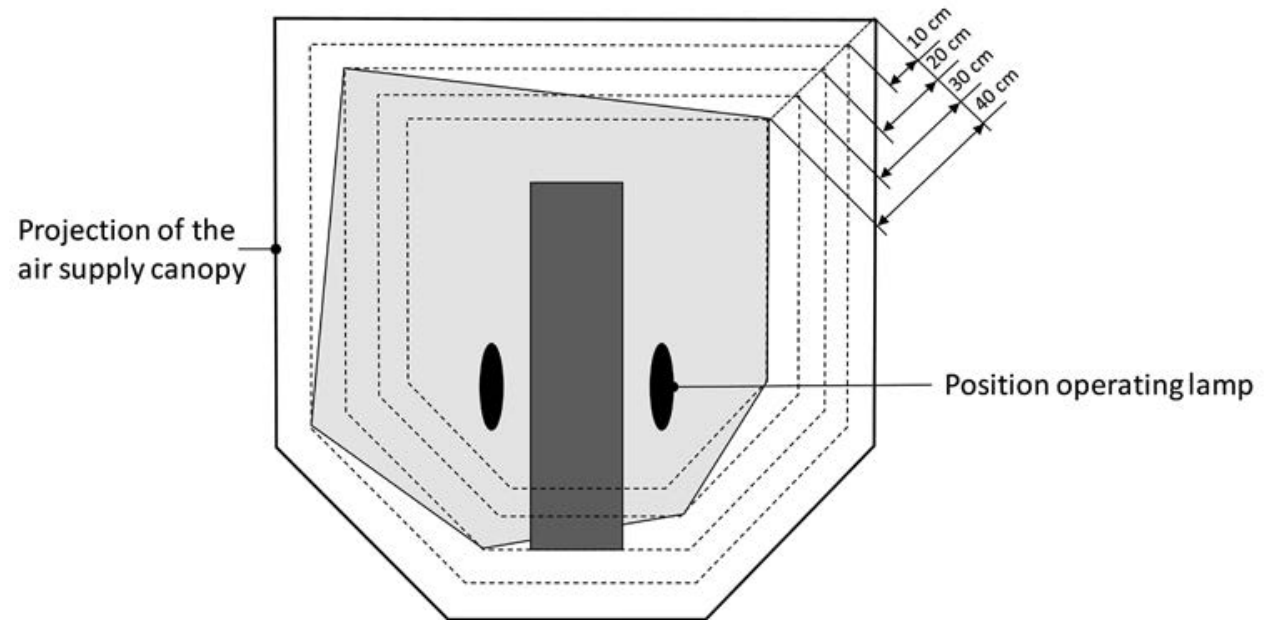

Figure 9.2. Asymmetric protected area (degree of protection $>2$ ) measured by TNO according to VCCN-guideline 7 at an anonymous hospital. ${ }^{11}$

Comparing systems by just a type identification is therefore insufficient and the results of those studies are not reliable (chapter 7 ). ${ }^{52}$ Comparing not clearly defined systems has no sense. If the type of systems is compared, at least the technical and process-related aspects as shown in figure 9.3 should be considered. A good comparison between air distribution systems is only possible for systems with the same amount of supplied air. Only in this way is the performance of the distribution system compared instead of the air volume. 


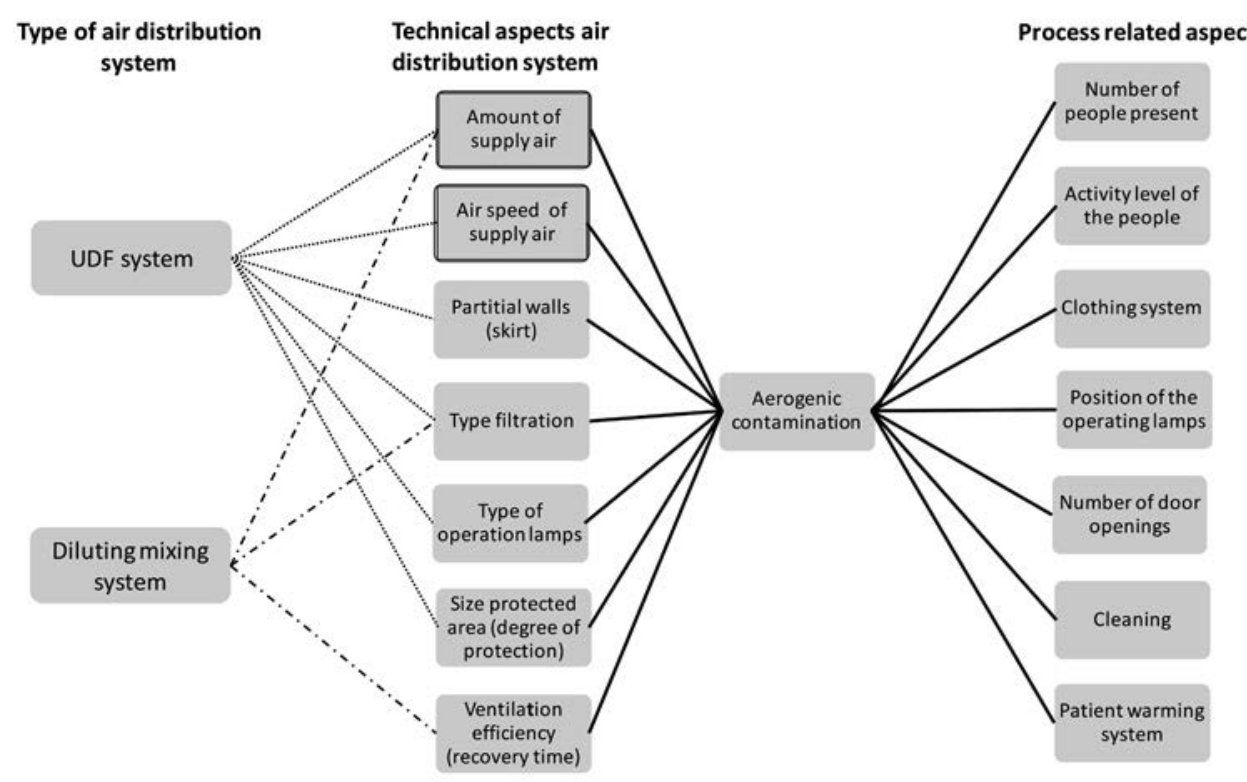

Figure 9.3. Aspects that determine the aerogenic contamination in an operating room.

What matters is the air cleanliness reached by the system with its specific characteristics at critical positions like the wound area, the instrument table and implants..$^{53}$ The difficulty of defining a solid relation between the number of aerogenic microorganisms and the frequency of $\mathrm{SSI}$ can be caused by the different measuring positions and sampling method as used. $27,49,50,54,55$ However the evident relation between type of system and number of aerogenic microorganisms is clearly demonstrated in a number of studies. ${ }^{8,27,50,56-62} \mathrm{Agodi}$ also shows in his study that a UDF system provides a more robust solution to reduce the number of $\mathrm{CFU} / \mathrm{m}^{3}$ and $\mathrm{CFU} / \mathrm{m}^{2}$.h than diluting mixing systems and small UDF systems referred to as "turbulent airflow ventilation". ${ }^{54}$ This is despite the fact that CFU counts of UDF systems are not always below the threshold value of $10 \mathrm{CFU} / \mathrm{m}^{3}$ or $350 \mathrm{CFU} /\left(\mathrm{m}^{2}\right.$.h) as suggested by Charnley, Lidwell and Friberg for ultraclean systems. ${ }^{49,50,54,63,64}$ Reduction of the number of aerogenic micro-organisms undoubtedly reduces the contamination of the surgical wound and implants. 
Most UDF systems deliver a larger amount of clean air to the room compared to diluting mixing systems. The delivery of large amounts of air (typically $9,000-10,000 \mathrm{~m}^{3} / \mathrm{h}$ for $9 \mathrm{~m}^{2}$ systems) can most effectively be carried out by UDF canopies. Some studies indicate that this amount of air supplied to an operating room is the most important variable to reduce CFU levels in an operating room and instrument lay-up room. ${ }^{35} \mathrm{~A}$ second order effect is the way the supplied air is distributed in the room (supply and exhaust). In UDF systems especially the air velocity is an important factor to consider. Above the operating table the airflow is easily disrupted by operating lamps, monitors and their support arms if supply air velocities are below 0.3-0.4 m/s. ${ }^{6,35,65,66} \mathrm{In}$ a well-controlled surgical process (process discipline optimised clothing system, limited number of door openings, etc.) low levels of CFU can also be realised by diluting mixing systems. However in case of disruption of this surgical process e.g. calamity or less controlled process with respect to the design boundaries, a diluting mixing system is less capable of coping with the disruption resulting in an increase of CFU level.

\section{2) Outcome variable of systems}

Some studies suggest that passive microbiologic sampling in operating rooms with settle plates, are a good predictor of the contamination of operating wounds. Other studies refer to active sampling as a good proxy for contamination of operating wounds. . $5,61,62,64,67-^{-}$ 70 The ratio between the number of CFU's measured on the settle plates and in the air may also depend on the type of clothing system and level of activity in the operating room. Friberg proposed to use a surface contamination rate of $<350 \mathrm{CFU} /\left(\mathrm{m}^{2} . \mathrm{h}\right)$ obtained by settle plates instead of $<10 \mathrm{CFU} / \mathrm{m}^{3}$ obtained by active sampling (slit sampler, impaction sampler or gelatine filter) to define ultraclean air systems ${ }^{64}$ Agodi found a significant correlation between bacterial contamination recorded during surgical activity by active sampling $\left(\mathrm{CFU} / \mathrm{m}^{3}\right)$ and that recorded by passive sampling (CFU/( $\left.\left.\mathrm{m}^{2} . \mathrm{h}\right)\right)$, figure $9.4 . .^{54}$ 


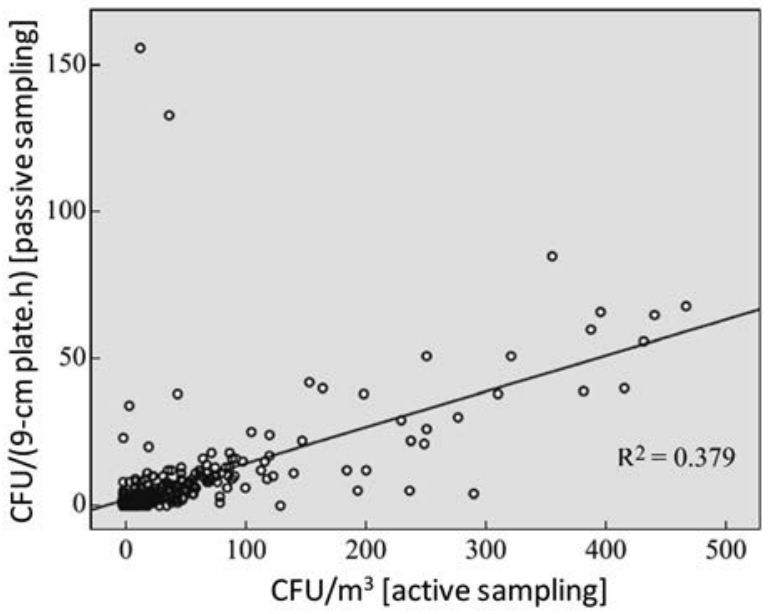

Figure 9.4. Correlation between microbial air contamination values measured by active (impaction) sampling [colony-forming units (CFU)/ $\mathrm{m}^{3}$ ] and microbial air contamination values measured by passive sampling by settle plates [CFU/(9-cm plate.h)].54

In diluting mixing systems an important factor is the deposition velocity of the microorganism carrying particles (figure 9.5). The most important mechanism for deposition of $>5 \mu \mathrm{m}$ particles is gravity. In clean rooms for electronics, optics and pharma it is recognised that it is hard to establish a direct relation between airborne particle counts and contamination of surfaces by these particles. This is mainly caused by the larger particles ( $\geq 25 \mu \mathrm{m}$ ) depositing on surfaces. ${ }^{71-73}$ The mechanism of deposition of larger particles that can carry microorganisms in operating rooms equipped with UDF systems has not been studied, it is not clear to what particle size UDF systems are effective e.g. preventing deposition of particles on critical surfaces in the operating room. This mechanism can explain why there is no clear relationship between the number of airborne microorganisms carrying particles and the results of passive sampling (settle plates) in operating rooms. 


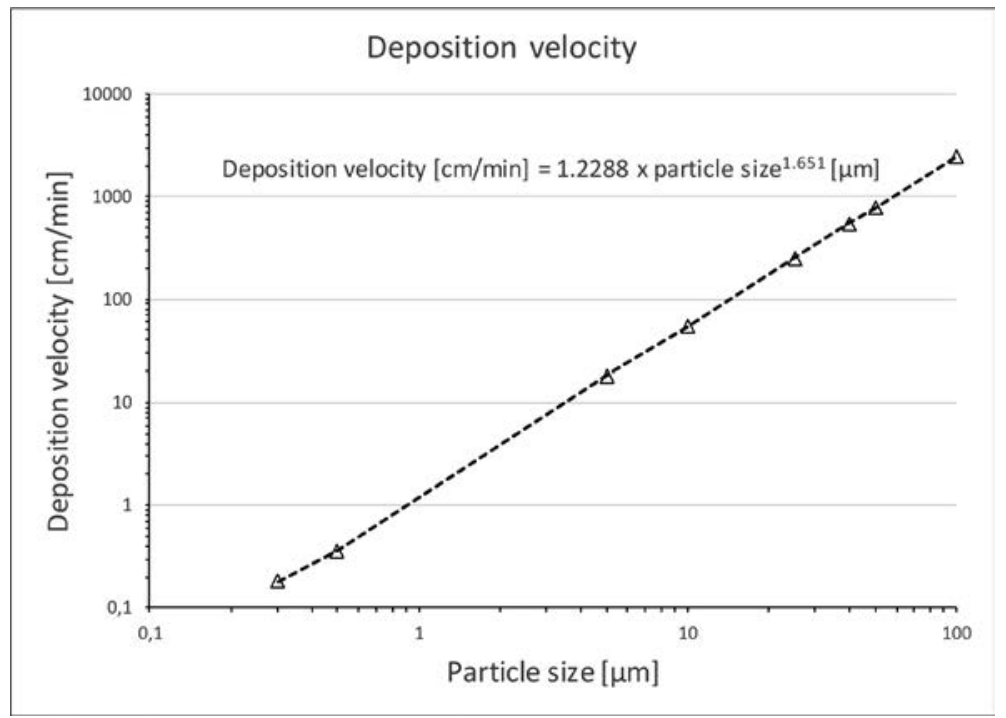

Figure 9.5. Deposition velocity obtained from observations in an ISO Class 8 clean room (turbulent mixing system). ${ }^{72}$

The performance of an air distribution system in operating rooms should be expressed in the ability/potential to discharge microorganisms carrying particles. The better the system is able to do so, the lower the chance of microorganism carrying particles depositing on instruments or in the operation wound. At rest this can be demonstrated by technical measurements with a defined source strength of particles and during real surgery this can be determined by measuring the number of $\mathrm{CFU} / \mathrm{m}^{3}$ or $\mathrm{CFU} /\left(\mathrm{m}^{2}\right.$.h). Strength and weakness of using $\mathrm{CFU} / \mathrm{m}^{3}$ or $\mathrm{CFU} /\left(\mathrm{m}^{2} . \mathrm{h}\right)$ as an indicator of the systems performance is that this outcome is not only depending on the characteristics of the air distribution system in the operating room but also on processes in the operating room.

In legal contracts between the customer and the contractor, it seems almost impossible to make the acceptance of a system dependent on matters on which the contractor has no influence, such as the processes in the operating room, clothing systems, number and behaviour of the staff. 
Especially because these processes have an influence on the source strength (CFU/ $\mathrm{m}^{3}$ or $\left.\mathrm{CFU} /\left(\mathrm{m}^{2} . \mathrm{h}\right)\right)$ the system has to eliminate, especially for diluting mixing systems.

This seems to be an important factor for systems being tested without a real surgical process taking place and why acceptance of a system is based on technical measurements. These tests can also be divided into two types (figure 9.6). One type of test is measuring the technical parameters like air velocity, amount of supply air, temperature and pressure difference. On the other hand, there is a more performance-based test in which a systems performance is challenged. This challenge is based on emission of particles by a controlled artificial source simulating the process in an operating room. These types of tests are recovery tests and entrainment or segregation tests. Preferably these tests should be conducted with the operating lamps monitors, including support arms, and as much as possible of the standard equipment, e.g. anaesthetic machines, diathermy in a defined standard position and in standby mode. Also heat sources can be applied to simulate the heat load during surgical procedures. Most of these performance tests are performed with small particles $(\leq 0,5 \mu \mathrm{m}) .^{9,10,12,14}$ So these tests demonstrate the performance of the system for airborne particles not taking into account de deposition of larger particles ( $>4$ $\mu \mathrm{m}$, the size of potentially microorganisms carrying particles) on surfaces. ${ }^{74,75}$ However before the performance-based tests are conducted technical tests shall be performed to demonstrate that the technical parameters are in compliance with the design values.

After the system is handed over to the client, tests may be conducted to demonstrate the performance of the system during ongoing surgical procedures by measuring both the CFU level in $\mathrm{CFU} / \mathrm{m}^{3}$ and $\mathrm{CFU} /\left(\mathrm{m}^{2} . h\right)$ at the critical position in the operating room e.g. close to the surgical wound, sterile instruments and possibly implants. For systems that are designed based on a specific source strength, resulting from the number of people and clothing system, this is a good way to demonstrate the performance. Designs of diluting mixing systems are often based on source strength. Also for situations where sterile materials e.g. instrument tables and implants are positioned at the edge or even outside of the protected zone of a UDF system, these test are valuable to gain insight into the effect of this arrangements (chapter 8). ${ }^{53}$ 
CFUs at the critical positions in the operating room are the best measurable predictors for the clinical outcome parameter SSI that is related to the air distribution system. Active sampling is related to airborne microorganisms carrying particles while passive sampling is related to deposition of (large) microorganisms carrying particles on surfaces. Passive sampling is more sensitive to local air flows and (small) particles do not settle undisturbed. ${ }^{70}$ This results in a less sensitive but easier to use method giving an indication of the deposition of large microorganisms carrying particles in the wound, on instruments and implants. Both methods must be used in parallel to get a complete picture of the risk on aerogenic contamination of instruments and operating wounds.

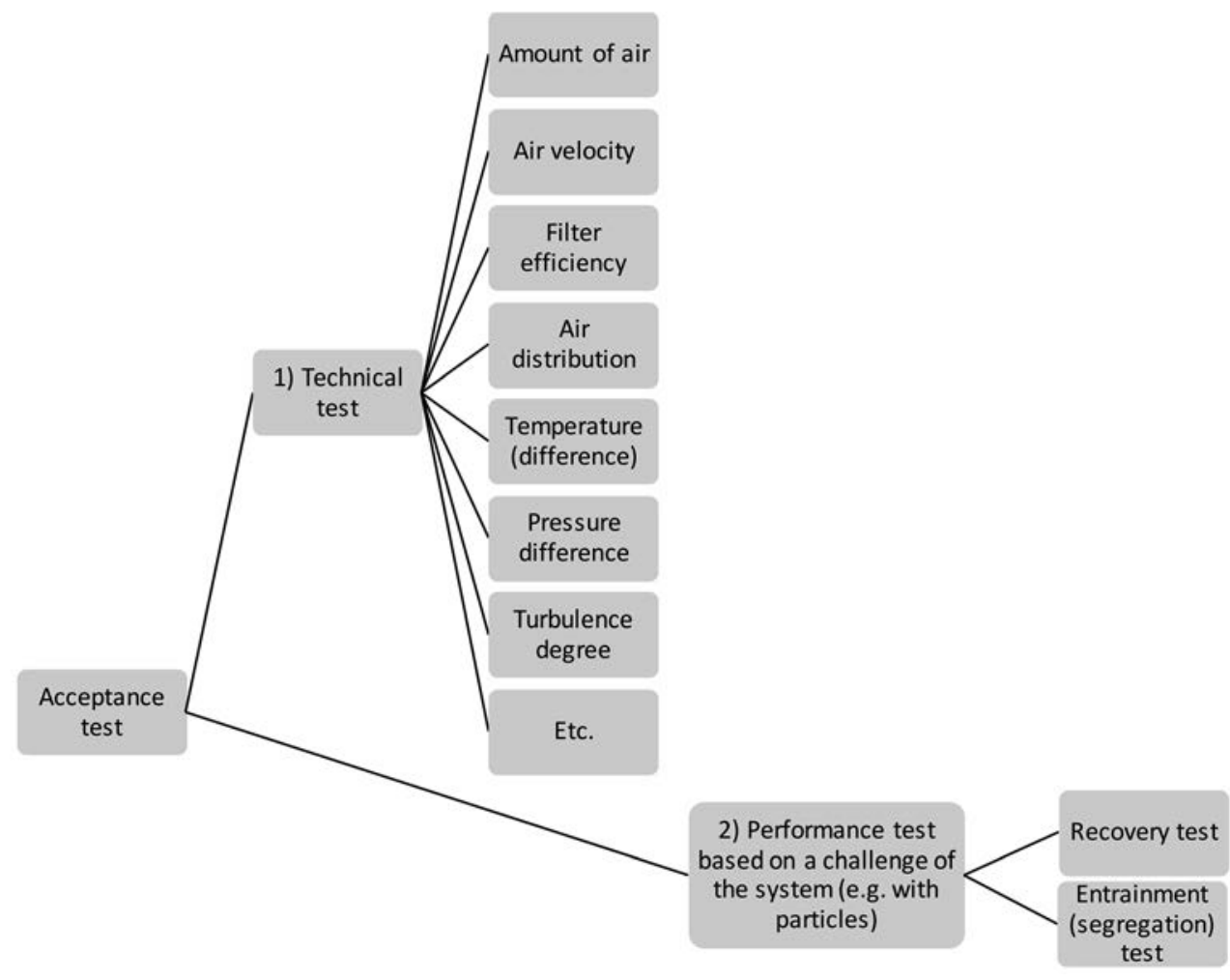

Figure 9.6. Types of acceptance tests. 


\subsection{Future direction and concluding remarks}

The air distribution system is important in reducing the number of microorganisms carrying particles thus reducing the number of microorganisms on the instruments and in the surgical wound. The air distribution system also protects the staff against harmful substances like surgical smoke and anaesthetic gasses.

To make better-informed choices possible for the type of air distribution system and to be able to apply these systems in the most effective way, further research is still necessary. This is necessary not only in the field of optimising the performance of systems with regard to the removal efficiency of potentially microorganisms carrying particles but also in relation to the investment and maintenance costs. The suggested future research topics are:

1) The source and contamination route of microorganisms causing SSI

2) Comparison of systems on an unequivocal comparison basis

3) The size of the protected zone during ongoing surgery

4) Reducing the negative effects of operating lamps on the air flow at UDF systems

5) Improving the air quality during surgical procedures performed outside the operating complex

1) The source and contamination route of microorganisms causing SSI

Many studies show that SSI of implants are caused by exogenous microorganisms, but some others suggest that SSIs may have also an endogenic source. ${ }^{63,76-89}$ Arthroplasties may e.g. get infected via a hematogenous route from a bladder or soft tissue infections. These endogenous hematogenous infected prostheses may occur during lifetime, and mostly they occur > 1year after implantation. 
Endogenous infection is suggested also in the early postoperative period when patients who carry S. aureus in their nose showed less deep SSI when they are treated with mupirocine to prevent infection with these bacteria. ${ }^{86,90}$ There is however not much information about the origin of the exogenous contaminating bacteria of surgical wounds.

Lidwell isolated a wide variety of microorganisms from septic joints after total hip or knee joint replacement ( $n=86$ of which 63 were from conventional ventilated operating rooms and 23 from operating rooms with UDF systems from a total of 8052 operations). ${ }^{91}$ In 14 cases there was sufficient information to identify a possible source of the staphylococci. Based on that it was concluded that $50 \%$ of the patients were nasal carriers and one was also a perineal carrier. In two infected wounds the strain carried by the patient was the same as isolated from the wound. In the infected wound also $S$. aureus strains from the surgeons and surgical team were found.

The microorganisms that cause exogenous infections originate from the surgical team direct (via the air) or indirect via hands and instruments or may originate from operations previously carried out in the operating room. Knobben showed that microorganisms will transfer between different types of materials used in the operating room. ${ }^{92}$ Moist donors transfer bacteria much easier than dry surfaces and the bacteria adhere best to theatre gown material. To lower the risk of post operative infection it is suggested to dip the surgical gloves in a chlorhexidine splash-basin every 10 minutes. This is an easily applicable method to decrease bacterial transfer into the wound. Whyte suggests in his study that approximately $98 \%$ of the microorganisms in the patients surgical wound in a diluting mixing system is transferred directly or indirectly by the air. ${ }^{62} \mathrm{He}$ also showed that only a small amount fell directly into the surgical wound, this amount was estimated at $30 \%$. The other $70 \%$ came into the surgical wound indirectly by deposition on other surfaces. More research is needed to clarify these aspects. Also more studies need to be conducted to investigate the mechanism of deposition of larger particles (potentially carrying microorganisms) in UDF systems during surgery. 


\section{2) Comparison of systems on an unequivocal comparison basis}

There are no studies that compare the effect of using a UDF and mixing system with the same amount of supply air and a clear definition of other relevant variables (figure 9.1) on the risk for SSI's. There is also a lack of studies addressing the investment and operational costs of different systems. In these studies, a correct comparison basis must also be maintained, whereby a distinction should be made between a new building situation and renovation. The hypothesis is that UDF systems with the same amount of outdoor air (ODA) and the same amount of secondary air (SEC) have comparable investment and operating costs as mixing systems, figure 1.2. If these proposed studies are carried out, this can contribute positively to the discussion regarding different types of air distribution systems.

\section{3) The size of the protected zone during ongoing surgery}

Determination of the size of the realised protected area takes place without a surgical process taking place (at rest). ${ }^{10,12,14}$ It is assumed that the protected zone has about the same dimensions during surgery as at rest, although personal moves, and more heath is produced. However, the difference in size of the protected zone at rest and during surgical procedures has not been studied yet. Research is needed to determine the size of the protected area during ongoing surgery as well as at rest. On the basis of such research, it can be demonstrated from the point of view of aerogenic contamination where it is justified to position the instrument tables.

\section{4) Reducing the negative effects of operating lamps on the air flow at UDF systems}

The industries can design types of operating lamps that provide the necessary light with minimum disturbance of the UDF air flow and a low surface temperature. Also more research should be performed in using high performance head lamps instead of fixed operating lamps. Modern technology makes it possible to create high performance and energy efficient (LED) lights with low weight and long-lasting battery packs. This type of light is always focusing on the right place providing the surgeon optimal lighting conditions. 
When using this type of head lights conventional operating lamps may be no longer needed. Besides a less disturbed UDF air flow this can reduce the investments and operational cost as well.

5) Improving the air quality during surgical procedures performed outside the operating complex

Further research should be conducted to investigate if mobile systems can be used to reduce the aerogenic contamination at the surgical wound and sterile instruments during smaller surgical procedures performed at places that are not designed for large operations, as day care surgery, treatment rooms, private clinics, rooms in outpatient clinics and even in general practitioner practices. The contamination of air and instruments as well as the frequency of SSI should be monitored carefully in all new developed creative air handling systems, designed for such special situations and locations. 


\section{References}

1. Traversari R, Goedhart R, Schraagen JM. Process simulation during the design process makes the difference: Process simulations applied to a traditional design. Health Environments Research and Design Journal. 2013;6(2).

2. Traversari AAL, Bottenheft C, Louman R, van Heumen SPM, Böggemann J. The effect of operating lamps on the protected area of a unidirectional down flow (UDF) system. Health Environments Research and Design Journal. 2017;10(3):40-50.

3. Traversari AAL, Bottenheft C, van Heumen SPM, Goedhart CA, Vos MC. Effect of switching off unidirectional downflow systems of operating theaters during prolonged inactivity on the period before the operating theater can safely be used. Am J Infect Control. 2017;45(2):139-144.

4. Traversari AAL, Goedhart CA, Dusseldorp E, et al. Laying-up of sterile instruments in the operating theatre: Equal or superior protection by using a horizontal unidirectional air flow system. J Hosp Infect. 2013;85(2):125-133.

5. Lapid-Gortzak R, Traversari R, van dL, Lesnik Oberstein SY, Lapid O, Schlingemann RO. Mobile ultra-clean unidirectional airflow screen reduces air contamination in a simulated setting for intra-vitreal injection. Int Ophthalmol. 2016.

6. Whyte W, Bailey PV. Effectiveness of a partial-wall laminar-flow system with special regard to air supply temperature. J Soc Environ Eng. 1978;17(4):29-32.

7. Ritter MA, Eitzen HE, French MLV, Hart JB. The effect that time, touch and environment have upon bacterial contamination of instruments during surgery. Ann Surg. 1976;184(5):642-644.

8. Knobben BAS, van Horn JR, van dM, Busscher HJ. Evaluation of measures to decrease intra-operative bacterial contamination in orthopaedic implant surgery. $J$ Hosp Infect. 2006;62(2):174-180.

9. Departement of Health. HTM 03-01 part A: Heating and ventilation systems health technical memorandum specialised ventilation for healthcare premises. The Stationery Office (TSO); 2007.

10. DIN 1946-4:2008. Ventilation and air conditioning - part 4: VAC systems in buildings and rooms used in the health care sector. DIN. 2008.

11. VCCN Richtlijn 7. Methode voor testen en classificeren van operatiekamers en opdekruimten in rust. Vereninging Contamination Control Nederland. 2017:1-36. 
12. Önorm H 6020. Lüftungstechnische anlagen für medizinisch genutzte räume projektierung, errichtung, betrieb, instandhaltung, technische und hygienische kontrollen. Österreichisches Normungsinstitut. 2015.

13. EN-ISO 14644-1:2015. Clean rooms and associated controlled environments- part 1:Classification of air cleanliness by particle concentration. CEN (European Committee for Standardization). 2015.

14. SWKI VA105. Raumluftechnische anlagen in medizinisch genutzten räumen (planung, realisierung, qualifizierung, betrieb). Schweizerischer Verein von GebäudetechnikIngenieuren. 2015.

15. Zoon WAC, van dH, Loomans MGLC, Hensen JLM. On the applicability of the laminar flow index when selecting surgical lighting. Build Environ. 2010;45(9):1976-1983.

16. Lee $\mathrm{S}$, Liang $\mathrm{C}$. Effect of ventilation rate on air cleanliness and energy consumption in operation rooms at rest. Environmental Monitoring and Assessment. 2018;190(3):178.

17. Alsved $\mathrm{M}$, Civilis $\mathrm{A}$, Ekolind $\mathrm{P}$, et al. Temperature-controlled airflow ventilation in operating rooms compared with laminar airflow and turbulent mixed airflow. J Hosp Infect. 2017;98.

18. Gong N, Zhou J, Liu S, Esparza S, Raju U. Air flow rate control strategies and energy saving for operating rooms. . Indoor Air 2014 - 13th International Conference on Indoor Air Quality and Climate. 2014:353-359.

19. Dettenkofer $M$, Scherrer M, Hoch V, et al. Shutting down operating theater ventilation when the theater is not in use: Infection control and environmental aspects. Infection Control and Hospital Epidemiology. 2003;24(8):596-600.

20. Collantes E, Mauffrey C, Lewis C, Brewster M. A review of 1241 trauma cases: A study of efficiency in trauma theatres. Injury. 2008;39(7):742-747.

21. Schubert M, Musolff A, Weiss $\mathrm{H}$. Influences of meteorological parameters on indoor radon concentrations ( $222 \mathrm{Rn}$ ) excluding the effects of forced ventilation and radon exhalation from soil and building materials. J Environ Radioact. 2018;192:81-85.

22. Baurès $E$, Blanchard $O$, Mercier $F$, et al. Indoor air quality in two french hospitals: Measurement of chemical and microbiological contaminants. Sci Total Environ. 2018;642:168-179. 
23. Lu Y, Liu J, Lu B, Jiang A, Wan C. Study on the removal of indoor VOCs using biotechnology. J Hazard Mater. 2010;182(1-3):204-209.

24. Memarzadeh F, Manning A. Reducing risks of surgery. ASHRAE J. 2003;45(2):28-33.

25. Chosky SA, Modha D, Taylor GJ. Optimisation of ultraclean air. the role of instrument preparation. The Journal of bone and joint surgery.British volume. 1996;78(5):835-837.

26. Huys J. Sterilization of medical supplies by steam. https://books.google.nl/books/about/

Sterilization_of_medical_supplies_by_ste.html ?id=RQ3ZXwAACAAJ\&redir_esc=y.

27. Darouiche RO, Green DM, Harrington MA, et al. Association of airborne microorganisms in the operating room with implant infections: A randomized controlled trial. Infection Control and Hospital Epidemiology. 2017;38(1):3-10.

28. Friberg BE, Burman LG, Friberg S. Zoned exponential, vertical and horizontal ultraclean laminar airflows. no differences in bacteriological efficiency. Acta Orthop Scand. 1998;69(2):169-172.

29. Friberg B. Ultraclean laminar airflow ORs. AORN J. 1998;67(4):841-842, 845-851.

30. Howorth FH. Prevention of airborne infection during surgery. The Lancet. 1985;325(8425):386-388.

31. Lewis JR. Operating room air distribution effectiveness. ASHRAE Transactions. 1993;99(pt 2):1191-1200.

32. Schmidt P. Air control in operating theatres. Heizung Lufung Haus Techniek. 1987;38(3):145-153.

33. Allander C, inventorSystem for ventilating clean rooms. 1966.

34. Gormley T, Markel TA, Jones HW, et al. Methodology for analyzing environmental quality indicators in a dynamic operating room environment. Am J Infect Control. 2017;45(4):354-359.

35. Nordenadler J. Något om skyddsventilation i operationsrum. KTH; 2011.

36. Stauning MT, Bediako-Bowan A, Andersen LP, et al. Traffic flow and microbial air contamination in operating rooms at a major teaching hospital in ghana. $J$ Hosp Infect. 2018. 
37. Smith EB, Raphael IJ, Maltenfort MG, Honsawek S, Dolan K, Younkins EA. The effect of laminar air flow and door openings on operating room contamination. $J$ Arthroplasty. 2013;28(9):1482-1485.

38. Andersson AE, Bergh I, Karlsson J, Eriksson BI, Nilsson K. Traffic flow in the operating room: An explorative and descriptive study on air quality during orthopedic trauma implant surgery. Am J Infect Control. 2012;40(8):750-755.

39. Murgier J, Coste JF, Cavaignac E, et al. Microbial flora on cell-phones in an orthopedic surgery room before and after decontamination. Orthopaedics and Traumatology: Surgery and Research. 2016;102(8):1093-1096.

40. Reinmüller B, Ljungqvist B. Modern cleanroom clothing systems: People as a contamination source. PDA J Pharm Sci and Tech. 2003;57(2):114-125.

41. Tammelin A, Ljungqvist B, Reinmüller B. Comparison of three distinct surgical clothing systems for protection from air-borne bacteria: A prospective observational study. Patient Safety in Surgery. 2012;6(1):1-6.

42. Tammelin A, Ljungqvist $B$, Reinmüller $B$. Single-use surgical clothing system for reduction of airborne bacteria in the operating room. J Hosp Infect. 2013;84(3):245247.

43. Ljungqvist $B$, Reinmüller $B$. Clothing systems evaluated in a dispersal chamber. journal of Parenteral and Pharmaceutical Science. 2014;19(2):67-69.

44. Brandt C, Hott U, Sohr D, Daschner F, Gastmeier P, Rüden H. Operating room ventilation with laminar airflow shows no protective effect on the surgical site infection rate in orthopedic and abdominal surgery. Ann Surg. 2008;248(5):695-700.

45. Breier A, Brandt C, Sohr D, Geffers C, Gastmeier P. Laminar airflow ceiling size: No impact on infection rates following hip and knee prosthesis. Infection Control \& Hospital Epidemiology. 2011;32(11):1097-1102.

46. Hooper GJ, Rothwell AG, Frampton C, Wyatt MC. Does the use of laminar flow and space suits reduce early deep infection after total hip and knee replacement?: The ten-year results of the new zealand joint registry. Journal of Bone and Joint SurgeryBritish Volume. 2011;93-B(1):85-90. 
47. Dale H, Hallan G, Espehaug B, Havelin LI, Engesæter LB. Increasing risk of revision due to deep infection after hip arthroplasty: A study on 97,344 primary total hip replacements in the norwegian arthroplasty register from 1987 to 2007. Acta Orthopaedica. 2009;80(6):639-645.

48. Fitzgerald RH. Reduction of deep sepsis following total hip arthroplasty. Ann $N$ Y Acad Sci. 1980;353(1):262-270.

49. Charnley J. Postoperative infection after total hip replacement with special reference to air contamination in the operating room. Clin Orthop Relat Res. 1972;87:167-187.

50. Lidwell OM, Lowbury EJ, Whyte W, Blowers R, Stanley SJ, Lowe D. Effect of ultraclean air in operating rooms on deep sepsis in the joint after total hip or knee replacement: A randomised study. Br Med J (Clin Res Ed). 1982;285(6334):10-4.

51. Cacciari P, Giannoni R, Marcelli E, Cercenelli L. Cost evaluation of a ventilation system for operating theatre: An ultraclean design versus a conventional one. Annali di igiene: medicina preventiva e di comunita. 2004;16 (6):803-809.

52. Jutte PC, Traversari RAAL, Walenkamp GHIM. Laminar flow: The better choice in orthopaedic implants. The Lancet Infectious Diseases. 2017;17(7):695-696.

53. Traversari R, Van Den Broek $P$, Saurwalt $F$. Wat nu als het beschermd gebied kleiner is dan verwacht? Ned Tijdschr Med Microbiol. 2017;25(1):14-18.

54. Agodi A, Auxilia F, Barchitta M, et al. Operating theatre ventilation systems and microbial air contamination in total joint replacement surgery: Results of the GISIOISChIA study. J Hosp Infect. 2015;90(3):213-219.

55. Sadrizadeh S, Tammelin A, Ekolind P, Holmberg S. Influence of staff number and internal constellation on surgical site infection in an operating room. Particuology. 2014;13(1):42-51.

56. Botzenhart K, Hoppenkamps G. Wound contamination in conventionally airconditioned operating rooms as compared to laminar-flow-operating-rooms. Zbl.Bart.Hyg. 1978;167:29-37.

57. Torbjöm A, Dalén $\mathrm{N}$, Jörbeck $\mathrm{H}$, Hobom J. Air contamination during hip and knee arthroplasties - horizontal laminar flow randomized vs. conventional ventilation. Acts Orthop Scand. 1995;66(1):17-20. 
58. Lucht $\mathrm{U}$. The bacterial contamination of the air in an orthopedic operating room before and after laminar air flow. A comparative study in relation to total hip alloplasty]. Ugeskr Laeger. 1983;145(11):820-3.

59. Suzuki A, Namba Y, Matsuura M, Horisawa A. Airborne contamination in an operating suite: Report of a five-year survey. J Hyg. 1984;93(3):567-573.

60. Talon D, Schoenleber T, Bertrand X, Vichard P. Performances en activité de différents types d'installation de traitement de l'air au bloc opératoire. Ann Chir. 2006;131(5):316-321.

61. Lidwell OM, Lowbury EJL, Whyte W, Blowers R, Stanley SJ, Lowe D. Airborne contamination of wounds in joint replacement operations: The relationship to sepsis rates. J Hosp Infect. 1983;4(2):111-131.

62. Whyte $\mathrm{W}$, Hodgson R, Tinkler J. The importance of airborne bacterial contamination of wounds. J Hosp Infect. 1982;3(2):123-135.

63. Lidwell OM. Clean air at operation and subsequent sepsis in the joint. Clin Orthop. 1986;211(211):91-102.

64. Friberg B, Friberg S, Burman LG. Inconsistent correlation between aerobic bacterial surface and air counts in operating rooms with ultra clean laminar air flows: Proposal of a new bacteriological standard for surface contamination. $J$ Hosp Infect. 1999;42(4):287-293.

65. Gandra P, Ljungqvist B, Reinmülller B. Unidirectional air flow systems with low velocities in operating rooms-a comparison between measured values od airborne viables particles and theoretical calculated values with the dilution principle. European Journal of Parenteral \& Pharmaceutical Sciences. 2017;22(3):82-86.

66. Ljungqvist B, Nordenadler J, Reinmüller B. Results from a swedish surveyinvestigations in operating rooms. European Journal of Parenteral \& Pharmaceutical Sciences. 2013;18(4):125-127.

67. Whyte W, Hambraeus A, Laurell G, Hoborn J. The relative importance of the routes and sources of wound contamination during general surgery. II. airborne. J Hosp Infect. 1992;22(1):41-54.

68. Taylor GJ, Bannister GC. Infection and interposition between ultraclean air source and wound. J Bone Joint Surg Br. 1993;75-B(3):503-504. 
69. Pasquarella C, Sansebastiano GE, Ferretti S, et al. A mobile laminar airflow unit to reduce air bacterial contamination at surgical area in a conventionally ventilated operating theatre. J Hosp Infect. 2007;66(4):313-319.

70. SIS-TS 39:2015. Microbiological cleanliness in the operating room - preventing airborne contamination - guidance and fundamental requirements. Swedish Standards Institute. 2015.

71. Agricola K. Real-time particle deposition monitoring of operational cleanroom quality. J IEST. 2016;59(1):40-52.

72. Whyte W, Agricola K, Derks M. Airborne particle deposition in cleanrooms: Calculation of product contamination and required cleanroom class. Clean Air and Containment Review. 2016(26):4-10.

73. Menant N, Faye D, Nouet P, Lafontan X, Lellouchi D. Monitoring of particle deposition in cleanrooms: State-of-the-art. 2014 Symposium on Design, Test, Integration and Packaging of MEMS/MOEMS (DTIP). 2014:1-4.

74. Noble WC, Lidwell OM, Kingston D. The size distribution of airborne particles carrying micro-organisms. J Hyg. 1963;61(4):385-391.

75. Tavitian JD, Ong SM, Taub NA, Taylor GJS. Body-exhaust suit versus occlusive clothing. The Journal of Bone and Joint Surgery. 1991;5:5-7.

76. Link T, Kleiner C, Mancuso MP, Dziadkowiec O, Halverson-Carpenter K. Determining high touch areas in the operating room with levels of contamination. Am J Infect Control. 2016;44(11):1350-1355.

77. Sossai D, Dagnino G, Sanguineti F, Franchin F. Mobile laminar air flow screen for additional operating room ventilation: Reduction of intraoperative bacterial contamination during total knee arthroplasty. Journal of Orthopaedics and Traumatology. 2011;12(4):207-211.

78. Wakeam E, Hernandez RA, Rivera Morales D, Finlayson SRG, Klompas M, Zinner MJ. Bacterial ecology of hospital workers' facial hair: A cross-sectional study. J Hosp Infect. 2014;87(1):63-67.

79. Tammelin A, Hambracus A, Stahle E. Routes and sources of staphylococcus aureus transmitted to the surgical wound during cardiothoracis surgery: Possibility of preventing wound contamination by using special scrub suits. Infection control and hospital epidemiology. 2001;22(6):1-9. 
80. Salassa TE, Swiontkowski MF. Surgical attire and the operating room: Role in infection prevention. Journal of Bone and Joint Surgery - American Volume. 2014;96(17):1485-1492.

81. Brohus $H$, Balling KD, Jeppesen D. Influence of movements on contaminant transport in an operating room. Indoor Air. 2006;16(5):356-372.

82. Konigsberg BS, Valle CJD, Ting NT, Qiu F, Sporer SM. Acute hematogenous infection following total hip and knee arthroplasty. J Arthroplasty. 2014;29(3):469-472.

83. He R, Yang L, Guo L, Chen H, Zhang Y, Jiang DM. Management of acute hematogenous infection following total knee arthroplasty: A case series of 11 patients. Orthopaedic Surgery. 2016;8(4):475-482.

84. Heggeness MH, Esses SI, Errico T, Yuan HA. Late infection of spinal instrumentation by hematogenous seeding. Spine. 1993;18(4):492-496.

85. Botzenhart K, Hoppenkamps G. Wound contamination in conventionally airconditioned operating rooms as compared to laminar-flow-operating-rooms. Zbl.Bart.Hyg. 1978;167:29-37.

86. Bode LGM, Kluytmans JAJW, Wertheim HFL, et al. Preventing surgical-site infections in nasal carriers of staphylococcus aureus. N Engl J Med. 2010;363(1):1-3.

87. Kalmeijer MD, Coertjens $\mathrm{H}$, van Nieuwland-Bollen PM, et al. Surgical site infections in orthopedic surgery: The effect of mupirocin nasal ointment in a double-blind, randomized, placebo-controlled study. Clinical Infectious Diseases. 2002;35(4):353358.

88. Persson $\mathrm{M}$, Linden J. Wound ventilation with ultraclean air for prevention of direct airborne contamination during surgery. Infect Control Hosp Epidemiol. 2004;25:297301.

89. Lelieveld-Vroom M, Anneke Anna Maria Z, Peter Alexander N. The incidence of decolonizing patients of staphylococcus aureus nasal carriage undergoing breast cancer surgery in the netherlands. British Journal of Medical and Health Research. 2018;5(3):26-34.

90. Kluytmans J, van Belkum A, Verbrugh $\mathrm{H}$. Nasal carriage of staphylococcus aureus: Epidemiology, underlying mechanisms, and associated risks. Clin Microbiol Rev. 1997;10(3):505-20. 
91. Lidwell OM, Lowbury EJL, Whyte W, Blowers R, Stanley SJ, Lowe D. Bacteria isolated from deep joint sepsis after operation for total hip or knee replacement and the sources of the infections with staphylococcus aureus. J Hosp Infect. 1983;4(1):19-29.

92. Knobben BAS, van der Mei HC, van Horn JR, Busscher HJ. Transfer of bacteria between biomaterials surfaces in the operating room- an experimental study. InterScience. 2006:790-799. 


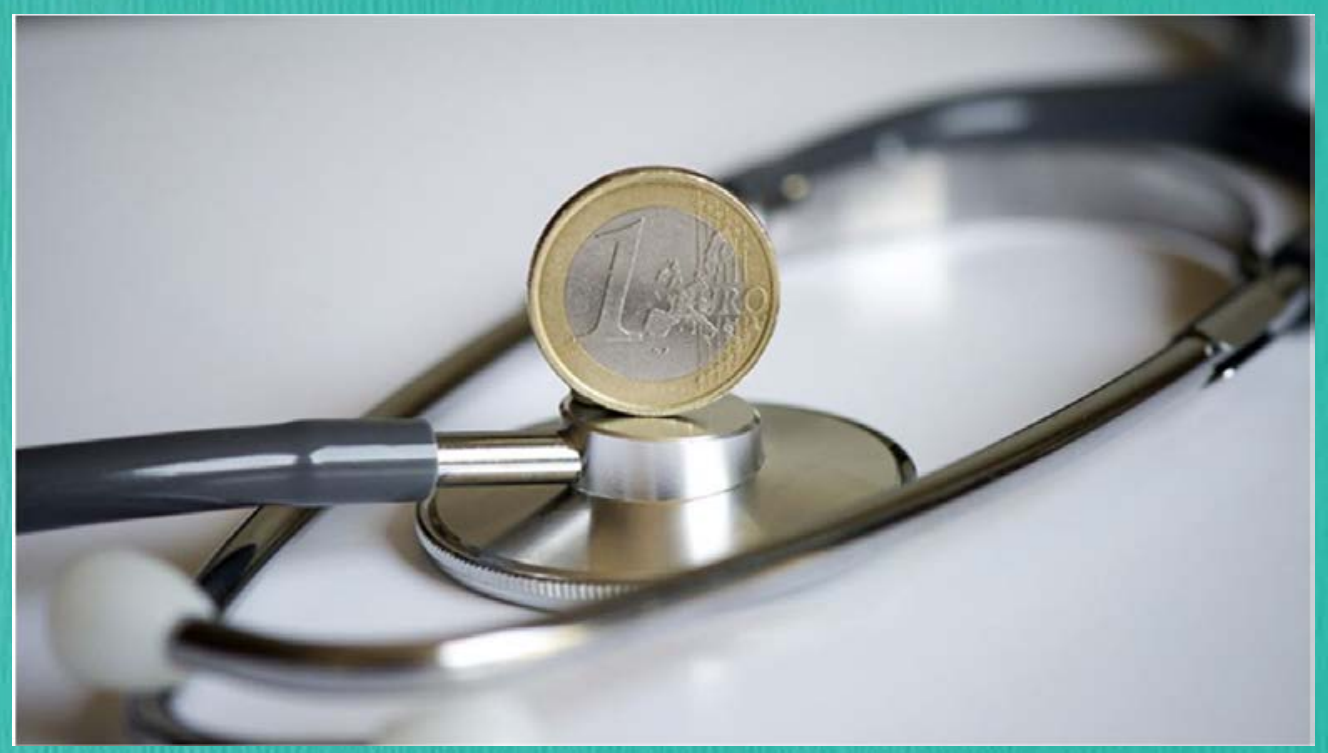


Chapter 10

\section{Valorisation}




\section{Valorisation}

The results of the studies presented in this thesis are helpful for improving UDF systems, reducing the amount of potentially microorganisms carrying particles at the critical positions in an operating room and instrument lay-up room, as well as realizing a more efficient design process of these facilities. These results may be important to design teams and to hospitals because they will help to use air distribution systems more efficient and a design based on these results will reduce the costs (operational and maintenance) of UDF systems. The results can easily be implemented and are already frequently used in new designs and refurbishment of air distribution systems in operating rooms and lay-up rooms in The Netherlands. This thesis also contributes to the discussion on the effectiveness of air distribution systems. It is clearly indicated that well-functioning air distribution systems in operating rooms will reduce the amount of potentially microorganisms carrying particles at critical positions in operating rooms and instrument lay-up rooms resulting in a reduced number of SSI caused by exogenous sources, and so a reduced risk of postoperative infections.

During the design process of operating rooms, the lay-out is often subject of debate. Some of the questions that have to be answered by the design team during this process are often: 1) what should be the size of the operating room? 2) what type of air distribution system should be used? 3) what should be the size of the protected zone? 4) should we use a supply bridge and what should be the height? 5) what is the best position of the patient access door and door towards the instrument lay-up room? In chapter 2 it is demonstrated that an area of 3 meter square is sufficient to contain the surgical team, the wound area and the instrument tables in about $95 \%$ of the procedures performed at an academic hospital setting. ${ }^{1}$ It is also demonstrated that in the case of larger dimensions of the operating room the unidirectional downflow canopy should not be positioned centrally in the operating room for optimal layout. 
The remaining space inside the operating room should preferably be situated on the side of the corridor, rather than being equally divided around the clean area. Positioning of the anaesthesia section on the side of the clean area also offers a better logistical layout of the operating room than in the traditional set-up where it is situated between the clean area and the entrance. In the anaesthetic working zone the activity level often is high and related to door openings resulting in a high local source of pollutants. Whether the suggested position has a negative effect on the number of microorganisms carrying particles at critical locations (surgical wound and instrument tables) in the operating room has not been investigated yet.

To improve the UDF air flow a skirt around the canopy with a supply bridge was considered in the design used in the study for this thesis. ${ }^{2}$ The supply bridge was positioned 2.05 meter above floor level. In the Dutch situation, a supply bridge at a height of 2.05 meter provides a good balance between collisions with used medical equipment and for making connections in the slanted part of the supply bridge by employees and guiding the air flow as much as possible.

These results should be used as a starting point by the design teams when designing a system for an operating room. For comparable situations, the results may be used directly by hospitals and consultants to prepare the program of requirements. For types of operations and conditions not investigated in this study, the method described must be used to determine the minimum required size of the area to be protected by the air distribution system. Due to the availability of this information and method, the design team does not need to determine this in advance so that a design process is faster and more effective. ${ }^{3,4}$

Selecting new operating lamps is a difficult task. The amount of light, colour of the light and way to control the operating lamp are often the most important criteria for selection. Another aspect to be considered is the influence of the operating lamps on the air flow in the operating room. 
With modern operating lamps with LED lighting, the temperature of the lamp is often less of a problem, provided that the control gear is not integrated in the lamp. Especially when UDF systems are used the air flow may be negatively affected, reducing the ability to discharge microorganism containing particles. Chapter 3 addresses the impact of using operating lamps with an open structure versus operating lamps blocking the air stream and the effect of a skirt around the canopy. ${ }^{5}$ Using operating lamps with an open structure and using a skirt around the canopy improves the effect of UDF systems. These results may be used to improve the performance, protection against entrainment of potentially microorganisms carrying particles, of the UDF system..$^{6-9}$ The best operating lamp with respect to the influence on the air flow is an operating lamp that is positioned outside the air flow of a UDF system. The development of operating lamps should focus more on the design of systems that negatively influence the UDF air flow as little as possible. With modern high capacity and low weight batteries and LED lighting, it may be possible to develop portable lamps that are worn on the surgeon's head, that are comfortable and have sufficient light output, which could lead to redundancy of conventional surgical lamps. Systems could also be developed that are fully integrated into the ceiling where the light follows the field of vision of the surgeon. ${ }^{10}$ To get enough light in the body parts deep in the body, a combination of the abovementioned possibilities can offer a solution that minimally influences the UDF air flow.

This research also demonstrates that using a skirt may have a positive effect on the effectiveness of air distribution systems in operating rooms. If a skirt is used, in combination with a supply bridge or not, the disturbance of the UDF air flow can even be limited further improving the performance of air distribution systems in operating rooms. If a supply bridge is combined with a skirt, special attention should be paid to the connection between the supply bridge and the skirt, which must be seamlessly transferred on the side of the air flow. 
Hospitals have a big challenge to reduce energy consumption as required by the European energy regulations. ${ }^{11,12}$ The easiest way to reduce energy is to switch of systems when not in use like lights, medical equipment, heating and cooling systems etc..

The ventilation system in operating rooms also has periods of prolonged inactivity e.g. during nights and weekends. However, because of the limited research performed on this subject responsible duty holders are hesitant to do so. Chapter 4 shows that switching off the ventilation system during prolonged inactivity (during the night and weekend) has no negative effect on the air quality in operating theatres with UDF systems during normal operational hours. ${ }^{13}$ In this way not only energy will be saved but also the service life of filters may be extended. This will lead to reduction of operational cost (energy and maintenance). Switching of the ventilation systems of operating rooms contributes to the European goals for energy saving. ${ }^{11,12}$ Design teams should develop systems that are able to be switched of easily and will restart at short notice. During long periods of inactivity (during the night and weekend) precautions should be taken to prevent heating up the operating room due to internal load caused by e.g. medical equipment.

When considering the possible contamination of sterile instruments during the lay-up process it is way to perform these processes in separate instrument lay-up rooms with a proper air distribution system. In the Netherlands vertical UDF systems are often used in these instrument lay-up rooms. Vertical UDF systems may however have some disadvantages when applied in such setting. The disadvantage is that vertical UDF systems are not easy to install in an existing lay-up room or existing building because of limitations in the space above the false ceiling and often need cooling of the air flow to support the down flow of the UDF system. Chapter 5 demonstrates that horizontal UDF systems protect sterile instruments during the laying-up process against aerogenic contaminations. In this study it is concluded that a horizontal UDF system offers at least the same protection against aerogenic contamination as down flow systems for the laying-up process. $^{14}$ 
In comparison with downflow systems, horizonal UDF systems use less air and generate the same and even better results (level of particles and microorganisms carrying particles close to the sterile instruments). Other advantages of the horizontal UDF systems for laying-up instruments are that temperature difference is not needed to increase the air speed of the UDF system and the system is easier to install and maintain. With a reduction of the systems energy and maintenance cost as a result. After publication of this study more and more horizontal UDF systems for laying-up instruments have been implemented in the Netherlands. A potential risk is that these systems are not optimally attuned to the height of the instrument tables used e.g. the top of the table is positioned too high in relation to the position of the air supply system.

New operating rooms in the Netherlands are in most cases equipped with large UDF systems, typically $3 \times 3 \mathrm{~m}$. These systems are designed mainly for surgical processes that need several instrument tables and a Mayo stand. For local surgical procedures in a small area and a small number of sterile instruments e.g. eye and hand surgery the use of large UDF systems seems to be overdone. For these type of surgical procedures smaller UDF systems may be used. Chapter 6 shows that for intra-vitreal injection mobile UDF systems can safely be used. ${ }^{15}$ These types of systems are not only suitable for intra-vitreal injection but also for surgical procedures in a small area and a small amount of sterile instruments and medical equipment. This may reduce the number of operations that are performed in operating rooms with large UDF systems freeing up the operation room for the intended surgical procedures with large operating areas and many sterile instruments. More research and product development is needed to prove and optimise the effectiveness of these mobile UDF systems.

This thesis concludes that the performance of an air distribution system in operating rooms should be expressed in the potential to discharge microorganisms carrying particles. The better the system is capable to do so, the lower the chance of microorganisms carrying particles depositing on instruments or in the operation wound. 
At rest this should be demonstrated by technical measurements with a predefined source strength of particles and during real surgery this could be determined by measuring the number of $\mathrm{CFU} / \mathrm{m}^{3}$ or $\mathrm{CFU} /\left(\mathrm{m}^{2}\right.$.h). Both strength and weakness of using $\mathrm{CFU} / \mathrm{m}^{3}$ or $\mathrm{CFU} /\left(\mathrm{m}^{2} . \mathrm{h}\right)$ as an indicator of the systems performance is that the outcome not only depends on the characteristics of the air distribution system in the operating room but also on the processes performed in the operating room.

These processes affect the source strength (CFU $/ \mathrm{m}^{3}$ or $\left.\mathrm{CFU} /\left(\mathrm{m}^{2} . h\right)\right)$ that the system has to eliminate, this applies in particular to diluting mixing systems. The more robust the air distribution system, the more limited the effect on the source strength will be.

Future directions of research are presented in this thesis that should be conducted on the topic of aerogenic contamination control in operating rooms and instrument lay-up rooms. 


\section{References}

1. Traversari R, Goedhart R, Schraagen JM. Process simulation during the design process makes the difference: Process simulations applied to a traditional design. Health Environments Research and Design Journal. 2013;6(2):58-76.

2. Whyte W, Bailey PV. Effectiveness of a partial-wall laminar-flow system with special regard to air supply temperature. J Soc Environ Eng. 1978;17(4):29-32.

3. Bayramzadeh S, Joseph A, Allison D, Shultz J, Abernathy J. Using an integrative mockup simulation approach for evidence-based evaluation of operating room design prototypes. Appl Ergon. 2018;70:288-299.

4. Stichler JF. State of the science in healthcare design. HERD: Health Environments Research \& Design Journal. 2017;10(2):6-12.

5. Traversari AAL, Bottenheft C, Louman R, van Heumen SPM, Böggemann J. The effect of operating lamps on the protected area of a unidirectional down flow (UDF) system. Health Environments Research and Design Journal. 2017;10(3):40-50.

6. DIN 1946-4:2008. Ventilation and air conditioning - part 4: VAC systems in buildings and rooms used in the health care sector. DIN. 2008.

7. Departement of Health. HTM 03-01 part A: Heating and ventilation systems health technical memorandum specialised ventilation for healthcare premises. The Stationery Office (TSO); 2007.

8. Önorm H 6020. Lüftungstechnische anlagen für medizinisch genutzte räume projektierung, errichtung, betrieb, instandhaltung, technische und hygienische kontrollen. Österreichisches Normungsinstitut. 2015.

9. VCCN Richtlijn 7. Methode voor testen en classificeren van operatiekamers en opdekruimten in rust. Vereninging Contamination Control Nederland. 2017:1-36.

10. Luntsford PK, inventorSurgical Lighting system. patent 5,093,769. Oct. 4, 1990, 1992.

11. EU. Directive 2010/31/EU of the european parliament and of the council of 19 may 2010 on the energy performance of buildings (recast). Official Journal of the European Union. 2010:13-35. 
12. EU. Directive $2012 / 27 / E U$ of the european parliament and of the council of 25 october 2012 on energy efficiency, amending directives 2009/125/EC and 2010/30/EU and repealing directives 2004/8/EC and 2006/32/EC. Official Journal of the European Union. 2012;55:1-97.

13. Traversari AAL, Bottenheft C, van Heumen SPM, Goedhart CA, Vos MC. Effect of switching off unidirectional downflow systems of operating theaters during prolonged inactivity on the period before the operating theater can safely be used. Am J Infect Control. 2017;45(2):139-144.

14. Traversari AAL, Goedhart CA, Dusseldorp E, et al. Laying-up of sterile instruments in the operating theatre: Equal or superior protection by using a horizontal unidirectional air flow system. J Hosp Infect. 2013;85(2):125-133.

15. Lapid-Gortzak R, Traversari R, van der Linden JW, Lesnik Oberstein SY, Lapid O, Schlingemann RO. Mobile ultra-clean unidirectional airflow screen reduces air contamination in a simulated setting for intra-vitreal injection. Int Ophthalmol. 2017;37(1):131-137. 


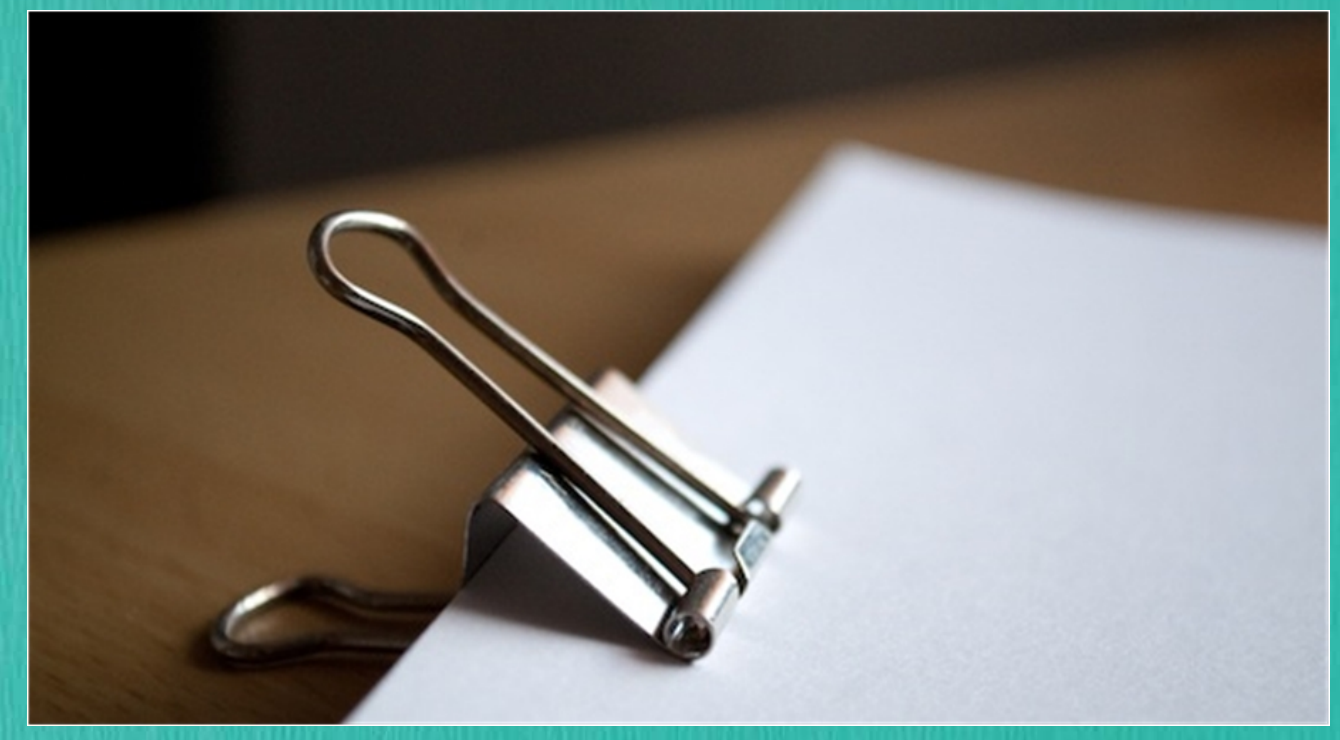


Chapter 11

\section{Summary}

Nederlandse samenvatting 


\section{Summary}

\subsection{Summary}

In this thesis, aerogenic contamination control in operating theatres is addressed in order to increase the understanding of the effect of technical measures to the protective effect in practice. The aim of these technical measures is to increase the protection against entrainment and deposition of potentially microorganisms carrying particles. This is especially of interest for the critical locations in an operating room and instrument preparation room. The questions answered in this thesis are:

1) Is a clean area of $3 \times 3$ meter, often used in Dutch operating rooms, sufficient to position the patient, sterile instruments and the surgical team?

2) Is the area that is protected by a UDF system influenced by a skirt, different types of operating lamps and the position of the lamp?

3) Is it possible to switch off the ventilation system of operating rooms during prolonged inactivity e.g. during the night and weekend without negative effects on the air quality during normal operational hours?

4) Can a horizontal UDF (UDHF) system in terms of prevention of contamination of the air safely be used during the laying-up process on the instrument table?

5) Does the use of a mobile ultraclean laminar airflow screen reduce the air-borne particle counts in a non-ventilated room to a level safe for the patient?

Is a clean area of $3 \times 3$ meter, often used in Dutch operating rooms, sufficient to position the patient, sterile instruments and the surgical team?

A size of the protected area of $3 \times 3$ meters is sufficient for most defined situations, provided a movable operation table is used. For interventions in polytrauma patients however bottlenecks regarding the dimensions of the clean area will probably arise. For this type of surgery, a size of $3.20 \times 3.20$ meter is proposed. Knowing the required size of the protected area in an operating room is very important during the design phase of the air distribution system in the operating room. Especially if UDF systems are used that generate a cleaner zone in an operating room. 
One must realize that outside this protected zone the number of microorganisms carrying particles is higher than inside this zone. However, determining the protected area that a UDF system can realize is measured in the "At rest" condition. This means that all equipment is present and in operation but without the process or the presence of people. As a result, the size of the protected area may deviate during operational circumstances.

In large operating rooms it is more effective to position the plenum eccentrically so additional space is created at the main entrance to the operating room rather than being equally divided around the UDF system. This way there is more usable space for temporary storage of equipment during the procedure.

To improve the UDF air flow a skirt around the canopy with a supply bridge was considered in the design used in the study for this thesis. The supply bridge was positioned 2.05 meter above floor level. For many staff, a height of 2.05 meter is workable for making connections in the slanted part of the supply bridge. It is also concluded that process simulations have great value during the design of an operating room lay-out.

\section{Is the area that is protected by a UDF system influenced by a skirt, different types of operating lamps and the position of the lamp?}

The size and quality of the protected zone by the air distribution system is influenced by a skirt and by the type of operating lamps. Using a skirt does not increase the size of the protected zone but it increases the quality of the zone protected by the air distribution system. With a skirt the protected zone is 100 times cleaner in the centre than without a skirt. Operating lamps with an open structure have a less negative effect on the quality (degree of protection) of the protected zone. These measures can be used in the design phase or can be used to improve the performance of existing systems. 
Is it possible to switch off the ventilation system of operating rooms during prolonged inactivity e.g. during the night and weekend without negative effect on the air quality during normal operational hours?

Switching off ventilation systems during prolonged inactivity can help to save energy. It is concluded that switching off the ventilation system during prolonged inactivity (e.g. during the night and weekend) has no negative effect on the air quality in UDF operating theatres during regular operational hours. After starting up the system, the protected area achieved the required degrees of protection within 20 minutes. The results also show a stable temperature difference within 23 minutes after starting up the system. In practice this time to start up the system is also needed for the preparation for trauma surgery. The time needed for preparing this type of surgery is estimated at 25 minutes. If laying-up instruments is performed in the operating room this start-up time must also be taken into account. It is only safe to start this process if the required degree of protection is reached. Switching off ventilation systems during prolonged inactivity does not only save energy but is also may extend the service life of filters. Both can lead to reduction of operational cost (energy and maintenance).

Can a horizontal UDF (UDHF) in terms of prevention of contamination of the air safely be used during the laying-up process on the instrument table?

The instruments used during surgery are also an important route for contamination of the surgical wound. It is demonstrated by measuring the number of particles and $\mathrm{CFU} / \mathrm{m}^{3}$ that horizontal UDF systems offer at least the same protection against aerogenic contamination as UDF downflow systems during laying-up processes. For laying-up processes the horizontal system offers a more robust solution than the downflow system, provided that a decent work process is used, and the height of the instrument table is adapted to the height of the supply plenum. 
Does the use of a mobile ultraclean laminar airflow screen reduce the air-borne particle counts in a nonventilated room to a level safe for the patient?

For surgery with a small surgical wound and a limited number of surgical instruments systems with a smaller protected area may be used. It has been shown that if a mobile air flow screen is used in a poorly ventilated room it protects against contaminations in the setting of intra-vitreal injections. However proper positioning and placing of the surgical drapes is critical. To do so it is important to adjust the setting precisely for each particular site, in order to determine the actual degree of protection present.

\section{Overall conclusion and discussion}

It is stated that UDF systems have the ability to protect an area against aerogenic contaminants in an effective way. The effectiveness of a system against entrainment of microorganisms carrying particles from outside the protected area and the ability to remove potential microorganisms carrying particles generated in this zone is however affected by many variables, figure 11.1

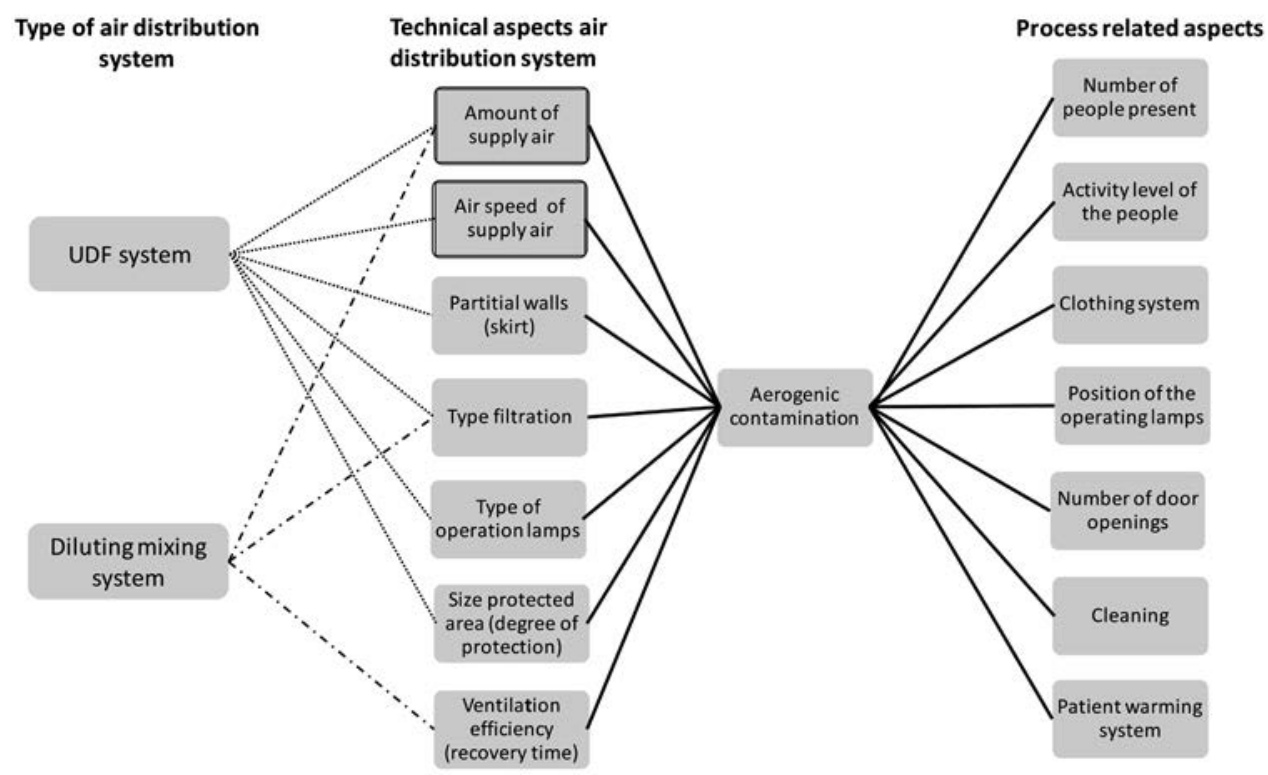

Figure 11.1. Aspects that determine the aerogenic contamination in an operating room. 
If different types of air distribution systems are compared, at least the technical and process-related aspects as shown in the figure 11.1 must be taken into account. A good comparison between the properties of air distribution systems is only possible for systems with the same amount of supplied air. Only in this way is the performance of the distribution system being compared and not the air volume. Most studies based on retrospective analyses of routine surveillance data have a major weakness. The embarrassment with these studies is that UDF or laminar flow system and diluting mixing system are not unambiguously defined. Most common approach in these studies is that the type of system used in the operating rooms, UDF or diluting mixing system, is obtained by a questionnaire. If a diffuser, canopy or plenum is used the system is often classified as UDF system without knowing whether this system performs as a UDF system based on performance tests.

It is also concluded that measuring the performance of a system based on a challenge by an artificial source of particles is a good indication for the effectiveness of a system during ongoing surgical procedures (recovery test, entrainment or segregation test). Systems that are designed based on a specific maximum source strength (number of people and clothing system) like diluting mixing systems, are more sensitive to disruption of the process than systems creating a protected zone. A disruption may be an increase of the number of people or calamities. The performance of these systems can best be demonstrated by CFU measurements during ongoing surgical procedures. This because during use there are regular deviations from the design conditions (e.g. number of persons in the operating room and discipline). This method may also be used if the protected zone is too small to contain the surgical wound, the surgical team and sterile instruments or if the UDF airflow is severely interrupted by obstacles such as support arms, monitors, working lamps with a closed structure or other ceiling mounted systems. These CFU measurements not only show the technical performance of the system, but also the effect of the processes on the aerogenic contamination. 


\section{Future direction}

Since much remains unclear in the route of infection of surgical wounds and implants, further research should focus on the source of wound contaminants, and infectioncausative bacteria. More investigations are needed about the proportion of bacteria that contaminate directly via the air, or indirectly via hands and instruments. More information about the role and importance of per- and early postoperative endogenous infection is needed to get a better insight of the relative role of the bacterial air quality in the operating room and eventual prophylactic measures in bacteria carrying patients.

There is a lack of studies concerning the investment and operational costs of different systems. In such studies, a better comparison basis must be maintained (figure 11.1), whereby a distinction must be made between a new build situation and renovation. The hypothesis is that UDF systems with the same amount of outdoor air (ODA) and the same amount of secondary air (SEC) have comparable investment and operating costs as mixing systems. If these proposed studies are carried out, this can contribute positively to the discussion regarding different types of air distribution systems. 


\subsection{Nederlandse Samenvatting}

In dit proefschrift wordt de beheersing van aërogene verontreiniging in operatiekamers behandeld om het inzicht in het effect van technische maatregelen hierop te vergroten. Het doel van deze maatregelen is om de bescherming tegen binnendringen en depositie van potentieel micro-organismen dragende deeltjes te verhogen. Dit is in het bijzonder van belang voor de kritieke locaties in een operatiekamer en opdekruimte. De vragen die in dit proefschrift worden beantwoord zijn:

1) Is een schoon gebied van $3 \times 3$ meter, zoals veelvuldig toegepast in Nederlandse operatiekamers voldoende in omvang om de patiënt, steriele hulpmiddelen en het chirurgische team te omsluiten?

2) Wordt het gebied beschermd door een UDF-systeem beïnvloed door een randafscherming, typen operatielamp en de positie van de operatielamp?

3) Is het mogelijk om het ventilatiesysteem van een operatiekamer uit te schakelen op de momenten dat er langdurig geen gebruik van wordt gemaakt bijvoorbeeld 's nachts en in het weekeinde zonder dat dit een negatief effect heeft op de luchtkwaliteit tijdens de normale gebruikstijden?

4) Kan een horizontaal UDF-systeem in termen van het voorkomen van contaminatie van de lucht veilig worden gebruikt tijdens het opdekproces van de instrumenttafels?

5) Reduceert een mobiel laminair luchtstroomsysteem het niveau van lucht-gedragen deeltjes in een niet geventileerde ruimte tot een niveau dat veilig is voor de patiënt?

Is een schoon gebied van $3 \times 3$ meter, zoals veelvuldig toegepast in Nederlandse operatiekamers voldoende in omvang om de patiënt, steriele hulpmiddelen en het chirurgische team te omsluiten?

Een afmeting van het beschermde gebied van $3 \times 3$ meter is voldoende voor de meeste van de gedefinieerde ingrepen onder voorwaarde dat een verplaatsbare operatietafel wordt gebruikt. Voor behandeling van multiple trauma zullen er waarschijnlijk knelpunten ontstaan met betrekking tot de omvang van het beschermde gebied. 
Voor dit type operatie wordt een omvang van 3,20 × 3,20 meter voorgesteld. Het is belangrijk om tijdens de ontwerpfase van het luchtsysteem in de operatiekamer de noodzakelijke omvang van het beschermde gebied te weten. Vooral indien gebruik wordt gemaakt van uni directionele flow (UDF) systemen waarmee een schonere zone in een operatiekamer wordt gerealiseerd. Buiten deze zone, beschermd door het systeem, is het aantal micro-organismen dragende deeltjes hoger. Het vaststellen van de omvang dat een UDF-systeem realiseert, vindt echter plaats tijdens de "At rest" situatie. Dit betekent dat alle apparatuur aanwezig en in bedrijf staat, maar zonder het proces of de aanwezigheid van mensen. Als gevolg hiervan kan de omvang van het beschermde gebied tijdens operationele omstandigheden afwijken.

In grote operatiekamers is het effectiever om het plenum excentrisch te positioneren, zodat er extra ruimte ontstaat bij de hoofdingang van de operatiekamer in plaats van dat de extra ruimte gelijkmatig wordt verdeeld rond het UDF-systeem. Op deze manier is er meer bruikbare ruimte voor tijdelijke opslag van apparatuur tijdens de ingreep.

Om de luchtstroom te verbeteren, is bij het ontwerp in de studie uit dit proefschrift gebruik gemaakt van een randafscherming om het plenum. Deze randafscherming was ook voorzien van een voorzieningenbrug. De onderzijde van deze voorzieningenbrug bevond zich op een hoogte van 2,05 meter. Voor veel medewerkers is een hoogte van 2,05 meter een werkbare hoogte voor het aansluiten van apparatuur op het schuine deel van de voorzieningenbrug. Er is ook geconcludeerd dat processimulaties van grote waarde is bij het ontwerpen van de indeling van een operatiekamer.

\section{Wordt het gebied beschermd door een UDF-systeem beïnvloed door een} randafscherming, typen operatielamp en de positie van de operatielamp?

De afmeting en kwaliteit van het beschermde gebied dat door het luchtdistributiesysteem wordt gerealiseerd kan door een randafscherming om het plenum heen en door het type operatielamp worden beïnvloed. 
Het gebruik van een randafscherming heeft de omvang van de beschermde gebied niet vergroot, maar heeft wel de kwaliteit van dit gebied verhoogd. Met randafscherming is het centrale deel van het beschermde gebied een factor 100 keer schoner dan zonder randafscherming. Operatielampen met een open structuur hebben een minder negatief effect op de kwaliteit (mate van bescherming) van het beschermde gebied. Deze maatregelen kunnen worden gebruikt in de ontwerpfase voor nieuwe systemen en ze kunnen worden toegepast om de prestaties van bestaande systemen te verbeteren.

Is het mogelijk om het ventilatiesysteem van een operatiekamer uit te schakelen op de momenten dat er langdurig geen gebruik van wordt gemaakt bijvoorbeeld 's nachts en in het weekeinde zonder dat dit een negatief effect heeft op de luchtkwaliteit tijdens de normale gebruikstijden?

Het uitschakelen van ventilatiesystemen bij langdurige inactiviteit kan een maatregel zijn waarmee energie wordt bespaard. Geconcludeerd is, dat het uitschakelen van het ventilatiesysteem bij langdurige inactiviteit (tijdens de nacht en het weekend) geen negatief effect heeft op de luchtkwaliteit in UDFoperatiekamers tijdens de reguliere bedrijfstijden. Na het opstarten van het systeem heeft het beschermde gebied binnen 20 minuten de vereiste mate van bescherming bereikt. De resultaten laten ook een stabiel temperatuurverschil binnen 23 minuten na het opstarten van het systeem zien. In de praktijk is deze tijd om het systeem op te starten ook nodig voor om voorbereidingen te treffen voor traumachirurgie. De benodigde tijd voor het voorbereiden van dit type operatie wordt geschat op 25 minuten. Het uitschakelen van ventilatiesystemen bij langdurige inactiviteit bespaart niet alleen energie, maar verlengt ook de levensduur van filters. Beide kunnen leiden tot verlaging van operationele kosten (energie en onderhoud). 
Kan een horizontaal UDF-systeem in termen van het voorkomen van contaminatie van de lucht veilig worden gebruikt tijdens het opdekproces van de instrumenttafels? De instrumenten die worden gebruikt tijdens chirurgie zijn ook een belangrijke route voor contaminatie van de chirurgische wond. Het is aangetoond, door het meten van het aantal deeltjes en het aantal $\mathrm{KVE} / \mathrm{m}^{3}$, dat UDF-systemen met een horizontale luchtstroming tenminste dezelfde bescherming bieden tegen aërogene verontreiniging als UDF-systemen met een verticale luchtstroom (downflow). Horizontale systemen bieden een robuustere oplossing dan het downflow-systemen, op voorwaarde dat een goed werkproces wordt gebruikt en de hoogte van het verticaal geplaatste plenum wordt afgestemd op de hoogte van de instrumententafels.

\section{Reduceert een mobiel laminair luchtstroomsysteem het niveau van luchtgedragen} deeltjes in een niet geventileerde ruimte tot een niveau dat veilig is voor de patiënt? Voor operaties waarin kleine chirurgische ingrepen worden uitgevoerd met een klein operatiegebied en een beperkt aantal chirurgische instrumenten, kunnen systemen die een beschermd gebied met beperkte omvang realiseren worden gebruikt. Er is aangetoond dat als een mobiel UDF-systeem wordt gebruikt in een slecht geventileerde ruimte, dit bij intra-vitreale injecties beschermt tegen verontreinigingen vanuit de omgeving. De juiste plaatsing en juist gebruik van afdekmaterialen is hierbij echter van cruciaal belang. Hierdoor is het van belang om per situatie de opstelling te optimaliseren en het niveau van bescherming voor die specifieke situatie vast te stellen.

\section{Algemene conclusie en discussie}

Er wordt gesteld dat UDF-systemen het vermogen hebben om een gebied op een effectieve manier te beschermen tegen aërogene verontreinigingen. De effectiviteit van een systeem tegen het binnendringen van potentieel micro-organismen dragende deeltjes van buiten het beschermde gebied en het afvoeren van potentieel micro-organisme dragende deeltje die in dit beschermde gebied worden gegenereerd, wordt echter door veel variabelen beïnvloed, figuur 11.2. 


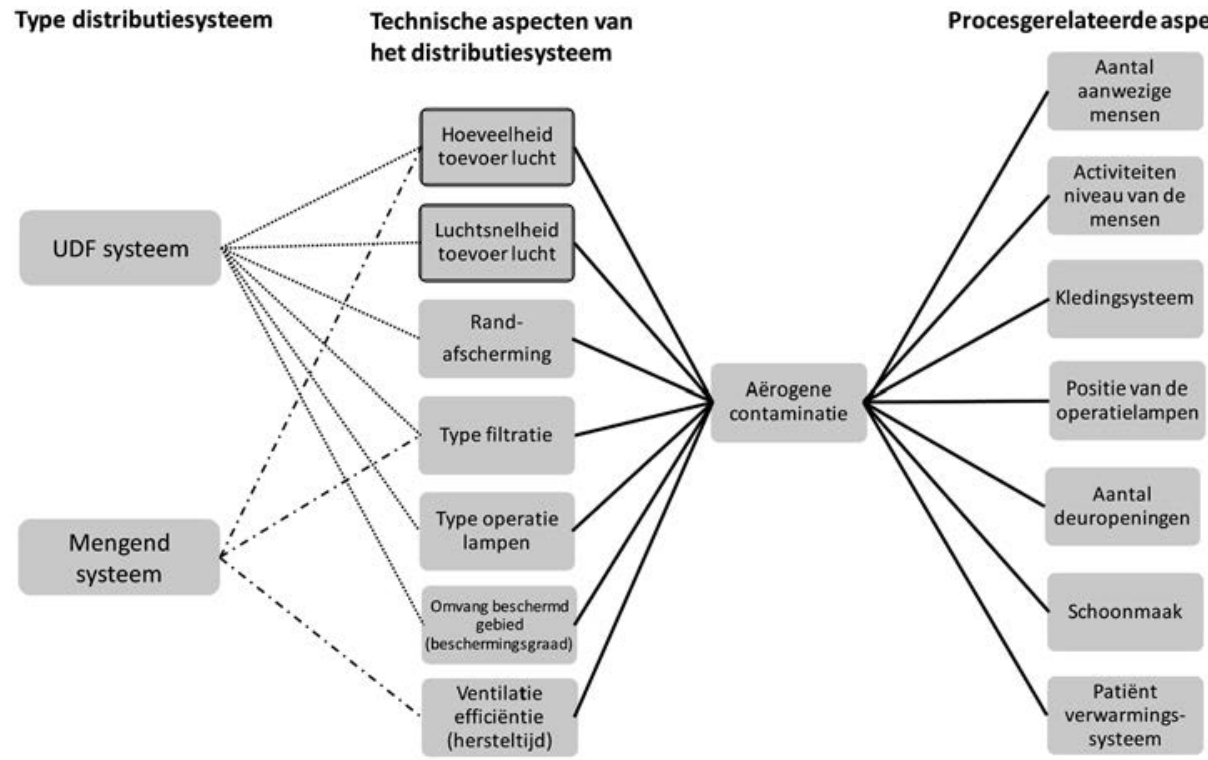

Figuur 11.2. Aspecten die de aërogene verontreiniging in een operatiekamer bepalen.

Als verschillende type systemen met elkaar worden vergeleken, moet tenminste rekening worden gehouden met de technische en procesgerelateerde aspecten zoals weergegeven in figuur 11.2. Een goede vergelijking tussen luchtdistributiesystemen in operatiekamers is alleen mogelijk voor systemen met dezelfde hoeveelheid toegevoerde lucht. Alleen op deze manier worden de prestaties van het distributiesysteem vergeleken en niet het luchtvolume. De meeste studies op basis van retrospectieve analyses van routinematige surveillancegegevens hebben een belangrijk knelpunt. Het knelpunt met deze studies is dat de UDF of mengende systemen niet eenduidig zijn gedefinieerd. De gebruikelijke benadering in deze studies is dat het type systeem dat in de operatiekamers wordt gebruikt, is verkregen middels een vragenlijst waarop wordt aangegeven of het een UDF of mengend systeem betreft. Echter als een plenum wordt gebruikt als toevoersysteem wordt een systeem als snel geclassificeerd als UDF-systeem zonder te weten of dit systeem ook zodanig presteert op basis van de feitelijke technische prestaties van het systeem. 
Er is ook geconcludeerd dat het bepalen van de prestaties van het systeem met behulp van een kunstmatig aangebrachte deeltjesbelasting (hersteltijdmetingen of beschermingsgraad) een goede indicatie geeft van de effectiviteit van het systeem tijdens chirurgische procedures. Systemen waarbij het ontwerp gebaseerd is op een specifieke maximale belasting, waaronder mengende systemen zijn gevoeliger voor verstoringen zoals afwijkingen van de ontwerpuitgangspunten bijvoorbeeld meer personen in de operatiekamer of bij een calamiteit. De prestaties van deze systemen kunnen het beste worden aangetoond door kolonie vormende eenheden (KVE) te meten tijdens chirurgische procedures. Dit omdat bij het gebruik regelmatig wordt afgeweken van de ontwerpuitgangspunten (o.a. aantal personen in de operatiekamer en discipline). Deze methode geldt ook voor de situatie waarbij het beschermde gebied te gering in omvang is om het operatiegebied, het chirurgische team en de steriele instrumenten te omvatten of als de luchtstroming ernstig wordt gehinderd door obstakels zoals draagarmen, operatielampen met een gesloten structuur, monitoren of andere aan het plafond gemonteerde apparatuur. KVE-metingen laten niet alleen de prestatie van het technische systeem zien maar geven ook het effect van het proces op de aërogene contaminatie aan. 


\section{Toekomstige richting}

Omdat veel onduidelijk blijft over de wijze waarop chirurgische wonden en implantaten infecteren, is verder onderzoek gewenst dat zich richt op de bron van de bacteriën die de wond contamineren of infecteren. Meer studies zouden moeten worden uitgevoerd die bestuderen welk deel van de wondcontaminanten direct via de lucht in de operatiekamer in de wond komt, of indirect via handen en instrumenten. Meer informatie is nodig over de rol en het belang van peroperatieve en vroeg-postoperatieve endogeen veroorzaakte infecties om een beter inzicht te verkrijgen in de relatieve betekenis van de bacteriële luchtkwaliteit op de operatiekamer, en de eventuele peri-operatieve profylactische maatregelen in patiënten die carriers zijn.

Studies zijn nodig naar de investerings- en operationele kosten van verschillende typen systemen. Bij deze studies moet een eenduidige vergelijkingsbasis worden aangehouden (figuur 11.2), waarbij ook onderscheid moet worden gemaakt tussen nieuwbouw en renovatie. De hypothese is dat UDF-systemen met dezelfde hoeveelheid buitenlucht (ODA) en dezelfde hoeveelheid secundaire lucht (SEC) vergelijkbare investerings- en operationele kosten hebben als mengsystemen. Indien deze voorgestelde onderzoeken worden uitgevoerd, kan dit een positieve bijdrage leveren aan de discussie over verschillende soorten luchtdistributiesystemen in operatiekamers en opdekruimten. 


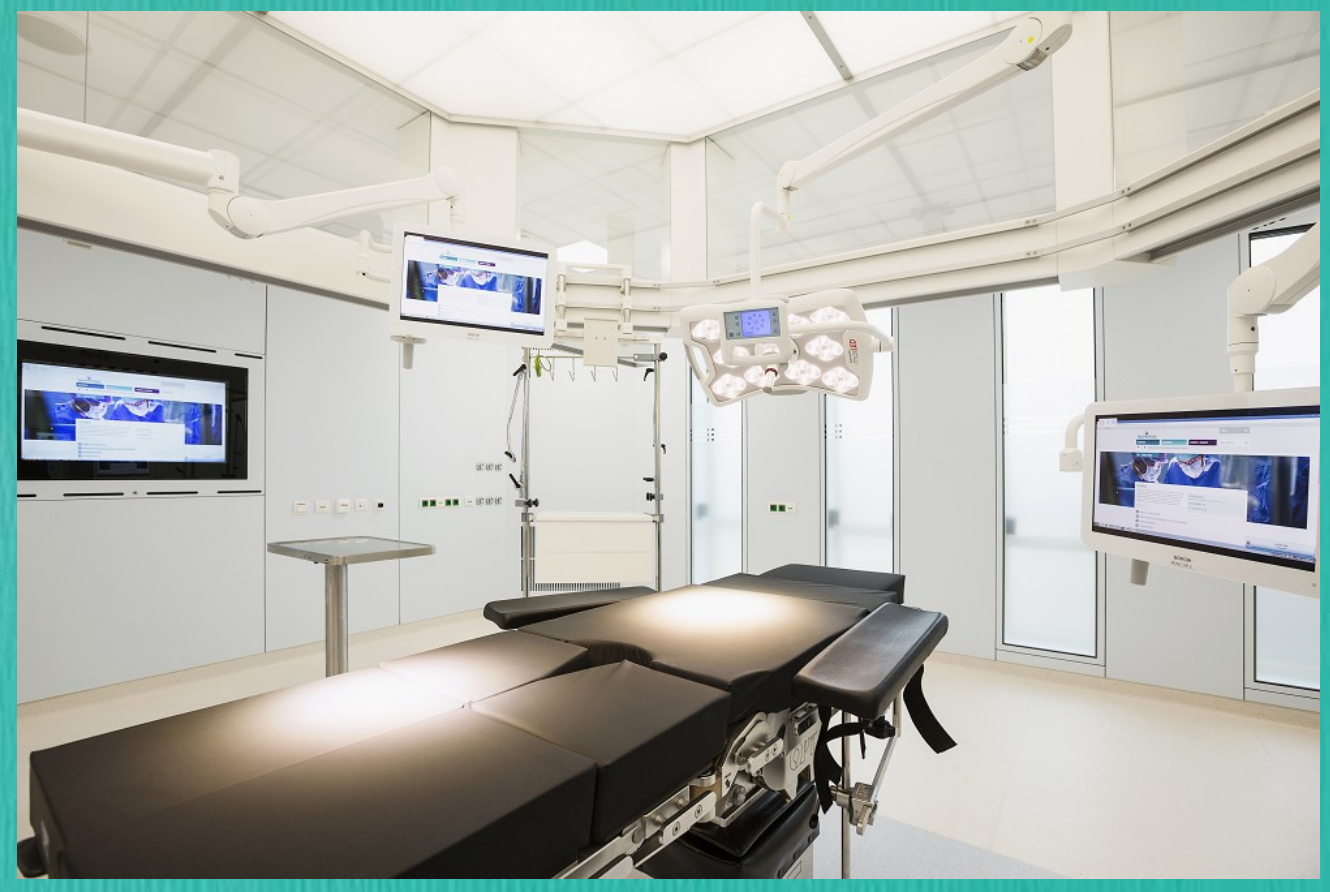




\title{
Appendices
}

\author{
A. Equations \\ B. Curriculum Vitae \\ C. List of publications \\ D. Dankwoord \\ E. Sponsors
}


Appendix A. 


\section{Aquations}

\section{A.1 Contamination removal efficiency}

The relative contamination removal efficiency $\varepsilon_{r}$ can be calculated for a specific point with equation 1 or for the average of the whole room with equation 2., ${ }^{1,2}$ Both can be used while room average values provide guidance to the overall performance of an air distribution system, values at specific points indicate areas where poor ventilation might occur. $^{3}$

$$
\begin{gathered}
\varepsilon_{r}=\frac{C_{f}-C_{t}}{C_{j}-C_{t}} \\
\overline{\varepsilon_{r}}=\frac{C_{f}-C_{t}}{\bar{C}-C_{t}}
\end{gathered}
$$

\section{Where}

$\varepsilon_{r} \quad$ is the relative contamination removal efficiency

$\bar{\varepsilon}_{r} \quad$ is the mean relative contamination removal efficiency

$C_{f}$ is the steady state concentration in the exhaust air terminal in number per $\mathrm{m}^{3} \mathrm{e} . \mathrm{g}$. this can be particles $/ \mathrm{m}^{3}, \mathrm{CFU} / \mathrm{m}^{3}$, etc.

$C_{t}$ is the concentration in the supply air terminal in number per $\mathrm{m}^{3}$

$C_{j}$ is the steady state concentration at point $j$ in number per $\mathrm{m}^{3}$

$\bar{C} \quad$ is the mean steady state concentration in the whole room in number per $\mathrm{m}^{3}$

The absolute removal effectiveness $\varepsilon_{a}$ is defined by equation 3 . The advantage of the absolute removal efficiency is that this parameter is always less than 1 and gives the direction of the change at a specific point. A value $<0$ means increase of the concentration over time and a value $>0$ means a decrease over time. The absolute removal efficiency is a better measure because the relative removal efficiency can decrease when the amount of flow increases. ${ }^{3}$ 


$$
\varepsilon_{a}=\frac{C_{0}-C_{j}}{\Delta C_{\max }}=\frac{C_{0}-C_{j}}{C_{0}-C_{t}}
$$

\section{Where}

$\varepsilon_{a} \quad$ is the absolute contamination removal efficiency

$\Delta C_{\max }$ is the difference between the initial concentration and the concentration in the supply air in number per $\mathrm{m}^{3}$

$C_{0} \quad$ is the initial concentration in the exhaust air terminal in number per $\mathrm{m}^{3} \mathrm{e}$.g. this can be particles $/ \mathrm{m}^{3}, \mathrm{CFU} / \mathrm{m}^{3}$, etc.

$C_{t} \quad$ is the concentration in the supply air terminal in number $/ \mathrm{m}^{3}$

$C_{j} \quad$ is the steady state concentration at point $j$ in number $/ \mathrm{m}^{3}$

If the mixing is ideal (contaminant removal effectiveness $=100 \%$ ) the concentration in a room based on a constant source strength can be calculated by equation $4: 4$

$$
C=\frac{S}{Q}
$$

\section{Where}

$C \quad$ is the resulting concentration per $\mathrm{m}^{3}$

$S \quad$ is the source strength in numbers/s, e.g. this can be particles/s, CFU/s, etc.

$Q \quad$ is the amount of clean supply air in $\mathrm{m}^{3} / \mathrm{s}$ 
If an initial concentration is present, without a constant source strength, the reduction of a concentration over time in a perfect mixed environment can be calculated by equation 5:

$C_{t}=C_{0} \cdot e^{-\frac{Q \cdot t}{V}}$

\section{Where}

$C_{t} \quad$ is the concentration at time $t$ per $\mathrm{m}^{3}$

$C_{0}$ is the initial concentration per $\mathrm{m}^{3}$

$e \quad$ is a mathematical constant, approximately equal to 2.71828

$Q \quad$ is the amount of clean supply air in $\mathrm{m}^{3} / \mathrm{s}$

$V \quad$ is the volume of the room in $\mathrm{m}^{3}$

$t \quad$ is the time in seconds after the initial concentration is present 


\section{A.2 Equation for the size distribution of bacteria carrying particles}

Whyte describes the size distribution of bacteria carrying particles with equation $6:{ }^{5}$

$P F(x)=\frac{1}{x \cdot \sigma \cdot \sqrt{2 \cdot \pi}} \cdot e^{-\frac{(\ln x-\mu)^{2}}{2 \cdot \sigma^{2}}}$

Where:

$P F=$ Probability frequency

$x=$ particle size

$\mu=2.48$

$\sigma=0.99$

\section{Size distribution of particles}

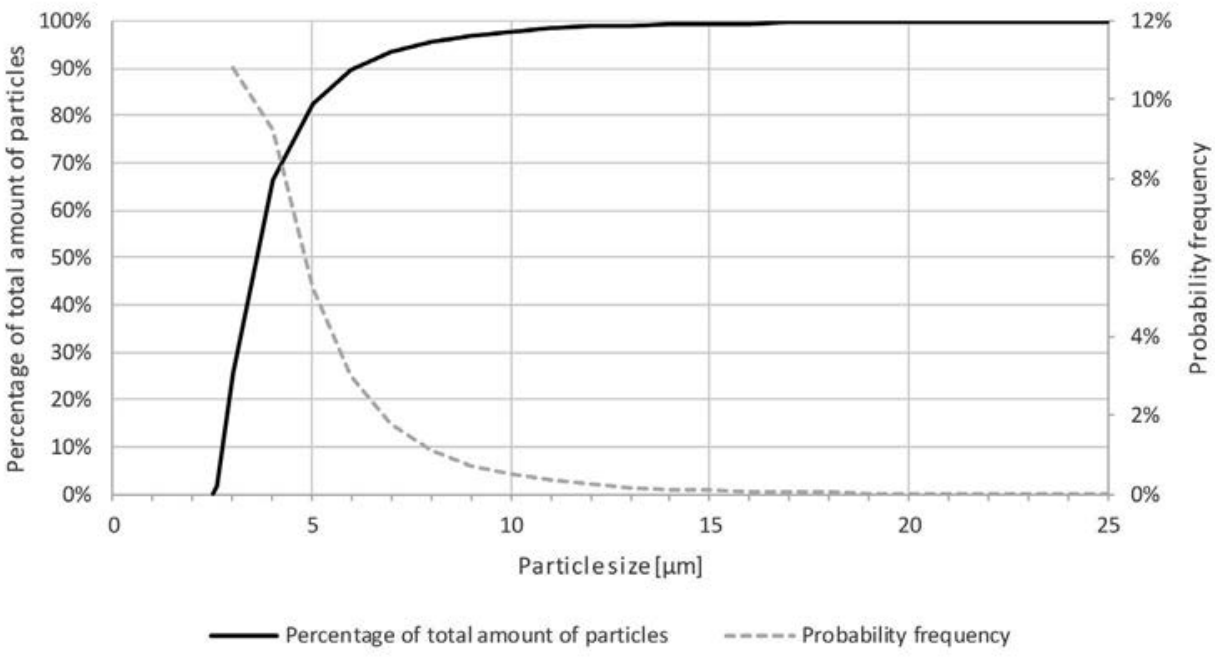

Figure 1. Size distribution of aerogenic particles. 


\section{References}

1. Sandberg M. What is ventilation? Energy in Buidings and. 1981;16(2):123-135.

2. European standard EN 138779. ventilation for non-residential buildings performance requirements for ventilation and room-conditioning systes. . 2007.

3. Liddament MW. A guide to energy efficient ventilation. Air Infilteration and Ventilation Center, (AIVC). 1996:252-252.

4. Nordenadler J. Något om skyddsventilation i operationsrum. KTH; 2011.

5. Whyte W, Green G, Whyte WM. Removal of microbe-carrying particles by high efficiency air filters in cleanrooms. International Journal of Ventilation. 2012;10(4):339-352. 
Appendix B. 


\section{Curriculum Vitae}

After completing primary and secondary education, Roberto followed a course in General Operations Technology (AOT) at Utrecht University of Applied Sciences where he graduated Cum Laude in 1993. Then he started working at TNO and fulfilled various functions there. In 2002 he graduated as a Master of Business Administration (MBA) at the Stichting Wetenschappelijke Opleidingen Twente (SWOT), now the TSM business school.

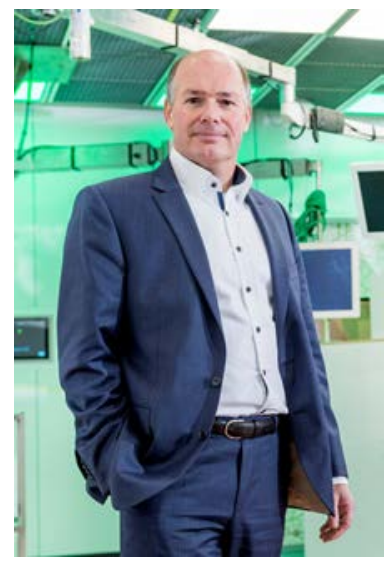

During his employment at TNO Roberto focused his work on heating and ventilation devices and systems related to energy efficiency and renewable energy. He also developed the TNO test and development center for heat pumps.

After 7 years of integral management of the refrigeration and cooling technology department at TNO, he made the transition internally to TNO Dutch Center for Health Assets (DUCHA) in 2009, now TNO Innovation Centre Buildings (ICB).

There he works as an expert on energy saving and renewable energy in healthcare, especially hospitals. He has developed into an expert in the field of air distribution systems and contamination control in operating theatres and isolation rooms as well as central sterilization departments. He is involved as an independent expert in numerous design processes, design evaluation and troubleshooting projects as well as training operating room staff. Roberto is also involved in drafting national and international guidelines for ventilating these high-risk departments in hospitals and has led various research projects resulting in scientific articles.

He completed his PhD at CAPHRI, Care and Public Health Research Institute. 
Appendix C. 


\section{List of publications}

1. Traversari R, Goedhart R, Schraagen JM. Process simulation during the design process makes the difference: Process simulations applied to a traditional design. Health Environments Research and Design Journal. 2013;6(2):58-76.

2. Traversari AAL, Goedhart CA, Dusseldorp E, et al. Laying-up of sterile instruments in the operating theatre: Equal or superior protection by using a horizontal unidirectional air flow system. J Hosp Infect. 2013;85(2):125-133.

3. Lapid-Gortzak R, Traversari R, van der Linden JW, Lesnik Oberstein SY, Lapid O, Schlingemann RO. Mobile ultra-clean unidirectional airflow screen reduces air contamination in a simulated setting for intra-vitreal injection. Int Ophthalmol. 2017;37(1):131-137.

4. Traversari AAL, Bottenheft C, Louman R, van Heumen SPM, Böggemann J. The effect of operating lamps on the protected area of a unidirectional down flow (UDF) system. Health Environments Research and Design Journal. 2017;10(3):40-50.

5. Traversari AAL, Bottenheft C, van Heumen SPM, Goedhart CA, Vos MC. Effect of switching off unidirectional downflow systems of operating theaters during prolonged inactivity on the period before the operating theater can safely be used. Am J Infect Control. 2017;45(2):139-144.

6. Traversari R, Van Den Broek P, Saurwalt F. Wat nu als het beschermd gebied kleiner is dan verwacht? Ned Tijdschr Med Microbiol. 2017;25(1):14-18.

7. Jutte PC, Traversari RA, Walenkamp GH. Laminar flow: The better choice in orthopaedic implants. The Lancet Infectious Diseases. 2017;17(7):695-696.

8. Traversari R, Den Hoed M, Di Giulio R, Bomhof F. Towards sustainability through energy efficientbuildings' design: Semantic labels. Entrepreneurship and Sustainability Issues. 2017;4(3):243-256.

9. Sleiman HA, Hempel S, Traversari R, Bruinenberg S. An assisted workflow for the early design of nearly zero emission healthcare buildings. Energies. 2017;10(7):1-26.

10. Traversari AAL, van Heumen SPM, Hoksbergen AWJ. The effect of using ceiling mounted systems for imaging in hybrid operating rooms on the level of colony forming units during surgery, Journal of Hospital Infection. 2018; doi: https://doi.org/10.1016/j.jhin.2018.10.016. 
Appendix D. 


\section{Dankwoord}

Lieve familie en vrienden, ik wil jullie enorm bedanken voor de ondersteuning die ik van jullie heb gekregen en het geduld dat jullie met mij hebben gehad tijdens het schrijven van het proefschrift. Niet alleen hebben jullie mij gemotiveerd om met dit traject te starten maar dat hebben jullie ook gedaan tijdens dit proces. Ik realiseer me dat ik jullie gedurende deze periode op sommige momenten wel eens tekort heb gedaan. Een dergelijk traject is in mijn ogen alleen mogelijk vanuit een veilige thuisbasis waarin iedereen volledig coöperatief, begrip- en liefdevol is.

Prof.dr. G.H.I.M. Walenkamp, emeritus-hoogleraar Orthopedie, beste Geert ik wil je bedanken dat je mij het laatste zetje hebt gegeven om aan dit traject te beginnen. Tijdens het traject heb ik me wel eens afgevraagd of je het niet te simplistisch hebt voorgesteld maar ik ben je enorm erkentelijk voor de inhoudelijke en motiverende discussie die we hebben gehad. Al waren we het in aanvang van een discussie niet altijd met elkaar eens we zijn op basis van inhoudelijke argumenten altijd goed uit de discussies gekomen. Ook wil ik je bedanken voor het geduld dat je met me hebt gehad en de ondersteuning die je hebt gegeven bij de afronding van het proefschrift. Ik heb diep respect voor je gedrevenheid en betrokkenheid om ook na je emeritaat het beste voor de patiënten te willen waarbij het voorkomen van postoperatieve infecties een belangrijk onderwerp voor je is. leder infectie is er één teveel als je naar het leed dat dit bij patiënten veroorzaakt kijkt is jouw motto.

Prof.dr. L.W. van Rhijn, beste Lodewijk ook jou wil ik bedanken voor je enthousiasme en inhoudelijke bijdrage en het meedenken tijdens mijn promotietraject. Je gedrevenheid en positieve energie werken aanstekelijk en hebben mij ook gemotiveerd. Ik waardeer het enorm dat jij altijd goed voorbereid was tijdens de gesprekken die we hebben gevoerd en alle stukken tot in detail had doorgenomen. 
Beste leden van de beoordelingscommissie dank voor het doornemen en beoordelen van mijn proefschrift. Ik realiseer me dat dit de nodige tijd heeft gekost tijdens een periode met prachtig (na)zomerweer. Dit uitnodigde meer uit om lekker ontspannen buiten te zitten dan een proefschrift door te nemen. Ook bedankt voor de suggesties op basis waarvan het proefschrift verder kon worden aangescherpt. Hopelijk zullen onze wegen elkaar in de toekomst ook blijven kruisen.

Beste medeauteurs van de wetenschappelijke publicaties die ten grondslag liggen aan dit proefschrift. Zonder jullie bijdrage was het niet mogelijk om de onderzoeken uit te voeren, de artikelen te schrijven en te publiceren. Tijdens de onderzoeken hebben we veelvuldig diepgaande en inspirerende discussies gevoerd die vaak weer de basis hebben gevormd voor vervolgonderzoek. Dus mede dankzij jullie is dit proefschrift tot stand gekomen. Het werken met enthousiaste en gedreven mensen is voor mij een inspiratiebron waar ik niet zonder kan.

Beste collega's ook jullie hebben een waardevolle bijdrage aan dit proefschrift geleverd al realiseren jullie dat wellicht niet. Dit hebben jullie gedaan door begrip te tonen dat ik soms wat met andere zaken bezig was en door werkelijk geïnteresseerd te informeren hoe het ervoor stond. Ik wil met name Norman Egter van Wissekerke en Stefan van Heumen bedanken omdat jullie mij veel zaken uit handen hebben genomen en soms als een extended memory fungeerden zodat de ballen niet dood op de grond vielen. Tevens wil ik jullie bedanken voor de bijdrage die jullie aan het proefschrift hebben geleverd door het te reviewen. Ik realiseer me dat dat een tijdrovende klus is geweest. Nancy Westerlaken bedankt dat jij dit als research manager van het InnovatieCentrum Bouw (TNO-ICB) mogelijk hebt gemaakt en in dat verlengde wil ik ook TNO als organisatie bedanken voor de vrijheid en mogelijkheden die worden geboden om te ontwikkelen. Ook wil ik de collegae die op welke wijze dan ook een bijdrage aan mijn promotietraject hebben geleverd bedanken voor hun inbreng en bijdrage. Zonder jullie was dit proefschrift niet tot stand gekomen. 
Sponsoren bedankt voor jullie financiële bijdrage zodat dit proefschrift gedrukt en verspreid kon worden. Hiermee hebben jullie bijgedragen aan het verspreiden van kennis waarmee luchtdistributiesystemen in operatiekamers en opdekruimten effectief kunnen worden ontworpen en toegepast.

Ik hoop dat dit proefschrift inspiratie biedt om technologieën en procedures verder door te ontwikkelen en toe te passen zodat aërogene contaminatie nog effectiever wordt gereduceerd. Uiteindelijk doen we het voor de patiënt. 
Appendix E. 


\section{Main sponsors:}

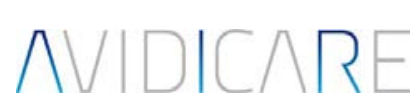

Scheelevägen 2

22381 Lund (Zweden)

+46(0)462756150

www.avidicare.com
Maastricht University

\section{() CAPHRI}

Universiteitssingel 40 6229 ER Maastricht +31(0) 43433882446 www.caphri.nl/

\section{.}

\section{Kuijpers}

Panovenweg 18

5708 HR Helmond

0492-57 8600

www.kuijpers.nl

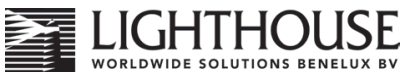

Van Heemstraweg 19A

6657 KD Boven-Leeuwen

+31 (0)487-560811

www.golighthouse.nl
Remmerden 124

3911 TZ Rhenen

+31(0)31761 4461

www.medexs.com

\section{GSModderkolk}

Nieuweweg 143

6603 BL Wijchen

+31(0) 0246486400

www.modderkolk.nl

11 innovation

Leeghwaterstraat 44

2628 CA Delft

+31(0)88 8662200

www.tno.nl 


\section{Sponsors:}

\begin{tabular}{cc}
\hline Rinterflow & Lagelandseweg 84 \\
De Stek 15 & 6545 CG Nijmegen \\
1771 SP Wieringerwerf & $+31(0) 883344000$ \\
+31 (0) 227602844 & www.kropman.nl
\end{tabular}



The Old Operating Theatre Museum \& Herb Garret
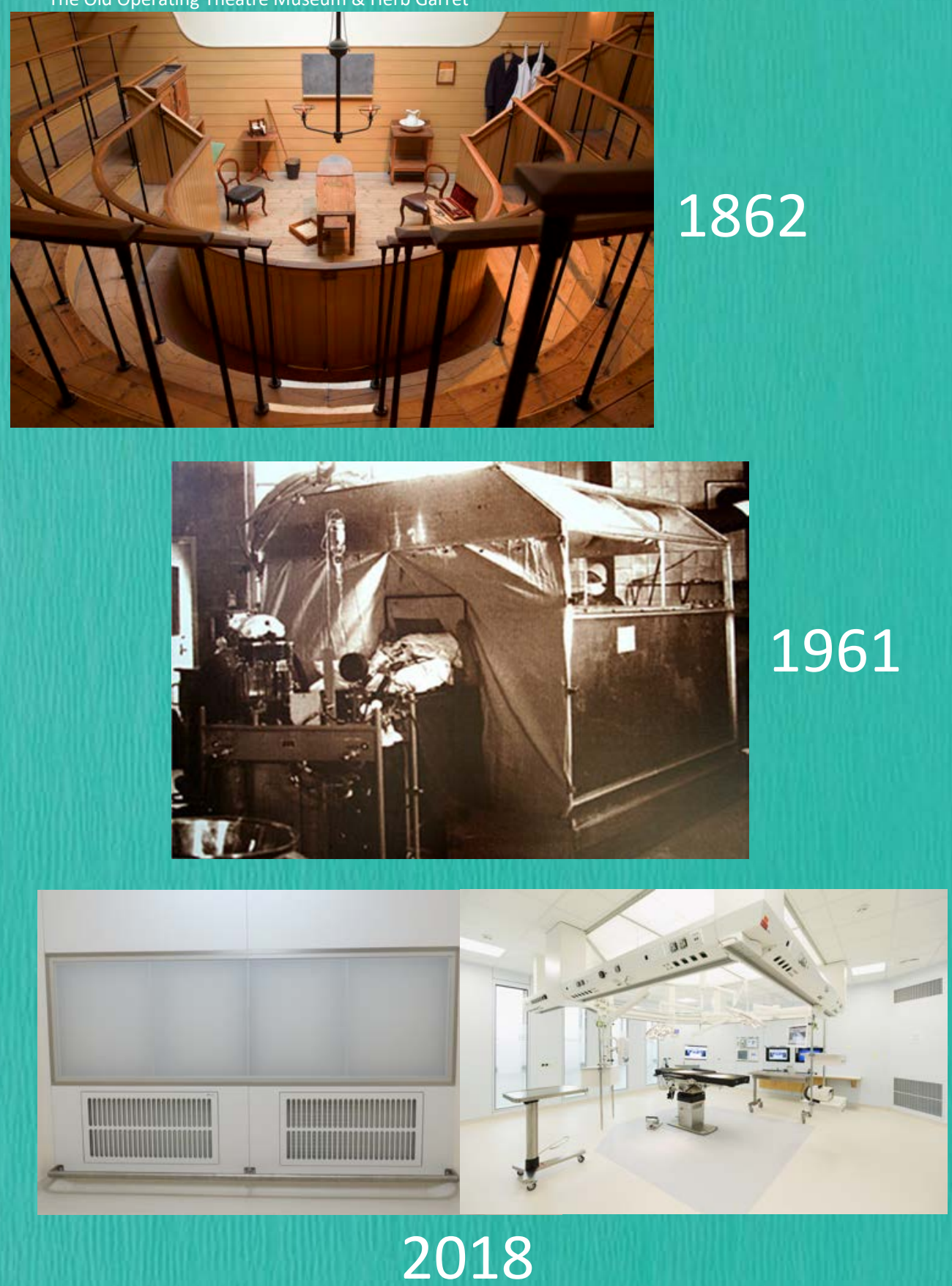

ISBN: $978-90-5986-490-0$ 